NUREG-0316

\title{
ALTERNATIVE ELECTRICAL TRANSMISSION SYSTEMS AND THEIR ENVIRONMENTAL IMPACT
}

Battelle Pacific Northwest Laboratories for

U. S. Nuclear Regulatory Commission 


\section{NOTICE}

This report was prepared as an account of work sponsored by the United States Government. Neither the United States nor the United States Nuclear Regulatory Commission, nor any of their employees, nor any of their contractors, subcontractors, or their employees, makes any warranty, express or implied, nor assumes any legal liability or responsibility for the accuracy, completeness or usefulness of any information, apparatus, product or process disclosed, nor represents that its use would not infringe privately owned rights.

\footnotetext{
Available from

National Technical Information Service

Springfield, Virginia 22161

Price: Printed Copy $\$ 6.00$; Microfiche $\$ 3.00$

The price of this document for requesters outside of the North American Continent can be obtained from the National Technical Information Service.
} 


\section{ALTERNATIVE ELECTRICAL TRANSMISSION SYSTEMS AND THEIR ENVIRONMENTAL IMPACT}

G. F. Schiefelbein

August 1977

Battelle Pacific Northwest Laboratories

P. O. Box 999

Richland, WA 99352

BNWL-1774

Prepared for

Division of Site Safety and Environmental Analysis

Office of Nuclear Reactor Regulation

U. S. Nuclear Regulatory Commission

Under Contract No. EY-76-C-06-1830 

ALTERNATIVE ELECTRICAL TRANSMISSION SYSTEMS AND

THEIR ENVIRONMENTAL IMPACTS

1. INTRODUCTION AND PURPOSE.

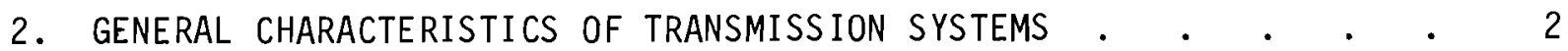

2.1 Alternating Current . . . . . . . . . . . . . 2

2.2 Direct Current . . . . . . . . . . . . . . . . . 3

3. OVERHEAD ALTERNATING CURRENT TRANSMISSION SYSTEMS • • • . $\quad$ • $\quad 6$

3.1 Circuit Capabilities . . . . . . . . . . . . . . 6

3.1 .1 Surge-Impedance Loading . . . . . . . . . 6

3.1 .2 Inductive Reactance . . . . . . . . . . 9

3.2 Alternating Current Transmission Line Losses . . . . 11

3.2.1 Conductor Surface Gradients . . . . . . . 12

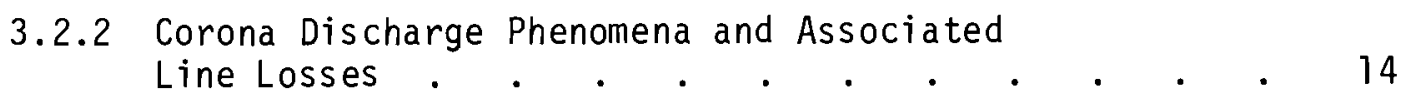

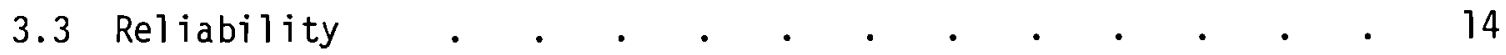

3.4 Weather Effects on Transmission Lines . . . . . . . 18

3.5 Transmission Line Construction Practices . . . . . . 21

3.6 Transmission Line Costs . . . . . . . . . . . 28

3.6 .1 ROW Costs . . . . . . . . . . . . . . 28

3.6.2 Total Transmission Costs . . . . . . . . . . . 28

3.7 Development Activities and Future Trends . . . . . . 30

3.8 Environmental Impact . . . . . . . . . . . 30

3.8 .1 Interferences . . . . . . . . . . . 33

3.8 .2 Visual Impact . . . . . . . . . . . . . 35

3.8 .3 Land Use and Ecology . . . . . . . . . . . 38

3.8.3.1 Intensive Use of Existing ROW . . . . 39

3.8.3.2 ROW Required for Tower Bases and
Access Roads . . . . . . . 40

3.8.3.3 Clearing Operations . . . . . . . . 42

3.8.3.4 Air Quality . . . . . . . . . 42

3.8.3.5 Microclimate . . . . . . . . . 44

3.8.3.6 Soil Quality . . . . . . . . . . . 44

3.8.3.7 Erosion . . . . . . . . . . . . 45 
CONTENTS (contd)

3.8.3.8 Water Quality and Aquatic Life . . . . . 46

3.8.3.9 Vegetation . . . . . . . . . . 47

3.8.3.10 Wildlife . . . . . . . . . . . . 48

3.8.3.11 Maintenance Impacts . . . . . . . 51

3.8.4 Minimizing Environmental Impact Through
Route Selection Techniques . . . . . . . . . . . . 54

3.8.5 Multiple Use Utility Corridors . . . . . . . . 54

3.8.6 Radio and Television Interference . . . . . . . 56

3.8 .7 Audible Noise . . . . . . . . . . . . . 59

3.8 .8 0xidant Generation . . . . . . . . . . 59

3.8.9 Electrostatic Effects of Overhead Transmission Lines. . 64

3.8.9.1 Voltage Gradients at Ground Leve1 • . • • 64

3.8.9.2 Perception and Shock Currents . . . . . 68

3.8.9.3 Let-Go Current and Fibrillation . . . . 77

3.8.9.4 Electromagnetic Effects . . . . . . 78

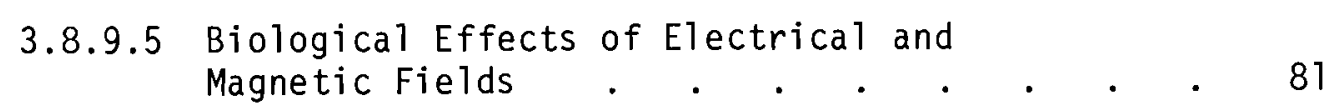

3.8.10 Conductor Clearances . . . . . . . . . . . . . 82

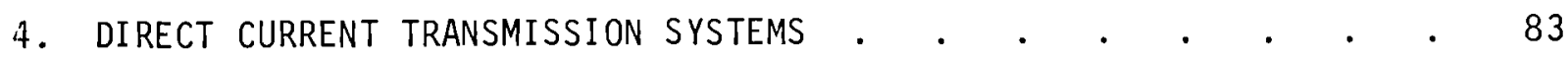

4.1 Advantages and Disadvantages of HVdC Transmission . . . 83

4.1.1 Reliability Considerations . . . . . . . . . 83

4.1.2 Economic Considerations . . . . . . . . . . 85

4.2 HVdc Development Activities and Future Trends . . . . 87

4.2.1 HVdc System Power Losses . . . . . . . . . . . 89

4.3 Environmental Impact . . . . . . . . . . . . 89

4.3.1 ROW Requirements . . . . . . . . . . . . 89

4.3.2 HVdC Electrical Fields . . . . . . . . . . . . 89

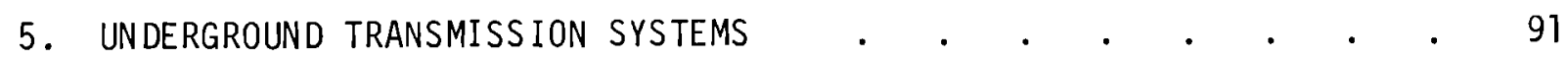

5.1 Alternating Current Underground Transmission . . . • • 91

5.2 Direct Current Underground Transmission _ . . . . . . 92

5.3 Reliability of Underground Systems . . . . . . . . . 92

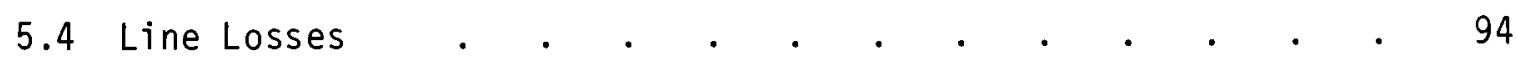


5.5 Development Activities and Future Trends . . . . . 94 5.5.1 Compressed Gas Insulation Systems . . . . . 95

5.5 .2 Cryogenic Cable Systems . . . . . . . . . 96

5.6 Weather Effects . . . . . . . . . . . 98

5.7 ROW Requirements . . . . . . . . . . . 98

5.8 Underground Transmission Costs . . . . . . . . . 98

5.9 Environmental Impact . . . . . . . . . . 101

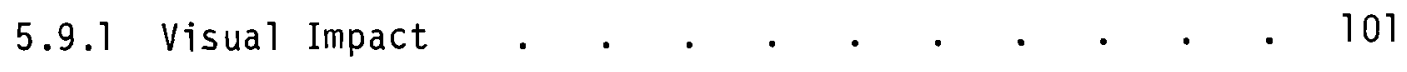

5.9 .2 Ecological Impact . . . . . . . . . 102

5.9.2.1 Construction Impacts . . . . . . 102

5.9.2.2 Maintenance Impact . . . . . . . 102

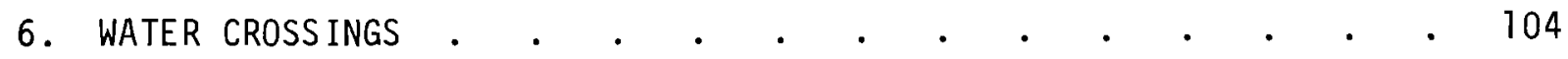

6.1 Overhead Crossings . . . . . . . . . . . 104

6.2 Underwater Systems . . . . . . . . . . . 104

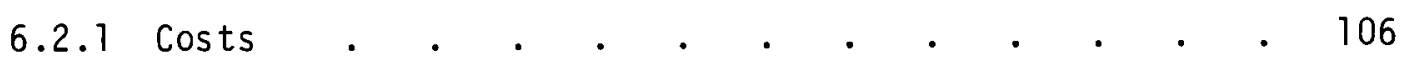

6.2.2 Environmental Impact . . . . . . . . . 106

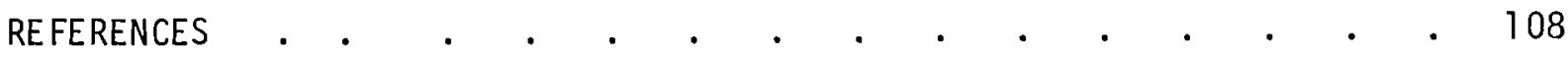

APPENDIX A: ENVIRONMENTAL CRITERIA FOR ELECTRIC TRANSMISSION LINES . A-1

APPENDIX B: RULE 232 OF THE NATIONAL ELECTRICAL SAFETY CODE . • • B- T

APPENDIX C: BIBLIOGRAPHY . . . . . . . . . . . . ${ }^{\circ} C_{-1}$ 


\section{FIGURES}

la Single Phase 60 Cycle ac. . . . . . . . . . . . . . . 3

lb Three-Phase 60 Cycle ac . . . . . . . . . . . . . . 3

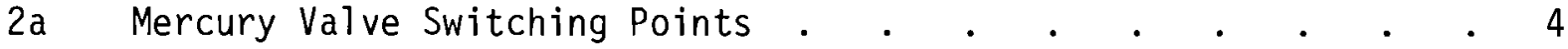

2b Direct Current Voltage with Alternating Current Ripple • • . 4

3 Relationship Between Transmission and Generation Technologies. • • • . . . . . . . . . . . . 7

4 Maximum AC Voltage in Use - 1883-1970 . . . . . . . . . . 7

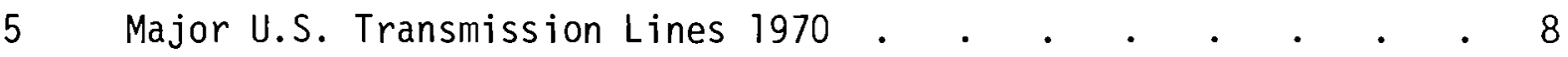

6 Relative EHV Transmission Capabilities . . . . . . . . . 10

7 Transmission Capability Versus Voltage Class. . . . . . . 10

8 Transmission Cost Versus Transmission Distance . . . . . . 10

9 Resistance Losses Per 100 Circuit Miles of Transmission . . . 12

10 Typical Conductor Bundle Surface Gradients, Circular

Subconductor Orientation, Single Circuit, $765 \mathrm{kv}$ (800 kv class) . 13

11 Transmission Line Cost Versus Designed Conductor Ice Load . . 18

12 Typical Lightning Shield Wire Configurations. . . . . . . 19

13 Electrical Energy Transmission Costs for 200 Miles . . . . 29

14 H-Frame Transmission Line Structures. . . . . . . . . 32

15 Recent Pole and Tower Designs . . . . . . . . . . . 36

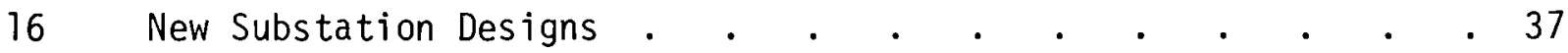

17 AM Radio Reception Quality Versus Signal-to-Noise Ratio . . . 57

18 Television Reception Quality Versus Signal-to-Noise Ratio

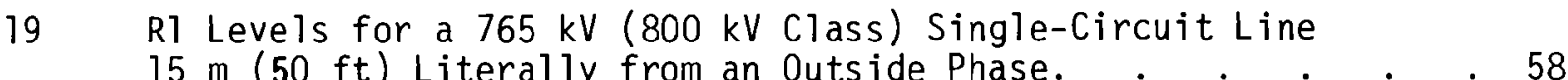

20 Calculated Audible Noise $d B(A)$ at $15 \mathrm{~m}(50 \mathrm{ft}$ ) from the Outer Phase of a $765 \mathrm{kV}$ ( $800 \mathrm{kV}$ Class) Single Circuit

Line. . . . . . . . . . . . . . . 61

21 Correlation of the Ratio of Corona Loss to Ozone Production

(P) and the Voltage Gradient (VG) for Various Conductors. . $\quad .62$

22 Space Potential Map for a $765 \mathrm{kV}$ Line at $15.24 \mathrm{~m}$ (50 ft)

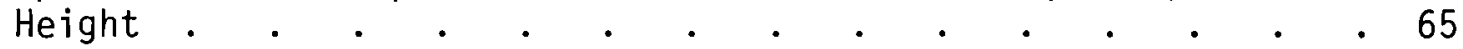

23 Electric Field Measured Under $765 \mathrm{kV}$ Transmission Line . . . 65

24 Voltage Gradient Under Center Phase of $765 \mathrm{kV}$ Line . . 66 


\section{Figures (cont'd)}

25 Voltage Gradient at $1 \mathrm{~m}$ Above Ground Shown for a $765 \mathrm{kV}$ Line with Conductor Heights at $12.8 \mathrm{~m}, 15.24 \mathrm{~m}, 18.29 \mathrm{~m}$, $21.34 \mathrm{~m}$.

Midspan Voltage Gradient at $1 \mathrm{~m}$ Above Ground for Two $525 \mathrm{kV}$ Lines.

27 Voltage Gradient at Ground Level for a Typical DoubleCircuit Geometry and Different Phase Arrangements . . . 67

28 The Effect of Ground Wires Below the Phase Conductors on the Voltage Gradient at Ground Level for a $1100 \mathrm{kV}$ Line . . . 68 Norton Equivalent Network

30 Induced Voltages and Currents as a Function of Resistance to Ground for a Typical Pickup Camper Parked Under a $525 \mathrm{kV}$ Line.

Normalized Open Circuit Voltage and Short Circuit Current vs Height for Persons Standing on Insulation Blankets Under a $525 \mathrm{kV}$ Line . . . . . . . . . . . . . . . 71 Effect of Gradient at Ground Level on Persons . . . . . . 73

Distribution Curve of Minimum Perceptible Alternating Current . . . . . . . . . . . . . . 74

34 Distribution Curve of Let-Go Values of Alternating Currents.

35 Fibrillating Currents Versus Body Weight for Seven Species of Animals

36 Profile of Calculated Magnetic Flux Density $(60 \mathrm{~Hz})$ at $1.5 \mathrm{~m}$ Above Ground for Transmission Lines Compared with Localized Fields from Typical Household Appliances . . . . 80

Transmission Cost $1000 \mathrm{MW}$ (70\% Load Factor) - Federal

Power Commission, 1970 .

38 Projected Development of Total Installed Capacity of HVdC

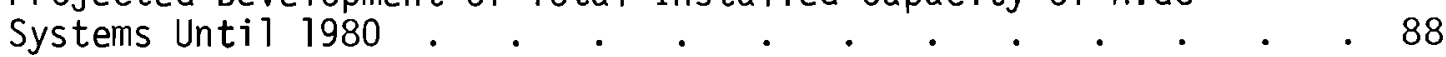

Comparison of Calculated and Measured Electrical Field Strengths Under A Line at $\pm 500 \mathrm{kVdc}$ and $\pm 600 \mathrm{kVdc}$ with Approximately $12.2 \mathrm{~m}$ Line to Ground Clearance . . . . . 90 Underground Transmission Cable Power Ratings. . . . . . . 93

41 Power Delivered Versus Cable Length for 0il-Filled Pipe-Type

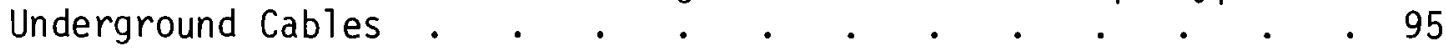

42 Change in Resistance Near Absolute Zero . . . . . . . . . . 97

43 Capabilities of New Underground Transmission Systems. . . . 99 


\section{Figures (cont'd)}

44 Estimated Specific Cost of Underground Cable Schemes. . . . 99

45 Typical Layout for a $230 \mathrm{kV}$ CGI Transmission Line . . . . 100

46 Typical Layout for a 500 kV CGI Transmission Line . . . . 100

\section{TABLES}

1 Transmission Line Mileages in United States, $230 \mathrm{kV}$

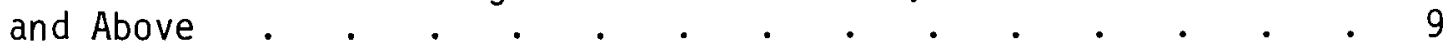

2 Transmission Line Outages, 1950-1964.

3 Bonneville Power Administration Construction Criteria for Conductor Clearance from Standing Trees . . . . . . . 23

4 Bonneville Power Administration Construction Criteria for Conductor Clearance from Falling Trees . . . . . . . 23

5 Typical Transmission Line Cost Data . . . . . . . . . . . 31

6 Cost Comparison for Principal Sprinkler Systems . . . . . . 34

7 Right-of-Way Requirements . . . . . . . . . . . . . . 39

8 Typical Transmission Line Requirements . . . . . . . . . 41

9 Approximate Acreage of Unstable (Danger) Tree Clearing Required for Typical BPA Transmission Lines as a Function of Voltage Level. . . . . . . . . . . . . . . . 43

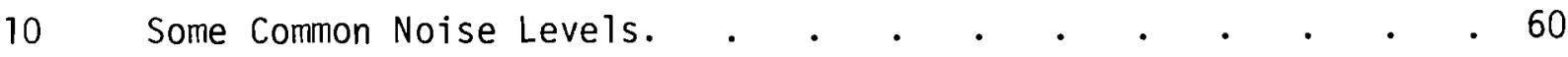

11 Ozone and $\mathrm{NO}_{\mathrm{X}}$ Production Rates Measured in the Laboratory for Bundle and Single Conductors. . . . . . . . 63

12 Electrical Shock Perception and Annoyance Levels. . . . . 75

13 Summary of Effects of Electric Currents on People . . . . . 79

14 Localized $60 \mathrm{~Hz}$ Magnetic Flux Densities Produced by Some Electrical Appliances . . . . . . . . . . . . 81

15 High-Voltage Direct Current Power Transmission Projects . • . 84

16 Comparison of $A C$ and DC Overhead Transmission Circuits of 5000 MW Capacity. . . . . . . . . . . . . 87 


\section{FOREWORD}

This report is one of a series sponsored by NRC, Environmental Projects, Division of Site Safety and Environmental Analysis, with the objective of improving its evaluation of environmental impacts associated with nuclear power stations. Such evaluations are required by the National Environmental Policy Act of 1969. The author of this report, Mr. G. F. Schiefelbein, received substantial assistance from Mr. G. S. Bingham and others of the Bonneville Power Administration, from C. R. Domeck and P. H. Leech of NRC, and from several colleagues at Battelle-Northwest. This assistance is gratefully acknowledged. 

1. INTRODUCTION AND PURPOSE

This document provides a general description of electrical transmission systems as an aid in determining their environmental impacts. Alternating current, direct current, overhead systems, underground systems, and water crossings are treated.

The most productive electric power system design usually consists of many high voltage (HV) transmission lines, connecting power plants at various locations to large electricity load centers. The power plants are installed at various locations for several reasons: the desirability of generating power as close as possible to the load centers, limitations on the quantity of pollutants that can be released to the environment at one location, or the siting of electric plants at the locations where hydropower or fuel is available.

In addition, construction of transmission lines interconnecting load centers and entire electrical systems allows interchange of peaking power and reduces the quantity of reserve generating capacity that must be installed. Installation of additional transmission lines for this purpose often costs much less than installing additional reserve capacity.

The proper design for a transmission system requires an involved analysis, considering variables such as capacity and voltage, economics, aesthetic impacts of both the transmission tower design and rights-of-way (ROW), and the effect of the system design on reliability. Compromises often must be made between the desire for the lowest cost system and the desires for high system reliability and low environmental impact. The lowest cost system, for example an overhead crossing of a river, may have a severe effect on a unique scenic view. The alternatives of undergrounding the line or using a longer route in order to preserve the view may cost several times as much. 


\section{GENERAL CHARACTERISTICS OF TRANSMISSION SYSTEMS}

Transmission systems are the networks of transmission lines for transporting large blocks of electrical energy. They are high voltage lines, 230,000 volts $(230 \mathrm{kV})$ and up, which connect generating stations, main substations, and electric utility systems. Subtransmission systems utilize intermediate voltages of $69 \mathrm{kV}$ to $230 \mathrm{kV}$. In contrast, distribution systems are the lower voltage lines that carry the electricity from substations to customers.

Electricity is generated in the United States by hundreds of independent utility companies and by government and publicly-owned organizations such as the Tennessee Valley Authority. Early in the century, there was wide disagreement on the best way to generate and sell electricity. The most suitable frequency (cycles per second) was a matter of controversy with some favoring al ternating current (ac) while others, such as Thomas Edison, preferred direct current (dc).

\subsection{Alternating Current}

As the number of utilities increased, the need to standardize frequency became paramount. Now nearly all electrical energy is generated and transmitted as alternating current on a three-phase, 60 cycle, constant voltage basis. The voltage passes from zero to a positive maximum, back through zero to a negative maximum, and back to zero in $1 / 60$ of a second as shown in Figure 1a. Three-phase refers to the fact that the cycling is occurring on three different conductors in a single ac circuit, with the positive and negative peaks occurring at $1 / 360 \mathrm{sec}$ intervals as shown in Figure $1 \mathrm{~b}$.

Alternating current power from generating stations is stepped up to high voltage by means of transformers for more efficient transmission of bulk energy. Transmission line voltages are $69 \mathrm{kV}$ or greater; the highest voltage presently being utilized is $765 \mathrm{kV}$ ac or $800 \mathrm{kV}$ dc.

The transmission network is tapped at numerous load centers and the electrical energy is transformed to lower voltages for delivery to consumers. The transformers which accomplish this are located at substations. From the substation, overhead lines or underground cables conduct the power 
1 CYCLE

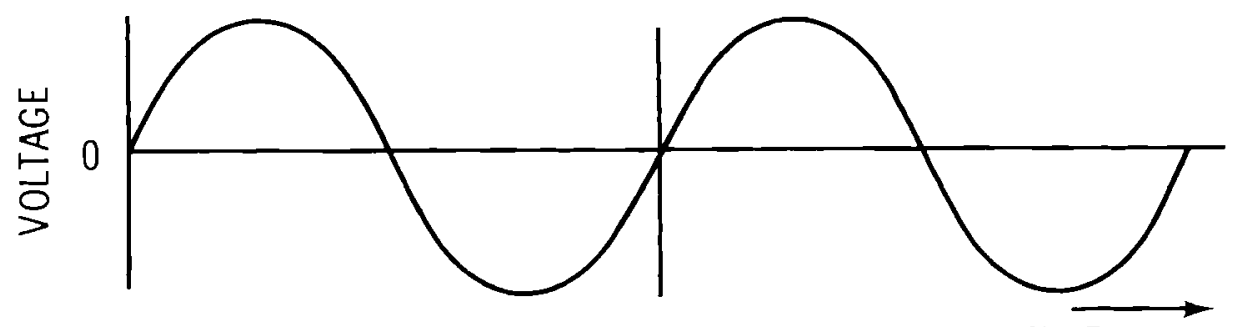

1/60 SEC

TIME

FIGURE 1a. Single Phase 60 cycle ac

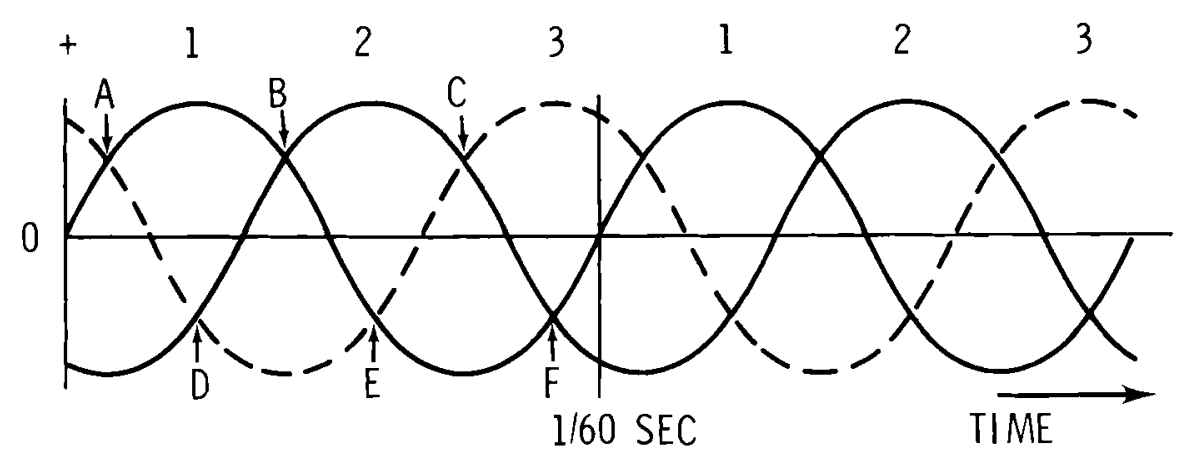

FIGURE 1b. Three-Phase 60 Cycle ac

to the point of use, where usually more small transformers reduce the voltage to the level desired by the consumer (usually 220 volts for residential use).

Various voltages are thus needed in the transmission and distribution of electrical energy and this is one reason why ac was adopted instead of dc, which cannot be transformed.

\subsection{Direct Current}

In early dc utility systems, transmission was accomplished at generator voltages. These systems were soon replaced by ac systems since dc cannot be transformed to higher voltages for transmission from generating facilities to load centers.

However, direct current requires only two conductors, one charged positively and the other negatively, instead of three as required for ac. This is an advantage for transmission in certain situations. For instance, electricity 
can be generated and transformed to high voltages as ac, converted to dc for transmission, and reconverted to ac prior to distribution. This is accomplished by switching the positive dc conductor from one ac phase source to another in a regular sequence, making sure it is always connected to the one which is most positive. Between points $A$ and $B$ on the curve shown in Figure $2 a$ it will be connected to phase 1 . At point $B$, the phase 1 voltage rapidly decreases while the phase 2 voltage approaches its positive maximum. Therefore, at point $B$ the positive dc wire is switched from phase 1 to phase 2; at point $C$ the positive dc wire is switched to phase 3 . Similar switching operations are carried out with the negative dc wire at points $D, E$ and $F$. Thus, the positive and negative dc connectors are charged by picking off the positive and negative peaks of the ac cycles. The resulting dc voltage between conductors has a $1 / 360 \mathrm{sec}$ ripple, Figure $2 \mathrm{~b}$, which is smoothed out by a series connected reactor.

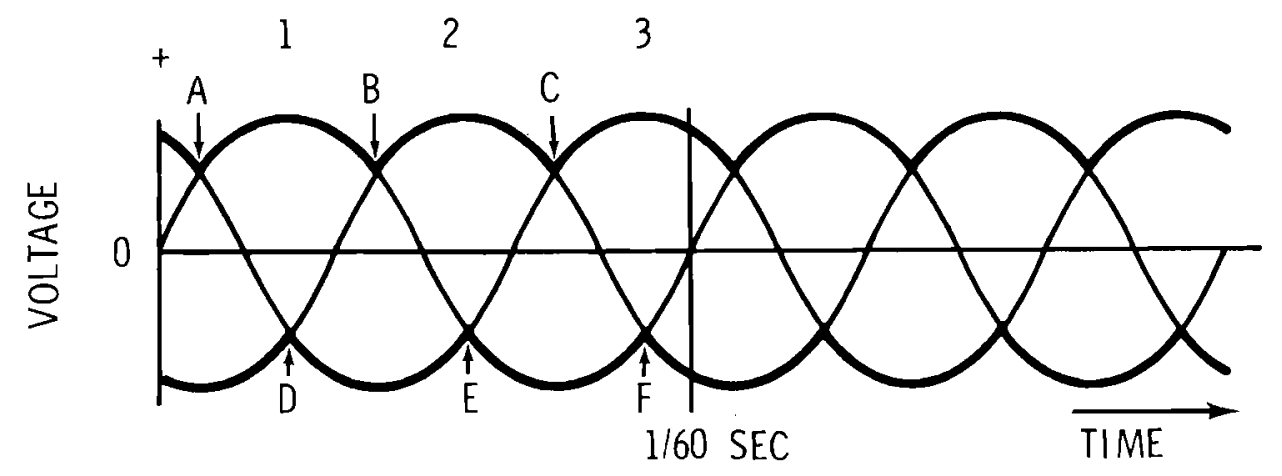

FIGURE 2a. Mercury Valve Switching Points

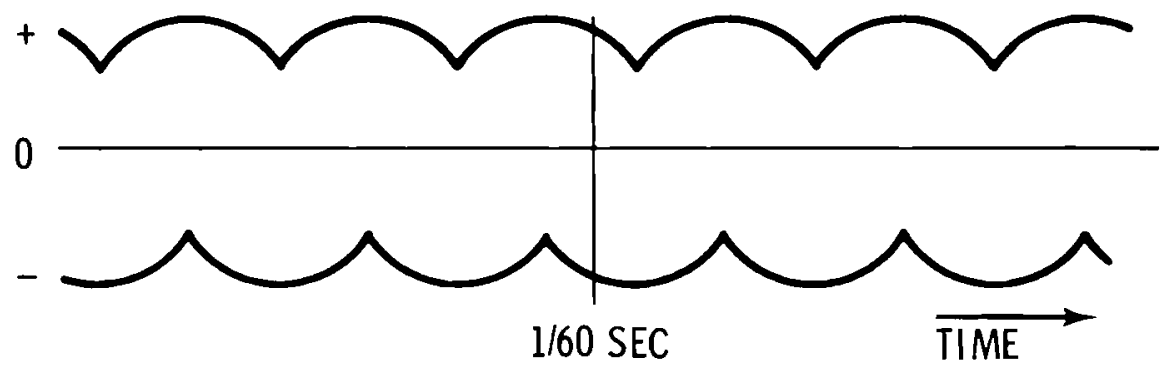

FIGURE 2b. 'Direct Current Voltage with Alternating Current Ripple 
The entire process is reversed at the receiving end of the transmission line to convert the dc back to ac. The switching, done with large mercury valves or solid state thyristors is controlled at both the sending and receiving end at the frequency of the respective ac system. Conversion to dc and back to ac is sometimes used to transfer power between ac systems operating at different frequencies (cycles per second) or to prevent frequency disturbances between interconnected systems. 


\section{OVERHEAD ALTERNATING CURRENT TRANSMISSION SYSTEMS}

For economic and technological reasons, nearly all electrical transmission in the United States today is by overhead lines carrying alternating current.

\subsection{Circuit Capabilities}

In recent years a dramatic increase in transmission line voltages has occurred. Figure 3 illustrates the relationship between generation and transmission technology. As the size of power generating facilities and demand loads have increased, transmission voltages have risen from a maximum of $230 \mathrm{kV}$ in 1923 to the present maximum of $765 \mathrm{kV}$. The historical increase in maximum transmission line voltages is shown in Figure 4. Figure 5 depicts the geographic location of United States transmission lines above $230 \mathrm{kV}$ as of 1970. The rapid growth of high voltage transmission line mileages, including projections to 1990, is shown in Table 1. Dramatic increases in mileages are expected for the extra high voltages (EHV) of $345 \mathrm{kV}$ and above.

The trend toward higher transmission voltages is dictated by economics of scale. A $500 \mathrm{kV}$ transmission line can transport six to twelve times as much electrical energy as a $230 \mathrm{kV}$ line and a $765 \mathrm{kV}$ line over twice that of a single circuit $500 \mathrm{kV}$ line. The advantages of higher transmission voltages are illustrated in Figures 6,7 and 8 . As shown in Figure 7 , the transmission capability of a $765 \mathrm{kV}$ line approaches 4000 megawatts (MW) for transmission distances of less than 100 miles. The actual power transfer capability of a transmission line is somewhat difficult to determine in general terms because of the interaction of an individual line with the network to which it is connected. It is probable that $500 \mathrm{kV}$-ac will be the most popular choice for transmission from large nuclear plants for some time.

\subsubsection{Surge-Impedance Loading}

The concept of surge-impedance loading is a convenient way to compare the load-carrying capability of lines of different voltage levels. Surgeimpedance load (SIL) is the power the line carries when the energy in the magnetic field due to current flow equals the energy in the static field due to voltage. While surge-impedance loading gives a useful benchmark 


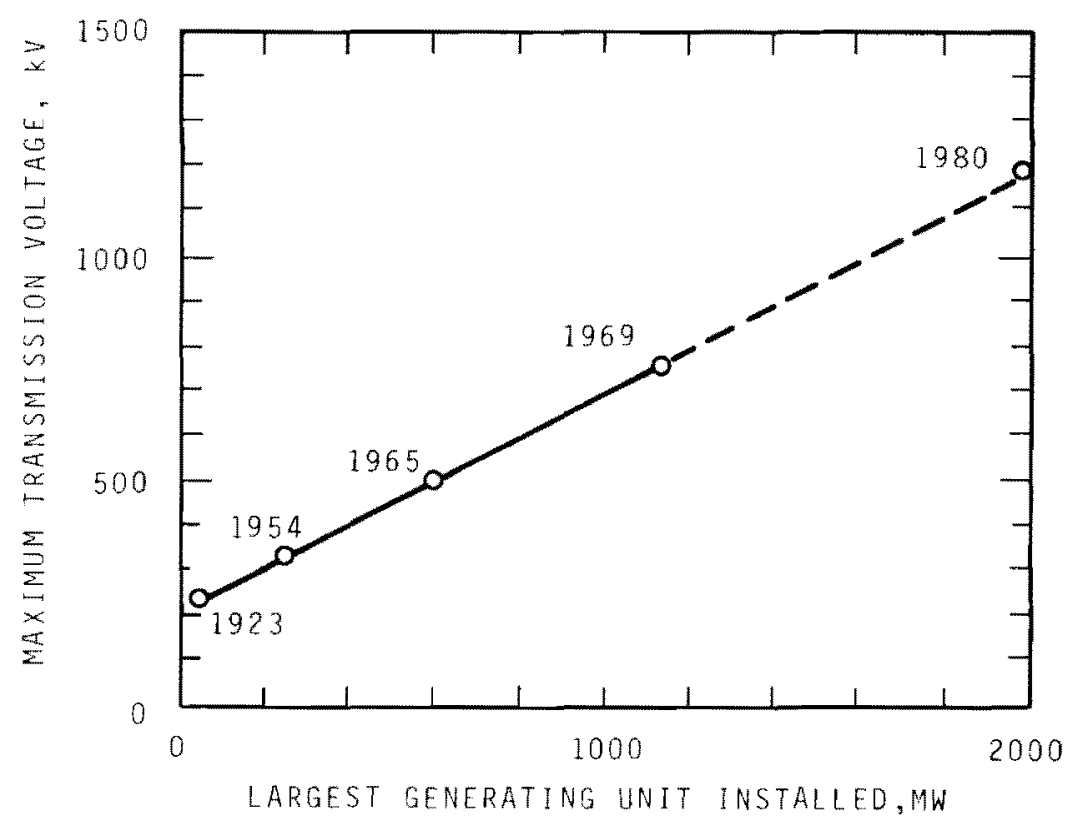

FIGURE 3. Relationship Between Transmission and Generation Technologies (3)

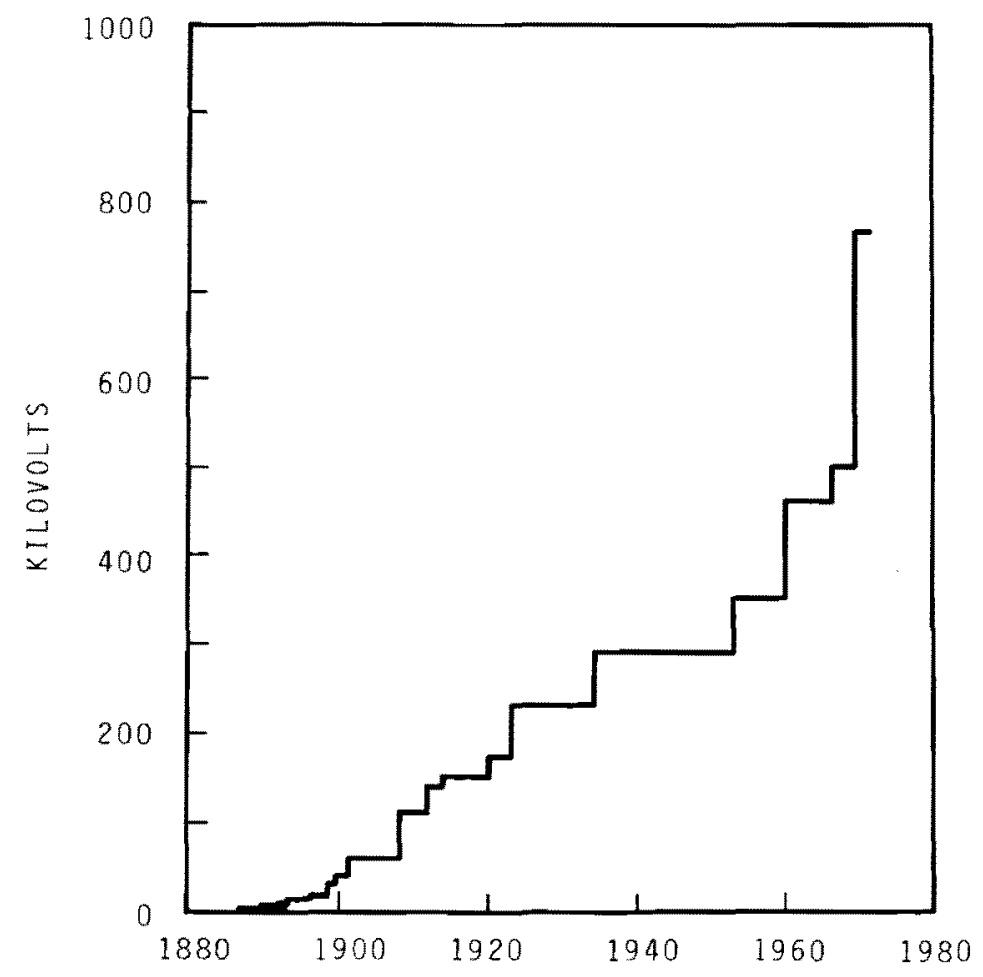

FIGURE 4. Maximum $A C$ Voltage in Use $1883-1970(1)$ 


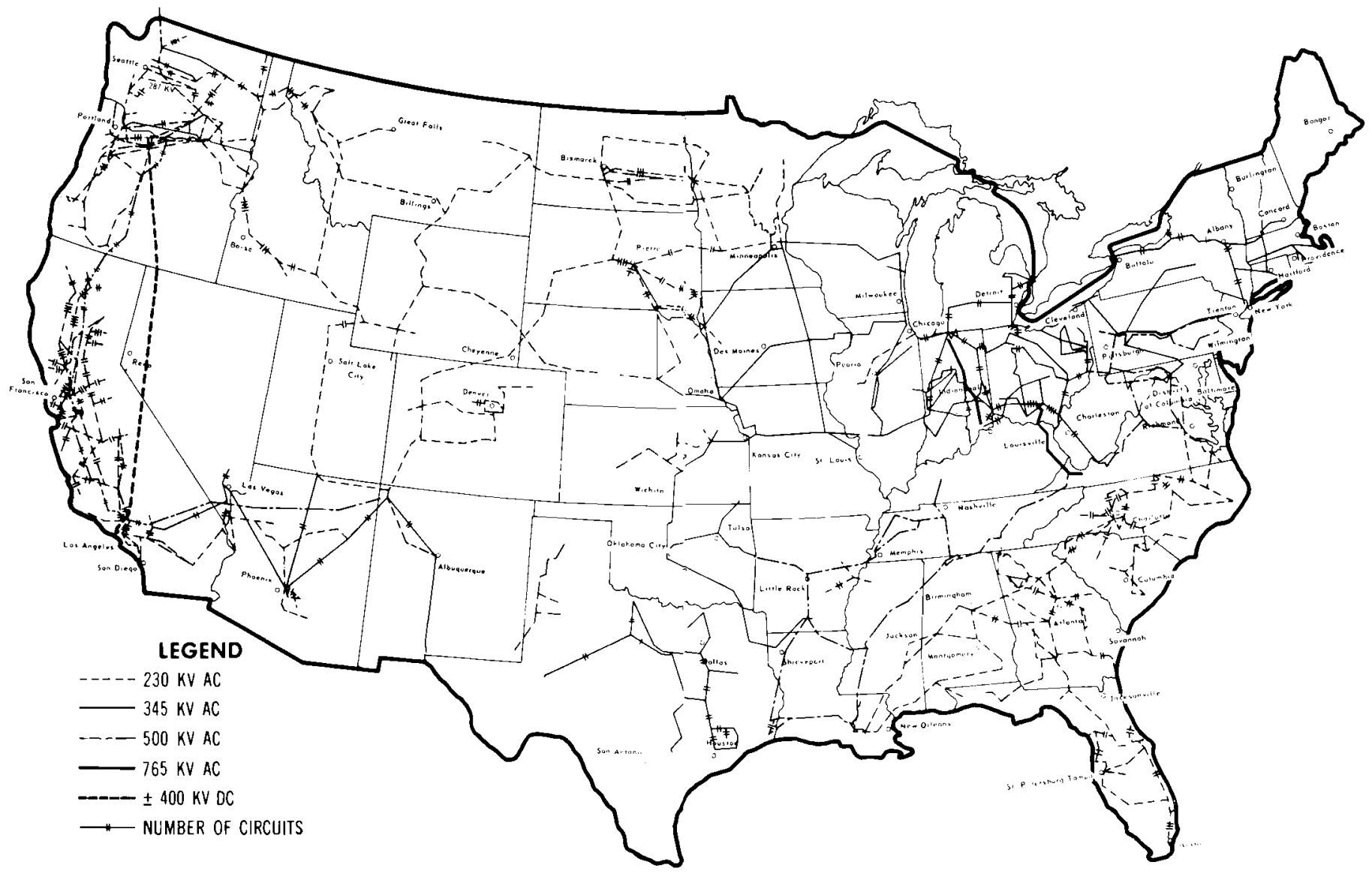

FIGURE 5. Major U.S. Transmission Lines $1970(1)$

(New England $230 \mathrm{kV}$ Omitted) 
TABLE 1. Transmission Line Mileages in United States, $230 \mathrm{kV}$ and Above $(1)$

\begin{tabular}{|c|c|c|c|c|c|c|c|}
\hline & $230 \mathrm{kV}$ & $287 \mathrm{kV}$ & $345 \mathrm{kV}$ & $500 \mathrm{kV}$ & $765 \mathrm{kV}$ & $\begin{array}{r} \pm 400 \\
\mathrm{kV}(\mathrm{DC}) \\
\end{array}$ & Total \\
\hline 1940 & 2,327 & 647 & & & & & 2,974 \\
\hline 1950 & 7,383 & 791 & & & & & 8,174 \\
\hline 1960 & 18,701 & 1,024 & 2,641 & 13 & & & 22,379 \\
\hline 1970 & 40,600 & 1,020 & 15,180 & 7,220 & 500 & 850 & 65,370 \\
\hline Mid 1975 & 56,640 & N.A. & 40,130 & 14,110 & 1,330 & 860 & $113,070^{(2)}$ \\
\hline $1980^{(a)}$ & 59,560 & 870 & 32,670 & 20,180 & 3,540 & 1,670 & 118,490 \\
\hline $1990^{(a)}$ & 67,180 & 560 & 47,450 & 33,400 & 8,940 & 1,670 & 159,200 \\
\hline
\end{tabular}

(a) 1970 estimates. By 1990 there may be significant applications of ac voltages higher than $765 \mathrm{kV}$ and more extensive use of high-voltage direct-current (HVDC) than that shown in the table.

for comparing the relative load carrying capabilities of different voltage circuits, it is usual to load short lines appreciably above the SIL (to values of 2.0 or greater) and, because of stability limitations, to reduce the loadings of longer lines to values of 0.7 or lower unless series-capacitor compensated.

\subsubsection{Inductive Reactance}

In an ac transmission system the inductive effects of ac current, which depend upon the conductor size, line length and the spacing between conductors, must be considered. The power which can be transmitted over an ac transmission line is proportional to the square of the voltage and inversely proportional to the inductive reactance of the system. Thus, reactance sets a stability limit on the maximum power which can be transmitted by an ac line.

Series capacitors can be used on some long-distance transmission lines to increase the steady-state and transient transmission capability by canceling the effect of part of the inductive reactance. For 1 ines several hundred miles long, the cost of this compensation at the most economic loading may approach one-fourth of the total investment for the lines and terminals. The 


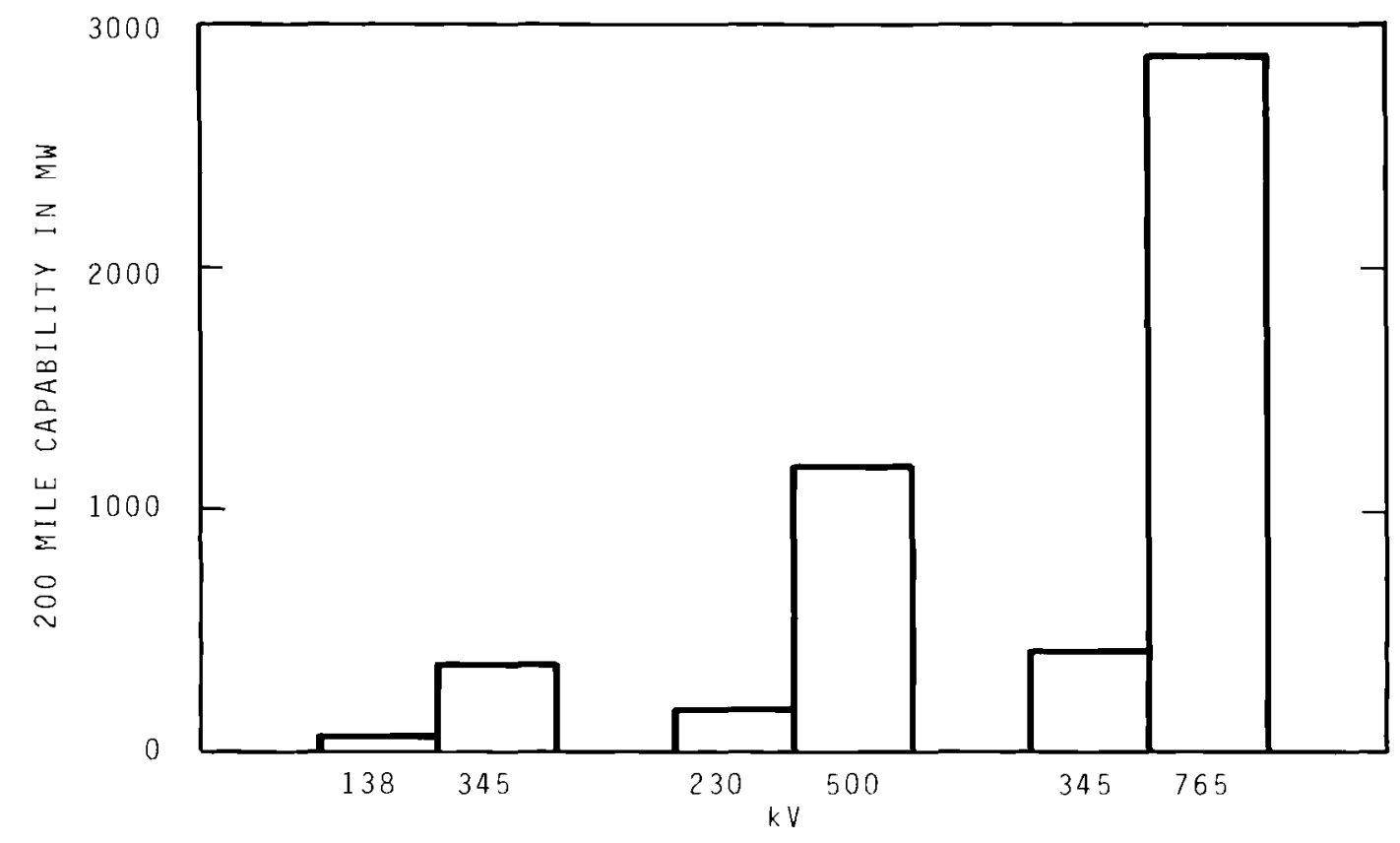

FIGURE 6. Relative EHV Transmission Capabilities (4)

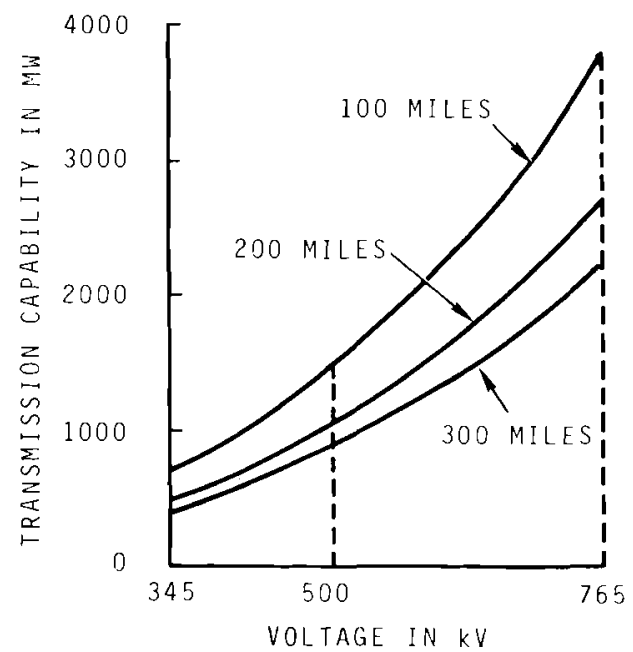

FIGURE 7. Transmission Capability Versus Voltage Class(5)

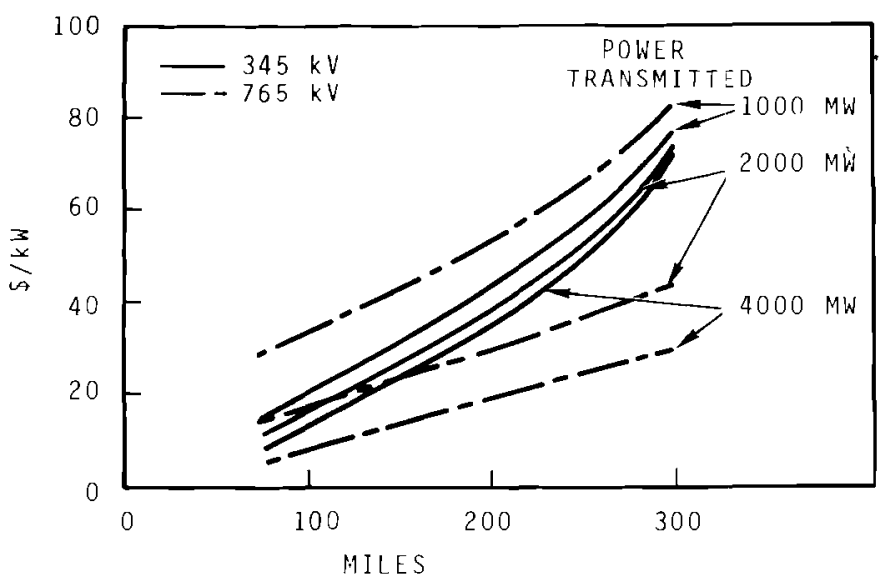

FIGURE 8. Transmission cost Versus Transmission Distance (5) 
use of series compensation (capacitance) on a long dual circuit $500 \mathrm{kV}$ line proposed by the Bonneville Power Administration (BPA) will increase its capacity from about $3000 \mathrm{MW}$ to nearly $5000 \mathrm{MN}$. (6)

Another device frequently used on ac transmission lines is the shunt reactor, which compensates for the capacitance between parallel conductors of an ac line. This capacitance produces a charging current in a transmission line and increases line voltage. Shunt reactors maintain the desired voltage on open or lightly loaded lines.

\subsection{Alternating Current Transmission Line Losses}

Al1 transmission 1 ines contain resistance, inductance and capacitance. The power transfer capability of a transmission line decreases as its length increases because of resistance losses in the circuit.

The resistance is determined by the conductor material, conductor size and line length. Since current flowing through the resistance is in phase with the voltage drop, the product of the resistance voltage drop across the conductor and the current flowing through the conductor represents the power loss in the conductor. (7)

$$
\begin{aligned}
& \text { Power loss (watts) }=E \text { (voltage drop) } \times I \text { ( } 1 \text { ine amperes) } \\
& \text { but, } E=I \times R \text { (resistance) } \\
& \text { so, power loss }=I^{2} \mathrm{R} \text { watts. }
\end{aligned}
$$

Doubling the current in a circuit results in four times the resistive power loss.

The current density in a wire carrying alternating current is greater near the surface of the wire, a phenomenon known as "skin effect". This "skin effect" is brought about by self-induced electromotive forces caused by the varying current in the conductor. The "skin effect" varies with frequency and has only a minor effect on resistance at the transmission frequency of 60 cycles per second.

Comparative resistance losses per 100 miles of transmission circuit are shown in Figure 9 for typical overhead EHV ac line designs now in service in the United States. 


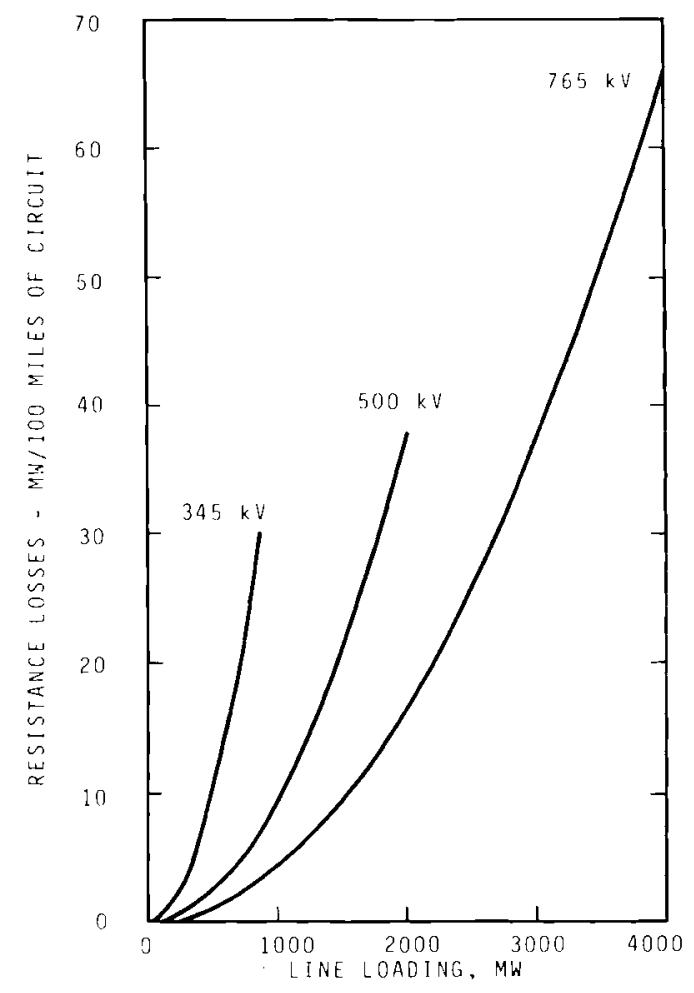

FIGURE 9. Resistance Losses Per 100 Circuit Miles of Transmission(1)

\subsubsection{Conductor Surface Gradients}

Knowledge of the electrical field at the surface of a transmission line conductor (conductor surface gradient) is necessary to evaluate corona discharge phenomena such as radio and television interference, audible noise and corona loss. Conductor surface gradient is a function of line voltage, phase spacing, conductor height and configuration, ground wire height and configuration and the diameter and spacing of individual subconductors in a conductor bundle.

The surface gradient of a conductor decreases as the conductor diameter increases. At $500 \mathrm{kV}$ or higher, conductors several inches in diameter would be required to obtain a reasonable surface gradient. However, when two or more reasonably sized conductors are spaced a few inches apart the surface gradients of the individual conductors merge so that the composite gradient is similar to that which would exist with one very large conductor. Since transmission line conductor sizes are often dictated by the need to reduce 
corona phenomena, especially radio and television interference, using bundled conductors instead of extremely large and heavy conductors saves considerable expense in tower, conductor and insulator costs. Figure 10 exhibits the varia. tion in conductor surface gradients obtained with various conductor bundles from a typical $765 \mathrm{kV}$ single circuit transmission line. (8)

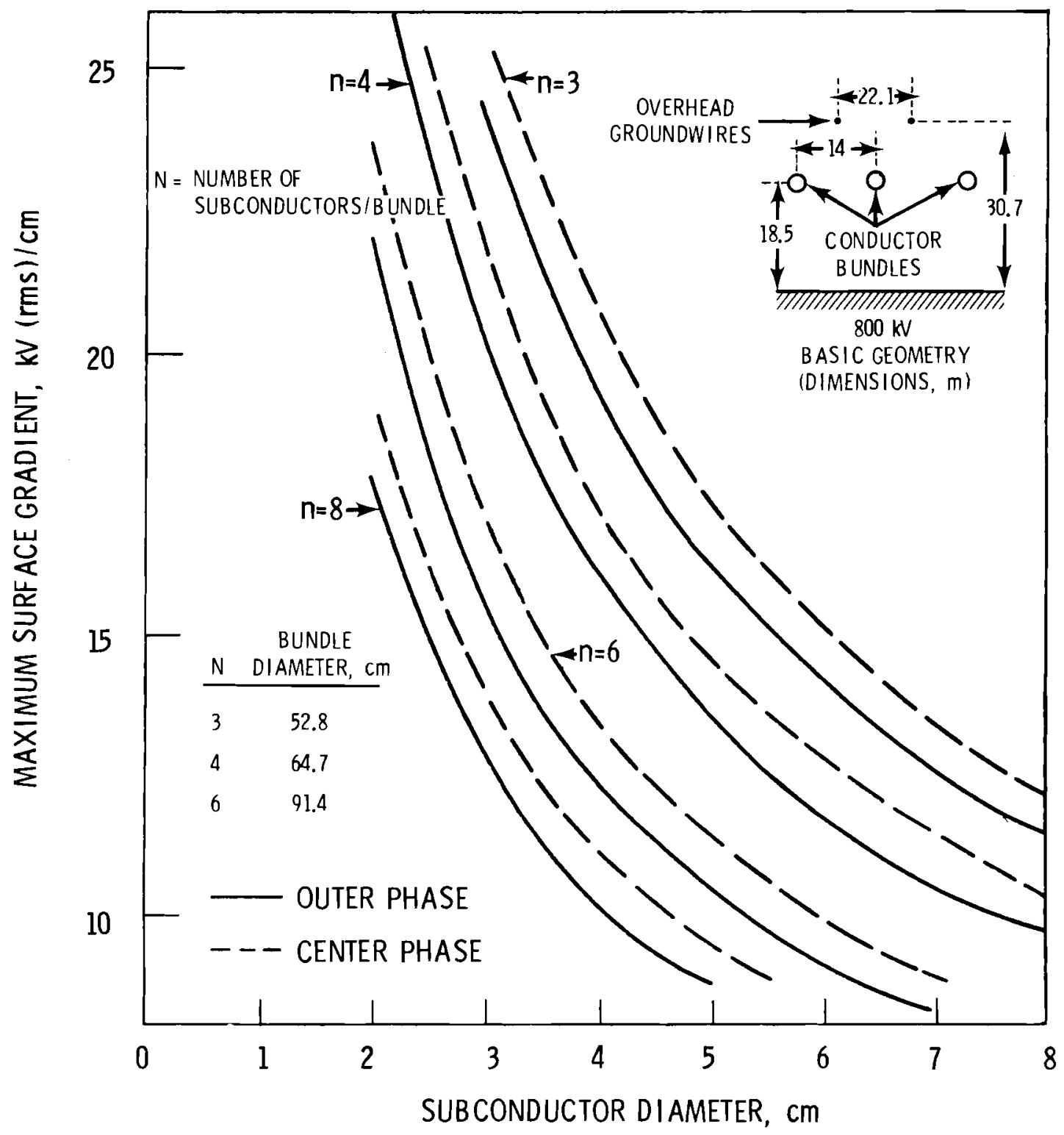

FIGURE 10. Typical Conductor Bundle Surface Gradients, Circular Subconductor Orientation, Single Circuit, $765 \mathrm{kV}$ $(800 \mathrm{kV}$ class $)(8)$ 


\subsubsection{Corona Discharge Phenomena and Associated Line Losses}

Corona discharge is another source of transmission line current loss common to both $\mathrm{ac}$ and dc circuits. When a conductor is charged to an electrical potential (voltage), the insulating medium surrounding the conductor (air in the case of overhead lines) is stressed by the electrical field surrounding the conductor. Although air is a good insulator at low voltage, the air molecules become ionized and conductive as the voltage is increased, producing visible arcs (corona streamers) at the higher extremes. The streamers may be either positive or negative. Several factors affect the breakdown strength of air as an insulator: air pressure, water vapor, conductor material and conductor surface irregularities.

On a conductor surface, an irregularity such as a contaminating particle may cause a voltage gradient concentration which can become a point source of discharge. The ionization of air in this region generates light, audible noise, radio noise, conductor vibration, ozone, and causes a dissipation of energy that results in line losses. Insects, dust, vegetation, leaf particles, spider webs, bird droppings and metallic surface irregularities on transmission line conductors are the chief causes of point sources of corona during fair weather. Heavy rain or wet snow results in a dramatic increase in corona due to droplets clinging to the conductors which act as sources of point discharge.

The energy loss due to corona discharge is minimal during fair weather, averaging on the order of 1 to $2 \mathrm{~kW}$ per mile of three-phase ac line at $500 \mathrm{kV}$. However, during heavy snow or rain, corona can approach $300 \mathrm{~kW}$ per three-phase mile at $500 \mathrm{kV}$. (6)

Radio and television interferences and other corona effects are discussed further in the section on environmental effects.

\subsection{Reliability}

Achieving a reliable power supply requires that extensive transmission systems operate as integral parts of a strongly interconnected network. As early as 1920, many small generating plants were either abandoned or interconnected into systems established to serve the needs of relatively large 
geographical areas. (1) Three principal objectives in providing adequate interconnection transmission capacity are:

- To support immediately any load area suddenly faced with a serious and unexpected deficiency in its normal generating supply. The network must have capacity to handle, well within stable limits, the automatic inflow of supporting power from the hundreds of generators in the surrounding interconnected network.

- To transfer, without serious restriction, capacity and power within regions and between regions to meet power shortages. Emergency shortages can arise from innumerable causes, such as delays in commercial operation of new generation, problems with new equipment, the failure of major generating units or other elements of the system, and unexpected peak demands caused by weather extremes.

- To exchange power on a regional basis and to achieve important reductions in generating capacity investment and in cost of power production.

The last objective is often a major factor in utility transmission and generation agreements. Frequently, individual systems are not able to finance or use economically the large steam-powered electric generating units now technically feasible; but by appropriate planning, mutual agreement and strengthening of transmission interties, the expenses inherent in the construction and operation of large units can be shared. Other benefits include: (1)

- The ability to schedule bulk power transfers over tie lines to take advantage of power-cost differentials among the areas.

- Diversity exchanges made possible by differing load characteristics due to seasonal patterns, time zones, and weather.

- Sharing of operating reserve to take advantage of different types of generation and to maximize efficiency in unit commitment and scheduling.

- Improvement in transient stability.

The proper design of a transmission system requires some knowledge not only of future loads but also of the location and way in which power will be 
generated to meet those loads. A transmission and generating system should be stable for relatively small changes of load or capacity and also for relatively large changes following, for instance, failure of a major intertie or generating plant. This "hard" stability is difficult to achieve in practice unless sufficient redundancy is built into the transmission grids.

While the utilities strive for both interregional and intraregional stability, primary emphasis is placed on interregional stability so that outages in the system in one region do not cascade to cause outages of facilities in interconnected regions. Present practice is to connect each unit at a generating station to at least two or more transmission circuits. With the exception of the Texas Interconnected Systems group, virtually all large utilities in the United States now operate synchronously, although the power transfer capabilities of some tie-lines are lower than those needed at times to meet peak demands in power shortage areas. In recent years the eastern twothirds of the contiguous United States was interconnected with the western systems through the "east-west ties" in the Rocky Mountain area. (See Figure 5). These ties have very limited capacity and are vulnerable to frequent tripping on power swings. (1)

The power transfer capabilities of EHV transmission lines are frequently limited by something other than thermal heating of the conductors. Conductor size is usually chosen so as to minimize corona loss, audible noise and radio and television interference. Therefore the size of transmission line conductors may exceed the minimum requirements for carrying current.

Transmission lines are subject to outages for a variety of reasons. A study by the Joint Committee on Line Outages, formed by the Institute of Electrical and Electronics Engineers and the Edison Electric Institute, reported in $1966^{(9)}$ the results of a survey of operating experience with alternating current transmission lines in the $230 \mathrm{kV}, 287 \mathrm{kV}$, and $345 \mathrm{kV}$ classes during the period 1950-64. Data covered 386 transmission circuits totaling 25,499 circuit miles. Selected data from the survey are presented in Table 2.

Many transmission lines are multiple circuit configurations which tend to reduce the impact of a fault on any one circuit. Most high voltage 
TABLE 2. Transmission Line Outages, 1950-1964(1)

Number of Outages

$230 \mathrm{kV} \quad 287 \mathrm{kV} \quad 345 \mathrm{kV}$

Types of Faults

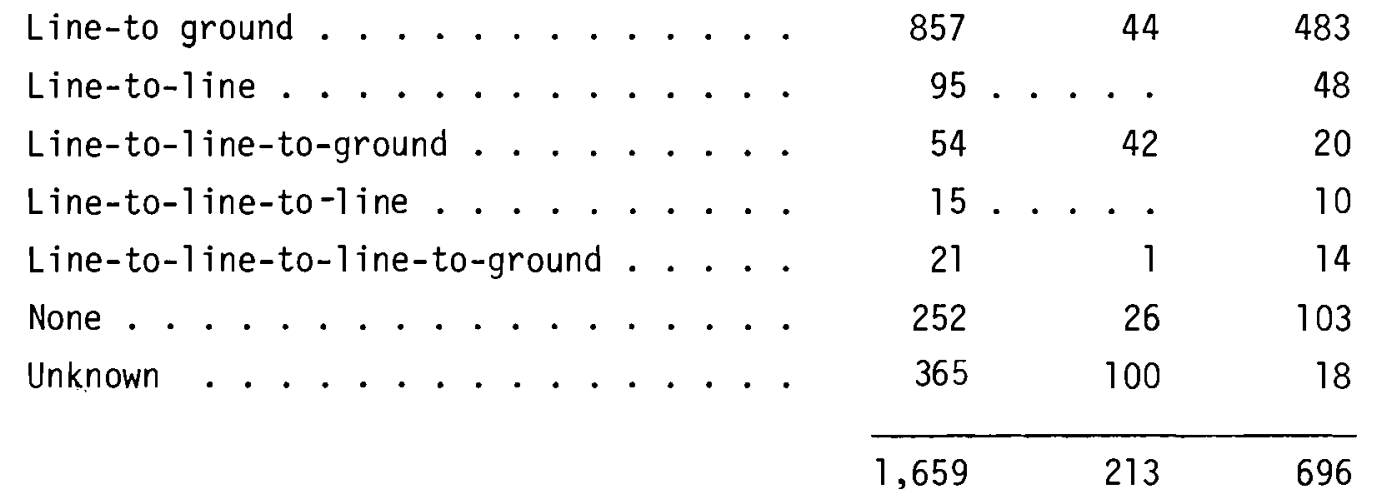

Outages Per 100 Miles Per Year

\begin{tabular}{|c|c|c|c|}
\hline Natural Phenomena ${ }^{(a)}$. . . . . . . . . & 0.680 & 1.834 & 3.459 \\
\hline System Operation (b). & 0.162 & 0.028 & 0.353 \\
\hline Line or Equipment Failure ${ }^{(c)}$. . . . . & 0.068 & 0.037 & 0.129 \\
\hline Human Act, Foreign Objects, and Unknown $(d)$ & 0.226 & 0.093 & 0.780 \\
\hline & 1.136 & 1.992 & 4.721 \\
\hline
\end{tabular}

Permanent Versus Temporary Outages

Percent

Percent of total outages classified as

"permanent" (i.e. line was not restored

to service automatically in a very short

time)....................... $31.9 \quad 23.5 \quad 18.2$

(a) Natural Phenomena - Icing, snow, sleet, lightning, wind, tornado, hurricane, vibrating conductors, insulator contamination, flood, and fire.

(b) System Operation - Overload, overvoltage, undervoltage, switching surge, instability, and misoperation of relays.

(c) Equipment Failures - Line conductor, cable, ground wire, insulator, control device, generator, transformer, other generating station or substation equipment, etc.

(d) Human Act, Foreign Objects, and Unknown - Aircraft impact, vehicular accident, tree damage, animal and bird actions, personnel error, vandalism (including gun-shot), sabotage, and unknown causes. 
transmission lines are equipped with high-speed relaying systems that detect abnormal conditions and initiate tripping of circuit breakers on a faulted line within $1 / 20$ of a second.

\subsection{Weather Effects on Transmission Lines}

Table 2 illustrates that a majority of transmission line outages are caused by natural phenomena such as lightning, wind, snow, icing, etc. Thus, meteorological studies are important in planning and design of electrical transmission lines. Figure 11 indicates the impact of designing for various conductor ice loads on transmission line costs.

Lightning is probably the greatest single cause of power line outages. When lightning strikes a transmission line conductor, the over-voltage surge may cause a flashover ( $\mathrm{arc}$ ) to another conductor, to a supporting tower, or to the ground. This fault is sensed by high speed circuit breakers which interrupt the circuit in times as short as three cycles (1/20 of a second).

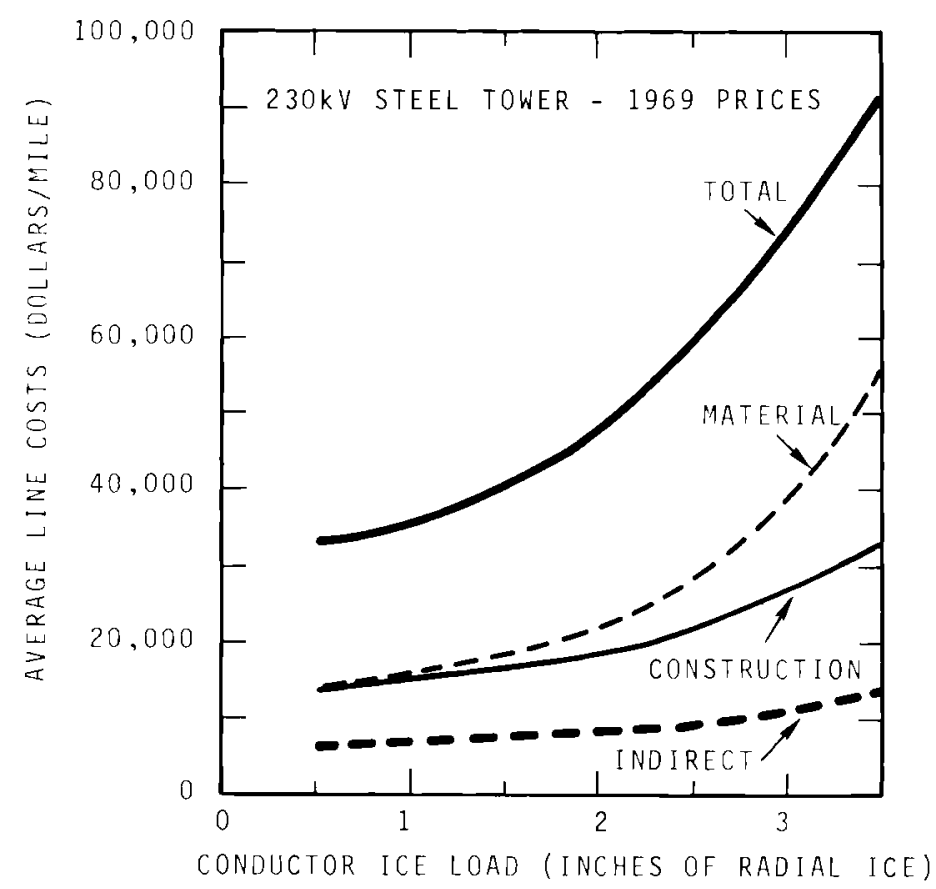

FIGURE 11. Transmission Line Cost Versus Designed Conductor Ice Load (10) 
As soon as the lightning-caused arc and associated ionized air path die out, the breaker recloses and the circuit operates normally unless permanent damage has occurred.

The design of a transmission line for lightning protection has a significant impact on transmission line costs. Transmission line lightning protection involves placing one or two grounded conductors (earthwires) near the top of the line supporting structures to intercept lightning strokes that would otherwise strike the circuit conductors. Typical lightning shield wire configurations are shown in Figure 12.

The BPA estimates the cost of double overhead ground wires for singlecircuit $500 \mathrm{kV}$ lines to exceed $\$ 13,000$ per mile (1976 prices). (11) In areas which have a high frequency of lightning storms, such as the Southeastern United States, lightning protection is used on nearly a11 transmission lines. (1)

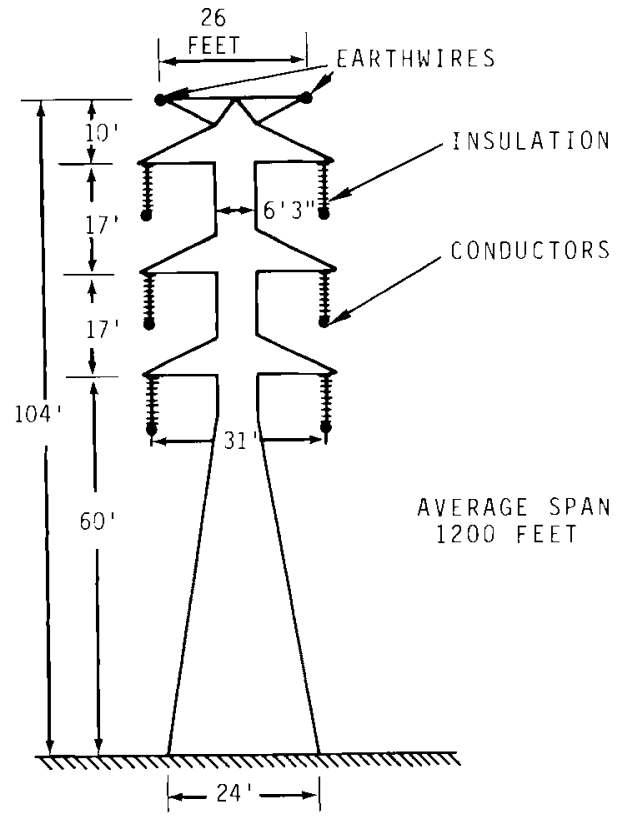

CONVENTIONAL 220-kV DOUBLE-CIRCUIT TOWER

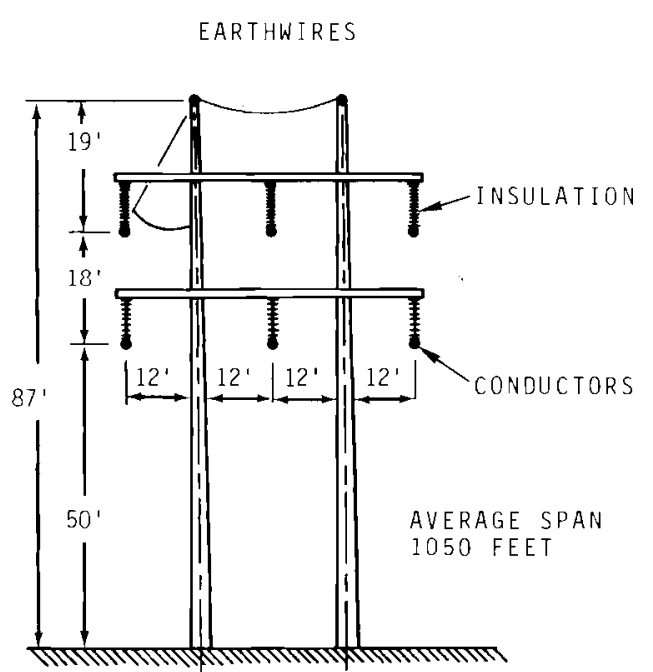

220-kV DOUBLE-CIRCUIT LINE, HORIZONTAL CONFIGURATION

FIGURE 12. Typical Lightning Shield Wire Configurations 
Transmission line designs and costs will vary significantly depending on the terrain and climatological conditions encountered. BPA uses the following five basic design conditions for transmission line structures:

- $100 \mathrm{mph}$ wind - conductors bare

- $40 \mathrm{mph}$ wind - conductors covered with $2 \mathrm{in}$. of rime or $3 / 4 \mathrm{in}$. of solid ice, or $56.6 \mathrm{mph}$ wind - conductor covered with $1 \mathrm{in}$. of ice

- No wind - conductors covered with 1-1/2 in. solid ice

- $40 \mathrm{mph}$ wind - conductor covered with $1 / 4$ in. ice and meeting the National Electrical Safety Code overload factors.

- Loading under broken wire conditions. Loads vary depending on tower type. If a line design encounters conditions more severe than these, span lengths between structures are shortened accordingly. (12)

The effect of corona discharge on line losses during foul weather was mentioned in the section on line losses. The increase in corona discharge during rain or snow increases radio and television interference from EHV transmission lines.

Insulator contamination interacting with moisture and pollutants in the atmosphere is a cause of faults due to insulator flashover. Insulators on overhead lines and outdoor terminal equipment are being exposed to increasing amounts of dust and air pollution contamination which increases the conductivity on insulating surfaces. As insulator strings become longer at the higher voltages, the flashover problem becomes worse because the voltage distribution across the total length is less uniform and the dielectric stresses are greater near the conductor end of the insulator. Development of an insulation system that is not significantly affected by contamination, or one which has the capability of maintaining more uniform voltage distribution acrass its entire length is being investigated.

During the 1971 California earthquake much of the equipment at the Sylmar Converter Station (Los Angeles end of the dc Pacific Intertie) was damaged. This caused renewed interest in the design and construction of damped earthquake-proof transmission facilities. 


\subsection{Transmission Line Construction Practices}

Much of the information in this section on transmission line construction practices was provided by the Bonneville Power Administration.

Major transmission line construction activities include surveys, rightof-way (ROW) and danger tree clearing, access road construction and/or improvements, excavation for and installation of footings, tower assembly and erection, stringing and tensioning conductors, and site restoration.

ROW clearing and access road construction are often concurrent as the first phase of construction. The time required to complete a sequence of construction from beginning the ROW clearing to site restoration is variable and depends on the size and length of the line, geographical location, topography, special restrictions, methods of construction, and type of equipment used.

Transmission towers are of two basic types. A suspension tower suspends the wires (conductors) above the ground and is used simply to maintain a minimum distance between conductors, and between conductors and ground. Dead-end towers are used at a spacing which will maintain and control the pull or tension in the conductors. Dead-end towers are designed to withstand both longitudinal and transverse conductor tension. As a consequence, dead-end towers are generally heavier than suspension towers. Dead-end towers are placed where a line angles sharply, and at intervals in straight sections to provide adequate stability for long spans, and in steep terrain where the line pitches up or down sharply.

The structural strength of wood poles limits their use generally to lines carrying power at voltages below $230 \mathrm{kV}$. In addition, the limited length of wood poles restricts the electrical clearance to ground that they can provide. Some $230 \mathrm{kV}$ and $345 \mathrm{kV}$ lines have been built using wood-pole structures, but in most instances the weight of the conductor required for higher voltages precludes economical spacing of the structures. Steel towers are generally used for even low-voltage transmission lines if structure spacing is limited 
by topography to $1000 \mathrm{ft}$ or more. Self-supporting lattice steel towers are generally used on $230-\mathrm{kV}$ and higher voltage lines since they are the most economical tower type for higher voltage lines.

A tower foundation normally has four footings. Each footing is installed in the ground and a tower leg extension is attached to each footing stub. There are various footing designs; for instance, BPA uses five basic types (grillage, concrete, pressed plate, grouted rock, and piling). (14) Pressed plate and grillage footings are the most common. Concrete, grouted rock, and pile footings are designed for special conditions, such as river crossings, esthetically-designed structures, and footings in solid rock and unstable soils.

Tubular steel, prestressed concrete, and laminated wood poles are used in special cases in urban and developing areas where close views warrant more aesthetic structures. They can be used for all voltages, but their use is limited because of high costs. Footings for these poles are of a different design than those for lattice towers.

Two preliminary activities, initial surveying for a line location and setting up contractor shop and vehicle storage areas, must occur before actual transmission line construction can begin. These areas are often used for the storage of equipment and material and are commonly referred to as the "staging areas." Equipment stored at these sites may include crawler tractors, back-hoes, cranes, various types of trucks and other equipment used during line construction. Material typically includes tower steel and bolts, conductor reels, insulators, culverts, and miscellaneous materials. Size of a typical staging area is 3 to 4 acres.

Clearing the ROW involves removal of all trees and brush within and adjacent to the ROW that could interfere with the safe operation of the transmission line and helispot landing sites. The BPA new-construction clearing criteria call for removal of those trees adjacent to the line that could fall directly into the line or towers. Trees adjacent to the ROW which could grow sideways into the flashover distance are also removed. These criteria are summarized in Tables 3 and 4. 
TABLE 3. Bonneville Power Administration Construction Criteria for Conductor Clearance from Standing Trees (14)

\begin{tabular}{cr}
$\begin{array}{c}\text { Nominal Line } \\
\text { Voltage }-\mathrm{kV}\end{array}$ & $\begin{array}{r}\text { Stand ing Tre } \\
\text { Minimum Clear }\end{array}$ \\
\cline { 2 - 2 } $115-\mathrm{kV}$ and lower & $10 \mathrm{ft}$ \\
$230-\mathrm{kV}$ & $15 \mathrm{ft}$ \\
$287-\mathrm{kV}$ & $17 \mathrm{ft}$ \\
$345-\mathrm{kV}$ & $17 \mathrm{ft}$ \\
$500-\mathrm{kV}$ & $18 \mathrm{ft}$
\end{tabular}

As sumptions:

1. Standing trees - trees growing under a static conductor or which may grow into a swinging conductor, assuming a conductor wind thrust of $8 \mathrm{lb} / \mathrm{ft}^{2}$.

2. Figures are based on standing trees having a 15-year growth factor at an average growth rate.

TABLE 4. Bonneville Power Administration Construction Criteria for Conductor Clearance from Falling Trees (14)

\begin{tabular}{lr}
$\begin{array}{c}\text { Nominal Line } \\
\text { Voltage - kV }\end{array}$ & $\begin{array}{r}\text { Falling T } \\
\text { Minimum Cle }\end{array}$ \\
\cline { 2 - 2 } $115-k V$ and lower & $1 \mathrm{ft}$ \\
$230-k V$ & $2 \mathrm{ft}$ \\
$287-k V$ & $2 \mathrm{ft}$ \\
$345-k V$ & $2 \mathrm{ft}$ \\
$500-k V$ & $3 \mathrm{ft}$
\end{tabular}

Assumptions:

1. Falling trees - trees that could fall or come within flashover distance of the outside conductor when falling.

2. Figures are based on falling trees having an 8-year growth factor at an average growth rate. 
Al1 trees and undergrowth must be cleared completely from helispots, tower erection sites, crane sites, and conductor reel and tensioning sites. In open forests BPA sometimes uses photogrammetry (land surveys using aerial photograph) to delineate ROW clearing limits even to the extent of identifying individual trees on or near the ROW that should be removed. (14) Using stereoscopic aerial photographs it is possible to identify tree species, growth factors, and the heights of individual trees to determine which should be cleared. This method is particularly useful in minimizing the amount of clearing required and associated visual impact. Furthermore, when compared to ground surveys, experience has proven it to be less costly.

Terrain conditions will determine the type of equipment to be used in clearing. In forest areas where slope, soil stability, and climatic conditions are favorable, a tractor equipped with a clearing blade and winch can normally be used to pile slash and move logs to loading sites. Rubber-tired log loaders and big-tired tractors are often used since they create less disruption to ground resources, as in sensitive marshlands.

Where terrain factors are unfavorable, or where the use of tractors could excessively damage the ground cover, a high-lead yarding operation may be used. Balloon and helicopter logging methods have also been used on some construction jobs. (14)

At wood-pole structure sites, BPA clears all trees, brush, stumps and snags, regardless of height or type, in an area $60 \mathrm{ft} \times 60 \mathrm{ft}$ for guyed structure sites, and a $30 \mathrm{ft} \times 30 \mathrm{ft}$ area for unguyed structures. (14) At most stee 1 tower sites an area approximately $150 \mathrm{ft} \times 150 \mathrm{ft}$ is cleared, although some sites require larger areas. Stumps are left to a maximum height of $6 \mathrm{in}$. above the ground. Trees may be topped in some visually sensitive areas where it is desirable for aesthetic reasons to retain certain trees that would otherwise come within minimum safe clearances of the conductors.

Nonmerchantable slash is burned in an approved manner, chipped, or occasionally left for wildlife cover. Burning methods can include both open-pile draft burning and high temperature controlled burning techniques. 
Roads are required for access to transmission lines, substations, and radio communication and control sites. These roads may be temporary for the purpose of moving heavy equipment, structural material, or other hardware to the construction site, or they may be permanent or semipermanent for use in maintaining the transmission line. It is BPA policy to provide ground access to every structure site except where this is prevented by terrain, expense, property owner objections, safety requirements, or severe environmental problems. (14) off ROW access roads range from 12 to $16 \mathrm{ft}$ wide. In mountainous terrain, their lengths have been from $1 / 4$ to $1-1 / 2$ miles of road per mile of line. In flat or rolling terrain, their lengths range from no constructed roads to one mile of road per mile of transmission line. In many cases, access roads will be located within the cleared ROW. Tower access roads are built to provide access to sections of the ROW from existing roads when the ROW is not suitable for through-road construction or passage.

When transmission lines cross relatively flat, easily accessible rangeland, permanent access roads may be unnecessary. Temporary access roads may be built across cultivated areas. In this event, BPA restores the land to its original condition when the roads are no longer needed for construction. If the land owner wishes, the roads can be left for his use. Permanent drainage systems are provided to control soil erosion; if the roads are not rocked, they are graded and seeded to control erosion. (14)

After the transmission line ROW is cleared and the access roads are built, tower construction begins. On a typical line with steel towers the initial line construction operation involves excavation for and installation of four footings, each of which supports one leg of the tower. The excavations for the footings vary with the size of the tower to be erected. On lower voltage 1 ines, the excavation for each footing may be only $8 \mathrm{yd}^{3}$. However, on higher voltage lines, excavations are often $100 \mathrm{yd}^{3}$, and may be as large as $300 \mathrm{yd}^{3}$ per footing. (14) A large backhoe is generally used to dig the excavations; however, where access is restricted, a clamshell or hand digging may be needed. After installation of tower footings, the excavations are backfilled and the site is restored as nearly as practicable to the original ground contours. 
After the footings and tower leg extensions are in place, the tower is assembled. A 150-ft $\times 150-\mathrm{ft}$ area within the ROW is normally used to assemble the tower sections before erecting the tower. The time required to assemble a tower will vary from 1 to 3 days, depending on the type and amount of steel. A mobile crane of 35-ton capacity or less is often used to assist the assembly crew, which normally consists of six to nine men.

As towers are assembled, the third major operation, erection, commences. This operation generally uses a rubber-tired or track-mounted crane of 35 to 90 ton capacity, weighing up to 70 tons. The crane 1 ifts the tower body over the leg extensions which are then bolted to the tower. When this operation is completed, the bridge or uppermost part of the tower is hoisted into place atop the tower body and bolted into place.

Cranes require a flat, horizontal work surface. Normally, a bulldozer clears and levels an area approximately $40 \mathrm{ft} \times 40 \mathrm{ft}$, usually within the cleared area used for assembly. The area leveled for the crane is frequently retained, especially in hilly wooded terrain, so that a crane may later be set up for line repair and maintenance without having to re-establish a level site.

The erection crew usually averages eight or nine men. It is not unusual for an erection crew to put up five 500-kV suspension towers in a single day. Erection by helicopter is sometimes preferred, particularly in environmentally sensitive areas.

One of the final operations in the construction of a typical transmission line is stringing and tensioning the conductors.

Lowboy trailers are used to transport the conductor reels to each stringing site. These sites will depend on the length and weight of conductor to be strung, and location of the towers, but will normally occur at intervals of 2 to 3 miles. Level areas are generally selected for stringing sites. Ir. mountainous terrain an area may be leveled (width of ROW $\times 200 \mathrm{ft}$ ) so the reels and pulling machine can be correctly aligned. 
A pulling machine with up to $25,000 \mathrm{ft}$ of steel cable (pulling line) is placed at one end of the section of line to be strung. The reel is set up at the other end. This equipment must be on level ground. After the pulling machine is in place, a sock line (either a nylon rope or a steel cable) is strung through stringing sheaves (pulleys) attached to the insulator strings at each tower. Actual stringing of the sock line may be done by tractor, helicopter, and/or manual methods. Helicopter stringing has become conventional because the costs are now more comparable to other methods and less environmental disruption occurs.

The sock line is attached to the pulling line on the pulling machine $\operatorname{drum}(s)$. The sock 1 ine is then used to pull the heavier pulling line through the sheaves to the conductor reel site. The conductor is then attached to the pulling line with a clamp. The pulling machine drum is then used to pull the pulling line and conductor through the sheaves. Generally, one or more crawler tractors of D-6 size or larger are used to temporarily secure the conductors once they are strung. After stringing is completed, the conductors must be pulled to the desired tension and lifted into place along with the dead-end assemblies at each dead-end tower. This is normally done by crawler tractors of D-6 equivalent or larger equipped with special tensioning or sagging winches.

After construction activities are completed, the ground around the tower sites, conductor reel sites, and puller site locations is reshaped, contoured to a condition consistent with the natural landscape, and seeded. In areas designated as cultivated land, the owner is reimbursed for the cost of subsoiling and replanting this crop. To minimize erosion and other damage BPA usually requires the land disturbed during construction activities to be restored within 30 days after construction is completed on each tract. (14) On projects that extend over several seasons, seed may be planted each season in order to minimize erosion, even though further disturbance will occur during the following season's construction activities. 


\subsection{Transmission Line Costs}

Significant differences in electrical transmission costs can occur, even within the same general geographical area, due to differences in such items as labor costs, route conditions, right-of-way (ROW) acquisition costs, and the length of line involved.

\subsubsection{ROW Costs}

Costs of transmission line ROW vary widely depending upon land use, terrain, transmission voltage, and competition for land. In some heavily populated areas it is virtually impossible to build overhead transmission lines so underground circuits may be used.

Many utilities have replaced lower voltage transmission lines with EHV lines or used multiple circuit configurations to increase the amount of power that can be transmitted over the same ROW. Right-of-way and clearing costs for some actual $500 \mathrm{kV}$ line installations, reported by the Federal Power Commission in $1970,{ }^{(1)}$ ranged from a low of $\$ 2000$ per mile for desert land to a high of $\$ 59,000$ per mile for land near an urban center (1968-1969 prices).

The width of ROW required by an overhead transmission line depends on many factors, including the type of poles or towers used to support the conductors and the configuration in which the conductors are supported. Typical ROW widths used by the BPA for estimating purposes range from $50 \mathrm{ft}$ for a $115 \mathrm{kV}$ circuit to $140 \mathrm{ft}$ for some $500 \mathrm{kV}$ circuits. (14)

\subsubsection{Total Transmission Costs}

The cost per unit of ac electrical energy transfer decreases with increasing voltage levels, even though total capital costs increase, because the capacity of transmission lines in stability-limited systems increases approximately as the square of voltage, while total costs increase at a lower rate. In addition, the line losses per unit of capacity are usually less with higher voltages.

For a given distance and load, there is an optimum voltage which results in a minimum cost per kilowatt-hour transferred, as shown in Figure 13. Figure 13 is based on the following assumptions: ${ }^{(1)}$ 


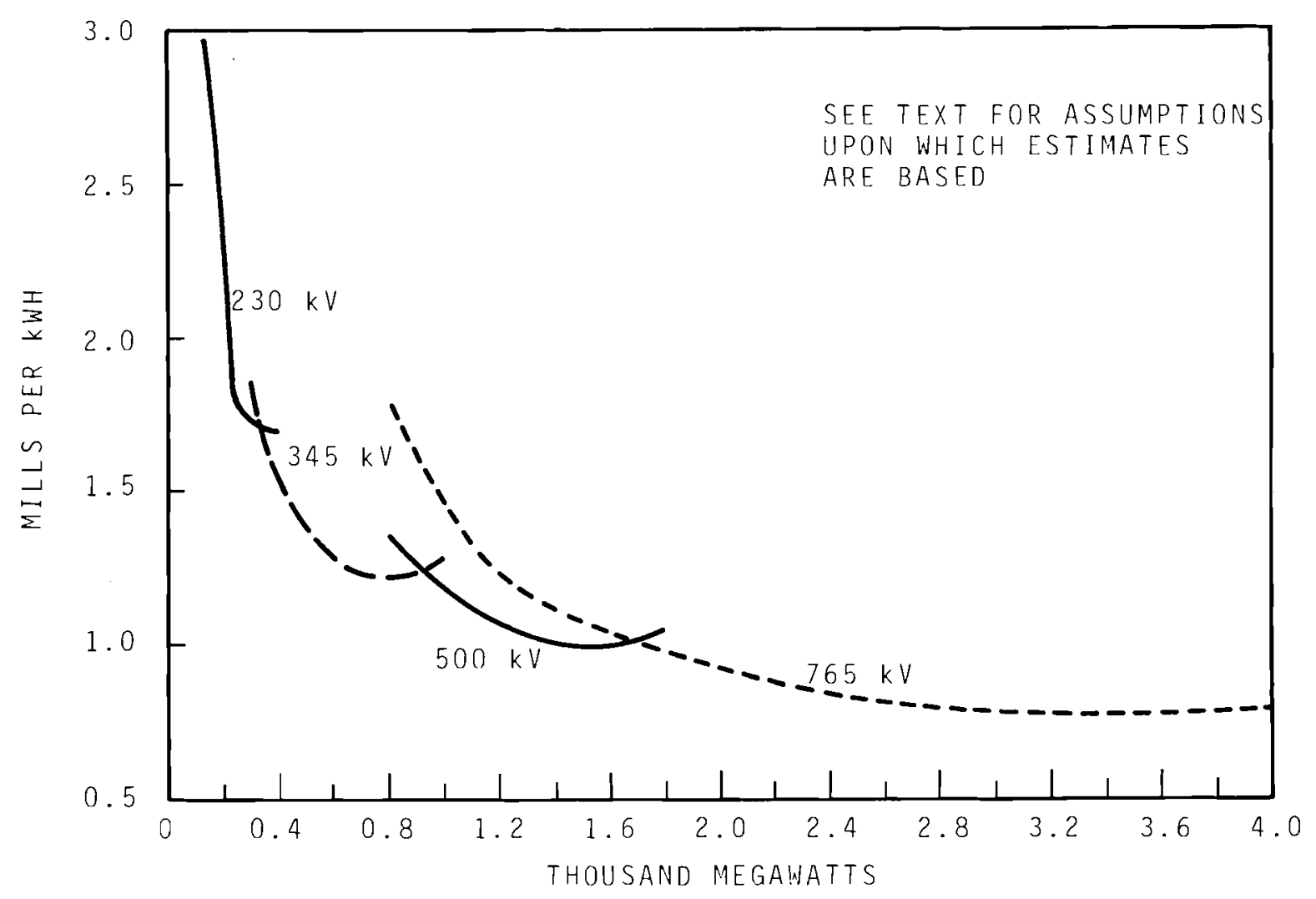

FIGURE 13. Electrical Energy Transmission Costs for 200 Miles (1)

- The cost of line ROW is $\$ 775$ per acre.

- The load factor is $70 \%$.

- Annual fixed charges are $12.5 \%$ for transmission 1 ines and $13.5 \%$ for substation facilities. Annual operation and maintenance costs are $1 \%$ of the investment cost in each case.

- Installed costs for substations include autotransformers, circuit breakers, and air-break switches, plus property cost of $\$ 26,400$ and site-development costs.

- Series compensation is used in discreet amounts of $20 \%, 40 \%$ or $60 \%$ where required and, in such cases, the installed costs of capacitors, protective equipment, and switchgear are included.

- Cost of capacity losses, transmission construction, and various installed costs of equipment $i$ tems are those appearing in the Federal 
Power Commission's 1968 Report, Hydroelectric Power Evaluation (FPC P-35), and its 1969 Supplement (FPC P-38). These costs are in 1968 dollars.

Because there are wide geographic variations in transmission line designs and costs, Figure 13 is intended to illustrate general relationships and should not be used for estimating costs.

Transmission line costs vary significantly according to geographical location, supporting structure (tower or pole), conductor configuration, and terrain. Some detailed transmission line cost estimates, based on material and construction cost information from BPA, ${ }^{(14)}$ are shown in Table 5 . The estimates are based on component prices in early 1976. It is interesting to note the cost differential between steel tower and steel pole $\mathrm{H}$ frame construction for $500 \mathrm{kV}$ lines. Three types of transmission structures are illustrated in Figure 14.

\subsection{Development Activities and Future Trends}

Transmission voltage levels have increased to conform to load growth. Transmission voltages above $765 \mathrm{kV}$ will be needed in the future and development activities are under way on ultra-high-voltage (UHV) transmission at levels as high as $2000 \mathrm{kV}$. (BPA is building two $1100 \mathrm{kV}$ test facilities in Oregon at the present time.) Flashover due to insulator contamination, switching surge voltages, and the reduction of audible noise are just a few of the problems which must be solved before transmission at voltages above $765 \mathrm{kV}$ can take place. Several investigations concerning possible subtle effects of strong electrical fields on humans and other life forms are underway at the present time. UHV transmission towers are being designed which will provide the conductor spacing required at voltages up to $1500 \mathrm{kV}$ while minimizing the ROW required.

\subsection{Environmental Impact}

There are now about 433,300 miles of overhead electrical transmission line (69 kV and above) installed in the 48 contiguous states. (2) The ROW requirement for these lines is between $4,000,000$ and 5,000,000 acres. 
TABLE 5. Typical Transmission Line Cost Data (Based on BPA Cost Estimates, 1976)

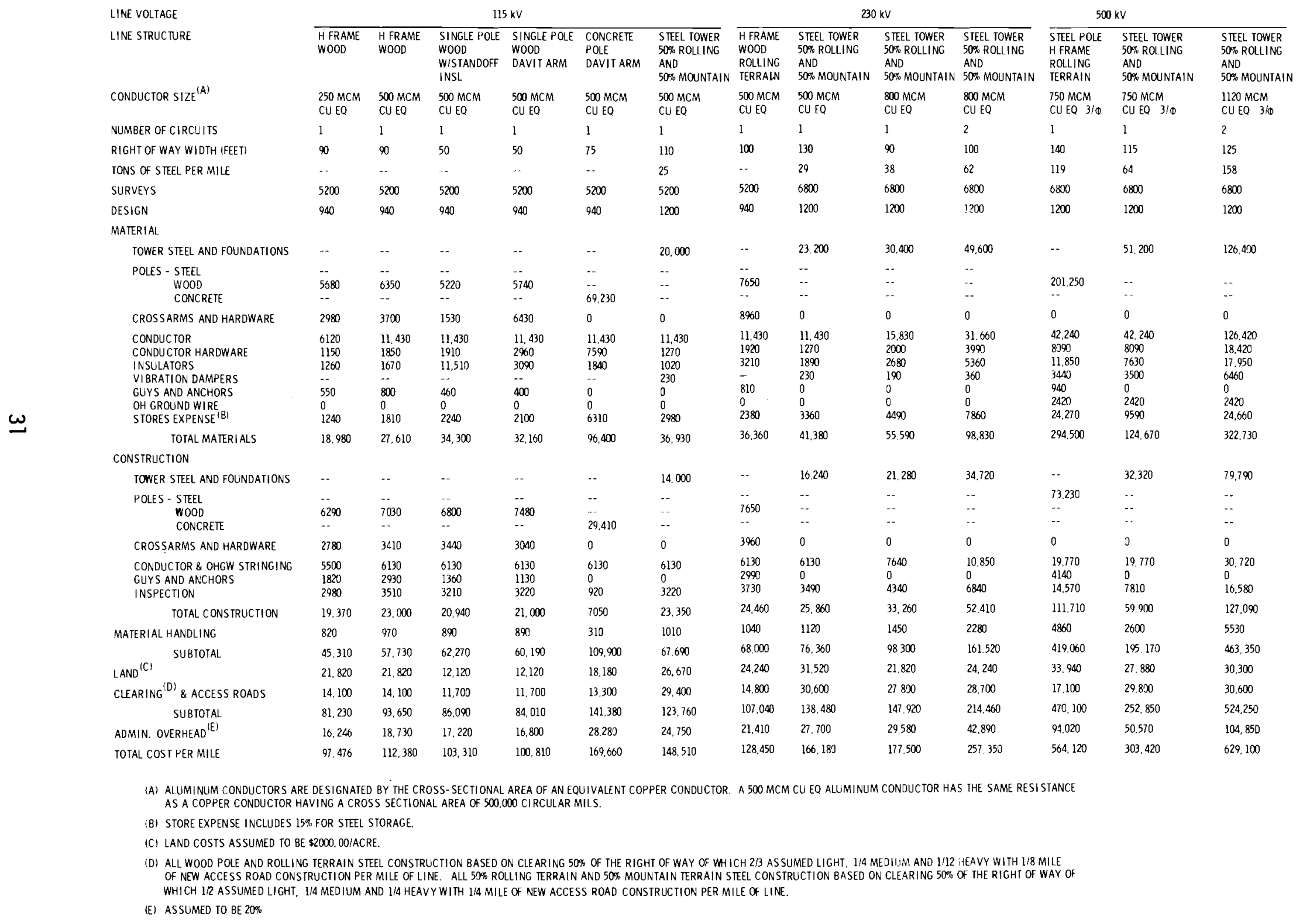




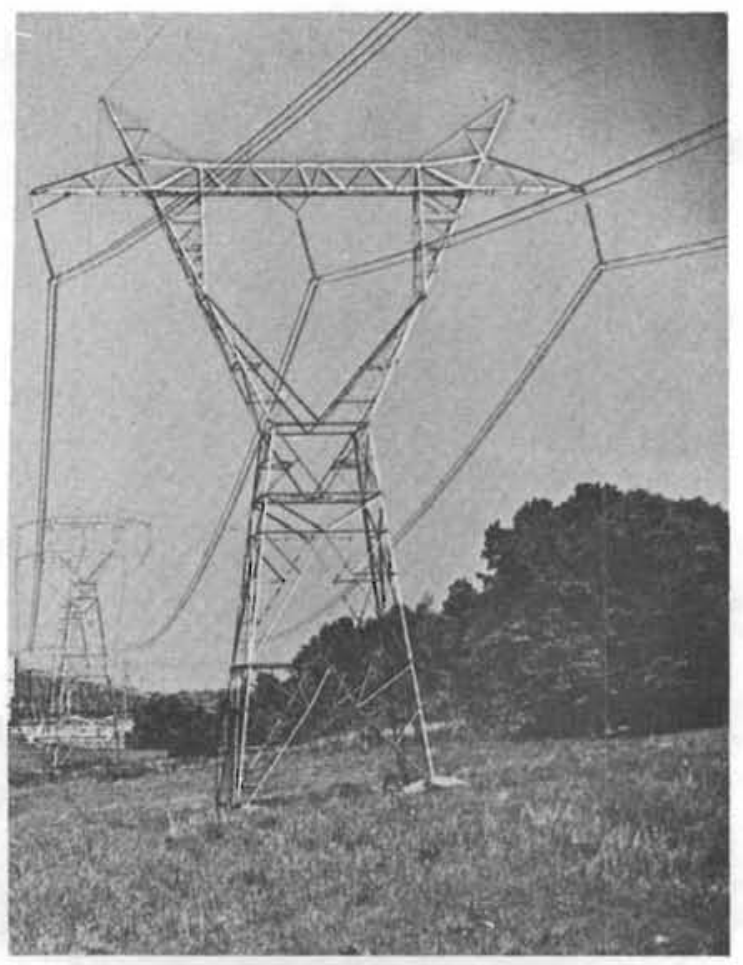

Lattice Tower

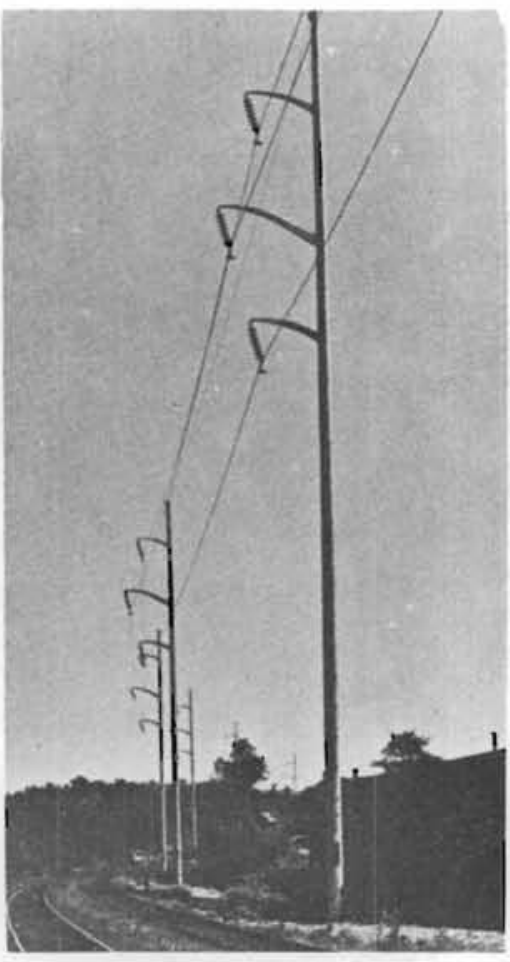

Steel Pole

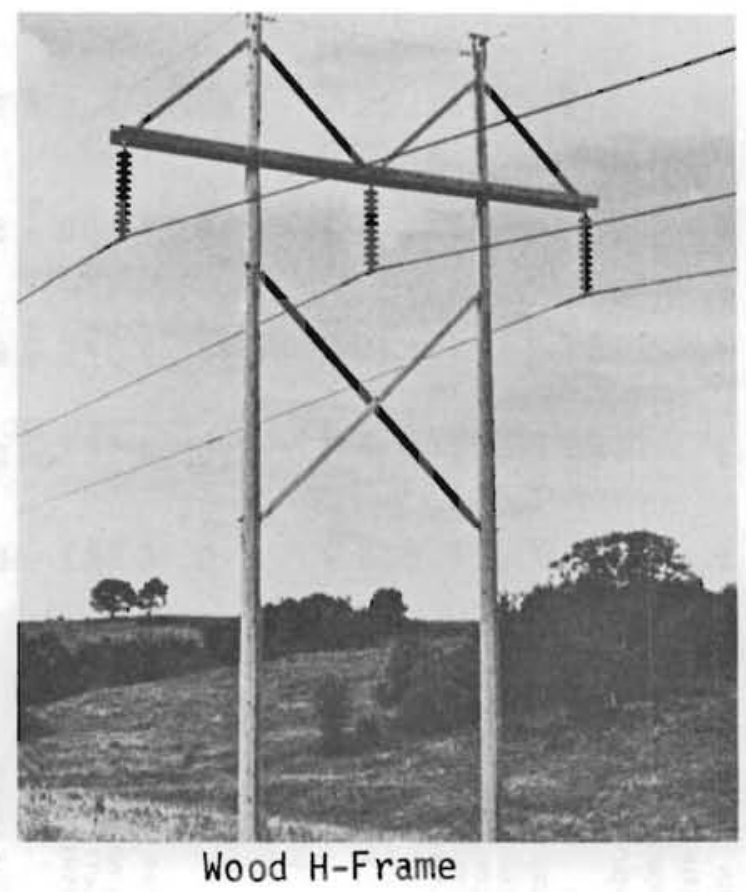

FIGURE 14. H-Frame Transmission Line Structures 
Estimates for 1990 indicate that there will be about 500,000 miles of electric transmission lines that will bring the total to approximately $7,000,000$ acres of ROW. (15)

\subsubsection{Interferences}

Overhead transmission lines may interfere with activities that could take place if the lines were not present. The most important interferences are described below.

- Transmission line structures remove some land from normal use in agricultural areas and may restrict the use of large agricultural equipment. Towers and poles can interfere with optimum placement of large circular irrigation systems which are becoming common. The systems cover about 130 acres using a rotating arm which is about $1 / 4$ mile long. If the irrigation system is in place, it may be possible to design and locate towers so that the circles are spanned by the conductors. Some of the systems (the electrically-driven type) are equipped with checking equipment which can reverse the direction of the sprinkler when it approaches the tower. Otherwise the system will have to be disconnected, pulled past, and reconnected on each pass. This can result in major pipe adjustments, a costly and time-consuming solution. If no satisfactory solution exists for a circular system, a change to other irrigation equipment may be required. This could increase farm capital and operating costs as shown in Table 6 .

- Transmission and distribution lines pose an inherent hazard if objects such as hand-move portable irrigation pipe, construction booms, or other conducting materials are brought into close proximity to the line. Because conductor height from the ground increases with voltage, the probability of such accidents is greatest with lower-voltage lines. However, hand-move irrigation pipe is usually made in $40 \mathrm{ft}$ sections. This length is greater than the conductor to ground clearance at midspan of most lines, including $500 \mathrm{kV}$. 
TABLE 6. Cost Comparison for Principal Sprinkler Systems

\begin{tabular}{|c|c|c|}
\hline Type of System & $\begin{array}{c}\text { Relative } \\
\text { Capital Cost }\end{array}$ & $\begin{array}{c}\text { Relative } \\
\text { Labor Cost }\end{array}$ \\
\hline \multicolumn{3}{|l|}{ Set Type } \\
\hline Hand-move portable & 1.0 & $100 \%$ \\
\hline Tow-line & 1.5 & $40 \%$ \\
\hline Side-roll & 1.9 & $40 \%$ \\
\hline Giant sprinkler (stationary) & 1.2 & $75 \%$ \\
\hline Solid-set or permanent & $5.0 \&$ up & $20 \%$ or less \\
\hline \multicolumn{3}{|l|}{ Moving Type } \\
\hline Center-pivot or circular & 1.8 & $15 \%$ \\
\hline Trail-1ine & 2.0 & $35 \%$ \\
\hline Traveler (moving sprinkler) & 1.7 & $30 \%$ \\
\hline Rectangular (moving lateral) & 2.0 & $25 \%$ \\
\hline
\end{tabular}

Source: WSU Irrigated Agricultural Research and Extension Center, September 1971, Water Works, $3 \mathrm{pp}$.

- Transmission lines pose a potential obstruction to low-flying aircraft. In general, however, most transmission lines are below the minimum flight altitudes allowed by the Federal Aviation Administration (FAA) except for special operations such as crop dusting. FAA standards are followed in marking lines and structures. Additional precautions employed on large river crossings usually include airway beacon lights on towers, colored spherical markers on conductors, and airway marker paint colors on towers.

- Radio and television reception adjacent to transmission lines may suffer some interference during foul weather in low signal strength areas. The presence and amount of interference depend on several factors. These factors are discussed later in Section 3.8.6.

- Transmission line construction will result in the dislocation of any residences located on the ROW.

- Transmission lines through timber production areas will result in permanent loss of the ROW to timber production. 
- Location of transmission lines near the crest of mountains or ridges may preclude removing nearby timber by conventional ridge-top techniques. Other more expensive logging techniques such as helicopter, balloon or the skyline system may still be used.

- Transmission lines located adjacent to major highways and throughways will probably preclude normal business development of these areas.

\subsubsection{Visual Impact}

One of the most frequent objections to overhead transmission lines is their adverse visual impact especially in scenic, recreational or highly forested areas. The national objective of improving the quality of the environment for the benefit of present and future generations and the concurrent rapid growth in demand for electrical energy make it apparent that improving the appearance of power transmission facilities and preserving scenic and related environmental values is very important in transmission line planning and design. There is great emphasis today on reducing the visual impact of overhead transmission lines by proper route selection, strategic placement of towers, judicious ROW clearing, landscaping of ROW, selection of more pleasing tower designs, the use of compatible colors which cause the transmission line to blend in with its surroundings, and improved substation designs. Figures 15 and 16 illustrate some of the newer, aesthetically pleasing concepts in tower and substation design.

To avoid adverse visual impacts, materials used to construct transmission structures and the colors of the components should harmonize as much as possible with the natural surroundings. Treated wood poles may be less obtrusive in forest or timber areas, while weathered galvanized steel or aluminum which is treated to reduce glare will be less apparent when the structures must be silhouetted against the sky or are viewed from a distance. Painted transmission poles and towers are sometimes used successfully to blend structures with the surrounding landscape.

The use of tapered steel poles rather than conventional towers has, in a number of cases, improved the appearance of ROW. With crossarms of pleasing shapes, the pole structures look clean and uncluttered. A disadvantage is 

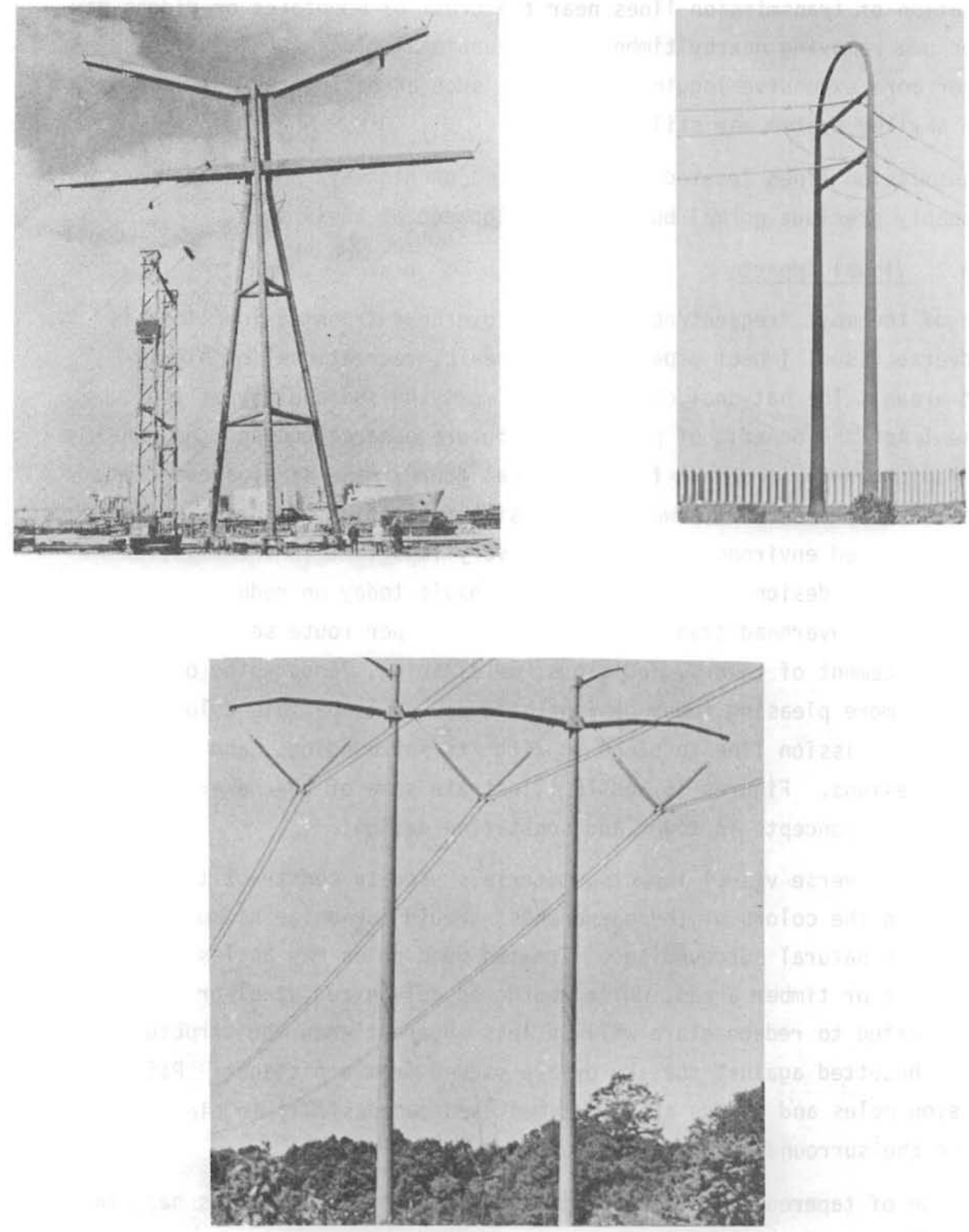

FIGURE 15. Recent Pole and Tower Designs 

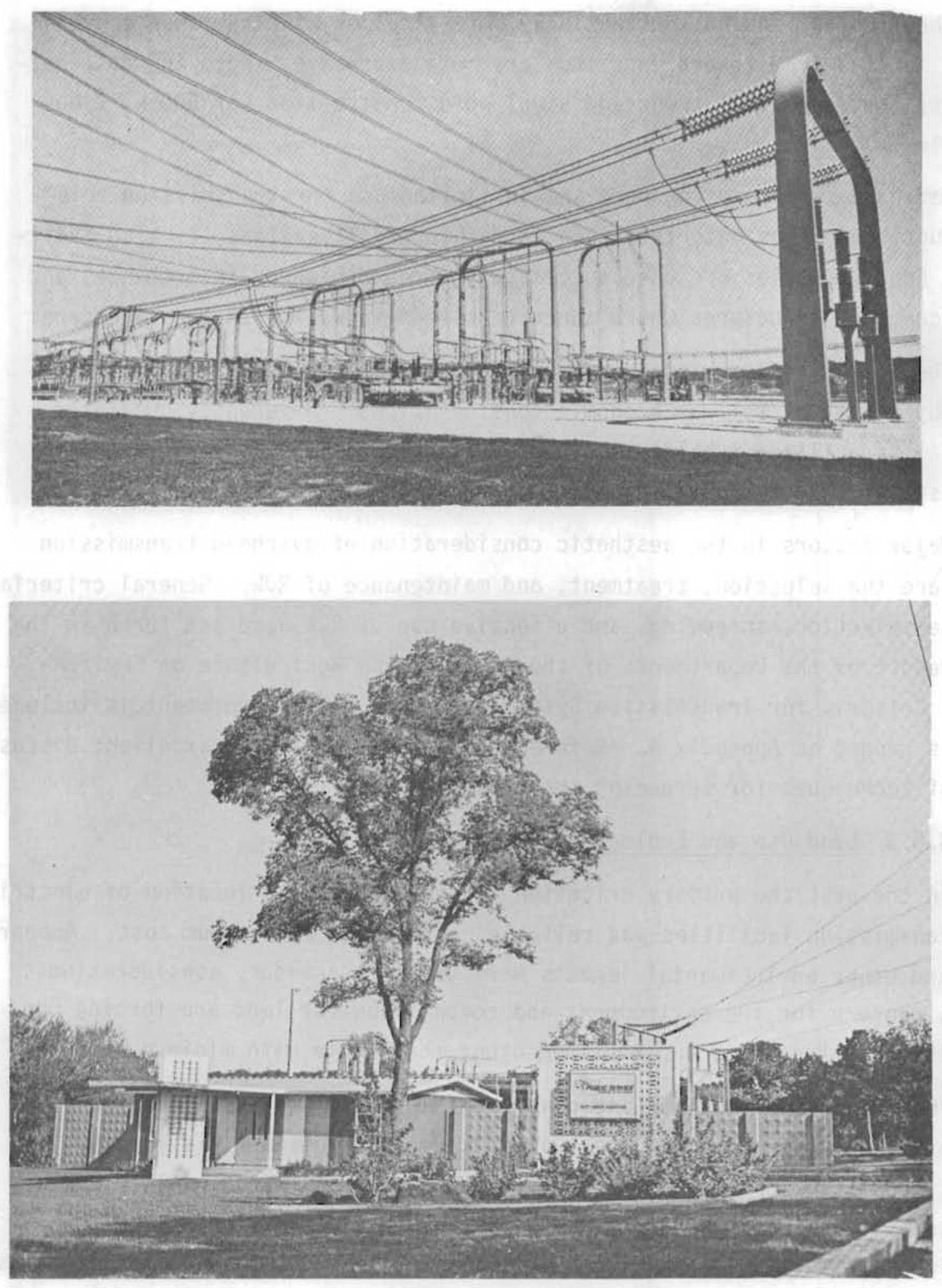

FIGURE 16. New Substation Designs 
that these poles require substantially more steel or aluminum than conventional lattice type towers, and thus are more expensive. Note the cost differential between steel tower and steel pole construction for $500 \mathrm{kV}$ lines in Table 5 .

Laminated wood and concrete are in limited use for transmission pole construction. 0ther material, such as reinforced fiberglass, is also available. Concrete poles are used successfully around highway interchanges and other concrete structures where concrete blends in well with the landscape.

The design of tranmission line structures is increasingly being influenced by visual as well as economic considerations. A recently completed $500 \mathrm{kV}$ line utilized tubular-steel poles even though the overall cost was at least twice as much as it would have been for lattice towers.

Major factors in the aesthetic consideration of overhead transmission lines are the selection, treatment, and maintenance of ROW. General criteria for the selection, screening, and effective use of ROW were set forth in the 1970 Report of the Departments of the Interior and Agriculture on Environmental Criteria for Transmission Systems. A copy of this document is included in this report as Appendix A. Reference 17 also contains an excellent discussion of techniques for screening transmission lines.

\subsubsection{Land Use and Ecology}

In the past the primary criterion for the design and location of electrical transmission facilities was reliable performance at minimum cost. Appearance and other environmental impacts were usually secondary considerations. Today, concern for the environment and competition for land are forcing consideration of locations and routings other than those with minimum costs.

The effects of location and construction of overhead transmission 1 ines may vary widely depending on the type of terrain involved. Air quality, microclimate, soil productivity, erosion patterns, and water quality may be affected, as well as vegetation and wildlife. Where the lines cross level grasslands or farming areas with easy access, the impact is significant almost exclusively at the tower and substation sites, and is of relatively short duration. In mountainous, forested areas, impacts are more serious, visible, and long-lasting. 
3.8.3.1 Intensive Use of Existing ROW. In many instances existing transmission ROW are upgraded by the addition of parallel circuits or replacing present circuits with higher voltage lines. Double circuit lines sharing a single set of line structures are not unusual. However, these solutions are not without their shortcomings. Paralleling multiple circuits on transmission corridors increases the major risk of serious curtailment of system reliability due to loss of all lines on a single ROW. The additional ROW width required for multiple parallel circuits may make screening the corridor very difficult. Upgrading existing lines to higher voltages usually requires that existing structures (towers, etc.) be replaced by structures adequate for the higher voltage, and may require that the existing lines be shut down during the construction phase. Table 7 indicates the ROW requirements for various transmission voltage levels and circuit configurations.

TABLE 7. Right-of-Way Requirements (14)

\begin{tabular}{|c|c|c|c|c|}
\hline $\begin{array}{l}\text { Voltage } \\
\quad(\mathrm{kV}) \\
\end{array}$ & Type & $\begin{array}{l}\text { Number of } \\
\text { Circuits }\end{array}$ & $\begin{array}{r}\text { Width } \\
(\mathrm{ft})\end{array}$ & $\begin{array}{l}\text { Acres/ } \\
\text { Mile }\end{array}$ \\
\hline 115 & Wood Pole & Single Circuit & 90 & 11 \\
\hline 115 & Steel Tower & Single Circuit & 110 & 13 \\
\hline 230 & Wood Pole & Single Circuit & 100 & 12 \\
\hline 230 & Steel Tower & Single Circuit & $90-125$ & $11-15$ \\
\hline 230 & Steel Tower & Double Circuit & 100 & 12 \\
\hline 345 & Steel Tower & Single Circuit & 140 & 17 \\
\hline 500 & Steel Tower & $\begin{array}{l}\text { Single Circuit } \\
\text { Delta Configuration }\end{array}$ & $125-135$ & $13-16$ \\
\hline 500 & Steel Tower & $\begin{array}{l}\text { Single Circuit } \\
\text { Flat Configuration }\end{array}$ & $140-160$ & $17-19$ \\
\hline 500 & Steel Tower & $\begin{array}{l}\text { Double Circuit } \\
\text { Delta Configuration }\end{array}$ & 165 & 20 \\
\hline 500 & Steel Tower & $\begin{array}{l}\text { Double Circuit } \\
\text { Verticle (Stacked) } \\
\text { Configuration }\end{array}$ & $105-140$ & $13-17$ \\
\hline $800 \mathrm{DC}$ & Steel Tower & $\begin{array}{l}\text { Single Circuit } \\
\text { Flat Configuration }\end{array}$ & $100-150$ & $12-18$ \\
\hline $1100^{(a)}$ & Steel Tower & $\begin{array}{l}\text { Single Circuit } \\
\text { Delta Configuration }\end{array}$ & 180 & 24 \\
\hline
\end{tabular}


Improvements in transmission technology have allowed utilities to minimize incremental impacts on land use. These improvements have, over the years, enabled utilities to transmit increasing amounts of power over approximately the same ROW width by means of constructing higher voltage, larger capacity lines. For example, in the 1950s, a Row $125 \mathrm{ft}$ wide was required for a 230-kV 1ine. Later, with the development of 345-kV technology, approximately twice as much power could be transmitted using a ROW $140 \mathrm{ft}$ wide. More recently, with the advent of 500-kV technology, a double circuit line on a ROW only 105 to $165 \mathrm{ft}$ wide can now carry approximately 25 times the power of a $230-k V$ line. (14)

Table 8 , based on data provided by BPA, 11 lustrates the advantages of higher transmission voltages in reduced land, steel, and capital cost requirements per megawatt of power transmitted.

3.8.3.2 ROW Required for Tower Bases and Access Roads. The 1and occupied by a tower or other line structure is usually unavailable for other uses. This land may range from a few square feet for a wood pole to $1600 \mathrm{ft}^{2}(0.037$ acre $)$ for the base of a large $500 \mathrm{kV}$ tower. Transmission lines also limit land use underneath conductors. To meet National Electric Safety Code Standards, Occupational Safety and Health Act Regulations, and provide ready access to transmission lines for maintenance, residences and other tall structures are generally not allowed on ROW. Conductor clearances are discussed further in a later section of this report.

Roads are usually required for access to transmission line towers, substations, and communication sites. For instance, "It is BPA's policy to provide ground access to every transmission line structure except where this is prevented by terrain, prohibitive expense, property owner objections, safety requirements or severe environmental problems." ${ }^{14)}$ Access to individual towers and structures may be provided by a road on the ROW or individual roads from existing highways and rural roads, whichever is most practical. Where possible, BPA uses existing farm or logging roads for access. BPA's off-ROW access roads usually range 12 to $16 \mathrm{ft}$ wide.

Land may also be required for aircraft landing areas along transmission lines in heavily forested or remote areas. Aerial inspection and routine 
TABLE 8. Typical Transmission Line Requirements (14)

\begin{tabular}{|c|c|c|c|c|}
\hline & $\begin{array}{c}230-k V \\
\text { Single- } \\
\text { Circuit Line } \\
\end{array}$ & 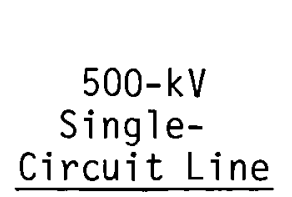 & $\begin{array}{c}500-k V \\
\text { High-Capacity } \\
\text { Double- } \\
\text { Circuit Line } \\
\end{array}$ & $\begin{array}{l}\text { 1,100-kV } \\
\text { High-Capacity } \\
\text { Single- } \\
\text { Circuit Line(a) }\end{array}$ \\
\hline Tons of steel per mile & $20-40$ & $60-90$ & $150-225$ & 340 \\
\hline Tons of conductor per mile & 13 & 32 & 98 & $130-160$ \\
\hline \multicolumn{5}{|l|}{ Transmission capacity } \\
\hline MW Capacity & 200 & 1,500 & 5,000 & 10,000 \\
\hline Width of ROW (feet) & $90-125$ & $105-160$ & $105-165$ & $170-190$ \\
\hline $\begin{array}{l}\text { Transmission capacity per foot } \\
\text { of ROW width, MW/foot }\end{array}$ & $1.6-2.2$ & $9.4-14.3$ & $30-48$ & $53-59$ \\
\hline $\begin{array}{l}\text { No. of lines required/ } \\
10,000 \mathrm{MW} \text { capacity }\end{array}$ & 50 & 7 & 2 & 1 \\
\hline $\begin{array}{l}\text { Relative Line }(s) \text { cost per mile } \\
\text { of } 10,000 \text { MW capacity }\end{array}$ & 4.4 & 1.0 & 0.7 & 0.5 \\
\hline $\begin{array}{l}\text { Acres of ROW required per mile } \\
\text { of } 10,000 \mathrm{MW} \text { capacity }\end{array}$ & $545-760$ & $89-136$ & $25-40$ & $21-23$ \\
\hline
\end{tabular}

Amount of land (acres) removed from productivity per mile of 10,000 MW capacity ROW

$\begin{array}{lrrrr}\text { Forest land } & 545-760 & 89-136 & 25-40 & 21-23 \\ \text { Cropland } & 6 & 2 & \text { Less than } 1.0 & \\ \text { Other (rangeland, etc.) } & 3 & 1+ & \text { Less than } 1.0\end{array}$

(a) In developmental state - Estimates provided for purposes of comparison only. Source: Data furnished courtesy Bonneville Power Administration. 
maintenance of transmission lines are frequently done using small planes or helicopters. In forests or areas where natural clearings are unavailable, BPA provides "helispots" for landing areas. These are areas along the ROW which are cleared of all vegetation and debris to a height of 6 in. Both emergency and multipurpose sites are built. The emergency sites are located to provide safe emergency 1 anding areas. The emergency site has a $150 \mathrm{ft} 40^{\circ}$ glide path, while the multi-purpose sites have a $450 \mathrm{ft} 10^{\circ} \mathrm{glide}$ path on two sides. Helispots are spaced about 1 mile apart and are usually located on ridges and knolls to provide ready access to tower sites. Natural or man-made clearings (fields, logging roads, former tower assembly sites, etc.) are utilized whenever possible.

Land requirements for substations may be from 2 to 50 acres, depending primarily on the voltage and the number of lines served.

3.8.3.3 Clearing Operations. In forested areas, transmission line construction begins as a logging operation. Clear cutting is done for tower sites, access roadways, crane sites, conductor reel and puller sites, and helispot sites. Selective cutting is done on the remaining Row; various tree clearings are needed for transmission lines at different voltage levels. Table 9 shows BPA estimates of the clearing required.

3.8.3.4 Air Quality. Air quality is affected by open burning of slash and unmarketable timber from the logging. Alternatives to open burring include chipping, tub or pit burning, and burning in high temperature portable burners. However, the impact of providing access for the burners or heavy chipping equipment may outweigh the advantages of these methods in some cases.

The BPA has investigated the use of air curtain combustors, ${ }^{(14)}$ which operate at high temperatures and thus burn more completely, reducing emissions. A camran "Portapit" screen burner was used during construction of the Trojan-Allston Transmission Lines No. 1 and No. 2 in 1973. On the TrojanAllston line, 202 acres of slash were cleared at a cost of $\$ 399,000$ or approximately $\$ 1975$ per acre. ${ }^{(14)}$ The average cost for normal open draft burning is $\$ 900$ per acre (1975 prices). The $\$ 1975$ per acre does not include costs of windrowing the slash and building improved roads needed to move the burner. 
TABLE 9. Approximate Acreage of Unstable (Danger) Tree Clearing Required for Typical BPA Transmission Lines as a

Function of Voltage Level (14)

\begin{tabular}{|c|c|c|c|c|}
\hline \multirow{2}{*}{$\begin{array}{c}\text { Timber } \\
\text { Classification } \\
\end{array}$} & \multirow{2}{*}{$\begin{array}{l}\text { Average } \\
\text { Height of } \\
\text { Unstable } \\
\text { Trees (ft) }\end{array}$} & \multicolumn{3}{|c|}{$\begin{array}{c}\text { Voltage Level of Transmission Line } \\
\text { (Single Circuit) }\end{array}$} \\
\hline & & Clearing & Req. (Acres 0 & Timber/MiTe)(a) \\
\hline \multirow{3}{*}{ Douglas Fir } & 50 & 16 & 16 & 20 \\
\hline & 100 & 28 & 28 & 38 \\
\hline & 150 & 38 & 38 & 44 \\
\hline \multirow[t]{3}{*}{ Red Alder } & 50 & 16 & 14 & 18 \\
\hline & 100 & 26 & 26 & 32 \\
\hline & 150 & - & - & - \\
\hline \multirow[t]{3}{*}{ Ponderosa Pine } & 50 & 14 & 14 & 18 \\
\hline & 100 & 26 & 26 & 32 \\
\hline & 150 & 38 & 38 & 42 \\
\hline \multirow[t]{3}{*}{ Lodgepole Pine } & 50 & 12 & 12 & 16 \\
\hline & 100 & 26 & 26 & 32 \\
\hline & 150 & - & - & - \\
\hline
\end{tabular}

(a) Assumptions:

1. Unstable (danger) tree-falling trees that would come within minimum distances determined by the $\mathrm{kV}$ rating.

2. Figures for clearing are based on unstable trees having an 8-year growth factor at an average growth rate.

3. A standard 100-ft span is used for computation purposes. A minimum conductor to ground clearance was used based on kV rating.

4. These acreage figures for each timber classification were arrived at based on a transmission line on relatively level terrain passing through a solid stand of forest species (i.e., a 500-kV singlecircuit transmission line constructed through a Douglas Fir forest having an average tree height of $100 \mathrm{ft}$ would require the clearing of 38 acres of timber/mile). 
Unless it presents a fire hazard, slash may be scattered, lying close to the ground and providing wildlife cover. If open burning is indicated, slash should be stacked into a pile with greater height than diameter. "Highstacking" tends to eliminate dirt and other noncombustible material and helps assure efficient combustion. Officials from the Oregon Forestry Department have compared this method favorably with air-curtain combustion.

3.8.3.5 Microclimate. Removal of vegetation for ROW construction can induce microclimate changes of solar radiation, wind velocities, and air temperatures. The changes will likely be confined mainly to the immediate ROW in forests; they may be adverse or beneficial depending on site conditions. The directional orientation of the ROW and the width of the clearing will determine whether more solar radiation reaches the ground in the clearing, and whether patterns of the prevailing winds will change. Air temperatures depend partly on solar radiation and wind, thus may change also. Frost pockets may be formed as cold air flowing downslope is impeded by vegetation at the downhill edge of the ROW. Moisture infiltration and runoff rates will be altered, as will soil temperatures and erosion rates; soil productivity may be changed as a result.

3.8.3.6 Soil Quality. Soil productivity may be changed in many ways by construction. Excavation and backfilling may cause mixing of the soil profile; this may benefit or harm productivity. Soil infiltration and drainage may be disrupted, increasing erosion. Humus in the topsoil is dispersed by mixing and by removing vegetation. Unless mitigating measures are taken, it may be years before fertility is restored naturally to the topsoil after such changes. This impact can be alleviated by segregating topsoil during digging operations and replacing it during back-filling operations.

Vehicle and equipment movements can change the soil structure. Off-road vehicle movements, particularly during muddy periods or spring thaws, cause ruts and otherwise disturb the soil near the surface, increasing erosion by water and wind. Compaction of surface soil by movement of heavy equipment can reduce infiltration rates, restrict root penetration, hamper lateral and vertical movement of water through soil, inhibit gas exchange, and increase runoff. Reduced soil productivity is a direct result of compaction. 
3.8.3.7 Erosion. Increased erosion is another effect of ROW construction. Erosion is a natural process; it wears down the earth's surface through the action of water, wind, ice or gravity. Under normal conditions, natural processes create at least as much or more soil than is removed. Construction, causing vegetation removal, soil disturbance, and other changes in the natural environment, accelerates erosion. Studies have shown that sediment eroded from building and road construction sites is about 10 times greater than on land in cultivated row crops, 200 times greater than from pasture, and 2000 times greater than from forest 1 and. (18)

Erosion can occur as surface, single-particle processes or as mass movements. The surface process is more widespread and frequent al though the mass movements probably move greater total quantities of soil. (19) In surface erosion, the degree of movement is directly related to angle of slope, amount of water available for surface runoff, and ground disturbance. Mass erosion is a more subtle process involving the interaction of slope angles and soil water content with many factors which determine the physical and biological character of the soil. These movements include both those that originate on the ground surface and those that result from processes that occur at greater depths, and range from small quantities of soil moving short distances to whole hillsides moving down long slopes.

Erosion can accelerate and produce additional sedimentation. The process includes sheet, rill and gully erosion. Sheet erosion is the removal of a nearly uniform layer of soil from slopes as a result of raindrop splash, and surface runoff that is not concentrated in distinct flow channels. When the runoff volume is large, water concentrates in low areas, and erosion occurs in small rills. If left uncontrolled, these rills will continue to erode and form gullies with each successive large runoff.

In areas of abundant snow or rainfall, surface runoff produces the greatest erosion potential, especially on slopes denuded by ROW clearing and access road construction. Patterns of runoff may be affected by the location of roads, culverts, grading and structures. Unless properly done, movement of soil and changed drainage patterns caused by road construction can cause considerable erosion. 
Wind is a major cause of erosion in arid areas, where rainfall is scarce, vegetation is sparse, and soils are coarse to medium-textured. Topsoil blowouts may occur if these textured soils are exposed by construction and subjected to high winds. Re-establishment of vegetation is then more difficult and the land in and adjacent to the ROW is even more susceptible to wind erosion.

Gravity erosion includes landslides, rock falls and soil slippage. This mass wasting of rock and soil may be accelerated by building on excessively steep or unstable slopes.

The acceleration of natural erosion poses particular problems when crossing agricultural areas. Obstructions such as towers or poles tend to force tillage and seeding into the same pattern every year. Water will then collect at the same point year after year, establishing a more or less permanent surface erosion pattern. In arid areas, transmission towers and access roads can influence near-surface winds and result in sand blowing across cropland and the accumulation of sand dunes and thistles at the bases of towers. Under these conditions, natural vegetation and crops have more difficulty becoming established. Consequently, land in and adjacent to the ROW becomes increasingly more susceptible to wind erosion.

3.8.3.8 Water Quality and Aquatic Life. Transmission line location, construction and maintenance can also affect water quality. The most significant construction impact will probably be increased turbidity due to stream crossings by construction traffic and increased erosion until ground cover is reestablished at construction sites.

Increased turbidity is significant because of water's mobility; sensitive areas far downstream of the initial impacts will also be affected. Increased turbidity levels reduce light transmissibility, decreasing photosynthetic activity of aquatic vegetation. Changes in biological quality from nutrient or dissolved oxygen changes can affect aquatic vegetation, particularly algae. Increased algae can, in turn, produce undesirable effects on taste, odor and biologic quality of water, and also affect fish migration. Sedimentation may affect aquatic insect habitats, and can fill voids in stream bottom gravels and reduce their value as fish spawning areas. 
Some impacts on water resources, because of their secondary impact on other environmental conditions, can be long-term; for example, higher water temperature may result from increased exposure to sunlight, and could change dissolved oxygen levels. Transmission lines usually do not parallel streams but cross them at an angle; thus the stream surface exposed to increased sunlight is kept to a minimum. Also, chemicals transported overland or leached from disturbed soils and sediments can affect water quality and habitat for aquatic life, especially during and immediately after construction.

Snow melt can change the quality and distribution of water when changes in ground temperature and microclimate affect the rate of melting. Snow melt rate is higher in the relatively open ROW than in adjacent forest land, but the effect will likely be offset by higher rates of snow accumulation.

Except for changes in surface runoff, most of the hydrological impacts will be of short duration; occurring during and immediately following construction.

The ultimate impacts on aquatic life potentially affected by constructing and operating the line will be site specific and will depend upon the aquatic communities present in the vicinity, the importance of habitat types in relation to the amounts of similar ones present regionally, the productivity of affected aquatic habitat, the drainage area that may be affected adversely by constructing and operating the line, and the presence of any sanctuaries or preserves.

3.8.3.9 Vegetation. Once clearing and construction have ceased, the original vegetation returns through a gradual succession or change of vegetation types. The general succession of vegetation tends to be from grasses and herbs to shrubs to a final cover of trees. However, the succession is likely to stop with the dominant or climax vegetation type for the particular region. Thus, in a grassland or shrub area, the recovery of original conditions is relatively rapid, though in arid regions grasses may take longer to fully recover. In a forest, however, the successional changes back to the original form and structure of the vegetation may take a long time. The natural succession of vegetation may be artificially curtailed by powerline maintenance activities which will be discussed later. 
3.8.3.10 Wildlife. The construction of transmission facilities may both benefit and harm wildlife, primarily by disturbing wildlife, and eliminating or modifying habitat. The impacts could be very significant if the habitat is critical to rare, threatened, or endangered species of wildlife. Impacts are most intense in or near forested areas where major vegetation disturbance occurs during construction of transmission lines, substations, communication facilities and access roads.

Relatively few studies have been done on the effects of transmission ROW on wildlife. But, studies have been done on the effects of clearcut logging. One study, conducted at the Umatilla National Forest in eastern Oregon and Washington, compared habitat changes in clearcut and partially cut forest areas. (20) It was found that "in the clearcut, the plant cover responded quickly to the environmental changes initiated by logging. Increased light and moisture reaching the forest floor stimulated growth of remaining plants and disturbed areas provided optimum conditions for the germination and establishment of new species." Some of the most abundant new species were bull thistle, willow weeds, mountain thermopsis, and sticky currant. Seeded timothy accounted for most of the increase in grass cover in one area; and indigenous grasses and sedges, particularly Columbia brome and Ross sedge, increased rapidly at the other area. "During the five growing seasons following logging, elk use was highest in the clearcut and lower in the partial-cut forest. Deer showed the same order of preference, but differences between habitat use were much smaller. Foilage was the obvious attraction in the clearcuts since the early stages of plant succession provided little hiding cover. Adjoining uncut stands provided excellent cover."

A transmission ROW through a forest can provide additional habitat diversity. The ROW, although narrower than the adjoining type, may contain a relatively higher density of species. The tendency toward increased variety and density where two or more habitat types come together is referred to as the "edge effect."(21) For example, a study in Texas by W. D. Lay showed that margins of clearings had $95 \%$ more birds, representing $41 \%$ more species, than comparable areas in the interiors of adjacent woodlands. (22) However, the early stages of plant succession following clearcutting may not favor species normally associated with forest habitat. For example, Black and Hooven (23) 
conducted studies in the western Oregon Cascades and found that chipmunks, snowshoe hares, and flying and pine squirrels were less abundant in clearcuts than in mature forest habitat.

It has been suggested that wildlife migration patterns may be influenced by the creation of open transmission corridors through timbered areas. That is, large mammals may use these cleared paths to establish new migration routes, and populations of some animals may increase. Some species of wildlife may avoid crossing cleared areas and thus modify their movements.

In a recent study on the effects of high-voltage transmission lines on big game movement and behavior, the net effect of a transmission corridor in a forest environment in northern Idaho was found to benefit big game and many other species of wildlife. (24) Use of the transmission corridor by elk ar.d deer was low from mid-summer until the start of fall migration. Portions of the ROW that were free of snow during late winter and spring received intensive use, primarily for feeding. The primary reason for this, as vegetation analysis verified, is that both natural and manmade clearings in forested areas contain a greater percentage of understory vegetation than the surrounding forest. Investigations showed that animal use of particular clearings was based primarily upon the amount of food available. There was no apparent difference in animal behavior and length of use of transmission corridors as opposed to natural clearings. The presence of towers, audible noise and electric and magnetic fields within the ROW apparently did not influence behavior of animals observed during the study.

The same study noted that white-tailed deer, mule deer, elk, bighorn sheep, black bear, cougar, coyote, and bobcat were present on the Row at times during the study. Grouse (blue, spruce, and ruffed), ravens, hawks, owls, eagles, and many songbirds were also observed near or within the Row. The presence of abundant insect 1 ife within the corridor may have contributed to the presence of songbirds and grouse. Similarly, the predatory birds may have been attracted by a relatively high density of rodents. It appears that the "edge effect" created by the ROW clearing provided habitat for many diverse wildlife species.

Long-term effects on game can result from improved access for hunters in forested areas crossed by transmission lines, resulting in increased hunting pressure. The study concluded that for deer and elk, the added forage on 
the ROW during the critical winter period more than compensated for the additional stress imposed upon these species by increased hunting. Another

likely impact to wildlife is disturbance from recreational equipment such as off-road vehicles, trail bikes, and snowmobiles on ROW.

Actions which will reduce the ecological impact of transmission 1 ine construction (and maintenance, in some cases) include:

- Thorough examination of alternate routes so that very sensitive areas may possibly be avoided.

- Placing towers back from the edge of waterways.

- Carrying out slash disposal in a manner consistent with the least impact, and not allowing cleared vegetation to fall in streams.

- Re-establishing vegetative ground cover at tower sites and other cleared areas as soon as possible. Loosening the soil prior to seeding and the use of a straw or other mulch may assist in re-establishing ground cover.

- Using water bars or concrete, wood or metal retainers to control erosion until natural ground cover is re-established, leaving roots intact near waterways.

- Using cleared vegetation for erosion control, as at end of drainage ways to dissipate water.

- Careful monitoring of stream crossings by equipment to minimize sedimentation. Using simple fords with rocks; culverts or bridges only if needed, and riprapping banks to control erosion.

- Allowing wide buffer strips of vegetation along stream banks to help trap sediment runoff before it reaches the stream.

- Avoiding unnecessary removal of vegetation that shades streams.

- Using a "brush blade" instead of a dirt blade in bulldozer clearing operations where it is permissible to leave some ground cover.

- Avoiding application of herbicides in wetlands or near waterways.

- Generally confining construction in wetlands to frozen winter months and avoiding stream and riparian areas during flood season and when aquatic biota are seasonally abundant. 
- Avoiding dust controllers such as oil, asphalt cutback, and watersoluble polymers if they can enter runoff and cause adverse aquatic impact.

3.8.3.11 Maintenance Impacts. The ecological impact of transmission line maintenance programs stems primarily from the necessity to control vegetation, both on the ROW and access roads. Vegetation control is required to prevent potential damage to the transmission line which could interrupt service, maintain access roads in serviceable and safe condition, control weeds in weed control districts and maintain the ROW in a condition consistent with multiple uses and/or uses of areas adjacent to the ROW.

Vegetation management is accomplished by a variety of methods which vary considerably with terrain, climate, coils, type of vegetation, and landowner uses. BPA's past practice relied heavily on herbicides to reduce and elimiate undesirable vegetation. (14) The current emphasis on multiple use places a priority on the development of uses compatible with the operation and maintenance of the electrical facility. Good management practices indicate that the vegetation on the ROW can be converted from tall growing to low growing useful species with the added benefit of further reduction in the use of herbicides.

In rangeland, little, if any, vegetation control is necessary because vegetation rarely grows to a problem height. However, in both rangeland and in agricultural areas, weed infestation may occur following construction. Noxious weeds are those plants which have been designated by weed control agencies as hazardous to livestock or property and must be controlled. In agricultural areas or rangeland where noxious weeds pose a threat to domestic animals, it may be desirable to cooperate with local weed control districts or landowners in a planned eradication program. Such a program may include the application of herbicides.

Vegetation on the ROW and access may be removed using one or more of the following methods: ${ }^{(14)}$

- Foliage treatment consists of applying a herbicide diluted with water onto the foliage of the target vegetation. Foliage treatment may be done using ground equipment selectively or it can be broadcast aerially, 
in which case both target and nontarget vegetation may be affected. Aerial foliage treatment is an effective method of applying herbicides in inaccessible terrain and when controlling uniform stands of tal1 vegetation where selectivity is not necessary.

- Basal treatment consists of applying a mixture of herbicide and oil on the lower trunk of the target vegetation from about knee high $(2 \mathrm{ft})$ to ground level. When applied during the dormant season, treated trees will not normally leaf out during the following season, thereby avoiding the vegetative brownouts associated with foliage treatment.

- Frill, notch, or cup application of herbicide involves cuts through the bark to the cambium layer in a series around the circumference of the trees. Liquid herbicide is poured into the notches. This can be done at any time of year, but is most effective when performed during the dormant season. This is the safest method near streams, sensitive plants, or other areas of concern.

- Soil treatment is a method in which pelleted or granular herbicides are broadcast on the ground within the drip base of the tree or other target vegetation. Some pellets sterilize the soil for a short period, while others affect only the plants around which the pellets are applied. This is an excellent method for controlling individual trees, and is useful in locations inaccessible to vehicles.

- Cutting and stump treatment simply refers to cutting trees and brush and then spraying or painting the stumps with an $0 i 1$ or water based application of herbicide to prevent sprouting. A problem with this method is the disposal of the chipped material when chipping is required. It also requires that the chipper be hauled to the work site or the vegetation dragged to the chipper. In either case, desirable plants may be damaged. The remaining slash must be removed, burned, or scattered.

Foliage application of herbicides may be done by ground equipment, in which case the treatment is usually more selective; or it may be done by aircraft, in which case it is broadcast over a relatively wider area, affecting both target and nontarget (including off ROW) vegetation. Any selectivity in aerial application usually results from the varying susceptibility or tolerance of different plant species to the applied herbicide. 
Helicopters are usually preferred over fixed wing aircraft for aerial applications because they can fly lower and more slowly, and thus can direct the spray more closely to the target area. Aerial spraying may be the preferred method of control in some situations. For example, when controlling uniform stands of conifers or other uniform stands of tall growing vegetation, selectivity within the area to be treated may be unnecessary. In this situation, aerial application would be the most economical and, because there are none of the access problems and slash disposal problems associated with selective cuttings, etc., it may also have the least adverse environmental impact.

Broadcast application of herbicides, especially when performed aerially, may affect off-ROW and nontarget vegetation to some extent. Because of its limited selectivity, aerial application of herbicides is used less frequently by BPA than in the past. (14)

Two factors to consider in minimizing the effect of aerially-applied herbicides on off-ROW vegetation are drift and volatility. Volatility refers to the tendency of a chemical to go into the vapor state and is a source of off-ROW contamination by herbicides. Low volatile forms of herbicides should be used whenever possible. Drift can be minimized by curtailing aerial application during periods of strong winds and by controlling droplet size. Various chemicals can be added to spray solutions to enlarge droplet size, either by increasing the viscosity of the solution or by producing a large globule that carries the herbicide, thereby insuring that the degree of drift will be reduced $(25)$ and that the application will be less affected by high temperature. $(26)$

BPA's construction standards (Table 3 ) require removing any tree outside of the ROW which could fall into close proximity of the line after 8 years of growth. Criteria used to designate unstable trees along existing lines are more lenient than the construction standards; only the hazardous trees (leaners, decayed, insect infested, or other unstable trees) and trees which will grow within the maximum swing displacement of the conductor are removed. Stable trees, even though they are higher than the conductor, are allowed to remain. 


\subsubsection{Minimizing Environmental Impact Through Route Selection Techniques}

To minimize the negative environmental impact of transmission 1 ines, some organizations are using constraint mapping to select new transmission line locations. (27) This technique involves weighing economic, socio-cultural, topographical and ecological impact on alternative transmission line corridors.

The BPA has implemented a reconnaissance team approach to transmission line route evaluation; ${ }^{(28)}$ each alternative route is evaluated by an interdisciplinary team which may include a biologist, a geologist, a range management specialist, a forester and a transmission line engineer. BPA is also actively involved in developing a state-of-the-art systems analysis approach to facility siting aimed at minimizing environmental impact. (29)

\subsubsection{Multiple Use Utility Corridors}

Shared use of ROW between utilities, railroads, pipelines and highways is gaining increasing attention, especially in metropolitan areas and areas having land-use planning agencies. Some advantages for joint-use corridors are:

- Savings in ROW acquisition costs

- Conservation of 1 and for other uses

- Less fragmentation of land use

- Reduced visual and environmental impact

- Joint maintenance access roads.

There are also limitations associated with joint-use corridors, some of which are described below:

- High voltage transmission lines can cause inductive interference on railway signal and telephone circuits. Technological solutions to this problem do exist. (30)

- Gas pipelines and electrical transmission lines are usually not located in close proximity because pipeline failures could destroy the electrical line, ${ }^{(28)}$ and line-to-ground flashovers caused by lightning could perforate pipelines. 
- Accidents on railways or highways could damage transmission 1 ines and possibly cause additional injuries.

- Joint-use corridors must be planned far in advance to be successful.

- High voltage transmission lines may induce voltages on parallel metal objects, such as pipes, during construction on joint-use corridors. $(28,31)$

- Lack of mutual understanding about problems and differences in time phasing of the installation of facilities for different services often create problems. Electric lines, telephone lines and highways never seem to be needed on the ROW at the same time. Close coordination of the construction of various facilities built at approximately the same time on a joint ROW is required. The use of heavy construction equipment adjacent to previously installed facilities could create problems.

- Equipment failures of one utility service could cause serious damages to the other services (i.e., water line leaks could undermine transmission line towers).

- Acts of nature, such as earthquakes, could damage all utility services simultaneously.

- Since all utilities seldom originate or terminate in proximate locations, additional line costs will sometimes be incurred in getting to and egressing from the joint corridor.

Despite these drawbacks, joint-use utility corridors are being seriously considered in many areas. $(30,32)$ A recent study of the need for a national system of transportation and utility corridors concluded that the desirability of joint use can only be determined for specific situations through analysis of the trade-offs involved. (33)

In many cases, transmission line ROW can be used for unrelated secondary purposes. Possible uses include: cultivation of Christmas trees and other nursery stock; $(34,35)$ gardening, general agriculture, and pasture; planting for wildlife food and cover; and various recreational purposes such as hiking trails, bicycle paths, horse trails, snowmobile and all-terrain vehicle routes, nature study trails and open space areas. (1) Transmission ROW can provide 
new access to hunting and fishing areas. One study found that game hunters made heavy use of a transmission line ROW in Idaho. (24) These uses, under proper conditions, have both economic and environmental advantages, and the fact that they are permitted may create public goodwill. However, encouraging public use of ROW can lead to increased vandalism such as shooting at insulators and conductors. Increased environmental damage such as erosion, disturbance to wildlife, fire hazards and annoyed landowners can also result from uncontrolled use of ROW by recreational vehicles.

\subsubsection{Radio and Television Interference}

High frequency components associated with corona discharge cause radio and television interference. Corona has been discussed previously in Section 3.2.2. Radio-noise current is caused by the movement of charges close to the conductor surface where corona activity takes place. The charges moving in space induce variable charges (and thus currents) in the conductor in corona, in the ground, and in a 11 other nearby conductors. $(36,37)$ The induced currents depend on the characteristics of the corona and on the self and mutual capacitances of the conductors. $(36,37)$ The induced currents and the associated voltages and electromagnetic field propagate down the line causing radio and television interference miles from the point of origin.

The corona discharge process produces pulses of current and voltage on the transmission line conductors. The pulses are characterized by rise and decay time constants perhaps on the order of hundredths of microseconds and repetition rates which may be in the $\mathrm{MHz}$ range. The radio frequency band extends from $3 \mathrm{KHz}$ to $30,000 \mathrm{MHz}$. Therefore, the electromagnetic fields resulting from corona current pulses can cover a considerable portion of the radio frequency band. The level of radio interference (RI) and television interference (TVI) depends on the distance from the transmission line to the receiving device, the orientation of the receiving antenna, the transmission line geometry, line voltage and weather conditions. Drops clinging to conductors during heavy rain act as sources of point discharge. Television interference is seldom caused by line voltages of $345 \mathrm{kV}$ or less.

It is economically prohibitive to build EHV and UHV overhead transmission lines with conductors so large that no corona generation occurs under any condition. Therefore, each line must be designed so that radio and television 
noise levels are tolerable for the area in which it is located. For example, a particular RI and TVI noise level may be considered intolerable in a suburban area where radio and/or television signal strength is low, while some noise level may be tolerable in an urban or industrial area where ambient RI and TVI noise levels are high and radio and television signal strength is high. Therefore, it is recommended that each situation be examined individually using a relative measure such as "signal-to-noise" ratios. (37) To rate the interference level of a particular transmission line in a particular situation one must be able to determine both the field strength of the received signal in the absence of noise from the line and the field strength of noise from the line. Field strengths are measured using an appropriate antenna and a radio noise meter in the quasi-peak detector mode. (37) Figures 17 and 18 indicate reception quality versus signal-to-noise ratios expressed in decibles above $1 \mu \mathrm{V}$ per $\mathrm{m}$, for radio and television reception.

RI and TVI levels depend on corona levels which in turn depend on conductor surface gradients. Since conductor surface gradients are reduced by using bundled subconductors, this same method is used to control RI and TVI. RI and TVI are often the critical design factor in determining the number and size of sub-conductors required for conductor bundles on EHV transmission lines. Figure 19 shows the effect of the size and number of subconductors on RI levels at a fixed distance from a $765 \mathrm{kV}$ ( $800 \mathrm{kV}$ class) transmission 1 ine.

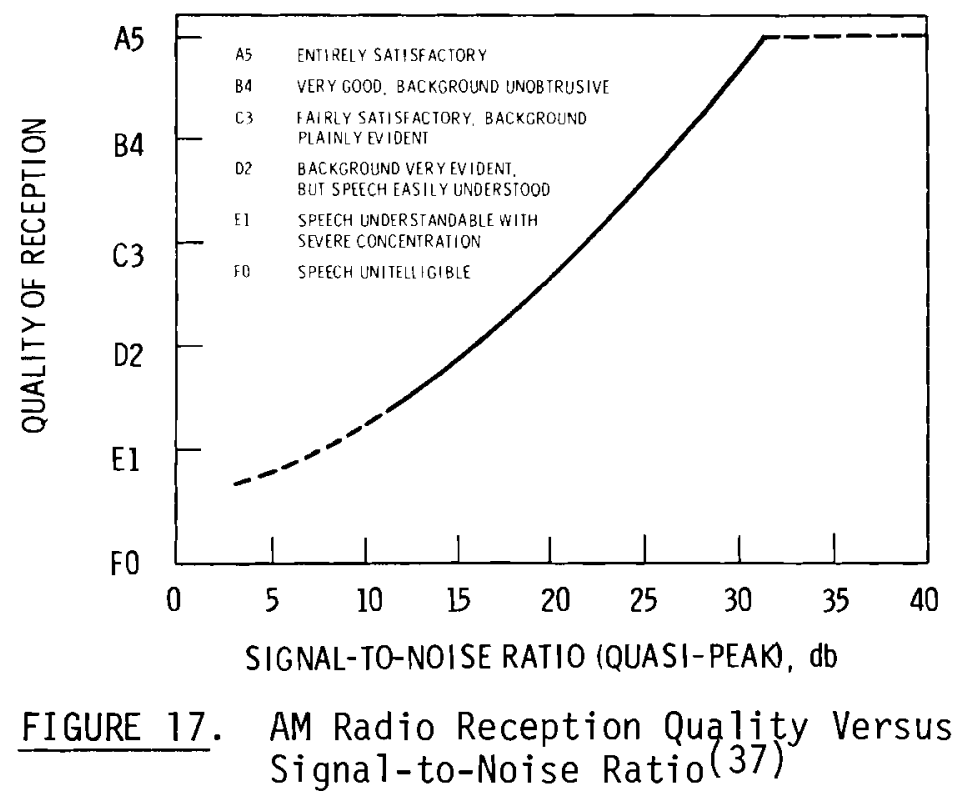




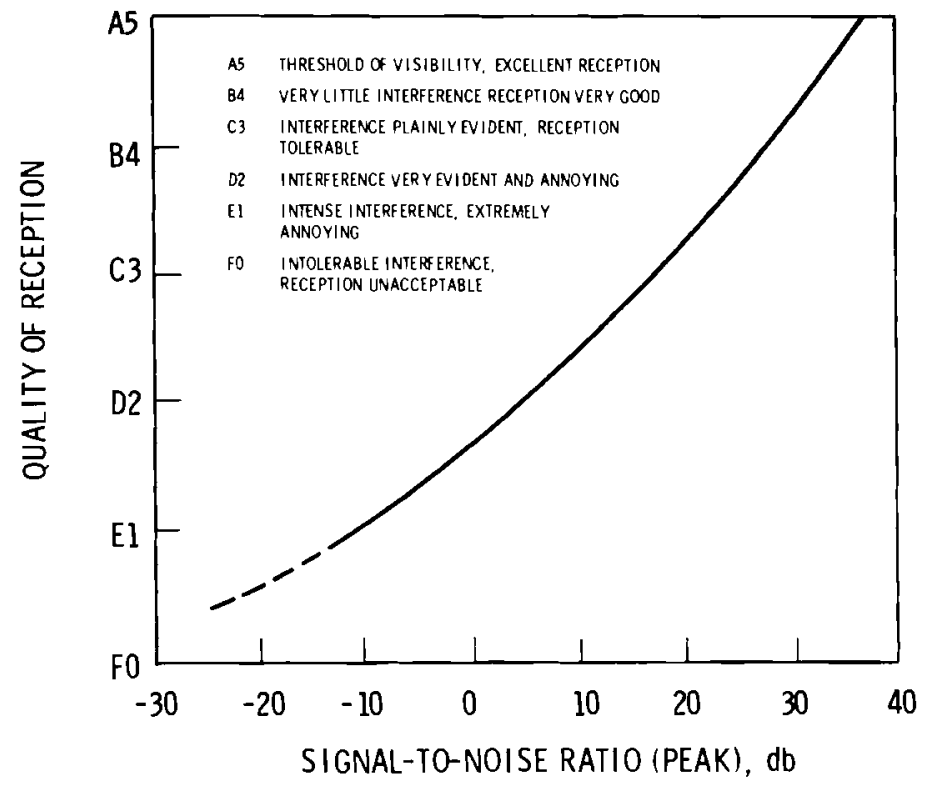

FIGURE 18. Television Reception Quality Versus Signal-toNoise Ratio for Conductor Corona Noise(37)

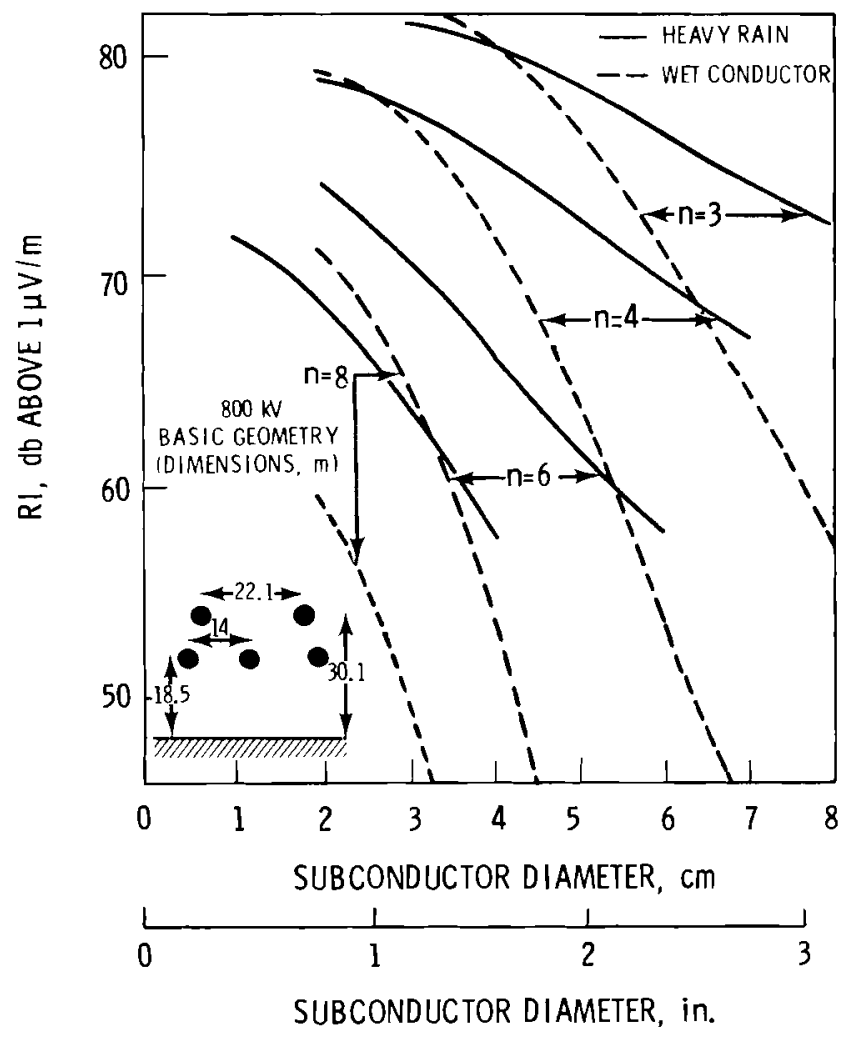

FIGURE 19. Rl Levels for a $765 \mathrm{kV}$ (800 kV Class) Single-Circuit Line $15 \mathrm{~m}(50 \mathrm{ft})$ Laterally from an Outside Phase $(\Lambda=$ Number of subconductors per phase) $(37)$ 


\subsubsection{Audible Noise}

With the advent of EHV transmission, a new noise source due to conductor corona discharge becomes apparent. At lower voltages little attention was paid to this problem since the noise levels were very low. At UHV voltages it is likely that audible noise will be a limiting design factor for transmission lines in the United States. ${ }^{(38)}$ Audible noise from transmission lines occurs primarily in foul weather. Water droplets impinging or collecting on conductors produce a large number of corona discharges, each creating a burst of noise.

Transmission line noise has two characteristic components, namely: broadband noise (variously described as frying, crackling, or hissing) and pure-tone components (hum) at frequencies of $120 \mathrm{~Hz}$ and multiples. (38) The broadband noise is caused by a random sequence of air pulses produced by corona discharges in the air at the surface of the conductor. The hum is caused by movement of space charge surrounding the conductor, which reverses air pressure twice every half-cycle due to the movement of positive and negative ions from and toward the conductor.

Table 10 indicates some common noise levels as a frame of reference. Figure 20 indicates the effect of conductor bundle diameter and number of subconductors on calculated audio noise levels for a $765 \mathrm{kV}$ line.

\subsubsection{Oxidant Generation}

Corona discharges from electrical apparatus can create ozone and to a minor extent other gases such as the oxides of nitrogen. The corona effect is the basis for commercial ozone generation. (39)

The generation of oxidants by EHV transmission line corona was first raised as an environmental issue in the early 1970's. (40) The exact mechanism for the formation of ozone and nitrogen oxides in electrical discharges is not understood. However, when electrical discharges occur in air or oxygen, they induce the overall reaction $30_{2} \rightarrow 20_{3} \cdot(40)$ The production of $\mathrm{NO}_{\mathrm{x}}$ (oxides of nitrogen) by corona discharges would be expected to be less than ozone because of the higher energy required to ionize the nitrogen molecule. (39) 
TABLE 10. Some Common Noise Leve $1 \mathrm{~s}$ (38)

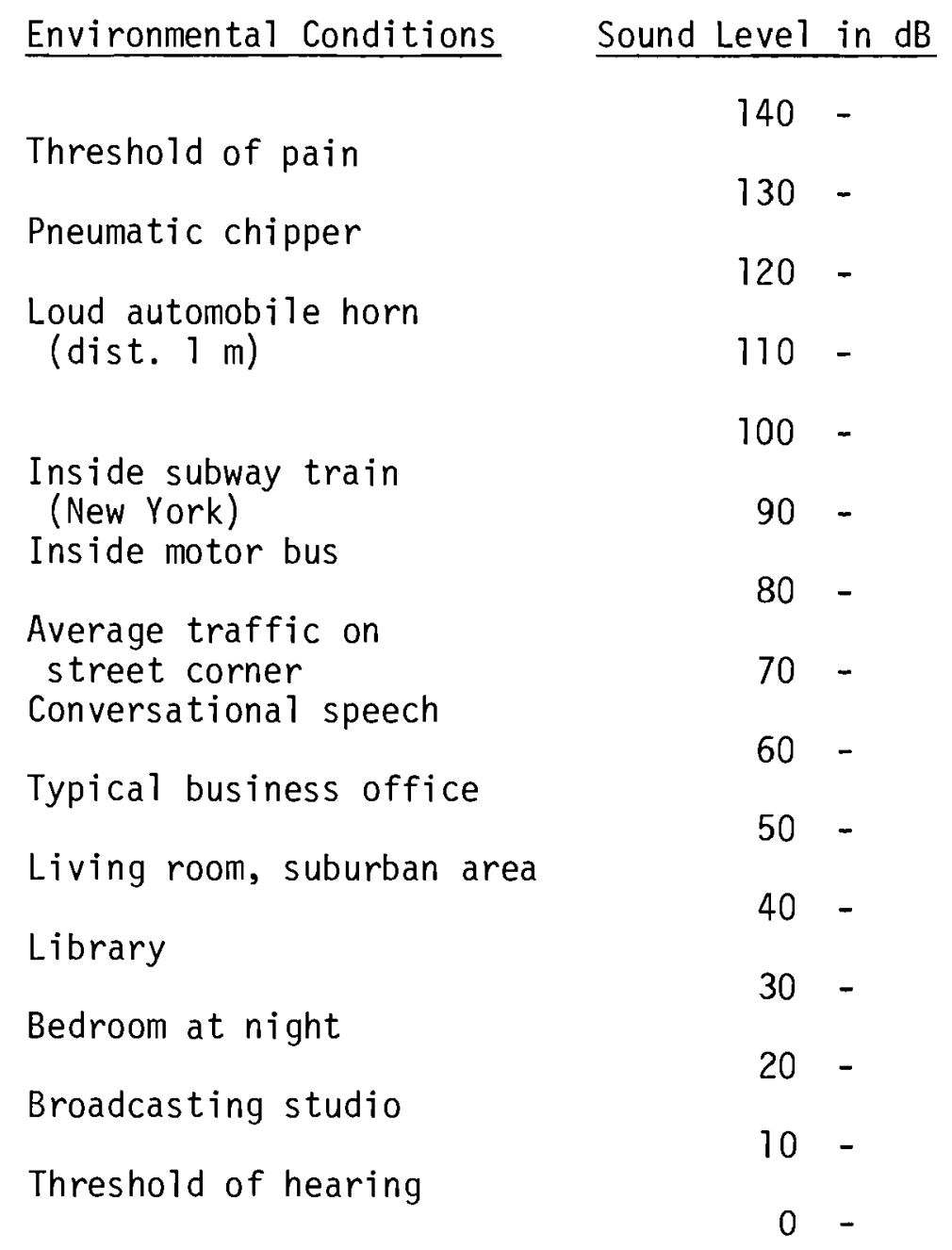

The "National Primary and Secondary Ambient Air Quality Standards," promulgated by the U.S. Environmental Protection Agency in 1971, 1imits the level for photochemical oxidant (primarily ozone) to 0.08 parts per million (ppm) by volume as a maximum 1-hour arithmetic mean concentration not to be exceeded more than once per year. The standard for nitrogen dioxide is $0.14 \mathrm{ppm}$ 24-hour concentration not to be exceeded more than once per year. Some state air quality standards are more restrictive. For example, Ohio photochemical oxidant standards set a maximum 1-hour mean concentration of $0.06 \mathrm{ppm}$ and a 24-hour mean of $0.02 \mathrm{ppm}$.

Reference 41 contains information on the effects of oxidants on humans, animals and vegetation. In general plants appear to be more sensitive to 


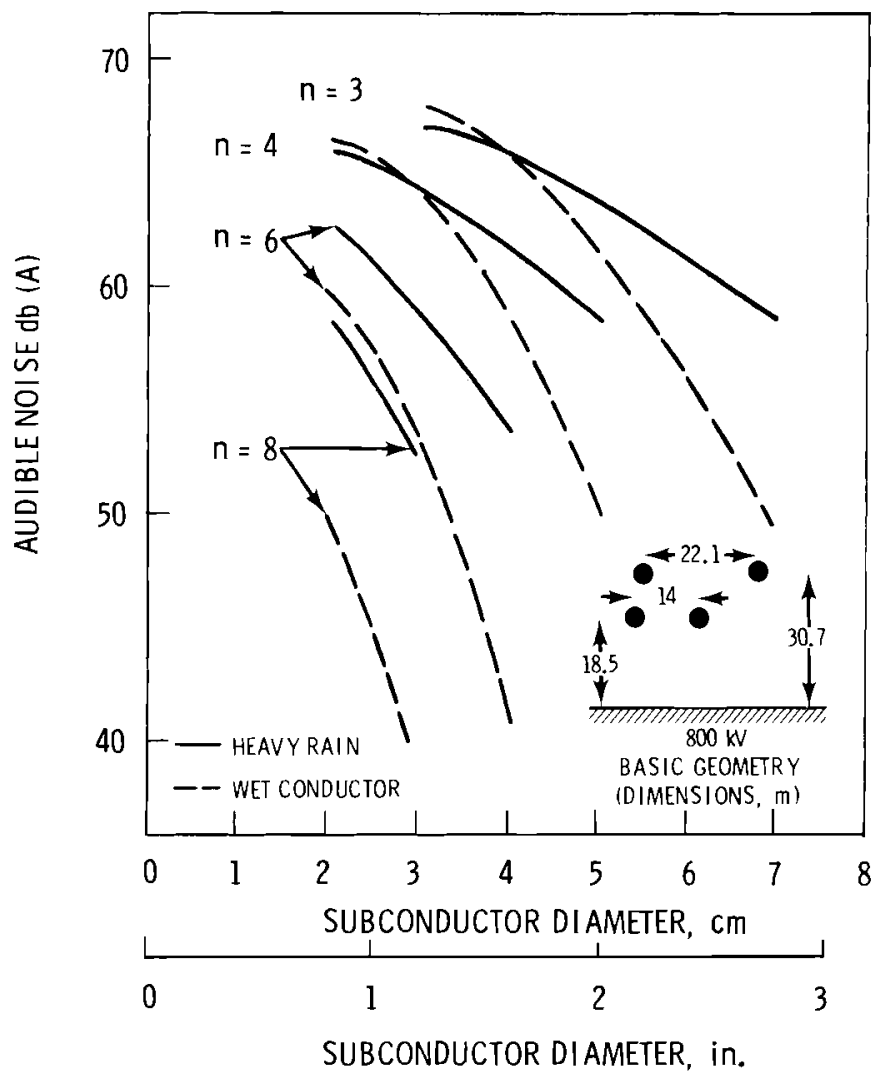

FIGURE 20. Calculated Audible Noise $d B(A)$ at $15 \mathrm{~m}(50 \mathrm{ft})$ from the Outer Phase of a $765 \mathrm{kV}$ (800 kV Class) Single Circuit Line(38)

ozone than animals. Plants such as the tomato, bean, spinach, tobacco and potato exhibited injury when exposed to ozone concentrations of 1.0 part per billion. However, exposure to ozone concentrations in the parts per million range are required before damage occurs in animals. (42)

The magnitude of oxidant production by transmission lines is, presumably, proportional to corona levels which in turn are proportional to conductor surface gradients. Therefore, transmission line design parameters and ambient conditions which reduce conductor surface gradient would be expected to reduce the oxidant production rate. This has been confirmed in high voltage laboratory experiments. Figure 21 indicates the correlation of the ratio of corona loss to ozone production ( $P, \mathrm{kWh} / \mathrm{gram} \mathrm{O}_{3}$ ) with conductor voltage gradient (VG, $\mathrm{kVrms} / \mathrm{cm}$ ) for several conductor configurations under various meteorological conditions. Table 11 exhibits ozone and $\mathrm{N}_{\mathrm{x}}$ production rates measured under laboratory conditions for various bundle and single conductors. 


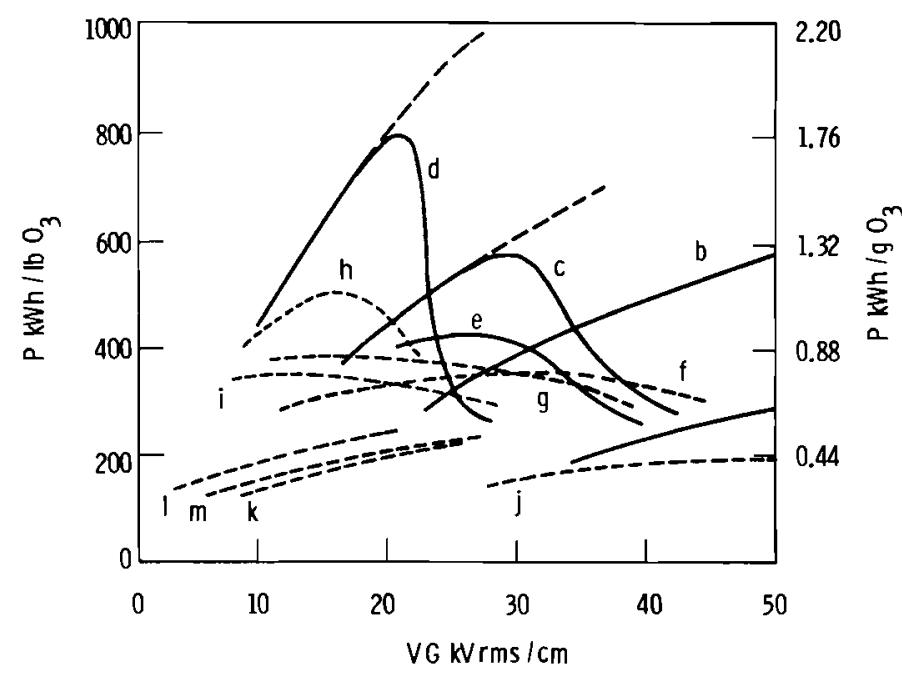

MEDIAN CURVES FOR DRY CONDITIONS:
a. $0.523 \mathrm{~cm}$
b. $1.13 \mathrm{~cm}$
d. $3.038 \mathrm{~cm}$
c. $1.626 \mathrm{~cm}$ and $2.174 \mathrm{~cm}$
e. $4 \times 0.523 \mathrm{~cm}$ and $4 \times 1.13 \mathrm{~cm}$ CONDUCTORS

MEDIAN CURVES FOR LIGHTER RAIN CONDITIONS
f. $1.13 \mathrm{~cm}$
h. $3.038 \mathrm{~cm}$
g. $1.626 \mathrm{~cm}$
i. $4 \times 1.13$ CONDUCTORS

MEDIAN CURVES FOR HEAVIER RAIN CONDITIONS:
j. $0.523 \mathrm{~cm}$
I. $3.038 \mathrm{~cm}$
k. $1.626 \mathrm{~cm}$
$\mathrm{m} .4 \times 1.13 \mathrm{~cm}$ CONDUCTORS

FIGURE 21. Correlation of the Ratio of Corona Loss to Ozone Production (P) and the Voltage Gradient (VG) for Various Conductors (43)

As indicated above, oxidant production rates by transmission lines have been determined under carefully controlled laboratory conditions. However, several extensive field tests $(40,42,43)$ along operating transmission lines have all shown that transmission 1 ine oxidant generation had no measurable effect on the oxidant concentrations present in the atmosphere at ground levels in the vicinity of the line. In other words, the ground level oxidant concentrations due to transmission line corona are indistinguishable from ambient oxidant concentrations.

Laboratory observations have shown that the typical half-life for the oxidants is less than 1 hour. (39) The half-life decreases as the relative humidity increases. These factors plus dispersion by wind reduce the oxidant concentrations due to transmission lines to indistinguishable levels in actual field tests. 
TABLE 11. Ozone and $\mathrm{NO}_{x}$ Production Rates Measured in the Laboratory for Bundle and Single Conductors (44)

\begin{tabular}{|c|c|c|c|c|c|}
\hline \multirow[b]{2}{*}{$\begin{array}{c}\text { Conductor } \\
\text { Diameter, } \\
\text { in. } \\
\end{array}$} & \multirow[b]{2}{*}{$\begin{array}{l}\text { Conductor } \\
\text { Corona }\end{array}$} & \multirow{2}{*}{$\begin{array}{c}\text { Gradient } \\
\text { Factor, } \\
\text { kVrms/cm/ } \\
\text { kVrms } \\
\end{array}$} & \multicolumn{2}{|c|}{ Production Rates } & \multirow{2}{*}{$\begin{array}{c}\text { Corona } \\
\text { Loss } \\
\text { Range, } \\
\text { W/ft }\end{array}$} \\
\hline & & & $\begin{array}{c}\text { 0zone, } \\
10^{-2} 1 \mathrm{~b} \\
\mathrm{kWh}\end{array}$ & $\begin{array}{c}\mathrm{NO}_{\mathrm{x}}, \mathrm{i}^{-2} \mathrm{ib} \\
\mathrm{kWh}\end{array}$ & \\
\hline \multirow[t]{4}{*}{$4-1.345$} & Dry & 0.0455 & 0.14 & - & $0-20$ \\
\hline & Earthed & & 0.14 & - & $0-20$ \\
\hline & Wet & & 0.17 & 0.1 & $0-15$ \\
\hline & Wet & & 0.28 & 0.1 & $15-40$ \\
\hline \multirow[t]{4}{*}{$4-1.196$} & Dry & 0.0499 & 0.1 & - & $0-20$ \\
\hline & Dry & & 0.33 & 0.03 & $0-60$ \\
\hline & Wet & & 0.2 & 0.1 & $0-40$ \\
\hline & Rain & & 0.3 & 0.03 & $0-30$ \\
\hline \multirow[t]{4}{*}{$4-0.990$} & Dry & 0.0582 & 0.24 & 0.04 & $0-30$ \\
\hline & Earthed & & 0.38 & 0.06 & $0-40$ \\
\hline & Wet & & 0.50 & 0.1 & $0-15$ \\
\hline & Wet & & 0.94 & 0.1 & $15-50$ \\
\hline \multirow[t]{2}{*}{1.745} & Dry & 0.0750 & 0.53 & 0.02 & $0-70$ \\
\hline & Rain & & 0.2 & 0.01 & $30-50$ \\
\hline \multirow[t]{3}{*}{1.345} & Dry & 0.0933 & 0.94 & 0.06 & $0-20$ \\
\hline & Dry & & 1.4 & 0.14 & $20-40$ \\
\hline & Ra in & & 0.94 & 0.06 & $0-20$ \\
\hline \multirow[t]{3}{*}{1.196} & Dry & 0.103 & 1.3 & 0.11 & $0-30$ \\
\hline & Dry & & 3.5 & 0.40 & $30-50$ \\
\hline & Rain & & 1.7 & 0.13 & $0-20$ \\
\hline \multirow[t]{3}{*}{0.990} & Dry & 0.121 & 1.6 & 0.05 & $0-40$ \\
\hline & Dry & & $\begin{array}{l}1.2, \\
1.4\end{array}$ & 0.15 & $0-60$ \\
\hline & Rain & & 1.6 & $\begin{array}{l}0.08 \\
0.14\end{array}$ & $0-30$ \\
\hline 0.092 & Dry & 0.974 & 0.70 & 0.012 & $0-60$ \\
\hline
\end{tabular}




\subsubsection{Electrostatic Effects of Overhead Transmission Lines}

Overhead electrical transmission lines generate electrostatic and electromagnetic fields which induce voltages and currents in nearby objects. With the advent of EHV transmission and the prospect for UHV lines in the future, electrostatic and electromagnetic effects have taken on a new importance.

3.8.9.1 Voltage Gradients at Ground Level. Electrical fields are discussed in terms of field intensity, or voltage gradient, which is measured in volts per meter. The magnitude of electrical fields produced by high voltage transmission lines is a complex function of line voltage and line geometry, including conductor height, conductor spacing and orientation, conductor bundle makeup and geometry, and phase arrangements.

For example, Figure 22 shows a space potential map for a $765 \mathrm{kV}$ line with a conductor height of $50 \mathrm{ft}$. Equipotential lines and voltage gradient magnitudes at $1 \mathrm{~m}$ and $3 \mathrm{~m}$ are shown for a cross section of the 1 ine. Figure 23 indicates the differences in voltage gradient under a midspan cross section of a $765 \mathrm{kV}$ line at $1.5 \mathrm{~m}$ and $0.2 \mathrm{~m}$ above ground level. Figure 24 indicates the variation in voltage gradient measured along a longitudinal axis under the center phase of the same $765 \mathrm{kV}$ 1ine. Figure 25 indicates the variation in voltage gradient expected $1 \mathrm{~m}$ above ground level at the midspan cross section of a $765 \mathrm{kV}$ single circuit line for 4 different conductor heights. Figure 26 shows the measured voltage gradients at $1 \mathrm{~m}$ above ground level at the midspan cross sections of two BPA single circuit $525 \mathrm{kV}$ test lines with different conductor heights and orientations.

For double circuits, the voltage gradient is influenced not only by the additional variations in conductor geometries, but also by the phase arrangements of the two circuits. Figure 27 illustrates the effect of phase arrangements on the ground level voltage gradient of a $525 \mathrm{kV}$ double circuit line.

The presence of ground wires below the phase conductors can greatly reduce electrostatic effects. As shown in Figure 28, a bundle of two ground 
GROUND WIRE 7 - \#6 ALUMOWELD, $0.00617 \mathrm{~m}\left(0.243^{\prime \prime}\right)$ RADIUS, $\pm 11.38 \mathrm{~m}\left( \pm 37.5^{\prime}\right)$ HORIZONTAL, 32.2m (106') VERTICAL

CONDUCTOR $4 \times$ DIPPER, 1.386" diam. , 18" SPACING, 0.221m EQUIV. RADIUS, $\pm 15.24 \mathrm{~m}\left( \pm 50^{\prime}\right)$ HORIZONTAL AND $15.24 \mathrm{~m}\left(50^{\prime}\right)$ VERTICAL

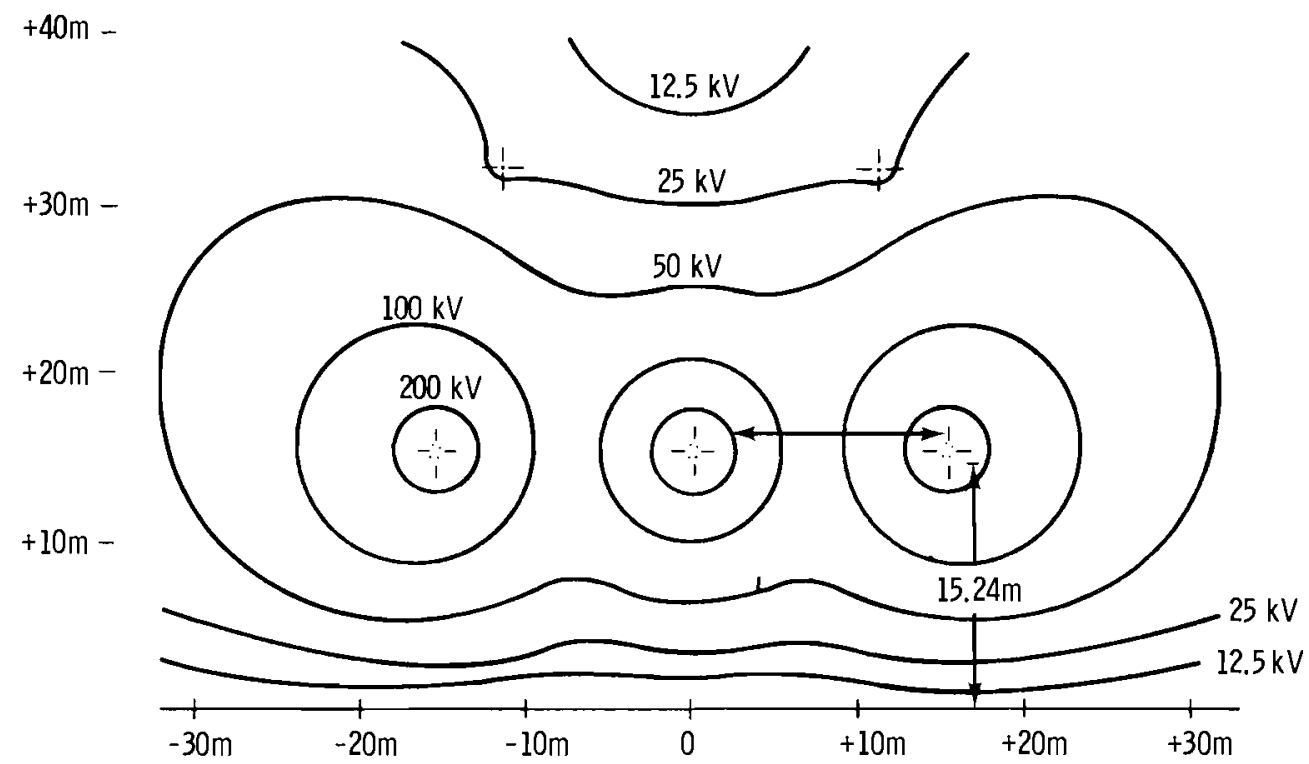

FIGURE 22. Space Potential Map for a $765 \mathrm{kV}$ Line at $15.24 \mathrm{~m}(50 \mathrm{ft})$ Height (45)

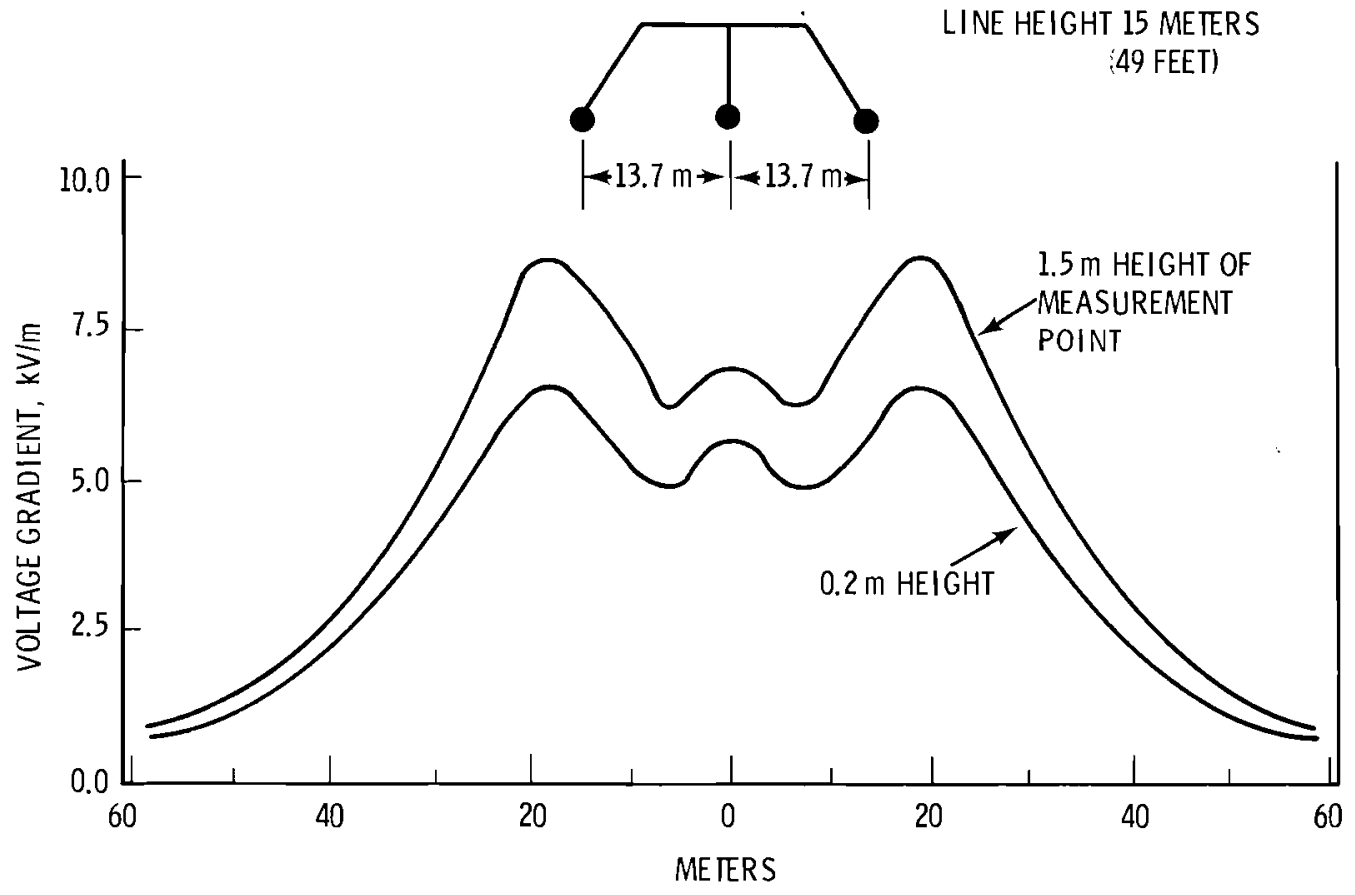

FIGURE 23. Electric Field Measured Under $765 \mathrm{kV}$ Transmission Line(46) 
TOWER \#1
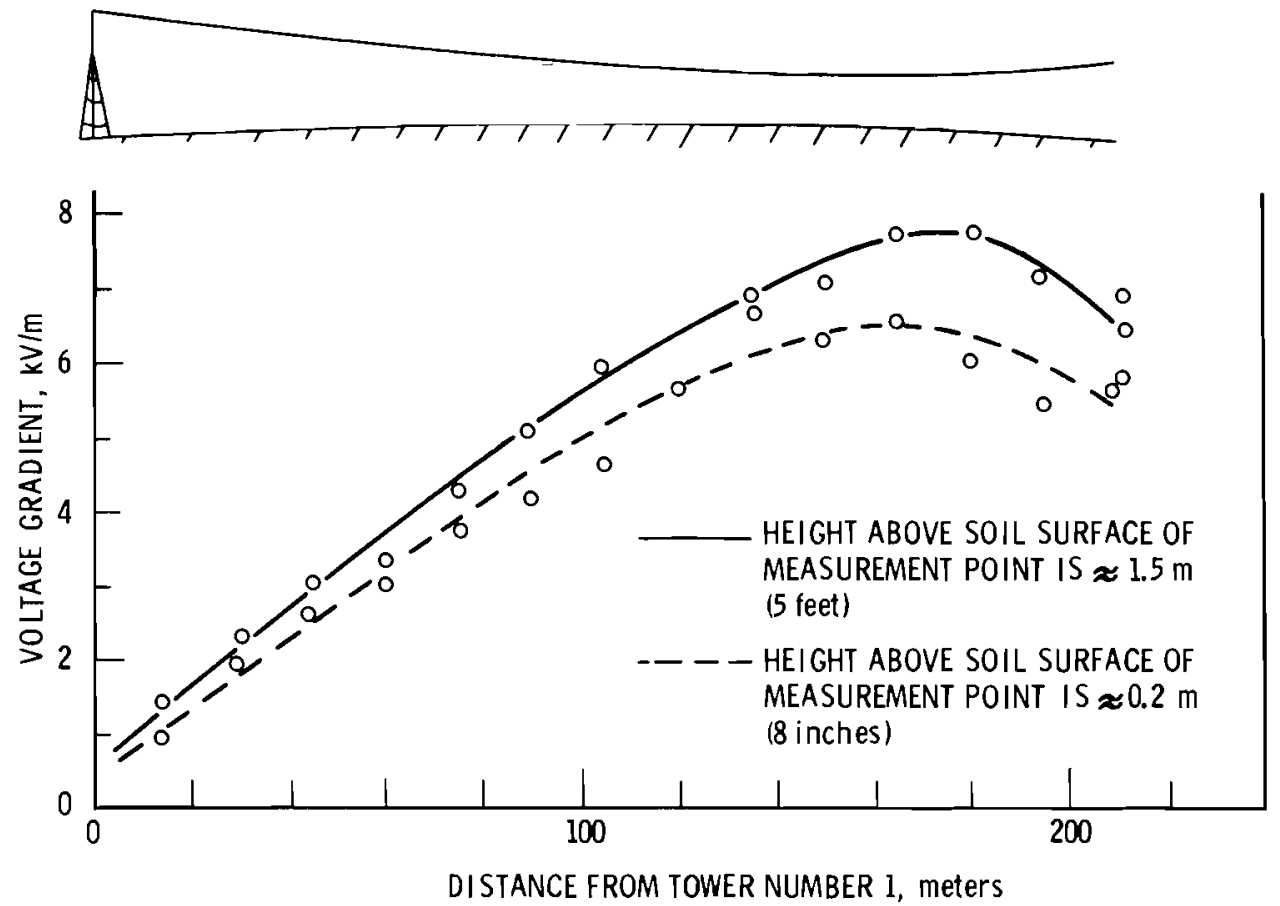

FIGURE 24. Voltage Gradient. Under Center Phase of $765 \mathrm{kV}$ Line (46)

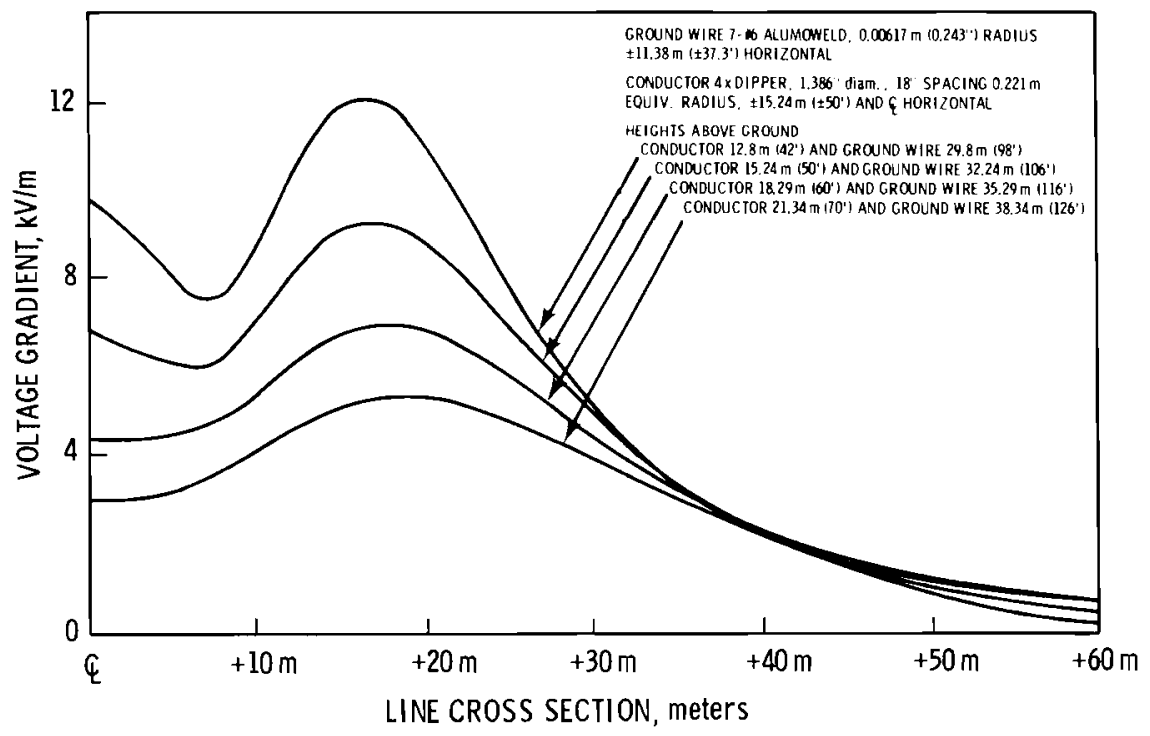

FIGURE 25. Voltage Gradient at $1 \mathrm{~m}$ Above Ground Shown for a $765 \mathrm{kV}$ Line with Conductor Heights at $12.8 \mathrm{~m}, 15.24 \mathrm{~m}, 18.29 \mathrm{~m}, 21.34 \mathrm{~m}(45)$ 


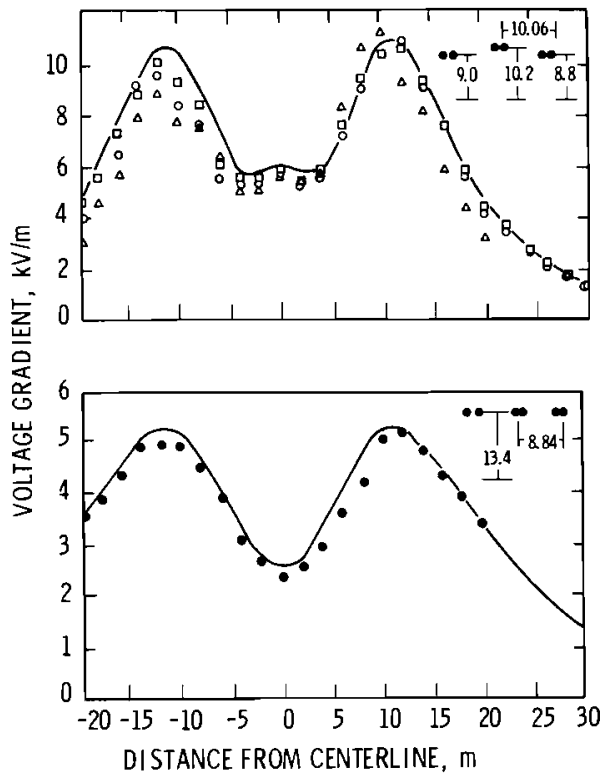

FIGURE 26. Midspan Voltage Gradient at $1 \mathrm{~m}$ Above Ground for Two $525 \mathrm{kV}$ Lines (47)

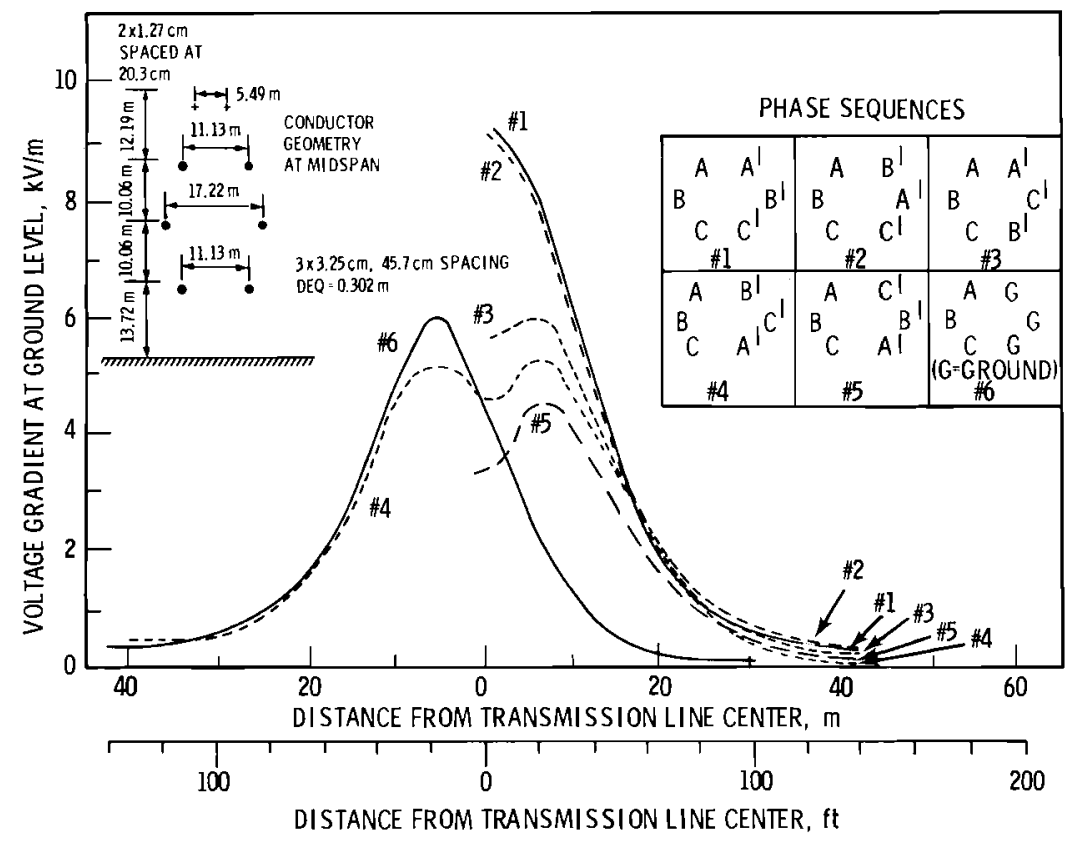

FIGURE 27. Voltage Gradient at Ground Level for a Typical DoubleCircuit Geometry and Different Phase Arrangements. $V=525 \mathrm{kV}$. Phase arrangement \#1, superbundle, corresponds to the maximum ground gradient (and the minimum conductor gradient). Phase arrangement \#5, lowreactance, corresponds to the minimum ground gradient (and the maximum conductor gradient and maximum power transfer capability). (48) 


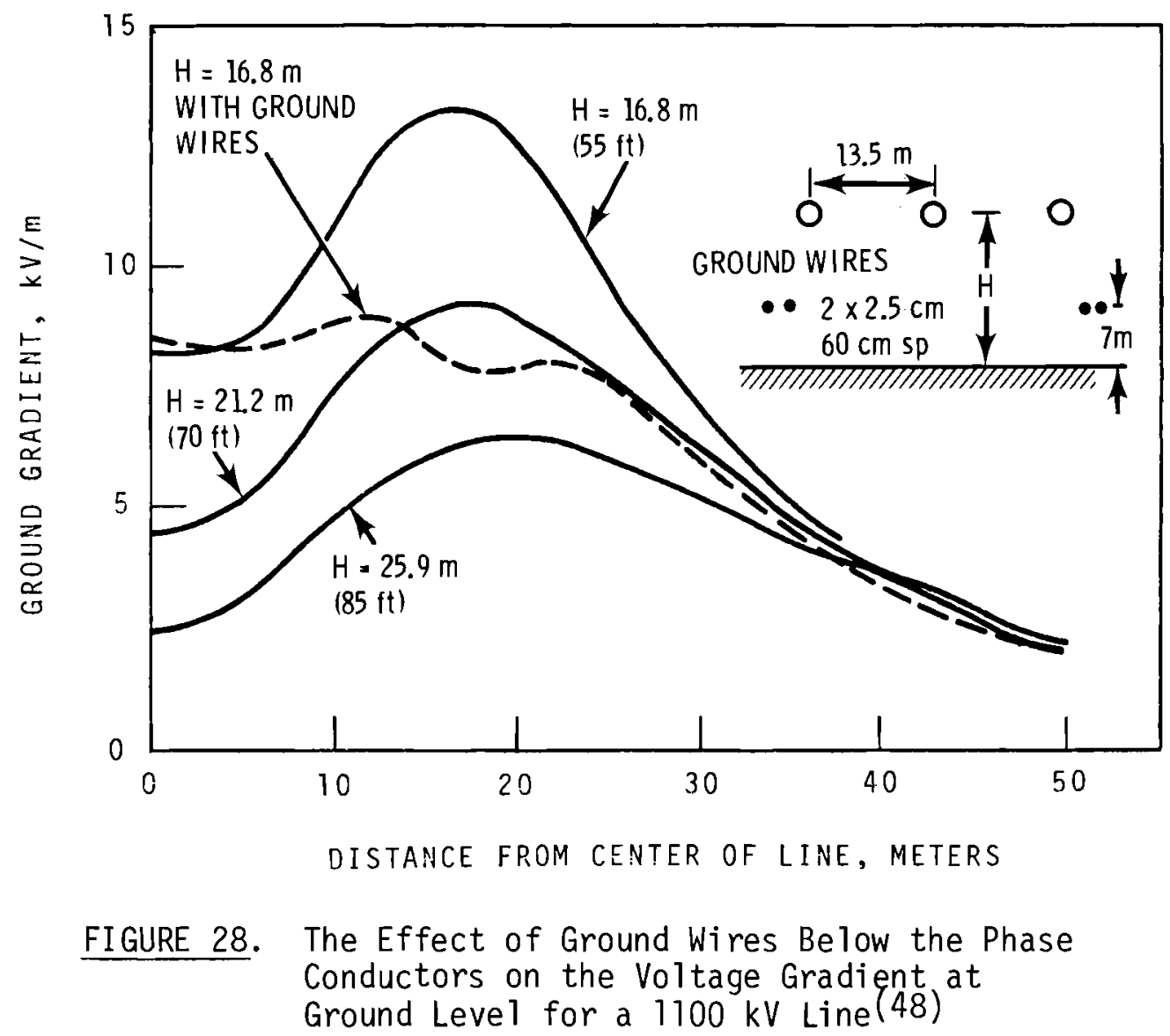

wires placed off the outer phases at the point of maximum gradient and $7 \mathrm{~m}$ above ground level had the same effect as a $4.5 \mathrm{~m}(15 \mathrm{ft}$ ) increase in conductor height. ${ }^{(48)}$

Generalized curves found in Reference 48 may be used for calculating the voltage gradient expected at ground level for many single circuit geometries and two double circuit geometries.

\subsubsection{Perception and Shock Currents. An object located under an ac} transmission line is capacitatively coupled to each of the phase wires of the line. The object also has an impedance to ground which is composed of its capacity to ground in parallel with its resistance to ground. This capacitive coupling to the line and impedance to ground form a series circuit so that a current flows through the object to the ground and a voltage appears between 
the ground and the object. The current flowing through the object to ground is dependent on the electrical resistance in the circuit while the voltage the object acquires with respect to the ground is a function of the impedance of the circuit. A Norton equivalent network can be developed for an object under a transmission line as shown in Figure 29. To develop this equivalent circuit, both open circuit voltage (Voc) and short circuit current (ISC) are needed. Deno ${ }^{(45)}$ and Braken ${ }^{(47)}$ suggest the following steps for computation of open circuit voltage and short circuit current.

- Predict or measure the ground-level phasor magnitude voltage gradient, $\tilde{E}$ in $V / m$, without the object present.

- Estimate the charge collecting equivalent area, $\mathrm{S}$ in $\mathrm{m}^{2}$, from test data or by translating the dimensions of the object into a known solution shape: e.g., a cylinder or rectangle.

- Compute the short-circuit current by the formula $I_{S C}=\varepsilon_{0} \omega E S$. Where $\varepsilon_{0}=$ the permittivity of free space, $8.85 \times 10^{-12} \mathrm{~F} / \mathrm{m}$

$\omega=$ the angular frequency of the unperturbed electric field $E$ (the object is assumed not to influence the charge distribution on the 1 ine).

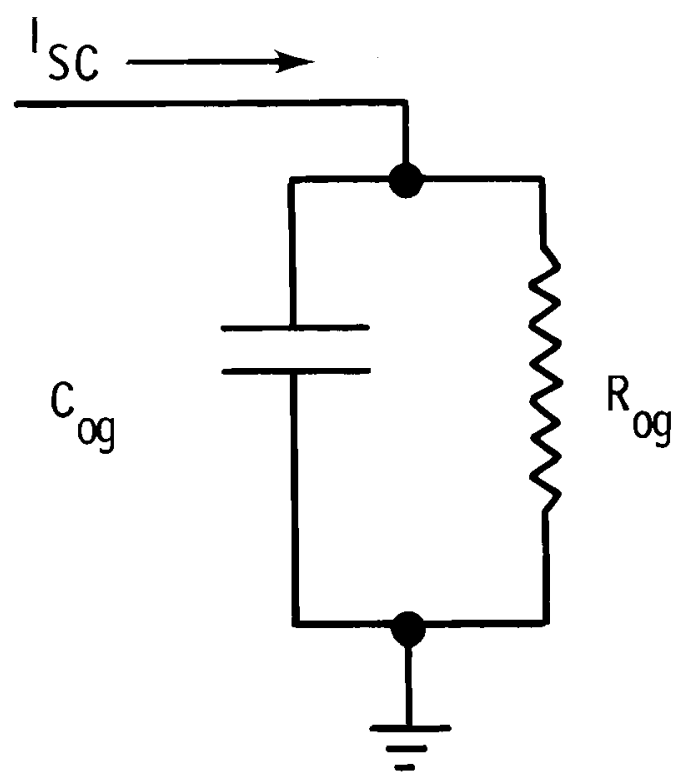

FIGURE 29. Norton Equivalent Network (48) 
- Measure or estimate from test data the capacitance of the object to ground, $\mathrm{C}_{\text {og }}$ in $\mathrm{F}$.

- Estimate the leakage resistance of the object to ground, $R_{\text {og }}$ in ohms, and evaluate the open-circuit voltage by the formula

$$
\tilde{v}_{o c}=\tilde{I}_{s c} /\left(j \omega C_{o g}+1 / R_{o g}\right) V
$$

Figure 30 shows measured values for induced voltages and currents as a function of resistance to ground for a typical pickup camper parked under a $525 \mathrm{kV}$ line. (47) Figure 31 shows measured values of normalized open circuit voltage and normalized short circuit current versus height for persons standing on insulation blankets under a $525 \mathrm{kV}$ line. ${ }^{(47)}$
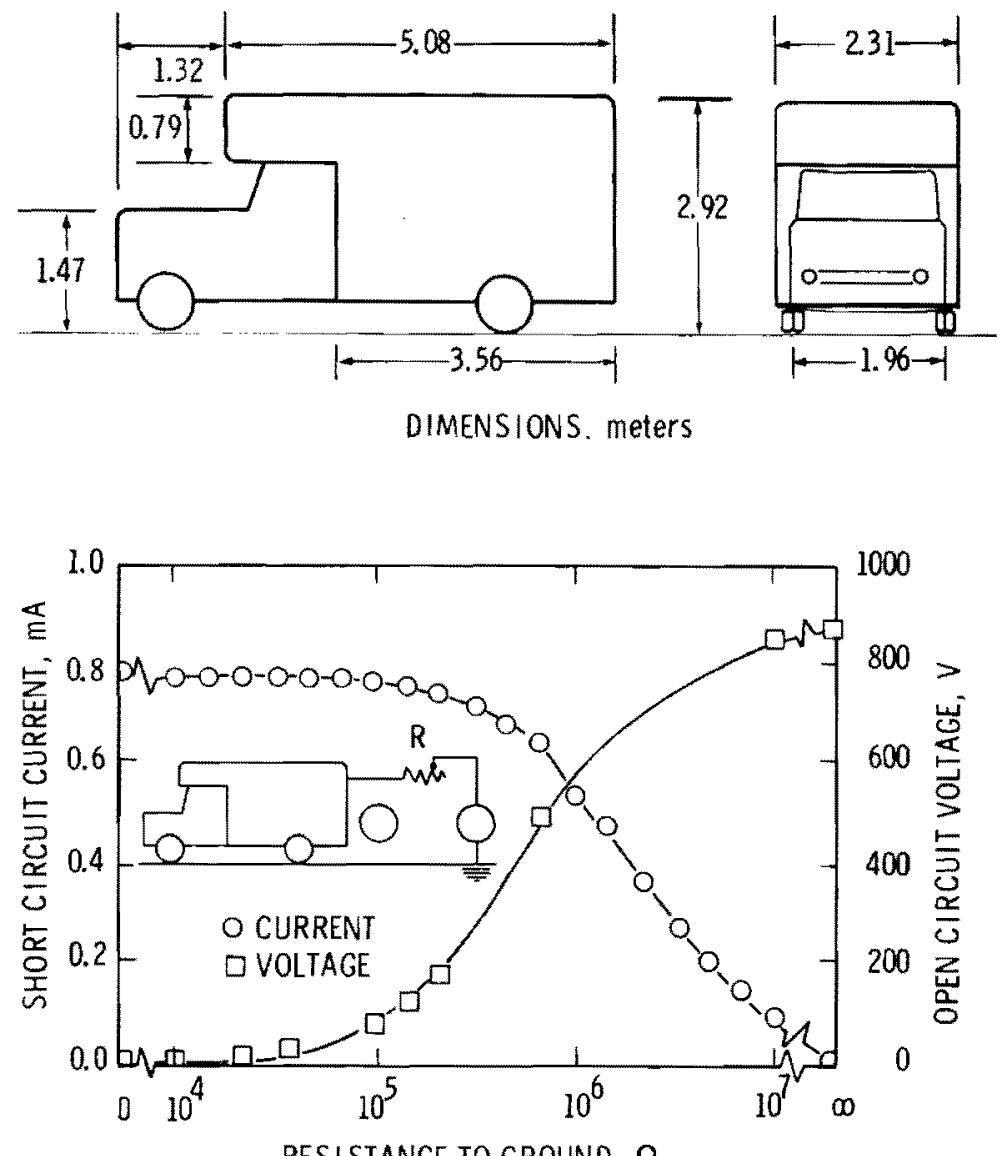

RESISTANCE TO GROUND, $\Omega$

FIGURE 30. Induced Voltages and Currents as a Function of Resistance to Ground for a Typical Pickup Camper Parked Under a $525 \mathrm{kV}$ Line(47) 

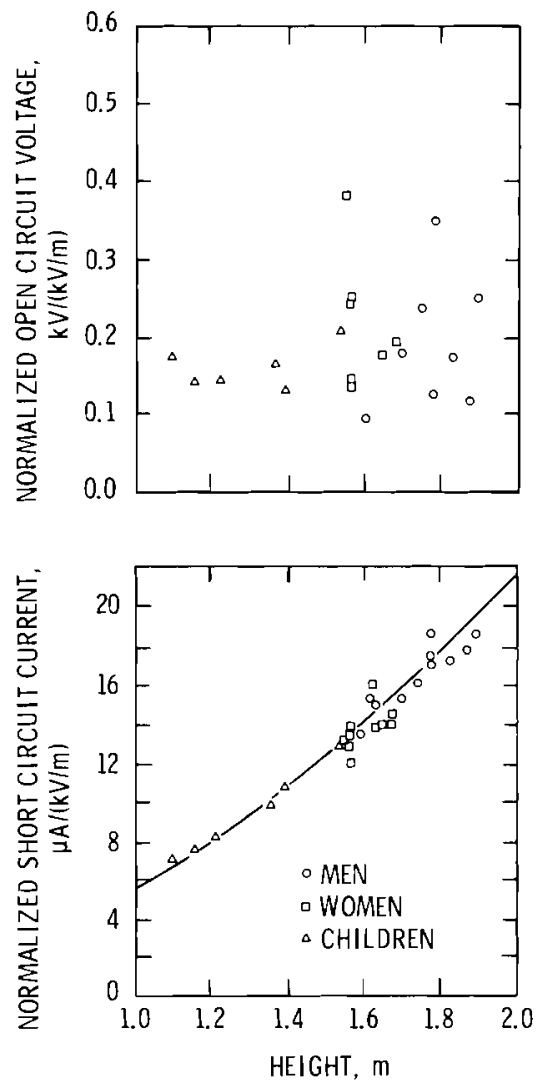

FIGURE 31. Normalized Open Circuit Voltage and Short Circuit Current vs Height for Persons Standing on Insulation Blankets Under a $525 \mathrm{kV}$ Line(47)

The data in Figure 31 indicate an average induced current value of $16 \mu \mathrm{a} /(\mathrm{kV} / \mathrm{m})$ for a person $1.75 \mathrm{~m}$ tall standing on insulation. (Complete details of these measurements are in the cited reference.)

When people or animals are in a strong electrical field, currents flow in their bodies and spark discharges may occur which are below the threshold of perception. Other phenomena, such as hair stimulation and tingling sensations, may also be present. The reactions to electrical fields are very subjective and depend on particular situations. It is very difficult to relate values of current, voltage, or energy to sensation for each situation.

Tests were conducted under Project UHV to determine the sensations felt by people at various electrical field gradient levels. (48) 
Emphasis was put on the kind of sensation and its degree of acceptability. Twenty-seven people, on different occasions, were asked to walk under a test line and then fill out a questionnaire concerning the sensations they felt. Analysis of the answers showed:

- The most common sensations were hair nerve stimulation due to hair erection ( $80 \%$ of the cases) and tingling between body (particularly arms) and clothes (64\% of the cases). The above two sensations, however, are seldom of concern, except at very high gradient as shown in Figure 32.

- More unacceptable sensations, although less frequent, were sparks: head hat; feet - shoes; legs - boots. Enough statistical data are not yet available on these subjects. The sparks can occur as gradients as low as 15 to $20 \mathrm{kV} / \mathrm{m}$.

- Handling conductive objects under the line can also be of concern. Touching an object of a certain size can often be painful if the person, the object, or both are insulated from ground.

From Figure 32 the threshold of perception for more than 10\% of the cases lies between 10 and $15 \mathrm{kV} / \mathrm{m}$. The gradient is not the actual gradient of the skin surface. The human skin "electric field recognition level" is approximately $240 \mathrm{kV} / \mathrm{m}$. (48) The presence of a man can, in fact, enhance the undisturbed gradient to such values. The correlation between voltage gradient at ground and local gradient on the skin surface is complex, as is the correlation between gradient and current in different sections of the body.

Subjective observations regarding the reaction, or the lack of it, of people exposed to high electrostatic fields ${ }^{(48)}$ may be summarized as follows:

- No abnormal reactions were observed for voltage gradients up to $25 \mathrm{kV} / \mathrm{m}$ in the absence of spark discharges.

- In the presence of repeated spark discharges, people reacted with nervousness and inability to continue work. Generally repeated spark discharges would not be encountered in normal work or under a transmission line.

- Changes, if any, appeared not permanent and normal conditions would be recovered by the next day. 


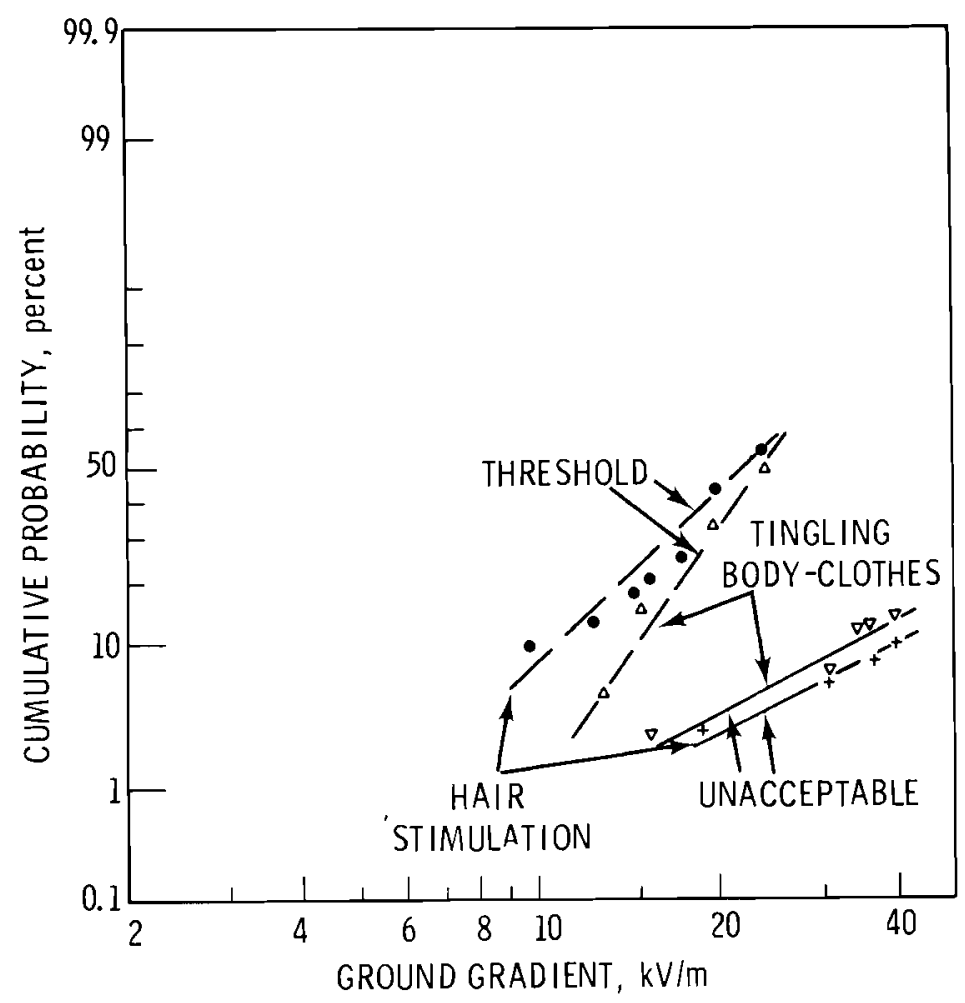

FIGURE 32. Effect of Gradient at Ground Level on Persons

(48)

Observation of the behavior of animals is very limited. Work to date has indicated no visible change in grazing, feeding and drinking habits of cattle on a conductive damp terrain such as grass, for electrical fields up to $18 \mathrm{kV} / \mathrm{m}$. As fields are increased, phenomena such as corona from ears has greatly disturbed animals. On dry nonconductive ground, spark discharges might occur between grounded objects and the body of animals.

Different parts of the body vary in sensitivity to electrical current. Dalziel ${ }^{(49)}$ has investigated the human threshold of perception to the passage of both alternating currents and direct currents. In practice the perception on the hands, when current flows between one hand and the other (one hand is grounded and the second hand touches an energized electrode), is most important. Experimental results from Dalziel ${ }^{(49)}$ are shown in Figure 33 for alternating current. The data follow a normal distribution with large dispersion (ratio 1 to 4 between $1 \%$ and $99 \%$ values). Average values for men equal $1.1 \mathrm{~mA}$ for 


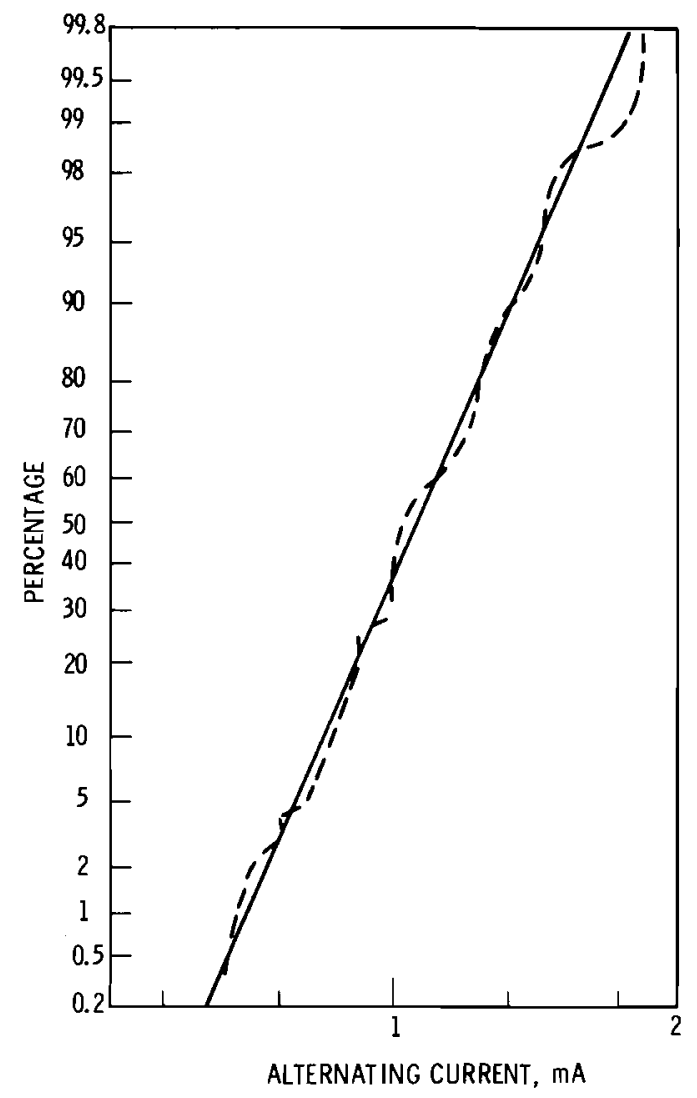

FIGURE 33. Distribution Curve of Minimum Perceptible Alternating Current (Data from 167 Men)(49)

$60 \mathrm{~Hz}$. The first sensation for alternating current is stinging. At frequencies above $100 \mathrm{kHz}$ the stinging sensation changes to one of heat.

Bracken has also reported on measurements to determine the levels of perception and annoyance for steady state current and spark discharge shocks. (47) These measurements are described below:

"The steady state current measurements were made with an adjustable current shunt in parallel with the hand of the subject. Contact to the hand was made by pressing down on two electrodes with $1.75 \mathrm{~cm}$ flat washer contacts. The electrodes were spaced $6.35 \mathrm{~cm}$ apart and consequently did not contact a 11 the subjects' hands in the same place. The smaller children necessarily had to make one contact with part of their fingers. The subject varied the current through one hand by adjusting the shunt resistance with the other hand. The 
current source was a large camper which was parked on hotline blankets just beyond the outside phase of a $525 \mathrm{kV} 1$ ine in a field strength of 10 to $12 \mathrm{kV} / \mathrm{m}$. The maximum short circuit current from the truck was about $2.5 \mathrm{~mA}$ and the open circuit voltage ranged from 1.2 to $2.2 \mathrm{kV}$. Subjects stood on the ground so there was some leakage current through the shoes. For the men, measurements were also made with the subjects insulated from ground. In this case the mean perception and annoyance levels dropped 10 to $20 \%$ indicating that significant leakage was present when standing on the ground."

The results of the steady state current measurements are shown in Table 12 .

"The maximum and minimum current levels are listed as we11 as the mean, since the validity of the latter can be questioned with such a small sample. The annoyance levels in all cases were below the maximum current available from the camper. The mean perception level of $1.0 \mathrm{~mA}$ measured for men is in agreement with the value found by several investigators for grip contact at $60 \mathrm{~Hz}$. ${ }^{(50)}$ There was not a strong correlation between measured levels and age (size) of children. The minimum levels in this and the subsequent tests were experienced by a $20.7 \mathrm{~kg} 7$-year-old girl.

Transient discharge shocks under transmission lines can occur either when a grounded person touches an insulated object or when

TABLE 12. Electrical Shock Perception and Annoyance Levels ${ }^{(47)}$

\begin{tabular}{|c|c|c|c|c|c|c|c|}
\hline Test, Units & Sample & Mean & $\begin{array}{l}\text { Perception } \\
\text { Min } \\
\end{array}$ & Max & Mean & $\begin{array}{c}\text { Annoyance } \\
\text { Min }\end{array}$ & $\operatorname{Max}$ \\
\hline $\begin{array}{l}\text { Short circuit } \\
\text { current through } \\
\text { hand, mA }\end{array}$ & $\begin{aligned} 6 & \text { men } \\
10 & \text { women } \\
6 & \text { children }\end{aligned}$ & $\begin{array}{l}1.0 \\
0.9 \\
0.6\end{array}$ & & $\begin{array}{l}1.3 \\
1.4 \\
0.9\end{array}$ & $\begin{array}{l}1.6 \\
1.5 \\
1.5\end{array}$ & $\begin{array}{l}0.9 \\
1.0 \\
0.5\end{array}$ & $\begin{array}{l}2.0 \\
2.4 \\
2.0\end{array}$ \\
\hline $\begin{array}{l}\text { Discharge from } \\
\text { umbrella, } \\
\mathrm{kV} / \mathrm{m}\end{array}$ & $\begin{array}{l}8 \text { men } \\
10 \text { women } \\
6 \text { children }\end{array}$ & $\begin{array}{l}1.9 \\
3.2 \\
3.0\end{array}$ & $\begin{array}{l}1.5 \\
2.0 \\
2.0\end{array}$ & $\begin{array}{l}2.4 \\
3.5 \\
3.5\end{array}$ & & $\begin{array}{l}2.4 \\
2.5 \\
3.0\end{array}$ & $\begin{array}{l}4.2 \\
8.0 \\
4.7\end{array}$ \\
\hline $\begin{array}{l}\text { Discharge to } \\
\text { ground rod, } \\
\mathrm{kV} / \mathrm{m}\end{array}$ & $\begin{array}{l}8 \text { men } \\
10 \text { women } \\
6 \text { children }\end{array}$ & $\begin{array}{l}6.5 \\
4.5 \\
5.3\end{array}$ & $\begin{array}{l}6.0 \\
3.0 \\
3.0\end{array}$ & $\begin{array}{l}8.0 \\
8.6\end{array}$ & $\begin{array}{l}- \\
9.2 \\
7.5\end{array}$ & $\begin{array}{c}- \\
7.0 \\
5.0\end{array}$ & $\begin{array}{l}-- \\
12.3 \\
10.0\end{array}$ \\
\hline
\end{tabular}


an insulated person touches a grounded object. A shock representative of the first category was introduced by having the subjects approach the transmission line holding an umbrella. The wooden umbrella handle effectively isolated the metal frame from the person who, during the course of the test, would discharge the umbrella by moving their thumb near the metal release button just above the handle. The field strengths at which perception and annoyance occurred were determined from a measured field strength grid laid out prior to each test."

The results of this test are shown in Table 12 .

"Again the size of the sample makes the mean value only a representative number which should be substantiated with a more extensive testing program. The open circuit voltage on the umbrella held with the handle $1.2 \mathrm{~m}$ high was found to be a linear function of field strength with a slope of 1.2 for each subject. No attempt was made to estimate the voltage of perception and annoyance discharges, because umbrella height and impedance to ground were not controlled.

Spark discharges from an isolated person to a grounded object were simulated when the electrically isolated subjects touched ground rods. The ground rods were driven at points of known field strength and the subjects touched them with the finger tips while standing on hotline blankets. In order to minimize field distortion, other persons and objects were kept well away from the subject in both spark discharge tests."

The extremes and means for field strength at perception and annoyance levels are 1 isted in Table 12.

In most situations involving shock currents due to overhead transmission lines there is little danger of direct physiological harm. (48) It is also important that situations involving painful or annoying sensations be avoided. Continuous $60 \mathrm{~Hz}$ currents become objectionable to humans at 
values of about $2 \mathrm{~mA}$. Work at Project UHV indicates objectionable values for spark discharges starting at 700 to 1200 volts for a capacitance of $100 \mathrm{pF}$ $($ energy $=0.5 \mathrm{~mJ})$.

3.8.9.3 Let-Go Current and Fibrillation. Control over muscles in which alternating current is flowing becomes increasingly difficult as the steady-state current intensity increases. Above a certain value of current it is impossible for a person to release his grip on an object. The current intensity for which this situation first occurs is called the "let-gocurrent." Dalziel ${ }^{(49)}$ has reported the results of "let-go-current" tests on 134 men and 28 women. The results are shown in Figure 34 . The minimum let-go values are arbitrarily chosen as those with a probability of $0.5 \%$. Using that criterion, values of $9 \mathrm{~mA}$ for men and $6 \mathrm{~mA}$ for women are obtained. A more conservative value of $5 \mathrm{~mA}$ might be applied for children.

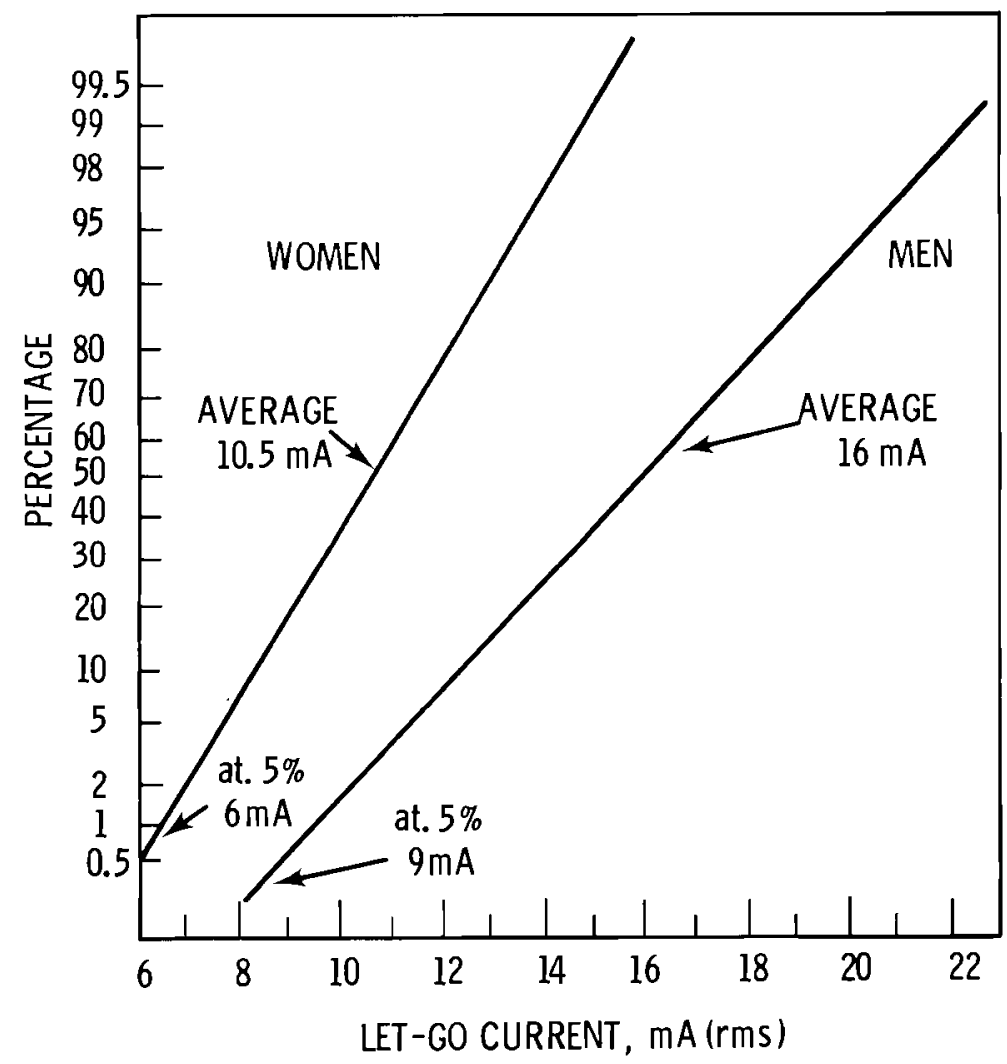

FIGURE 34. Distribution Curve of Let-Go Values of Alternating Currents. Data for 28 women and 134 men. (51) 
As body currents increase above the let-go values the danger of ventricular fibrillation also rises. From a practical point of view this term means that heart action and blood circulation stop. Once the heart goes into fibrillation it rarely recovers spontaneously. ${ }^{(49)}$ Fibrillating current values are shown in Figure 35 as a function of body weight for various species of animals. The IEEE working group on Electrostatic Effects has suggested a minimum primary stock energy value for people equal to 25 joule. Table 13 summarizes the effects of electric currents on people.

\subsubsection{Electromagnetic Effects. While electric field strength in the} vicinity of transmission lines depends on the voltages employed, the magnetic field is caused by currents flowing in the conductors. Magnetic field strength

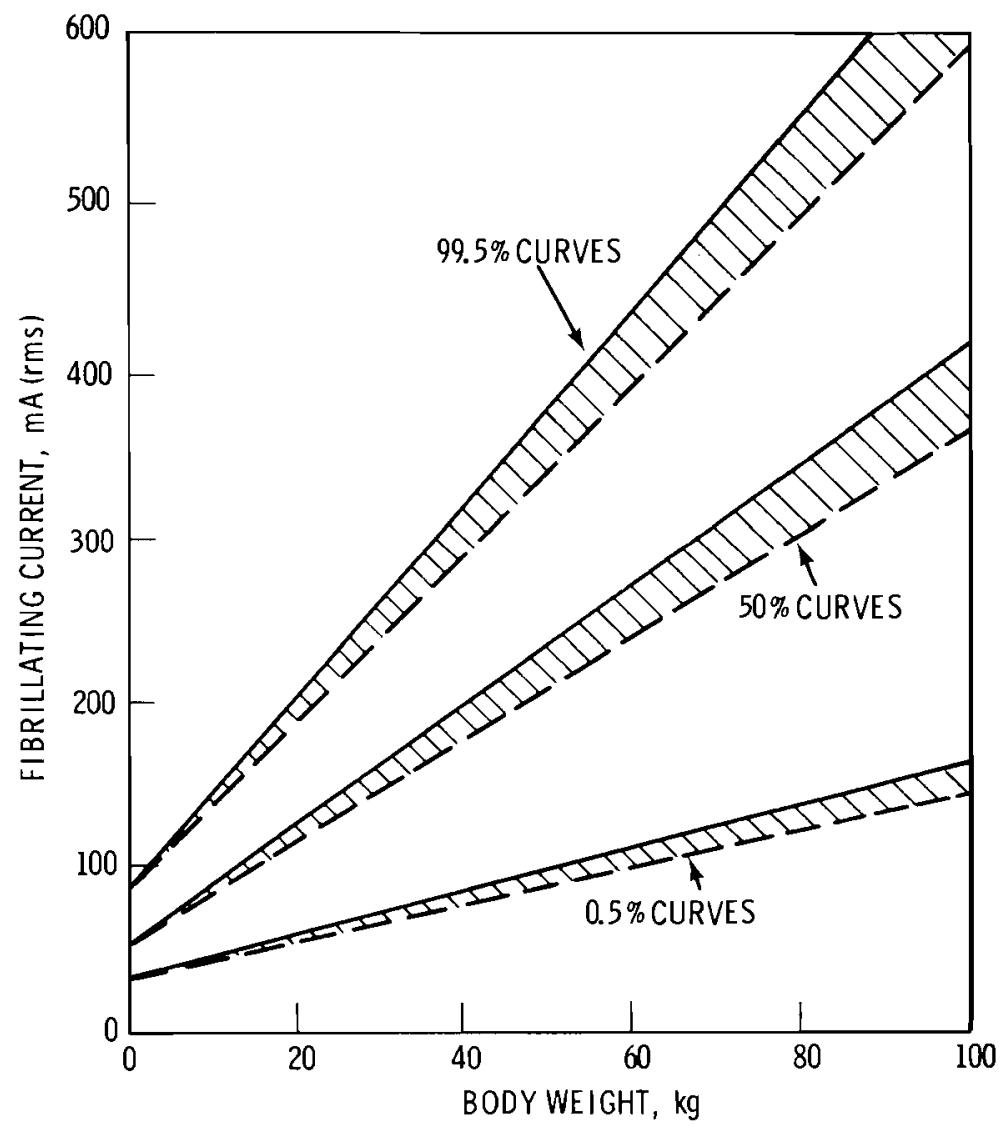

FIGURE 35. Fibrillating Currents Versus Body Weight for Seven Species of Animals (Calves, Dogs, Sheep, Cats, Rabbits, pigs, Guinea Pigs). Continuous curves: all animals considered; dashed curves, pigs omitted. (51) 
TABLE 13. Summary of Effects of Electric Currents
on People $(48)$

\begin{tabular}{|c|c|c|c|c|}
\hline \multirow[b]{2}{*}{$\begin{array}{l}\text { Threshold of } \\
\text { Perception }\end{array}$} & \multirow[b]{2}{*}{$\begin{array}{l}\text { men } \\
\text { women }\end{array}$} & \multirow{2}{*}{$\begin{array}{c}\begin{array}{c}\text { Continuous } \\
60-\mathrm{Hz} \text { Current } \\
\text { (rms) }\end{array} \\
1.1 \mathrm{~mA} \\
0.8 \mathrm{~mA}\end{array}$} & \multicolumn{2}{|c|}{ Spark Discharge } \\
\hline & & & $\begin{array}{l}C=1000 \mathrm{pF} \\
\mathrm{V}=350 \mathrm{~V}\end{array}$ & $E=0.12 \mathrm{~mJ}$ \\
\hline $\begin{array}{l}\text { Minimum } \\
\text { Secondary Shock }\end{array}$ & $\begin{array}{l}\text { men } \\
\text { women }\end{array}$ & $\begin{array}{l}1.8 \mathrm{~mA} \\
1.2 \mathrm{~mA}\end{array}$ & $\begin{array}{l}C=1000 \mathrm{pF} \\
V=700 \text { to } 1200\end{array}$ & $\underset{V}{E}=0.5$ to $1.5 \mathrm{~mJ}$ \\
\hline $\begin{array}{l}\text { Minimum } \\
\text { Primary Shock }\end{array}$ & $\begin{array}{l}\text { men } \\
\text { women } \\
\text { children }\end{array}$ & $\begin{array}{l}9 \mathrm{~mA} \\
6 \mathrm{~mA} \\
5 \mathrm{~mA}(\mathrm{a})\end{array}$ & & \\
\hline
\end{tabular}

(a) Value suggested by IEEE Working Group on electrostatic effects.

is expressed in units of gauss $(G)$. Typical magnetic field intensity measured $1.5 \mathrm{~m}$ above ground under various transmission lines is shown in Figure 36. Other measured $60 \mathrm{~Hz}$ magnetic fields found around common small appliances are included as a comparison. The magnetic field intensity near high-voltage ac overhead transmission lines is less than that found near many common electrical articles. Table 14 further illustrates this point. Magnetically induced voltages appear at the open ends of partly grounded loops on conductors such as fences, irrigation pipes and distribution lines parallel to high voltage circuits. Normally, one end of the conductor is grounded, and the earth serves as the remainder of the loop. A person who completes the loop will be subject to either a steady state or spark discharge shock. $(51,52,53)$ The threshold and let-go levels are the same as for electrostatically coupled currents although magnetically induced voltages usually are lower and the currents higher than in the electrostatic case. Proper grounding of conductive objects which parallel transmission lines will prevent the problem. 


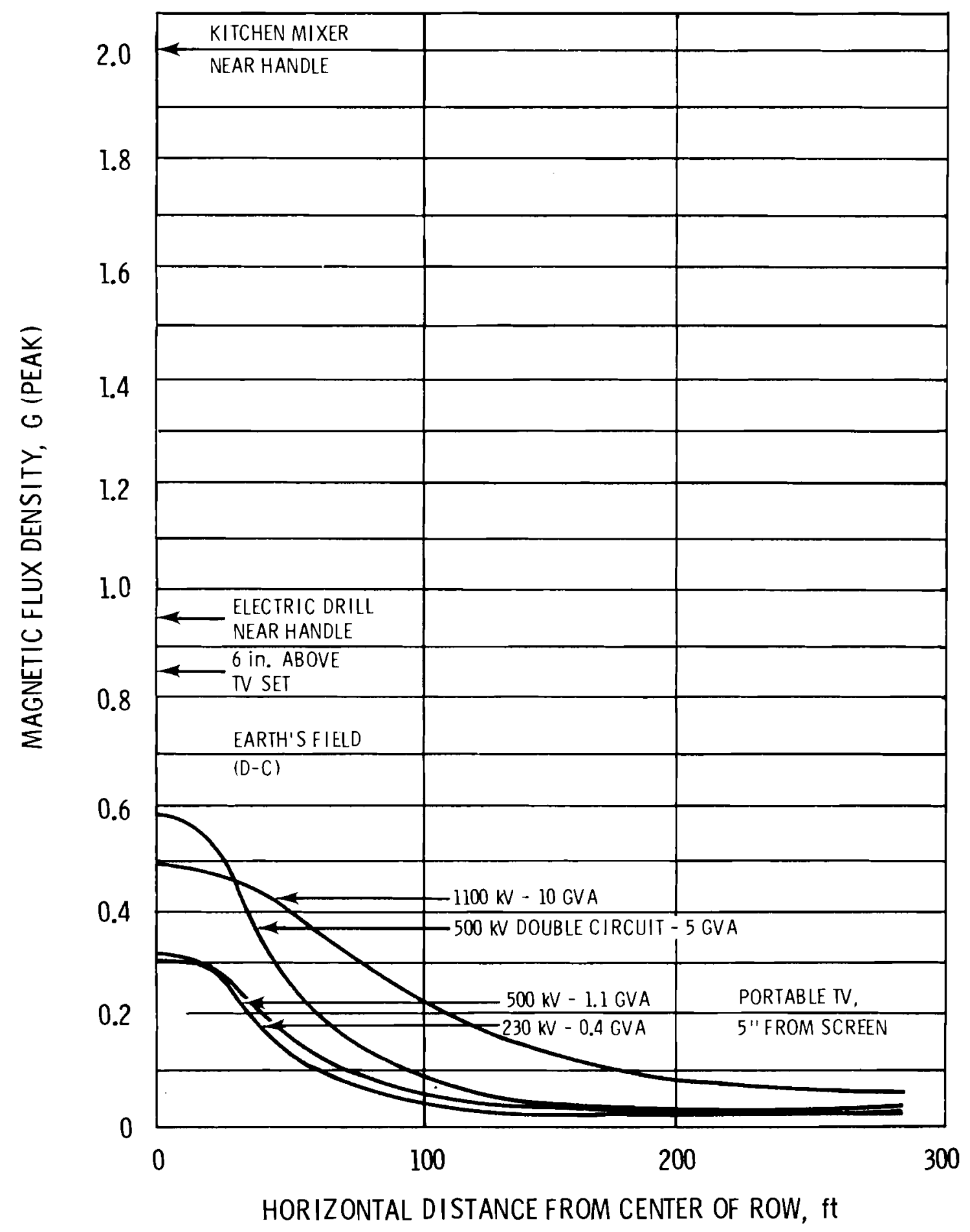

FIGURE 36. Profile of Calculated Magnetic Flux Density $(60 \mathrm{~Hz})$ at $1.5 \mathrm{~m}$ Above Ground for Transmission Lines Compared with Lofalized Fields from Typical Household Appliances (52) 
TABLE 14. Localized $60 \mathrm{~Hz}$ Magnetic Flux Densities
Produced by Some Electrical Appliances

10 to 25 Gauss
325 Watt Soldering Gun
Magnetic Stirrer
Power Feeder Cable
Hair Dryer

5 to 10 Gauss

Can Opener

140 Watt Soldering Gun

Fluorescent Desk Lamp

Kitchen Range

Electric Shaver

1 to 5 Gauss

Bench Grinder

Arc Welder

Food Mixer

Power Transformer

Induction Motor

Color Television Set

Food Blender

Electric Dril1

Portable Heater

\begin{tabular}{l}
0.01 to 1.0 Gauss \\
\hline Toy Auto Transformer \\
Garbage Disposal \\
Cloths Dryer \\
Black/White Television Set \\
Vacuum Cleaner \\
Heating Pad \\
Electric Toaster \\
Bell Transformer
\end{tabular}

0.01 to 0.1 Gauss

Home Electric Service Unit Kitchen Fluorescent Lamp

Dishwasher Laundry Washer

Phonograph

Calculator

Electric Iron

0.001 to 0.01 Gauss

Refrigerator

3.8.9.5 Biological Effects of Electrical and Magnetic Fields. Several investigations are underway regarding possible biological effects due to electrical and magnetic fields and induced currents below the level of perception. The results of these investigations, sponsored by the Electric Power Research Institute (EPRI), the Energy Research and Development Administration (ERDA) and others, are inconclusive at this time. 


\subsubsection{Conductor Clearances}

The National Electrical Safety Code now specifies minimum conductor-toground clearances for transmission lines in certain areas. (54) New code standards have been adopted which are more specific. (55) Rule 232 of the new standards is reproduced in Appendix $B$ of this report. The standards require a clearance sufficient to limit the short circuit current due to electrostatic effects on the largest truck, vehicle or equipment under a line to $5.0 \mathrm{~mA}$. 


\section{DIRECT CURRENT TRANSMISSION SYSTEMS}

High-voltage direct-current (HVdc) transmission is not used extensively in the U.S. at the present time. The most notable application of HVdc in the U.S. is the $850 \mathrm{mile-long} \mathrm{Pacific} \mathrm{Northwest-Southwest} \mathrm{Intertie} \mathrm{interconnecting}$ hydroelectric dams on the Columbia River with Los Angeles. This line operates at $\pm 400 \mathrm{kV}$ with a power transfer capability of $1440 \mathrm{MW}$.

The absence of reactive current and skin effect (p.11) in dc circuits allows the conductor material to be used more efficiently than is possible in ac circuits. Direct current transmission line costs are lower than those for ac, but the terminal facilities necessary to convert generated ac to dc for transmission and back to ac for consumption are very expensive. Power transmission capacities for some typical dc transmission projects are given in Table 15.

\subsection{Advantages and Disadvantages of HVdc Transmission}

For certain applications HVdc transmission has advantages over HVaC transmission.

\subsubsection{Reliability Considerations}

HVdc transmission has some reliability advantages. One is that by utilizing a bipolar (two circuit) arrangement with a suitable ground electrode or an insulated neutral conductor, a single dc circuit can operate at half capacity with one conductor out of service by using the earth as a return circuit. This emergency monopolar operation of a bipolar circuit with ground return results, however, in a large flow of earth return current. Careful design is needed to prevent possible undesired side effects.

The extent of effects of earth currents on buried metallic substructures, such as pipelines, during monopolar operation of a dc circuit, depends on the relative location of the ground electrodes with respect to the substructures and the configuration and resistivity of the geological formations of the area. The potential for corrosion damage can be minimized by: careful design and placement of the ground electrodes; limiting the duration of any emergency monopolar operation of the system; modification of existing cathodic protection installations which protect against other sources of corrosion damages; 
TABLE 15. High-Voltage Direct Current Power Transmission Projects (1)

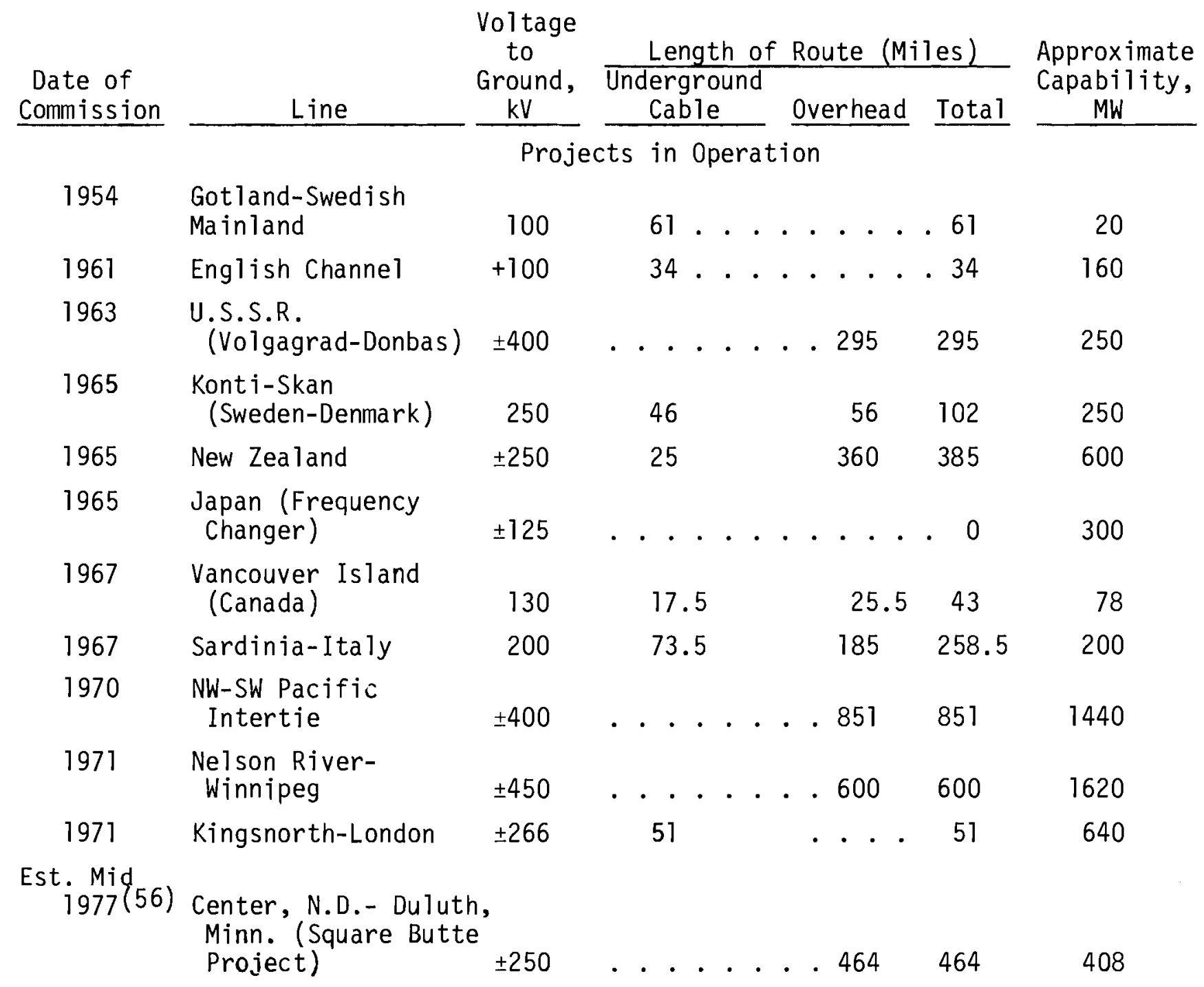

installation of automatically controlled cathodic protection devices which will respond to changes in ground currents; and installation of an insulated metallic return conductor for use during monopolar operation of a biopolar HVdc system. (1)

Additional reliability advantages of HVdc transmission include:

- The asynchronous nature of a dc line allows dc interties between ac systems, and does not transfer the ac transients between the systems in case of a disturbance. $(1,57)$ 
- HVdc lines have less lightning trip-out severity.

- HVdc has the ability to import power without increasing ac system short-circuit levels.

Direct current transmission circuits have the disadvantage that HVdc circuit breakers are not yet commercially available. (1) Short circuits on dc 1 ines must be interrupted by changing the terminal rectifier mode to inverter mode so that the fault current is blocked and the line discharged. Thus while dc lines can be tapped for branch circuits, a fault on any portion of the line necessitates shutting down the entire line. Also, because of its corrosion effects, monopolar operation of HVdc transmission may be unsuitable for shared corridors. (59)

\subsubsection{Economic Considerations}

The cost of a dc transmission line is about $65 \%$ of an equivalent overhead ac line because of reductions in ROW and materials required for conductors, and lighter supporting structures. (1) Direct current terminal conversion facilities are expensive, however, so overhead dc transmission usually is economically attractive only for relatively long lines. The cost of each Pacific dc intertie converter terminal was reported to be over $\$ 40 / \mathrm{kW}$. Converter terminal costs for the Square Butte Project (see Table 15) will be about $\$ 75 / \mathrm{kW}$. $(56)$

Some of the economic considerations in dc transmission, compared to ac, may be summarized as follows:

- Construction of the dc transmission line, overhead or underground, is less expensive.

- ROW requirements are less.

- For comparably rated 1ines, transmission line losses are less.

- Modern de lines do not add appreciably to the short-circuit capacity requirements of their receiving buses.

- Direct current transmission terminal stations are appreciably more complex and expensive than their ac counterparts, both for initial cost and operating and maintenance expenses. 
Generally HVdc overhead transmission lines become economically favorable over HVac lines for circuits longer than 400 to 500 miles. $(1,6,58)$ Figure 37 shows 1970 Federal Power Commission comparative transmission cost estimates for $500 \mathrm{kVac}$ and $\pm 400 \mathrm{kVdc}$ lines with $1000 \mathrm{MW}$ capacities. Table 16 compares economic factors for $765 \mathrm{kVac}$ and $\pm 750 \mathrm{kVdc}$ circuits with $5000 \mathrm{MW}$ capacities.

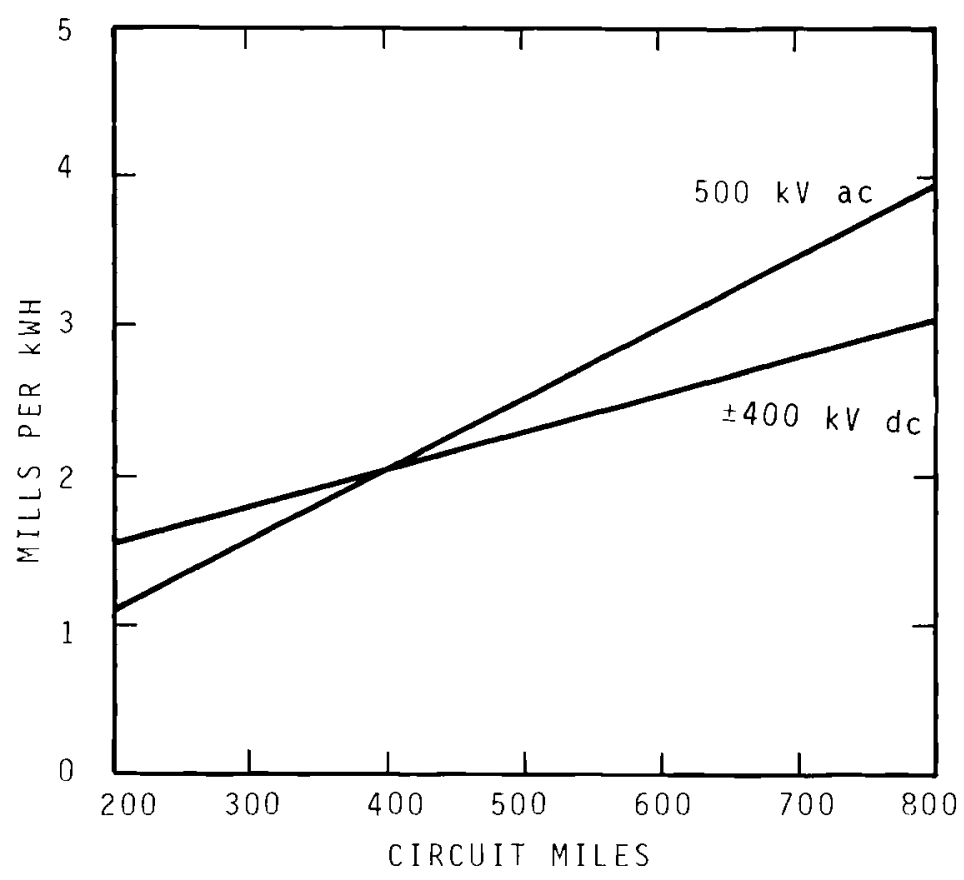

FIGURE 37. Transmission Cost $1000 \mathrm{MW}$ (70\% Load Factor) - Federa 1 Power Commission, 1970(1) 
TABLE 16. Comparison of $A C$ and $D C$ Overhegd Transmission Circuits of $5000 \mathrm{MW}$ Capacity(58)

Type

Voltage: Nominal

Maximum

Construction:

Capacity:

Land: Route Width Acres/Mile

Line Cost: (b)

Million \$/Mile

Terminal Cost: (b)

Million $\$ /$ Line

Power Losses:

Percent of yearly energy

Terminal losses per line (2 terminals)

$\begin{array}{ccc}\frac{D C}{ \pm 750 \mathrm{kV}} & & \begin{array}{l}765 \mathrm{kV} \\ \end{array} \\ & & 800 \mathrm{kV} \\ 500-\mathrm{mile} & & 500-\mathrm{mile} \\ \text { 0verhead } & & \text { Overhead } \\ \text { (Bi-polar) } & & \text { (2 lines) } \\ 5000 \mathrm{MW} & & 5000 \mathrm{MW} \\ 150 \mathrm{ft} & & 400 \mathrm{ft}(\mathrm{a}) \\ 18 & & 50\end{array}$

0.28

0.60

325

100

$\begin{array}{ll}4.0 \% & 5.0 \% \\ 2.3 \% & 0.4 \%\end{array}$

(a) Two lines - Flat Conductor Configuration

(b) Costs are estimated as of January, 1975.

\subsection{HVdc Development Activities and Future Trends}

The technology of high voltage direct-current transmission can now be applied with the same degree of confidence as ac power transmission. This confidence is reflected in the world-wide growth of HVdc systems in recent years. Figure 38 shows the total installed capacity of HVdc systems currently in operation, under construction or ordered. During the second half of this decade, the installed capacity of HVdc systems around the world is increasing at the average rate of $1400 \mathrm{MW}$ per year. ${ }^{(60)}$

A 464 mile-long HVdc line between Center, North Dakota, and Duluth, Minnesota, (Square Butte Project) is scheduled for completion in mid-1977. The line will operate at $\pm 250 \mathrm{kVdc}$ with a capacity of $408 \mathrm{MW}$. $(56)$

A feasibility report for a second Pacific Northwest-Southwest dc intertie has recently been completed. ${ }^{(60)}$ The study proposes construction 


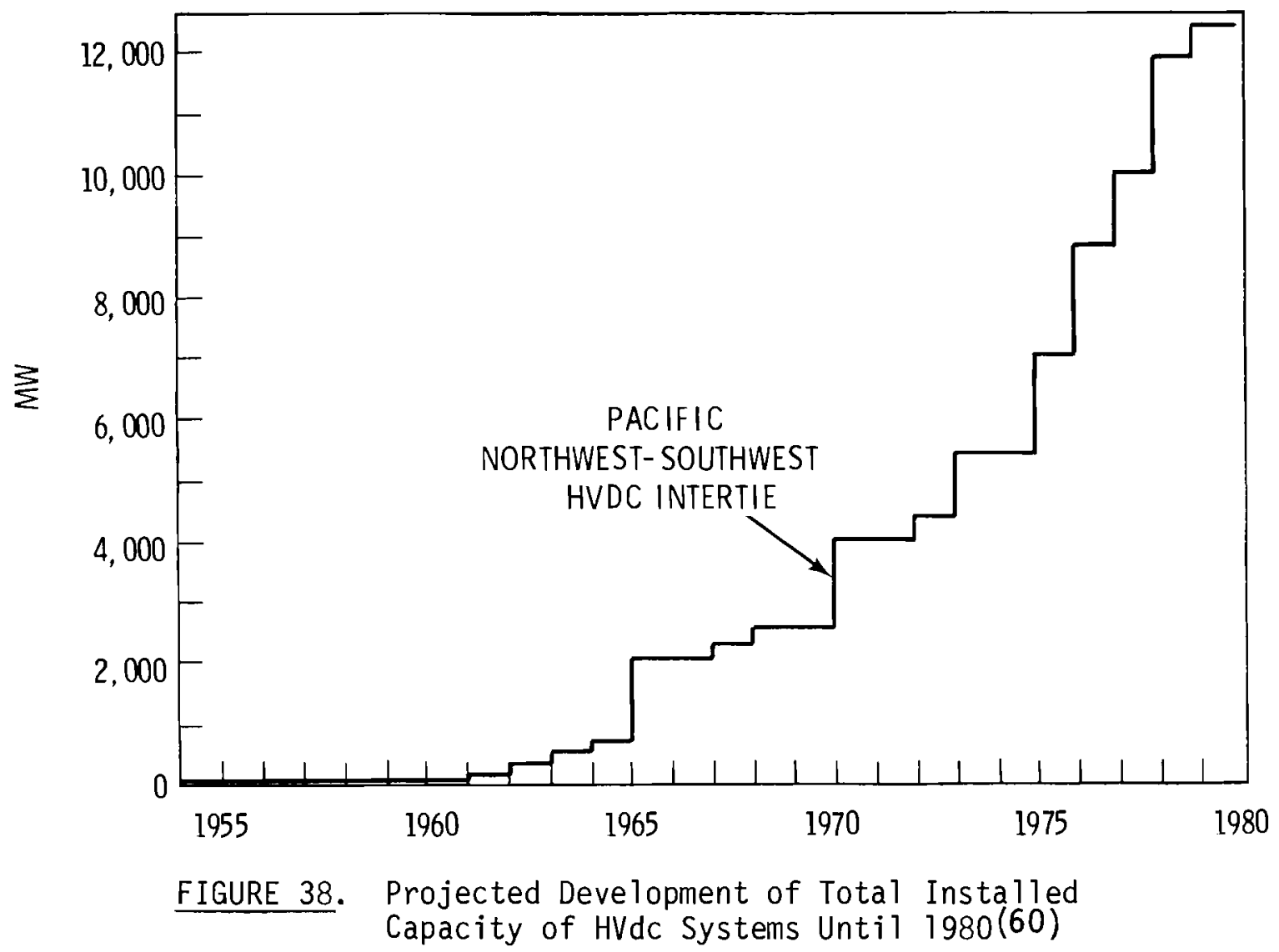

of a 1054 mile-long, $\pm 500 \mathrm{kVdc}$, overhead line with an ultimate capacity of 2200 MW between Celilo, Oregon, and Phoenix, Arizona.

In the past high voltage dc converter stations used mercury-arc valves to convert ac to $d c$ and vice-versa. Solid state valves (thyristors) are now available and the good performance of modern HVdc schemes using the solidstate valves has contributed to the high degree of confidence in HVdc systems. The square Butte line will utilize solid-state valve technology. Around the world there are eight new HVdc transmission projects under construction, all based on thyristor valve technology.

Another development in HVdc conversion equipment is a new type of mercury valve called the liquid metal plasma valve. This is a compact low-loss valve combining the favorable qualities of mercury-arc valve and vacuum tubes. Under the sponsorship of the Energy Research and Development 
Administration (ERDA), two prototype valves are being developed for testing at the Celilo Converter Terminal over a period of one year. Should the prototype prove itself in the testing, this type of valve could become a serious contender for use in future HVdc transmission schemes. (60)

If development of a suitable dc circuit breaker is successful, converter fault control could be eliminated, making possible the tapping of dc lines between terminals and thus enhancing the value of dc transmission for general use. (6)

\subsubsection{HVdc System Power Losses}

In a dc transmission system the voltage at the receiving end of a transmission line is always less than the voltage at the sending end, by an amount determined by the line current and the line resistance. The receiving end voltage equals the sending end voltage minus the voltage drop in the line, which equals the line current times the 1 ine resistance. (7) In general HVdc line losses are less than for comparable ac systems. (1) However, this is usually more than offset by the power losses present in the dc conversion terminals (see Table 16).

\subsection{Environmental Impact}

In general the environmental implications of HVdc systems are similar to those for HVac systems, though there are some differences.

\subsubsection{ROW Requirements}

ROW requirements for dc transmission lines are about the same as for equivalent ac lines with a delta conductor configuration (see Table 7 ).

\subsubsection{HVdc Electrical Fields}

The prediction and measurement of electric fields from HVdc lines is not so well developed as for HVac 1ines. The major complication is the presence of air ions generated by corona, which modifies the conductivity of the air in the vicinity of the HVdc line. The presence of the unidirectional fields causes movement of the air ions toward oppositely polarized conductors. For 
ac, the periodic reversal of polarity probably tends to prevent the air ions from leaving the vicinity of the conductor or corona source. For dc, a distribution of charges in space is formed which controls the electric field. The electric field spatial distribution is thereby affected by meteorological conditions, such as by the wind imparting an additional velocity bias to the air ions.

Figure 39 compares results developed by the approximate analys is and averaged measurement results for $\pm 500 \mathrm{kVdc}$ and $\pm 600 \mathrm{kVdc} 1$ ines with static wind conditions. (61) Voltages are developed on insulated objects in the vicinity of HVdC lines via charging by air ions. (46) The short circuit current appears to be about two orders of magnitude less than for a comparable HVac situation.

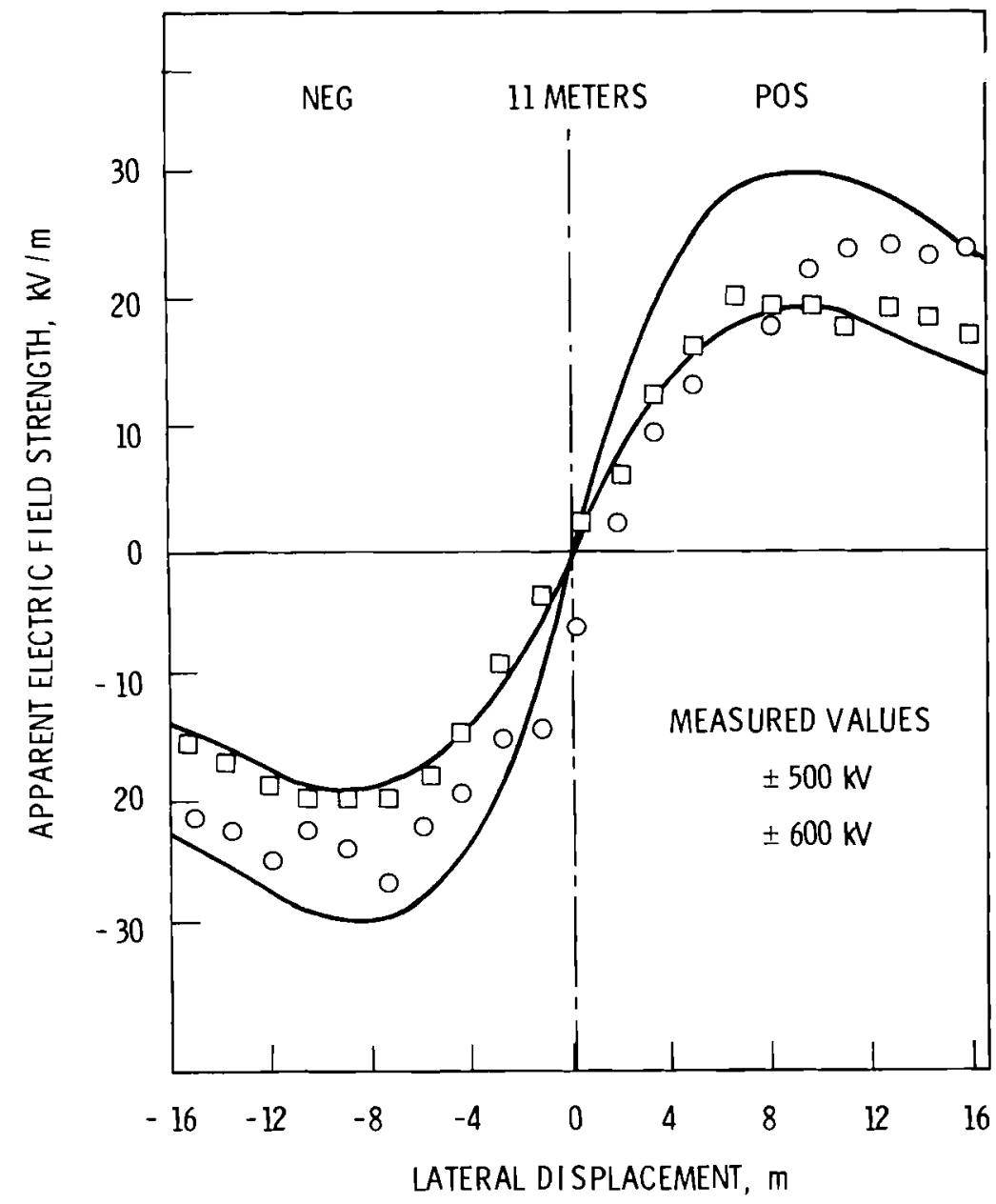

FIGURE 39. Comparison of Calculated and Measured Electrical Field Strengths Under A Line at $\pm 500 \mathrm{kVdc}$ and $\pm 600 \mathrm{kVdc}$ with Approximately $12.2 \mathrm{~m}$ Line to Ground Clearance(61) 


\section{UNDERGROUND TRANSMISSION SYSTEMS}

Underground electrical conductor cables are used extensively in low voltage electrical distribution systems, but not for transmission systems at higher voltages. In 1970, there were about 2,000 miles of underground transmission lines in the United States, mostly in densely populated areas where overhead ROW are not available or are prohibitively expensive. (1)

\subsection{Alternating Current Underground Transmission}

A major difficulty of underground ac transmission lines is a continuous flow of so-called capacitive "charging current" between the conductor and the protective outer sheath. An insulated cable stores electrical energy much the same as a capacitor. With ac circuits, this charging current flows into and out of the cable as the voltage reverses. Its magnitude increases with voltage and varies inversely with the thickness of the insulation and directly with the length of the cable. At 345-kV, using commercially available oil and paper insulated cable, practically all of the current-carrying capability of the uncompensated underground conductor is utilized by this charging current in a distance of about 26 miles. Therefore, no capability is left for useful current to be transmitted unless very expensive and bulky compensation equipment is periodically installed along the line.

Another factor prohibiting extensive undergrounding of transmission systems is insulation. Overhead lines are insulated by the air surrounding the conductors and by the long strings of supporting insulators. Underground lines require very high quality insulation around each conductor, with the insulated conductors enclosed in a conduit, generally an oil-filled pipe. Although insulation has improved, the cost is still high because of the exacting work required. The most common method is to wrap each conductor with an oil-impregnated insulating material. The physical size of the conductors limits the amount of cable which can be manufactured in a continuous length so frequent splices are required. This splicing is a critical, painstaking operation which may occupy two cable splicers and their helpers for as long as 200 hours per splice. (1) 
Problems are also encountered in connections between underground 1 ines and substations. Abrupt insulation changes cause very large concentrated electrical stresses which can only be eliminated, using current techniques, by terminating the cable above ground in an expensive device known as a "pothead." The internal construction of a pothead is very complex, both mechanically and electrically.

One of the highest voltage ac underground transmission cables currently in service is $345 \mathrm{kV}$, and the most extensive system is that of the Consolidated Edison Company in the New York City area. A higher voltage installation, utilizing $525 \mathrm{kV}$ self-contained oil-filled type cables, connects the new power plant and $500 \mathrm{kV}$ switchyard at Grand Coulee Dam. $(62,63)$ Paper is used as the insulating medium. Due to a $600 \mathrm{ft}$ elevation difference of the cable ends, the system operates at an oil pressure of $2651 \mathrm{~b} / \mathrm{in}^{2}$ to maintain oil circulation. The complete installation involves three circuits (nine cables) with an average length of about 6,000 $\mathrm{ft}$. Some maximum power ratings for various types of underground transmission cables are shown in Figure 40 .

\subsection{Direct Current Underground Transmission}

Fewer technical problems are encountered in placing dc transmission lines underground than for ac systems. For example, the charging current problem does not exist with dc. In addition, the transmission of dc underground requires burying only two conductors instead of the three required for ac. However, the high cost of conversion terminals discussed previously applies to underground as well as overhead dc transmission. This high cost effectively prohibits the extensive use of underground dc transmission cables except for long lines in heavily developed metropolitan locations or where long underwater crossings are necessary (see Table 15)

\subsection{Reliability of Underground Systems}

According to the Advisory Committee on Underground Transmission, in its 1966 report to the Federal Power Commission, overhead lines have more outages than underground lines per unit of length, but the outages are usually much shorter in duration. (1) Underground lines have the disadvantage of poor accessibility. Because of the longer repair time for underground systems, 


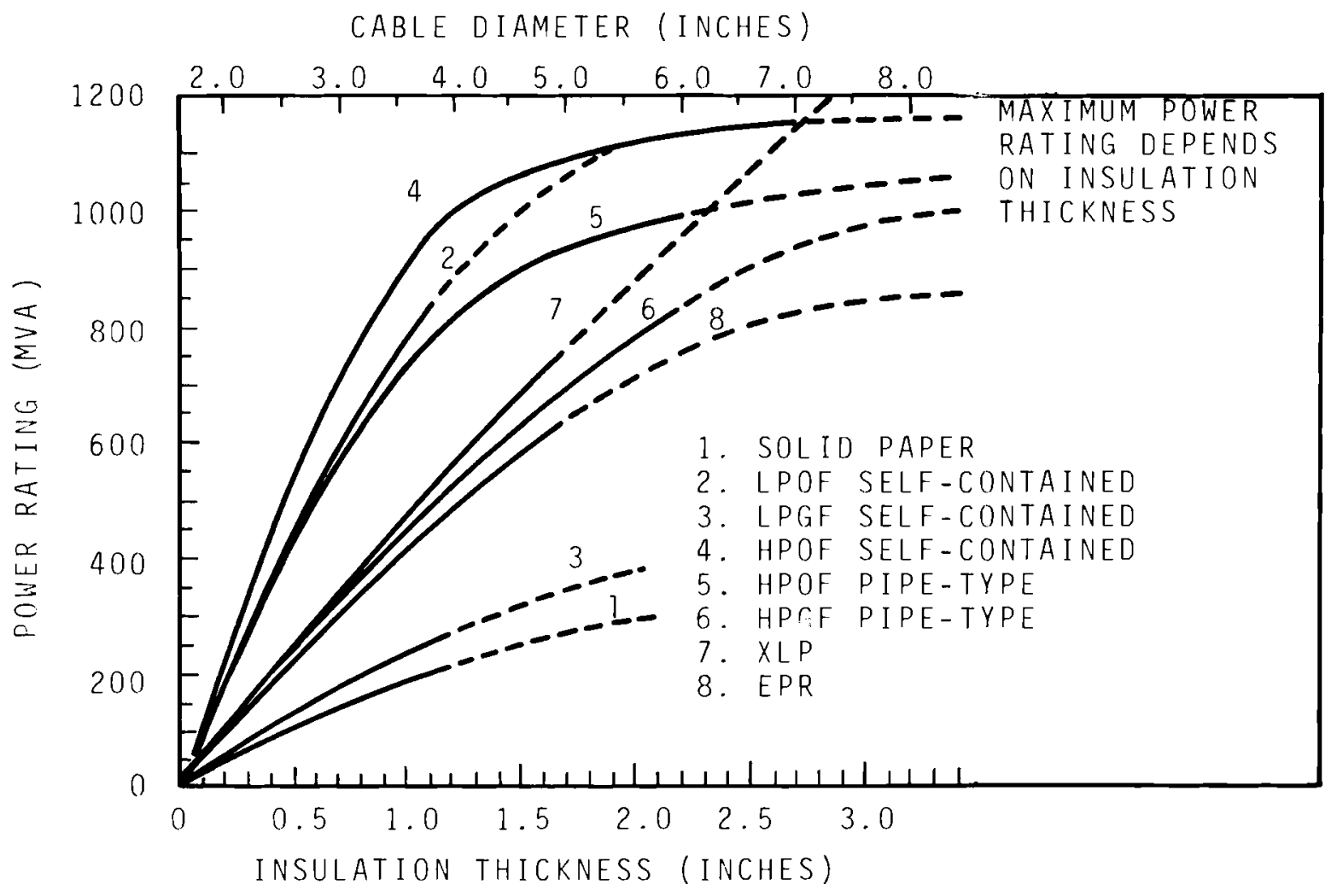

NOTE: CABLE DIAMETER SCALE IS ONLY FOR CABLES WITH NON-ANNULAR CONDUCTORS

MAXIMUM RATINGS OF VARIOUS TYPES OF CABLE

\begin{tabular}{ccc}
$\begin{array}{c}\text { MAXIMUM } \\
\text { POWER RATING } \\
\text { MVA }\end{array}$ & $\begin{array}{c}\text { OPERATING } \\
\text { VOLTAGE, } \\
\text { KV }\end{array}$ \\
\cline { 1 - 1 } 220 & & 69 \\
850 & & 345 \\
270 & & 69 \\
1,160 & & 550 \\
990 & & 550 \\
900 & & 345 \\
780 & & 230 \\
630 & & 230
\end{tabular}

FIGURE 40. Underground Transmission Cable Power Ratings (64) 
expensive duplicate facilities are sometimes installed to reduce the risk of overlapping outages. Overhead lines are more flexible because connections and repairs are relatively simple and they can be converted to higher voltage if necessary. Underground systems cannot easily be altered.

The removal of heat due to resistance heating is a problem with underground systems. A backfill of high thermal conductivity sand or concrete is sometimes used to improve heat removal.

\subsection{Line Losses}

Underground ac transmission line losses due to the charging current problem were discussed in Section 5.1. This problem is alleviated to a great extent when a compressed gas insulated (CGI) system is used. The CGI systems are just beginning to be used.

\subsection{Development Activities and Future Trends}

The extremely difficult problems of obtaining transmission line ROW in urban areas plus more recent concerns about aesthetic and other environmental effects of overhead 1 ines have resulted in extensive development activities related to underground transmission facilities. Among the major problems of long HVac underground cables is the capacitive "charging current" which was discussed previously (p.91). The result of this effect at various voltages is $i 11$ ustrated in Figure 41. The large compensation necessary creates serious probiems in the design and operation of an underground ac system and adds materially to the cost. Several manufacturers and utilities are working on various methods of increasing pipe-type cable ratings by forced circulation of cooling 0il. This approach may increase capability and lower transmission costs for both existing and future oil insulated pipe-type cable installations.

Other goals of underground transmission research and development include the development of compressed gas insulation (CGI) systems; development of cryogenic and superconducting cables; reduction in cable installation costs; improved joint use of ROW; and development of advanced concepts such as underground microwave transmission. 


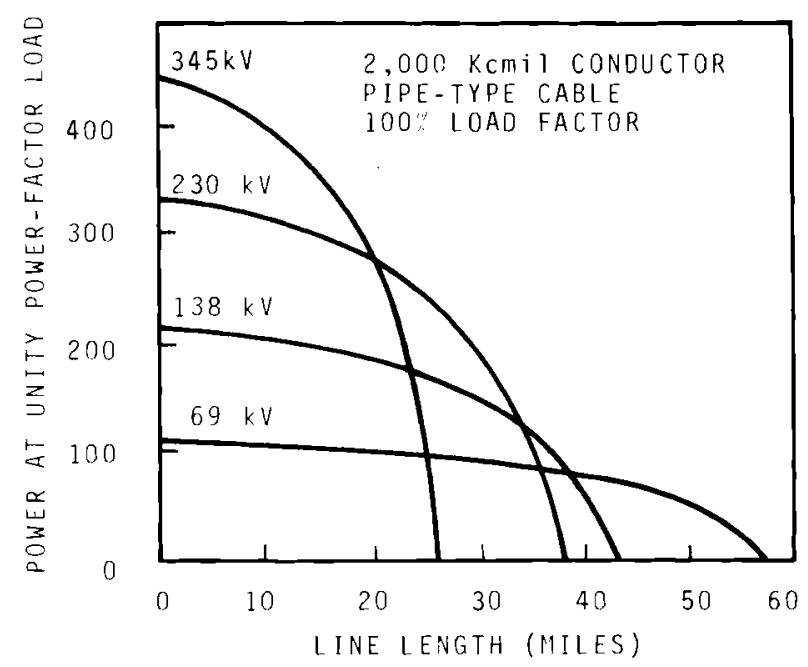

FIGURE 41. Power Delivered Versus Cable Length for
0il-Filled Pipe-Type Underground Cables $(64)$

\subsubsection{Compressed Gas Insulation Systems}

One of the most promising recent developments in underground transmission technology is the CGI system. This system utilizes sulfur hexafluoride $\left(\mathrm{SF}_{6}\right)$ gas as an insulating medium, has no dielectric loss and very low charging current. The critical distance (the distance at which the charging current reduces the line capacity to zero) for a 345-kV CGI system is about 250 miles. ${ }^{(65)}$ In contrast, the critical distance for an oil-filled pipetype 345-kV cable system is on the order of 26 miles (Figure 4l). Similarly, the critical distance for a 500-kV CGI system is about 200 miles.

In addition to low charging current, the CGI system has other potential advantages: ${ }^{(65)}$

- The $\mathrm{SF}_{6}$ insulating medium has properties similar to commonly used refrigerants. Therefore, it is possible that the insulating medium can be used as a refrigerant for direct evaporative cooling of the conductors.

- The expensive cable splicing operation is eliminated since the CGI system employees plug type connections for joining sections of conductors together.

- The CGI system uses an aluminum outer sheath (pipe). Sections of the transmission system are connected by welding the outer sheaths together. 
The largest size aluminum sheath (pipe) which can currently be extruded is about $22 \mathrm{in}$. in diameter. This limits $\mathrm{SF}_{6}$ underground systems to one conductor per sheath. If larger sheaths become available capable of containing all three conductors of an ac circuit in one sheath, trenching and other installation costs could be reduced significantly.

A11 CGI underground systems are currently hand made. If mass production techniques are developed for $\mathrm{SF}_{6}$ underground systems, costs might be reduced to three to four times of that for equivalent overhead systems.

Several separate projects using CGI underground transmission systems are now being carried out. A $520 \mathrm{ft}$ section of $\mathrm{SF}_{6}$ gas insulated underground transmission cable was installed by Consolidated Edison Company. (66) This section is rated for 2000 MVA at $345 \mathrm{kV}$. The BPA installed a prototype 500-kV CGI cable on its system in the summer of 1974 to gain design, construction, and operational experience. The prototype installation was built in one span of a $500 \mathrm{kV}$ line near Ellensburg, Washington. This CGI cable installation is $630 \mathrm{ft}$ long. (67)

\subsubsection{Cryogenic Cable Systems}

The resistance of most conductive metals decreases with decreasing temperature as shown in Figure 42. Development results on a nitrogen-cooled system, using conductors with dielectric spacers in a high-vacuum insulation, were sufficiently encouraging that a $345-k V$ cable was proposed which is said to be competitive with oil-paper-insulated pipe-type cable for capacities of about 100 MVA. (1) If progress continues as projected, a resistive cryogenic system may be available for utility application for circuits of about 4000 MVA capacity by about the end of the 1970s. Both liquid hydrogen and nitrogen were used as coolants, but liquid nitrogen appears to be the better choice for the near future.

For some conductive materials the resistance does not drop off smoothly with reductions in temperature. Instead the resistance of these materials decreases drastically when some critical temperature is reached. This 


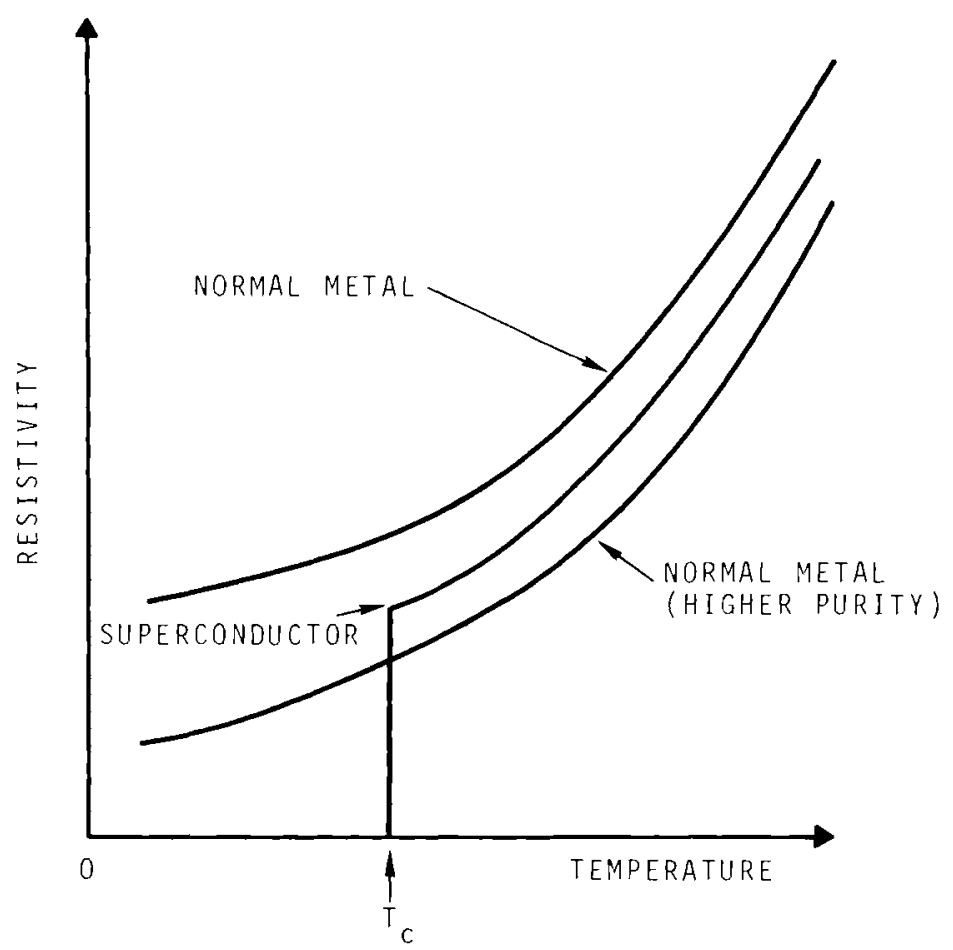

FIGURE 42. Change in Resistance Near Absolute Zero (68)

phenomenon is known as superconductance. Investigations up to now indicate that superconducting cryogenic systems, as distinguished from resistive systems, have little advantage in the 3000 to 5000 MVA capacity range, but may be attractive in the 7000 to 10,000 MVA range. While there does not appear to be a near-term requirement for circuits in this higher capacity range, R\&D on superconducting systems is being done with a view to longer-term needs.

Since known superconducting materials require liquid helium temperatures (below $-450^{\circ} \mathrm{F}$ ) to maintain a superconducting state, efforts were made to develop materials with superconducting states at higher temperature. This would greatly reduce cost by reducing refrigeration requirements.

Several manufacturers and utilities are involved in HVdc underground transmission research. High-voltage dc and cryogenic cable systems may be an ideal combination for underground installations in congested metropolitan 
areas. The unique advantages of no charging current and freedom from frequency variations may make underground dc transmission attractive even for short distances in metropolitan areas, in spite of the expensive conversion facilities necessary. Some recent studies comparing HVdc to $345-k V$ ac cable projected a breakeven distance of about 30 miles for underground 1 ines in heavily developed areas. Some projected capacities and costs for new underground transmission systems are shown in Figures 43 and 44. (68)

\subsection{Weather Effects}

One obvious advantage of undergrounding transmission lines is the virtual elimination of wind, ice, snow, and sleet storm damage, which can devastate overhead systems. Flood damages, on the other hand, are more severe for some underground systems.

\subsection{ROW Requirements}

Underground transmission lines of up to $500 \mathrm{kV}$ usually require a ROW about $50 \mathrm{ft}$ wide, at least where vegetation with extensive root systems exists. This type of vegetation must be eliminated to prevent the root systems from penetrating the pipes containing the conductors and preventing excessive removal of moisture from the soil in the area of the pipes. Removal of the moisture reduces the ability of the soil to transfer heat away from the pipes, causing excessive conductor temperatures and reduced current carrying capacity. This problem can be alleviated by using a high thermal conductivity backfill as described in Section 5.3.

Installation of underground transmission systems requires a trench from 3 to $10 \mathrm{ft}$ wide and about 4 to $6 \mathrm{ft}$ deep. Thus, the ROW must be sufficiently wide to accommodate the necessary digging and pipe-laying equipment. Typical cross-section layouts for 230 and 500-kV CGI systems are shown in Figures 45 and 46 .

\subsection{Underground Transmission Costs}

Underground construction costs of high voltage transmission using currently available technology are significantly greater than those for overhead 1ines. It was estimated in 1970 that in suburban areas underground 1 ines cost on the average about $8-1 / 2$ times as much as overhead 1 ines at $138 \mathrm{kV}$ and about 


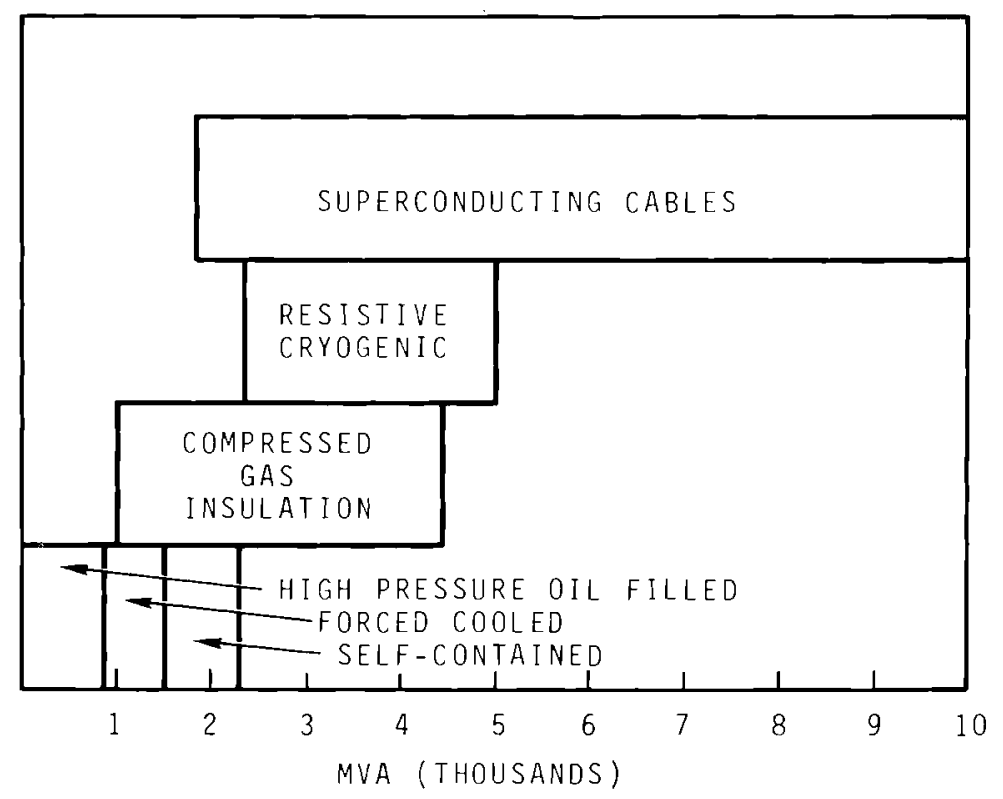

FIGURE 43. Capabilities of New Underground
Transmission Sys tems 68 )

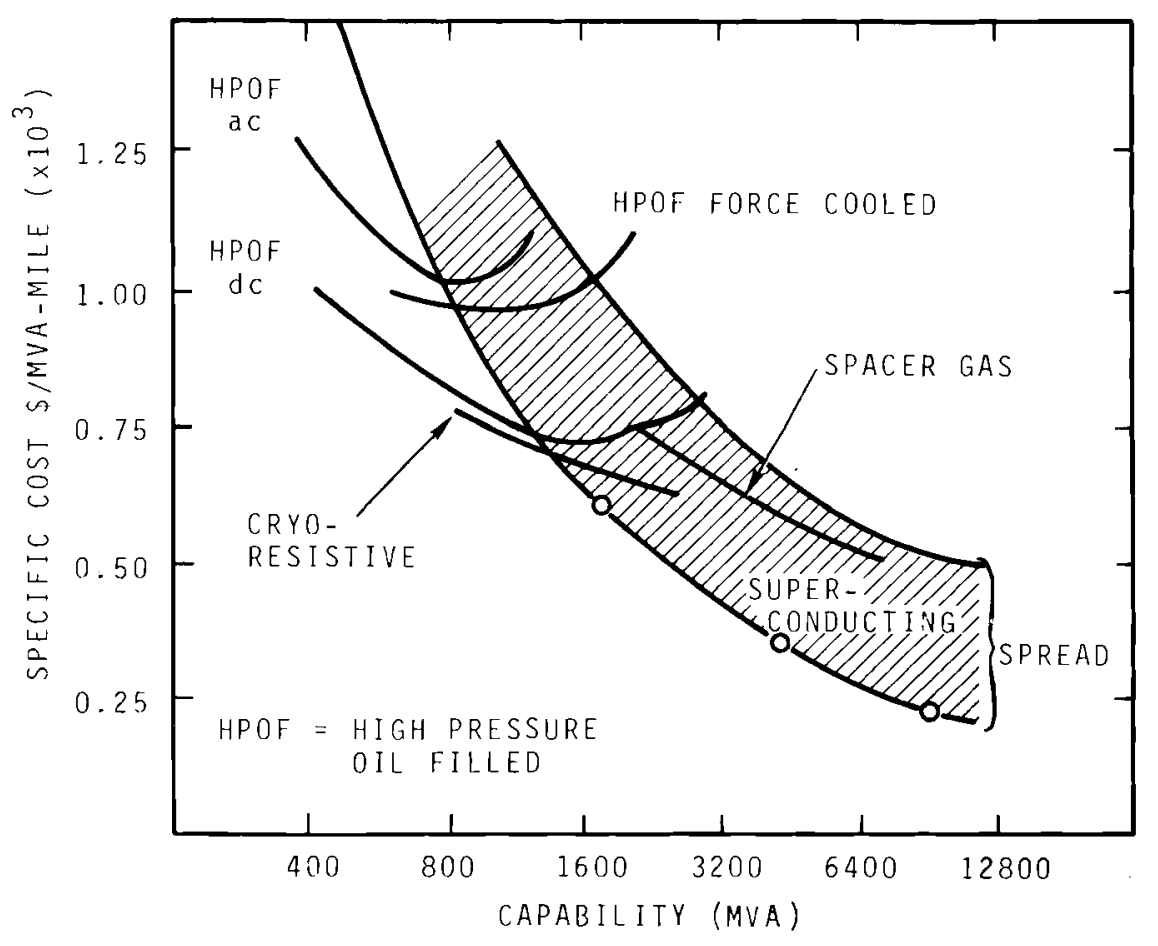
FIGURE 44. Estimated Specifjic Cost of Underground
Cable Schemes $(68)$ 


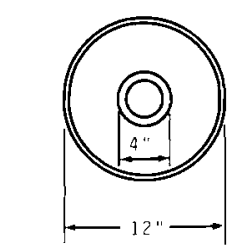

CONDUCTOR ANO SHEATH
DIMENSIUNS STANOARO OFSIGA

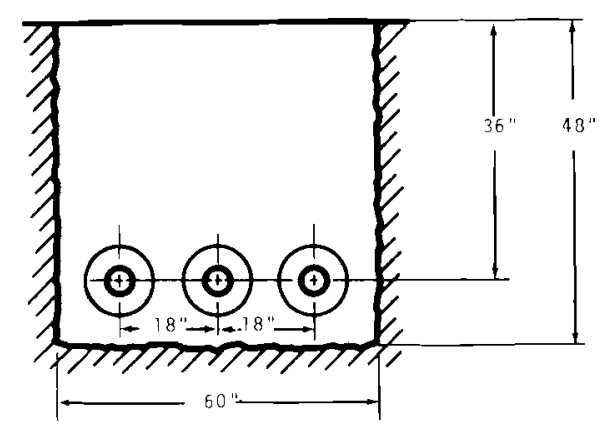

PHASE SPACING AND IRENCHING DIMENSIONS

FIGURE 45. Typical Layout for a $230 \mathrm{kV}$ CGI Transmission Line(69)
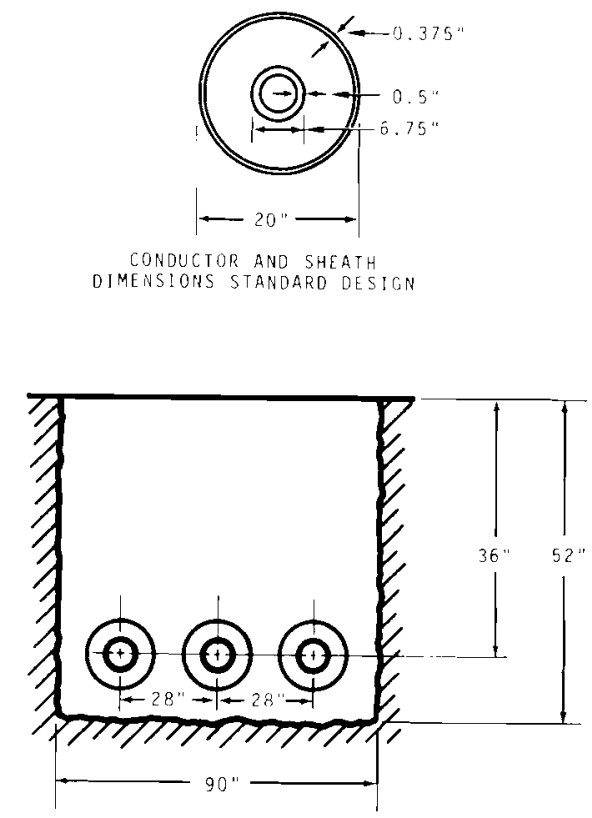

PHASE SPACIMG AND TRENCHING DIMEYSIONS

FIGURE 46. Typical Layout for a $500 \mathrm{kV}$ CGI Transmission Line(69) 
15 times as much at $345 \mathrm{kV}$. (1) Because of lower ROW costs in rural areas, the comparable figures were 10 and 19 times as much, respectively, for average conditions. (1) More recent estimates by Northeast Utilities System Companies indicated that $115 \mathrm{kV}$ and $345 \mathrm{kV}$ underground 1 ines were 3 to 13 times as expensive as equivalent overhead lines. (70) The use of concrete as a thermal backfill is reported to increase the current carrying capacity of some systems by $50 \%$ with only a $5 \%$ increase in the installed cost of the line. (71)

\subsection{Environmental Impact}

The various characteristics and available designs for underground transmission systems were discussed previously. The technology of underground transmission is in a state of rapid transition, especially that of CGI cable which utilizes $S_{6}$ gas as both an insulating and cooling medium. To date, most applications are for relatively short distances in metropolitan or other problem areas such as highway crossing or intersections of several HV transmission 1 ines where overhead 1 ines are undesirable. However, further improvements in design and in cost reductions could greatly enhance the practicality of routing underground systems along current overhead transmission or other utility ROW such as highways, railways or gas pipelines.

\subsubsection{Visual Impact}

The reduction of visual impact is one of several incentives for the large development effort being carried out on underground transmission. Many individuals find overhead transmission lines aesthetically unpleasing, especially in areas of great scenic beauty and in residential and recreational areas. One frequent complaint is that overhead transmission lines depreciate property values in their vicinity; in fact, this complaint has been the subject of several lawsuits.

While placing a transmission line underground usually reduces or eliminates adverse visual impact, this is not necessarily true for forested areas because vegetation with extensive root systems may be eliminated and access roads wi11 be retained. 


\subsubsection{Ecological Impact}

The differences in the ecological impact of underground transmission lines and the overhead systems discussed previously are primarily a matter of degree rather than of kind.

5.9.2.1 Construction Impacts. Underground systems occupy a narrow ROW which may reduce environmental effects in some instances. However, while overhead systems require the removal of trees and other vegetation over certain heights (see Tables 12 and 13), the underground systems require the removal of much more vegetation. This, in combination with the soil disturbance associated with digging the trench and burial of the lines, could result in greater erosion problems, particularly in areas dominated by short vegetation where, rather than construction impact being localized at tower sites, the entire length of the line would be affected.

Another important characteristic of underground as compared to overhead transmission systems is the greater reactive power loss that occurs along them. Because of this power, long oil-filled pipe-type underground systems require periodic reactor stations which in turn subject more land to construction and maintenance activities.

5.9.2.2 Maintenance Impact. Maintenance of underground transmission lines also produces a much greater impact on the environment than that for overhead systems. Heat produced by the line is dissipated through the earth surrounding it. This is facilitated by the use of soil moisture levels or the use of high thermal conductivity backfill. Plant transpiration is a major cause of reduced subsurface soil moisture levels. In an effort to reduce these soil moisture losses, vegetation control can be much more intensive on underground line ROW unless high thermal conductivity backfill is used. This is particularly true for the deeper rooted, woody species which can physically damage the buried lines. The higher soil temperatures in the vicinity of the buried line may retard the growth of some species and result in the complete elimination of those which are particularly sensitive to higher temperatures. 
Regardless of whether herbicide or manual techniques are used for woody vegetation control, the effect would probably be equally severe as far as the ROW vegetation is concerned, although manual cutting would probably have less effect on vegetation off the ROW because of the elimination of spray drift. Erosion would most likely be greater with manual vegetation control due to the requirements for regular access and soil disturbance from equipment used in the operation. Any required repairs or modifications of the system would require digging, so that erosion problems could be further aggravated.

The reduction of the underground line ROW to a primarily herbaceous vegetation cover would undoubtedly change the composition and abundance of animals living in the area. This change usually would result in a more diverse fauna and flora in the area so long as the quantity of any habitat types were not significantly reduced. Elimination of any species or a significant reduction in their populations is unlikely. If the areas develop a dense growth of relatively undisturbed herbaceous vegetation, the resulting cover and forage would promote the diversity and abundance of animals in the area.

Aquatic animal populations would be affected by any increased erosion due to construction and maintenance of underground systems. Underground systems would tend to eliminate the practice of leaving vegetation strips along banks of streams during construction. This plus digging a trench across the stream would further increase turbidity and sedimentation problems.

Reference 72 contains a detailed description of the construction and maintenance impacts of underground electric transmission systems. 


\section{WATER CROSSINGS}

Electrical transmission lines are often required to traverse bodies of water. The circumstances encountered by transmission line water crossings can vary from a narrow river crossing employing conventional towers and conductor spans to underwater lines between offshore islands and mainland areas 50 or more miles distant.

\subsection{Overhead Crossings}

Overhead transmission line water crossings are limited in the distances that can be traversed by the strength of available conductors and structures. One 345-kV overhead transmission line crossing of the Hudson River in New York utilizes reinforced lattice type towers which are $475 \mathrm{ft}$ high. The span between towers is $4273 \mathrm{ft}$ with a minimum river clearance of $165 \mathrm{ft}$. ${ }^{(73)}$

Overhead transmission line water crossings are conventionally located at the most economical site. Additional height is usually required for water crossings because the longer spans result in additional conductor sag. Therefore, where possible, towers are located on the highest land on either shore. Minimum conductor clearances may be greater over water crossings because of navigational use of the water body. Towers located at water crossings are usually equipped with airway beacon lights and painted airway marker point colors for safety reasons. In addition, colored spherical markers are placed on the conductors at frequent intervals.

Recently public pressure to design and locate overhead water crossings so as to minimize visual impact has increased. This is usually accomplished by setting towers well back from the shore line and by allowing vegetation to screen the towers from view. Where possible, tower placement on the skyline should be avoided. In many instances where an optimum site for a water crossing was located in an area of great natural beauty or high recreational use, public pressure forced the use of less desirable sites.

\subsection{Underwater Systems}

Underwater transmission lines are used mainly where the distances involved preclude the use of overhead systems. However, there is increasing 
public pressure to place transmission line water crossings underwater, especially in areas of scenic beauty. There is a possibility that some states may soon require all transmission line water crossings to be underwater. (74)

The types of underwater transmission systems available are basically the same as those used for underground transmission. Most of the underwater systems installed to date are of the solid dielectric (solid insulation) type. This type of submarine cable is generally limited to transmission voltages of $115 \mathrm{kV}$ or below. Recently there has been increased use of 0i1filled cable systems for underwater transmission at voltages up to $236 \mathrm{kV}$. A high-pressure self-contained oil-filled cable network operating at $138 \mathrm{kV}$ spans Long Island Sound between Norwalk, Connecticut, and Northport, New York. ${ }^{(75)}$ The 12 mile long interchange consists of 6 conductors, plus a spare, and is rated at 300 MVA transfer capacity.

High-voltage dc submarine transmission systems have been used more often in recent years. (See Table 2.) Examples include a 62 mile $220 \mathrm{kV}$ dc cable connecting the island of Sardina with the mainland; connections between mainland British Columbia and Vancouver Island; and a dc link between North Is land and South Is land in New Zealand. (76) In deciding between ac and dc submarine transmission systems, the critical distance was estimated to be 17 to 25 miles, above which dc is preferred.

Development work is underway on high voltage ( 345 to $500 \mathrm{kV}$ ) CGI (SF6) submarine cables with power transfer capabilities in excess of 2000 MW. (77) With such high capacity systems, river channels might be utilized as ROW into and out of many large cities. (76)

Underwater crossings in shallow waters are usually installed in trenches to protect them from mechanical damage from boat anchors, dredging operations, swift bottom currents and other sources of damage. In deep waters the cables are usually laid directly on the bottom.

Trenching costs for underwater installations vary considerably depending on the nature of the bottom material encountered. Suction dredging can be used where soft, rock-free bottom material is encountered. If rock and 
hard pan or solid rock is encountered, clamshell-type dredging and perhaps underwater blasting is required. Trenching under these conditions is very expensive.

Tunneling offers an alternative to trenching for underwater crossings. In most instances tunneling would be much more expensive than trenching. If adverse geological conditions are encountered, tunnel construction may have to be carried out within a steel caisson, and if water seepage is encountered, the tunnel may have to be completely lined.

During construction, tunneling requires the removal and disposal of a large amount of spoil. Considerable acreage will be used during construction for equipment, vehicles and spoil disposal. Tunneling does have the advantage that the transmission circuit is protected from the environment and is accessible for maintenance. With oil or gas pressurized cables contained in a tunnel, there is less chance for contamination of the environment in case of a cable failure. The high cost of tunneling may be reduced in the future through the use of tunneling machines used extensively on recent tunneling projects.

\subsubsection{Costs}

As stated previously, the cost of underwater transmission systems can vary greatly depending on the geological conditions encountered. In one study of alternatives for a $5000 \mathrm{ft}$-long, $345 \mathrm{kV}$ transmission line crossing of the Connecticut River in 1972, the following costs were estimated: ${ }^{(78)}$

$$
\begin{array}{lr}
\text { Overhead using lattice-type towers } & 345,000 \\
\text { Overhead using tubular steel towers } & 632,000 \\
\text { Underwater with trenching } & 4,000,000 \\
\text { Underwater with tunneling } & 6,550,000
\end{array}
$$

The example is cited for illustrative purposes only.

\subsubsection{Environmental Impact}

Underwater crossings of transmission lines are used either to alleviate visual impacts of overhead systems or because the distances involved are too 
great to be spanned by overhead systems. Only in the former case would the relative environmental impacts of the two systems be of interest.

The two main methods of constructing underwater crossings are trenching and tunneling. The environmental effects of trenching are primarily due to increased turbidity and sedimentation downstream of the site. The disturbances would usually be severe and of a short-term nature. The impacts were described in the section on overhead systems. Benthic life would be lost through removal or alteration of habitat and some additional direct mortality of aquatic organisms may occur in streams that flow over bedrock bottoms due to the blasting required.

Environmental effects of tunneling occur exclusively on land at the entrances to the tunnel and at the disposal sites where the material taken from the tunnel is dumped. The effects would be due primarily to erosion at these sites and along access roads.

Operation of the line may affect aquatic life because of the highenergy electrical field, although studies to date have been done only over 7 and. 


\section{REFERENCES}

1. The 1970 National Power Survey, Part I, the Federal Power Commission, U.S. Government Printing Office, Washington, DC.s Chapters I-12, I-13, I-15, I-21, December 1971.

2. "Transmission Miles Near Half a Million," Electrical World, p. 24, May 1, 1976.

3. J. G. Anderson, L. E. Zaffanella, G. W. Juette, Mikio Kawai and J. R. Stevenson, "Ultrahigh-Voltage Power Transmission," Proceedings of the IEEE, vol. 59, no. 11, pp. 1548-1556, November 1971 .

4. T. J. Nage1, "National and Regional Grids," IEEE Transactions on Aerospace and Electronic Systems, vol. AES-8, no. 4, pp. 492-497, July 1972.

5. G. S. Vassell and R. M. Maliszewski, "AEP 765-kV System: System Planning Considerations," IEEE Transactions on Power Apparatus and Systems, vol. Pas-88, no. 9, pp. 1320-1328, September 1969.

6. F. Schaufelberger, Bonneville Power Administration, U.S. Department of the Interior, Portland, OR., private communication, July 1973.

7. Robert H. Miller, Power System Operation, McGraw-Hi11 Book Company, New York, 1970.

8. A. N. Chaston, J. J. LaForest and A. R. Ramirez, "Electrical Characteristics of EHV-UHV Conductor Configurations and Circuits," Transmission Line Reference Book-345 kV and Above, Electric Power Research Institute, Palo Alto, CÁ., pp. 46-12T, 1975.

9. "Extra-High-Voltage Line Outages," paper No. 31TP66-417, IEEE Transactions on Power Apparatus and Systems, May 1967.

10. R. A. Kravitz and D. C. Leavengood, "Analyze the Weather for Safer Design," Electric Light and Power, pp. 71-73, January 1973.

11. J. J. Ray, Bonneville Power Administration, U.S. Department of the Interior, Portland, OR., private communication, November 1976.

12. D. C. Henry, Bonneville Power Administration, U.S. Department of the Interior, Portland, OR., private communication, June 1973.

13. Nikola P. Cuk, "Quake Dampers Save Equipment from Destruction," Electric Light and Power, pp. 49-51, May 1972.

14. R. A. Pries, Bonneville Power Administration, U.S. Department of the Interior, Portland, OR., private communication, September 1976. 
15. Electric Power and the Environment, sponsored by The Office of Science and Technology, U.S. Government Printing Office, Washington, DC, pp. $21-$ 35, 36-37, August 1970.

16. E. B. Lawless III, "Poles Supersede Towers at $500 \mathrm{kV}$," Electrical World, pp. 103-105, March 15, 1976.

17. Transmission and Distribution Rights-of-Way Selection and Development, Prepared for Consumers Power Company, Jackson, MI., by Johnson, Johnson and Roy, Inc., November 1970.

18. Controlling Erosion on Construction Sites, Agriculture Information BulTetin 347, Soil Conservation Service, U.S. Department of Agriculture, 1970.

19. D. N. Swanston, "Judging Impact and Damage of Timber Harvesting to Forest Soils in Mountainous Regions of Western North America," Western Reforestation Coord. Comm. Proc., pp. 14-19, 1971.

20. Paul J. Edgerton., "Big Game Use and Habitat Changes in Recently Logged Mixed Conifer Forest in Northeastern Oregon," Western Proceedings, Fifty-second Annual Conference of the Western Association of State Game and Fish Commissioners, Portland. OR., 1973.

21. J. T. Kitchings,, Shugart, H. H., and Story, J. D., Environmental Impacts Associated with Electric Transmission Lines, ORNL-TM-4498, Oak Ridge National Laboratory, Oak Ridge, TN., March 1974.

22. W. D. Lay, "How Valuable Are Woodland Clearings to Birdl ife," Wilson Bulletin, vol. 50, pp. 254-256.

23. H. C. Black and E. H. Hooven, "Response of Smal1-Mammal Communities to Habitat Changes in Western Oregon," Wildlife and Forest Management in the Pacific Northwest, H. C. Black editor, Forest Research Laboratory, Oregon State University, Corvallis, OR., pp. 177-186, 1972.

24. Big Game Movement Near a 500-kV Transmission Line in Northern Idaho, Prepared for Bonneville Power Administration by John G. Goodwin Jr., Western Interstate Commission for Higher Education (WICHE), Resources Development Internship Program (RDIP), Boulder, C0., June 27, 1975.

25. H. Gratkowski and R. Stewart, Aerial Spray Adjutants for Herbicide Drift Control, U.S.D.A., Forest Service General Technical Report PNW-3, 1973. 
26. Increasing droplet size in order to minimize drift onto nontarget vegetation has certain disadvantages. Some aerially applied herbicides, in order to be effective, require that a certain minimum number of droplets per square inch be applied regardless of the size of the droplet. Application of larger droplets will likely necessitate a larger overall rate of application. See pages 9-10 in John D. Buffington, Assessment of Ecological Consequences of Herbicide Use, also pages 14-17 in H. Gratkowski and R. Stewart, Aerial Spray Adjuvants for Herbicide Drift Control.

27. H. R. Schaal, "Constraint Maps - The Newest Tool in R/W Selection," Transmission and Distribution, pp. 26-31, April 1972.

28. K. E. Williams, Bonneville Power Administration, U.S. Department of the Interior, Portland, OR., private communication.

29. D. P. Hodel, Bonneville Power Administration, U.S. Department of the Interior, Portland, OK., Letter to G. F. Schiefelbein, June 8, 1973.

30. John Papamarcos, "Sharing Rights-of-Way," Power Engineering, pp. 26-33, June 1970.

31. "T\&D Systems," Electric Light and Power, pp. 88-95, September 1972.

32. J. C. Hill, "Shared Transmission Corridors Aid Grid Growth," Electric Light and Power, pp. 49-52, March 1972.

33. The Need for a National System of Transportation and Utility Corridors. Prepared by The Bureau of Land Management, U.S. Department of the Interior, Washington, D.C., July 1, 1975.

34. R. E. Abbott, "Green Thumb Works for Utility," Transmission and Distribution, pp. 26-28, August 1972.

35. H. E. Young, "ROW - If you Can't Burn or Spray - Make It Pay, "Electric Light and Power, pp. 55-57, April 1972.

36. D. W. Deno and M. G. Comber, "Corona Phenomena on AC Transmission Lines," Transmission Line Reference Book-345 kV and Above, Electric Power Research Institute, Palo Alto, CA., pp. 122-148, 1975.

37. M. G. Comber and G. W. Juette, "Radio and Television Interference," Transmission Line Reference Book-345 kV and Above, Electric Power Research Institute, Pa10 A1to, CA., pp. 149-191, 1975.

38. M. G. Comber and L. E. Zaffanella, "Audible Noise," Transmission Line Reference Book-345 kV and Above, Electric Power Research Institute, Palo Alto, CA., pp. 192-238, 1975. 
39. H. N. Scherer, Jr., B. J. Ware, C. H. Shih, "Gaseous Effluents Due to EHV Transmission Line Corona," IEE[ Transactions on Power Apparatus and Systems, vol. PAS-92, May/June 1973.

40. S. A. Sebo, J. T. Heibe1, M. Frydman, "Examination of Ozone Emanating from EHV Transmission Line Corona Discharges," Transaction Paper F75510-8 presented at the IEEE PES Summer Meeting, San Francisco, CA., July 20-25, 1975.

41. U.S. Department of Health, Education and Welfare, "Air Quality Criteria for Photochemical 0xidants," Washington, DC., National Air Pollution Control Administration, pp. 4-1 to 4-4, 1970.

42. J. T. Kitchings, H. H. Shugart, J. D. Story, Environmental Impacts Associated with Electric Transmission Lines, ORNL-TM-4498, Oak Ridge National Laboratory, Oak Ridge, TN., March 1974.

43. M. Frydman, A. Levy, S. E. Miller, "0xidant Measurements in the Vicinity of Energized $765 \mathrm{KV}$ Lines, IEEE Transactions on Power Apparatus and Systems, vol. PAS-92, May/June 1973.

44. J. F. Roach, V. L. Chartier, F. M. Dietrich, "Experimental 0xidant Production Rates for EHV Transmission Lines and Theoretical Estimates of Ozone Concentrations Near Operating Lines," IEEE Transactions on Power Apparatus and Systems, vo1. PAS-93, pp. 647-657, March/Apri1 1974.

45. D. W. Deno, "Transmission Line Fields," Transaction Paper F76-180-0 presented at the IEEE PES Winter Meeting, N.Y., NY., January 25-30, 1976.

46. Biological Effects of High Voltage Electric Fields, EPRI 381-1, prepared by the IIT Research Institute, Chicago, IL., for Electric Power Research Institute, Palo Al to, CA., November 1975.

47. T. D. Braken, "Field Measurements and Calculations of Electrostatic Effects of Overhead Transmission Lines," IEEE Transactions on Power Apparatus and Systems, vol. PAS-95, March/Apri1 1976.

48. D. W. Deno and L. E. Zaffanella, "Electrostatic Effects of Overhead Transmission Lines and Stations," Transmission Line Reference Book$345 \mathrm{kV}$ and Above, Electric Power Research Institute, Palo Alto, CA., pp. 248-280, 1975 .

49. Charles F. Dalziel, "Electric Shock Hazards," IEEE Spectrum, pp. 41-50, February 1972.

50. J. C. Keesey and F. S. Letcher, "Human Thresholds of Electric Shock at Power Transmission Frequencies," Arch. Environmental Health, vol. 21, pp. 547-552, 1970. 
51. IEEE Working Group on Electrostatic Effects of Transmission Lines, "Electrostatic Effects of Overhead Transmission Lines, Part 1, Hazards and Effects," IEEE Transactions on Power Apparatus and Systems, PAS-91, pp. 422-444, March/Apri1 1972.

52. Electrical Effects of Transmission Lines, prepared by the Bonneville Power Administration, Portland, OR., September 15, 1975.

53. IEEE Working Group on Electromagnetic and Electrostatic Effects of Transmission Lines, "Electromagnetic Effects of Overhead Transmission Lines - Practical Problems, Safeguards, and Methods of Calculation," paper T73441-3, presented at IEEE PES Summer Meeting and EHV/UHV Conference, Vancouver, B.C. Canada, July 15-20, 1973.

54. "American National Standard--National Electrical Safety Code," 1973 edition, Published by Institute of Electrical and Electronics Engineers, Inc., 345 East 47th St., N.Y., NY., 10017, pp. 110-155.

55. National Electrical Safety Code, Part 2, Safety Rules for the Installation and Maintenance of Overhead Electrical Supply and Communication Lines, April 1976, Secretariat-Institute of Electrical and Electronics Engineers, Inc., and National Bureau of Standards, Standards Office, IEEE, 345 East 47th St., N.Y., NY., 10017.

56. J. N. Roettger, Minnesota Power \& Light Co., Duluth, MN., private communication, September 1976.

57. L. A. Bateman, R. Haywood and R. F. Brooks, "Nelson River dc Transmission Project," IEEE Transactions on Power Apparatus and Systems, vol. PAS-88, no. 5, pp. 688-693, May 1969.

58. Assessment of Energy Parks VS. Dispersed Electric Power Generating Facilities, Volume I, Prepared for the National Science Foundation Office of Energy Research and Development Policy under grant OPE 74-22625A01 by Center for Energy Systems, General Electric Company, 777 14th St., N.W., Washington, DC 20005, pp. 3-1 to 3-17, May 30, 1975.

59. J. C. Hil1, "Shared Transmission Corridors Aid Grid Growth," Electric Light and Power, pp. 49-52, March 1972.

60. Technical Study Report on Pacific Northwest-Southwest Second D-C Intertie, Prepared by the System Studies Task Force, Mr. Ralph S. Gens, Bonneville Power Administration, Portland, OR., Chairman, February 1976.

61. Second Quarter Test Programs Report, EPRI-HVDC, Dalles Project, RP104-2, October to December 1974.

62. B. P. Bellport, "525-kV Cable Picked for Grand Coulee," Electrical World, pp. 29-31, Apri1 20, 1970. 
63. J. J. Ray, C. A. Arkell and H. W. Flack, 525-kV Self-Contained 0ilFilled Cable Systems for Grand Coulee Third Power Plant Design and Development, IEEE Transactions on Power Apparatus and Systems, PAS-93, pp. 630-639, March/Apri 11974.

64. L. A. Kilar, "Restraints on Cable Limit Power Capabilities," Electrical World, pp. 60-62, May 15, 1973.

65. J.J. Pachot, Bonneville Power Administration, U.S. Department of the Interior, Portland, OR., private communication, June 1973.

66. F. E. Fischer and J. A. Williams, "First Underground 345-kV Gas-Insulated Transmission System Energized," Transmission and Distribution, pp. 3739, May 1972.

67. Electric Light and Power, vo1. 53, no. 10, 0ctober 20, 1975.

68. E. B. Forsyth, Ed., Underground Power Transmission by Superconducting Cable, BNL-50325, Brookhaven National Laboratory, Upton, NY, March 1972 .

69. High Voltage Power Corporation, Westboro, MA.

70. Underground Transmission - State of the Art, Northeast Utilities Service Company, Hartford, CT, 06101, 1974.

71. F. R. Klumb, "SF6 System Moves Power Up the Tower," Electric Light and Power, pp. 46-48, July 1972.

72. Study of Environmental Impact of Underground Electric Transmission Systems, EPRI 7826, [ERDA E(49-18)-1608], Prepared for the ETectric Power Research Institute, Palo Alto, CA, 94304, and the Energy Research and Development Administration, Washington, D.C., 20545, by EDAW, Inc., San Francisco, CA.

73. H. Heisler, "Hardware: The Backbone of a River Crossing," Electric Light and Power, pp. 51-52, December 1972.

74. S. D. Barrett, "The A to $\mathrm{Z}$ of $\mathrm{SF}_{6}$," Electric Light and Power, pp. 33-35, December 1972.

75. P. Gazzana-Priaroggia, J. H. Piscioneri and S. W. Margolin, "The Long Island Sound Submarine Cable Interconnection," IEEE Spectrum, pp. 63-71, October 1971.

76. "New Incentives for Underground Transmission," Power Engineering, pp. 2631, December 1971.

77. E. R. Perry and J. N. Piscioneri, "First Gas-Insulated Submarine Cable Developed at 345-kV," Electric Light and Power, pp. 40-41, August 1972.

78. Connecticut River Transmission Crossings in the Middletown - Haddam Area, Northeast Utilities Service Company, Berlin, CT, August 1972. 

APPENDIX A

ENVIRONMENTAL CRITERIA FOR ELECTRIC TRANSMISSION SYSTEMS 
Appendix $A$ is a booklet, sponsored by the U.S. Departments of Interior and Agriculture, and is attached to this statement. Additional copies may be obtained by writing to the Superintendent of Documents, U.S. Government Printing Office, Washington DC, 20402. The price per copy is 65 cents. 


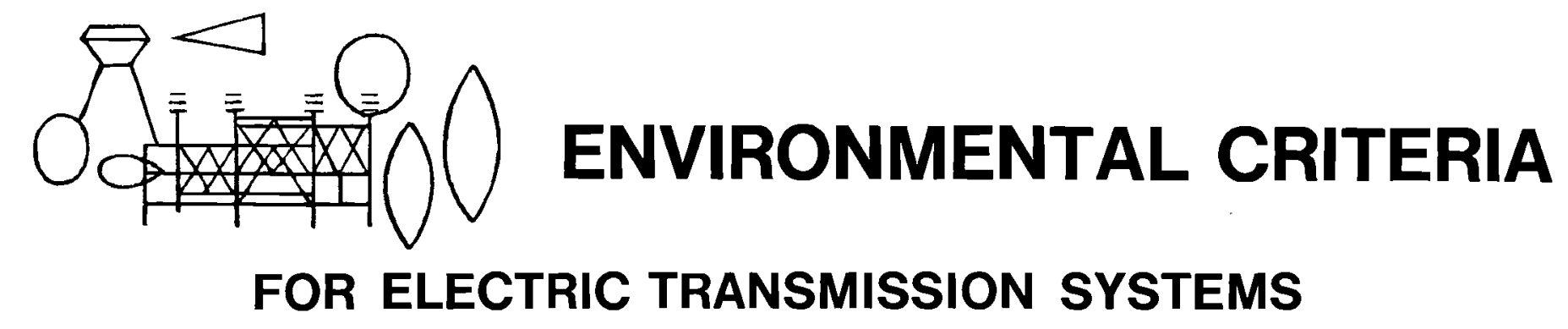




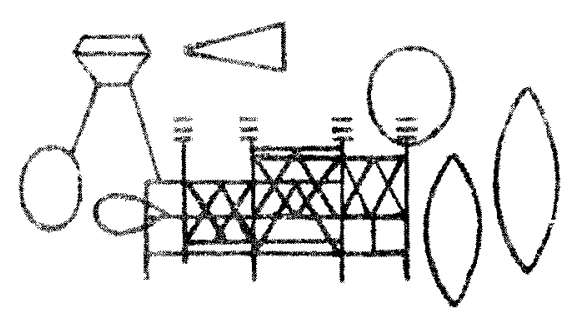

ENVIRONMENTAL CRITERIA FOR ELECTRIC TRANSMISSION SYSTEMS 
"...we in this century have too casually and too long abused our natural environment. The time has come when we can wait no longer to repair the damage already done, and to establish new criteria to guide us in the future."

\section{RICHARD NIXON}

Message on Environment

February 10, 1970 
In his Message on Environment on February 10, 1970, President Nixon stated that "The task of cleaning up our environment calls for total mobilization by all of us. It involves Government at every level; it requires the help of every citizen." The issuance of Environmental Criteria for Electric Transmission Systems represents a step that can be taken now to help restore harmony between man and his surroundings.

This publication is intended to serve as a guide to the planning and accommodation of needed electric transmission systems. All agencies in the Department of the Interior and in the Department of Agriculture have been directed to use the criteria. We urge all governmental agencies, the electric utility industry and private organizations to adopt the criteria in an effort to assure adequate environmental planning. A common reference document will enable all affected interests to more intelligently review and discuss the environmental aspects of electric transmission systems.

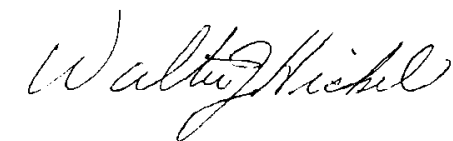

Walter J. Hickel

Secretary of the Interior

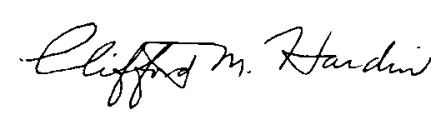

Clifford M. Hardin

Secretary of Agriculture 
specific circumstances, the criteria should be used as a guide only. It is intended that all criteria be considered; however, it is recognized that many will not be applicable to the specific system being reviewed. They should not be used to justify violations of existing safety regulations or the various codes applicable to the construction, operation, and maintenance of electric transmission systems.

The criteria were carefully written to serve as a reasonable guide to the review of transmission systems. It should be recognized that not all of the criteria may apply to a given set of circumstances, and where an application is questionable, interested parties should jointly seek a reasonable solution. Discussion and reasonable compromise between competing interests is the best mechanism for enforcement.

The electric utility industry is encouraged to make environmental costs known to the public so that unreasonable demands and excessive costs can be avoided. In most cases, these costs will be negligible. In some cases the costs will be so high that alternatives will have to be considered, or, it may be determined that no intrusion is tolerable regardless of the costs involved. While no attempt is made to outline cost guidelines, all additional costs should be fully justified. At the same time, management should consider as a part of their construction and their normal maintenance and operating budgets, the costs of these environmental considerations. 


\section{INTRODUCTION}

The electric utility industry is faced with a complex challenge in the 70's. It must provide the generation and transmission facilities that are and will be needed to meet the ever growing demand for reliable electrical power, and it must do this in a decade dedicated to the restoration and protection of our environment.

There are approximately 3600 electric utilities in the United States. These utilities operate over 300,000 miles of overhead electric transmission lines, which preempt nearly 4 million acres of land for right-of-way. With the demand for electric power doubling each decade, it is estimated that approximately 100,000 miles of new transmission lines will be constructed on $1 \frac{1 / 2}{2}$ million acres of right-of-way each decade for the balance of this century. These projections become even more significant when viewed as "but a part" of the total right-of-way requirements for highways, railroads, pipelines, and other utilities.

On January 1, 1970, President Nixon signed into law the National Environmental Policy Act of 1969, which states that it is the policy of the Federal Government ". . .to create and maintain conditions under which man and nature can exist in productive harmony." 
The publication of Environmental Criteria for Electric Transmission Systems is in accord with this policy.

The Federal Government is deeply involved with and can be properly considered a part of the electric utility industry. Federal agencies are engaged to varying degrees in the generation, transmission, and marketing of electrical power and in the regional planning required to meet this Nation's growing electrical demands. At the same time, these agencies are required to work with this industry in an effort to minimize its impact on our environment and specifically on the lands and programs that these agencies administer.

The electric utility industry faces an environmentally aroused general public. The questions being raised are difficult to answer to the satisfaction of this public and oftentimes adverse reactions cause delays that may create critical shortages. The industry must acknowledge by policy and deed the public's right to insist upon environmental protection. However, no less important is the general public's duty to acknowledge that the principal function of this industry is to supply energy at a reasonable cost where and when it is required. What remains to be defined then is the 
balance between these two significant concerns. Energy must be supplied and the environment will be protected.

The purpose of this report is to provide broadly based criteria which can be applied with judgment by the Federal land managing agencies to design regulations and enforce contractual standards of performance in the construction and maintenance of transmission systems. It is patently impracticable to include in a single document standards of environmental protection which will contain sufficient detail to cover every situation. This document will permit Federal agencies and all electric utilities to enter into the design and planning of transmission lines-particularly lines which cross Federal lands-with an understanding of the frame-of-reference in which their work will be appraised by the Federal Government.

The land managing agencies have the responsibility to protect the natural resources affected by transmission systems. They must determine the degree of protection required, which varies with the use of the land and its environmental values. 
Environmental considerations and the aesthetic needs of land set aside for parks, historic sites, national monuments and recreational areas will differ significantly from those of lands used; for example, for grazing or forestry. The environmental values to be considered by the land managing agencies relate to visual aesthetics, multiple land use, proper drainage, protection of game cover and fishing and spawning areas, and safeguarding the land against the damage caused by burning and flooding.

The Nation no longer can afford the profligate use of its land resources. Improved long-range land use planning, the more extensive use of utility corridors and the upgrading of existing systems will help to alleviate this problem. New technological developments may permit the undergrounding of transmission lines, the use of superconductors and even the transmission of electric power without wires. But for now, at a time when planning and construction must proceed without tomorrow's technology, there is a need for improved design, construction and maintenance of overhead transmission lines to protect the natural environment and to preserve the aesthetics of the countryside. The development of these criteria is directed toward this objective. 
This report represents an element of environmental planning. It establishes a frame-of-reference within which the land managing agencies will devise and implement regulations to protect and conserve the environment with respect to the construction of electric transmission facilities by the Federal Government or by non-federal entities on Federal land. It will also guide Federal agencies engaged in the construction of transmission systems on both public and private lands.

Environmental criteria for electric transmission systems are equally valid for construction of non-federal electric transmission systems which do not cross Federal lands. The electric utility industry is urged to adopt these criteria for their entire transmission systems. 



\section{COORDINATION}

The public interest is properly served when electric transmission facilities are planned, constructed and operated to provide the country with an adequate and reliable power supply that is compatible with our environment. The key to success in the efforts to minimize the impact and optimize the compatibility of electric transmission systems on the environment is coordination-involving the industry, all interested Federal, State and local governments (especially those with planning responsibilities) and the private sector. It is the responsibility of management to insure that this coordination takes place at the earliest possible time in the planning process.

The purpose of coordination is to identify all interests affected by the electric transmission facility, to explore alternatives and to resolve conflicts.

Environmental considerations must be placed in proper perspective with other vital issues such as reliability, cost and safety. The techniques for implementing environmental criteria are widely known in the electric utility industry. This industry is concerned with the environment and has demonstrated a willingness to incorporate environmental considerations into its plans. 
Just as reliability became a criterion against which plans and actions of the industry are measured, another criterion of equal importance must now be given comparable status-the environment.

There is a need for development of viable State and regional mechanisms to work with the electric utility industry to plan and review its future requirements. This type of mechanism does not now exist in most states and must be developed promptly if there is to be orderly growth and intelligent coordination of individual plans. Regional, overt, integrated planning will produce broad conceptual guidelines for future growth and will assist individual utilities to proceed with the design and construction of facilities required to meet their specific needs. Efforts are now being made to define and establish these mechanisms. Once established, "Environmental Criteria for Electric Transmission Systems" will be a useful document in their planning and review.

When a transmission system crosses lands administered by more than one Federal land-managing agency, it is in the public interest to have a coordinated review of this system. An uncoordinated, fragmented approach reduces the effectiveness of the Federal review and does not allow for an 
overview of the entire transmission system. If all alternatives are to be considered, the review must encompass the entire system, with an understanding of the electrical problems and considerations that should be a part of this review.

Technical staff assistance on electrical, structural, landscape, and design alternatives is available upon request from the Department of the Interior's Office of the Assistant Secretary--Water and Power Development, and the Department of Agriculture's Office of the Assistant Secretary-Rural Development and Conservation. The use of these talents will provide an unbiased, reasonable and coordinated input into the decision making that would remain with the landmanaging agencies or for Federal involvement in systems built on private lands.

Pre- and postconstruction conferences are key elements to local coordination. Once all affected interests have been identified and appropriate measures have been agreed upon to accommodate these interests, a preconstruction conference should be held to review and reaffirm the agreements. A similar postconstruction conference should also be held, following a physical inspection, to assure that these agreements have been implemented, and if not, what can be done. These conferences should be held between 
representatives of the affected interests and the builder of the transmission system. Where possible, the agreements should be written into right-of-way permits or other documents of comparable stature. Where Federal lands are involved, this should become standard practice. Finally, periodic tours of the completed transmission system should be made to see to it that the system is properly maintained and that repairs are made with the same care with which the system was constructed. 


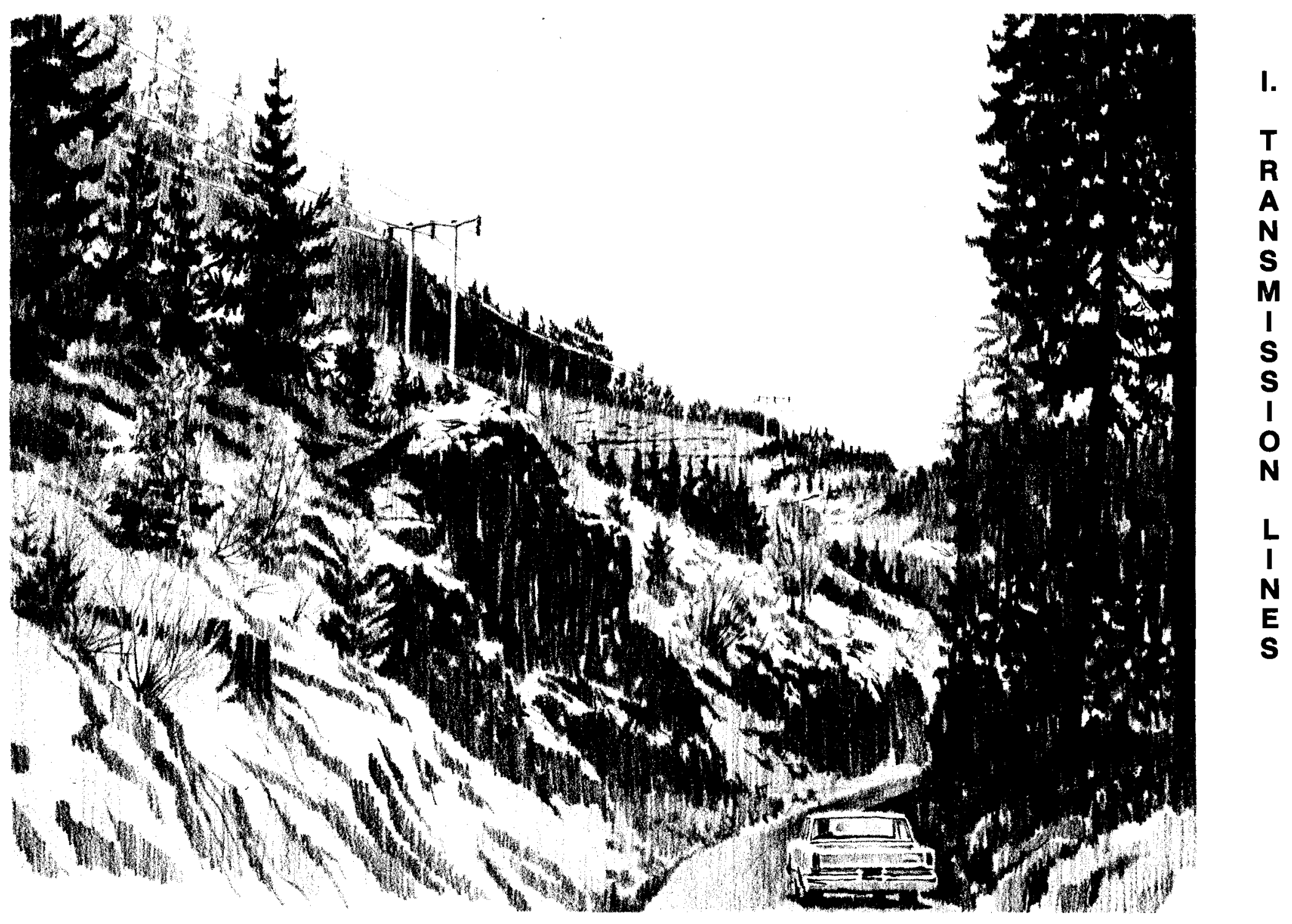





\section{A. General Comments}

Past experience has demonstrated that compliance with the following criteria will safeguard aesthetic and environmental values within the constraints imposed by the current state of high-voltage transmission technology. The development of an economically feasible underground transmission technology will require a redefinition of environmental transmission criteria.

These criteria are intended for use in rural areas and may not apply specifically to urban areas. 


\section{B. Selection of a Proposed Route or Corridor}

Concealment of transmission towers and lines is virtually impossible, but much can be done to make them less obtrusive and more attractive. Adherence to the following criteria will minimize the impact and optimize the compatibility of transmission facilities with the environment.

1. Rights-of-way should be selected to preserve the natural landscape and minimize conflict with present and planned uses of the land on which they are to be located.

2. Where possible, retirement or upgrading of existing lower voltage transmission circuits should be required to allow construction of higher voltage, higher capacity circuits on the existing right-of-way.

3. Properly sited established rights-of-way should be used where warranted for the location of additions to existing transmission facilities.

4. The joint use of electric transmission facilities by two or more utilities should be encouraged, when feasible, to reduce the total number of transmission lines constructed. 


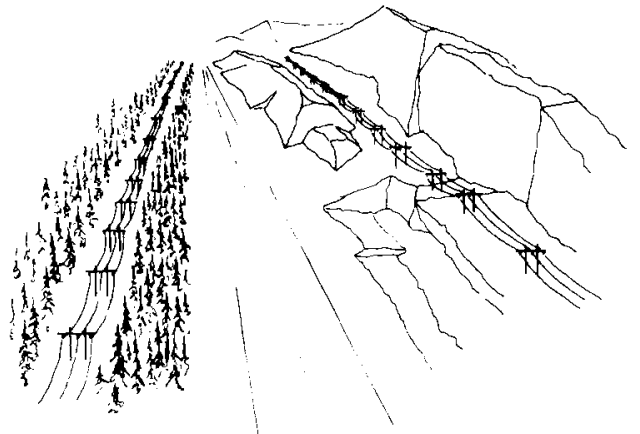

Place beyond ridges or timber
5. The joint use of rights-of-way with other types of utilities should be coordinated in a common corridor wherever uses are compatible.

6 . The relative advantages and disadvantages of locating a new line either adjacent to or widely separated from existing transmission lines should be considered. Rightof-way boundaries should be so located as to avoid creating unusable hiatus areas.

7. Rights-of-way should avoid heavily timbered areas, steep slopes, proximity to main highways, shelter belts and scenic areas.

8. Where possible, transmission line crossings of major roads in the vicinity of intersections or interchanges should be avoided.

9. Long views of transmission lines parallel to existing or proposed highways should generally be avoided. Alternative routes away from highways should be considered. Where ridges or timber areas are adjacent to highways or other areas of public view, overhead lines should be placed beyond the ridges or timber areas. 


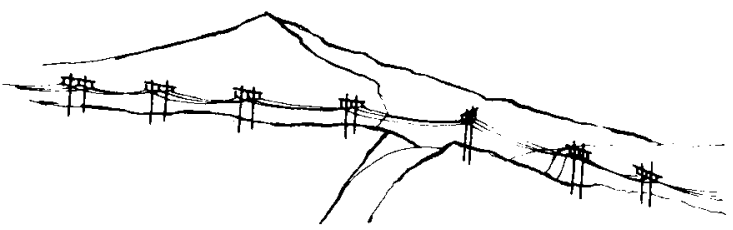

Avoid crossing at high points

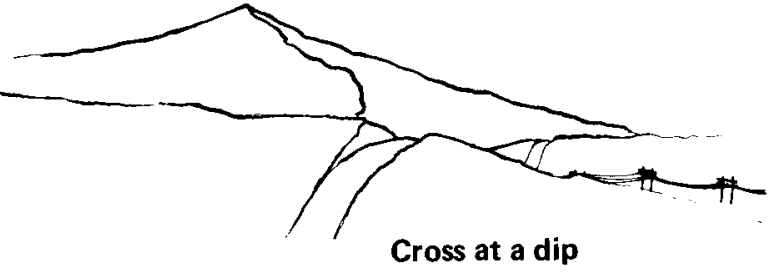

Cross at a dip

10. Avoid crossing at high points in the road so that the towers cannot be seen from a great distance. Instead, where possible, cross the highway between two high points, at a dip, or on a curve in the road.

11. Avoid open expanses of water and marshland and particularly those utilized as flight lanes by migratory waterfowl and as heavily used corridors by other birds. Avoid areas of wildlife concentrations such as nesting and rearing areas.

12. Where the transmission rights-of-way cross areas of land managed by Government agencies, State agencies or private organizations, these agencies should be contacted early in the planning of the transmission project to coordinate the line location with their land-use planning and with other existing or proposed rights-of-way. 


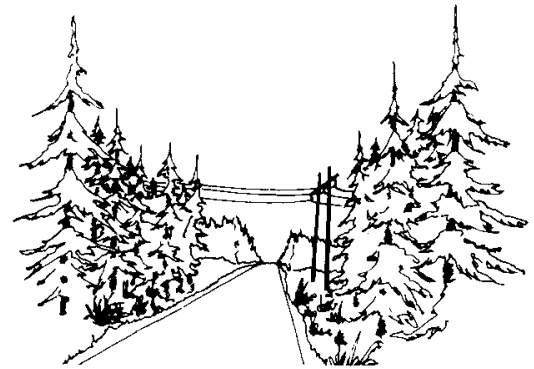

To retain natural growth

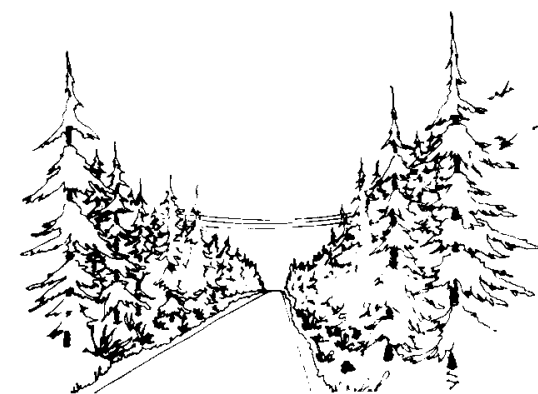

Use long span towers

13. In forest or timber areas long spans should be used at highway crossings in order to retain much of the natural growth or provide a planted screen along the highways.
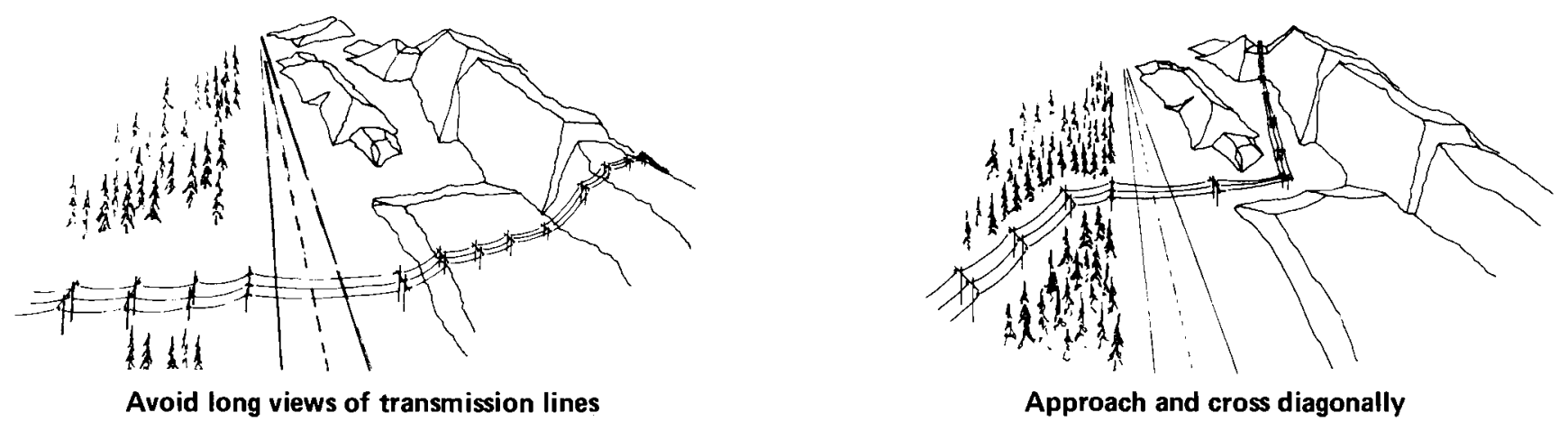

Approach and cross diagonally

14. Long views of transmission lines perpendicular to highways, down canyons and valleys or up ridges and hills should be avoided. The lines should approach these areas diagonally and should cross them at a slight diagonal. 


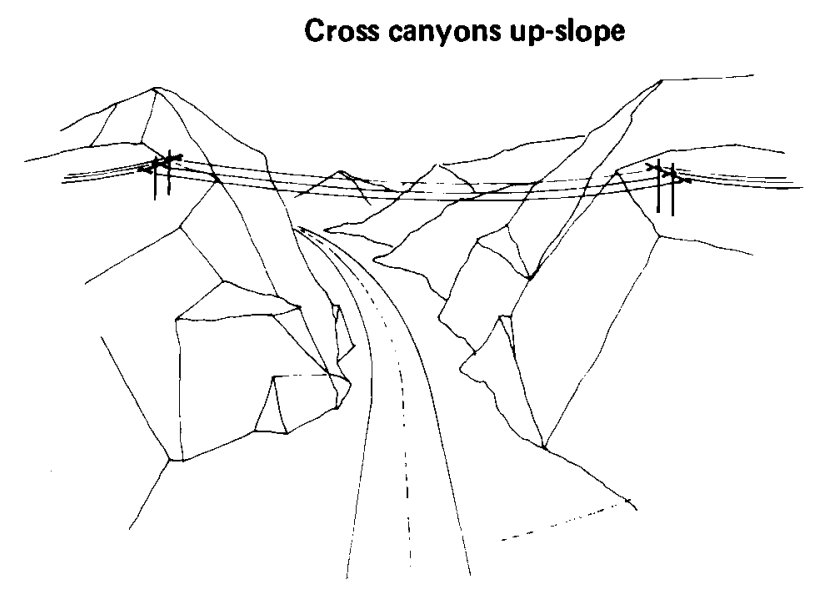

15. Transmission lines should cross canyons up-slope from roads which traverse the length of the canyon.

16. Transmission facilities should be located part way up slopes to provide a background of topography and/or natural cover where possible. Screen these facilities from highways and other areas of public view to the extent possible with natural vegetation and terrain.

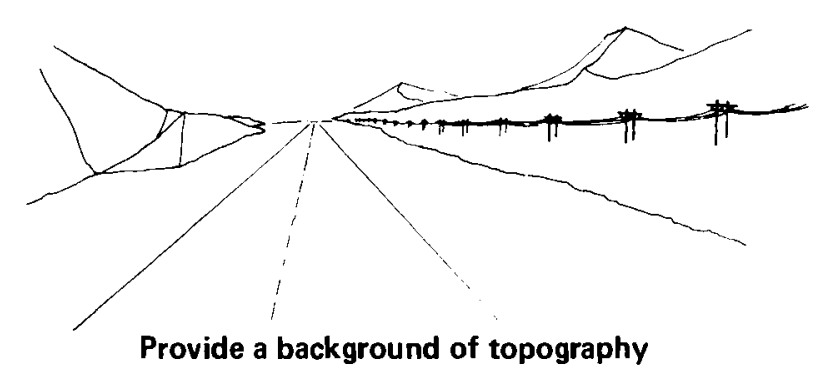

Provide a background of topography

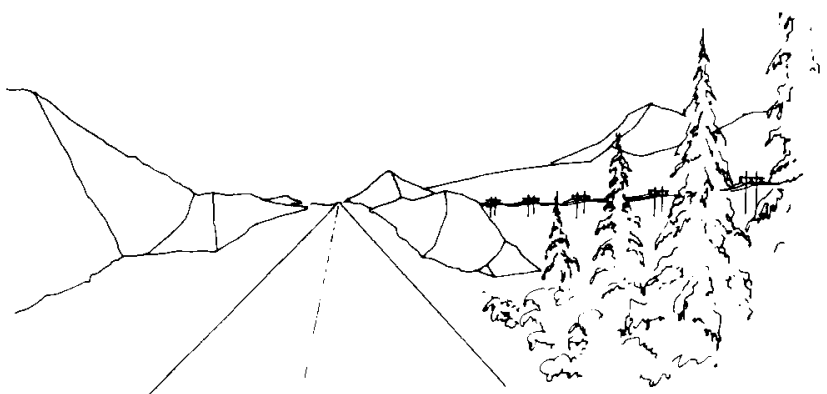

Screen with vegetation or terrain 


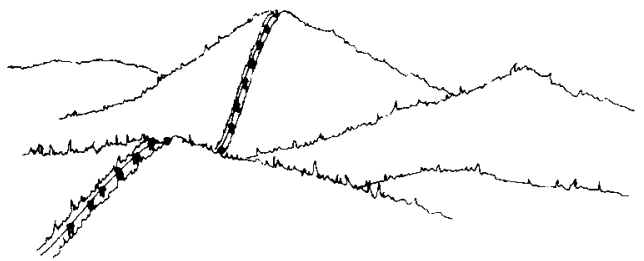

Avoid crossing at crests

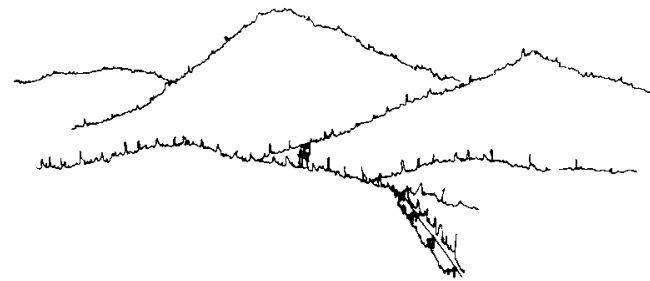

Facilities should not be silhouetted

17. Rights-of-way should not cross hills and other high points at the crests. To avoid placing a transmission tower at the crest of a ridge or hill, space towers below the crest or in a saddle to carry the line over the ridge or hill. The profile of the facilities should not be silhouetted against the sky.

18. Rights-of-way should avoid parks, monuments, scenic, recreation, or historic areas. If a line must be located in or near these areas, the feasibility of placing the line underground should be clearly determined. If the line must be placed overhead, it should be located in a corridor least visible to public view. Other criteria or conditions as necessary to minimize adverse impacts may be imposed by the agency administering the lands involved. 


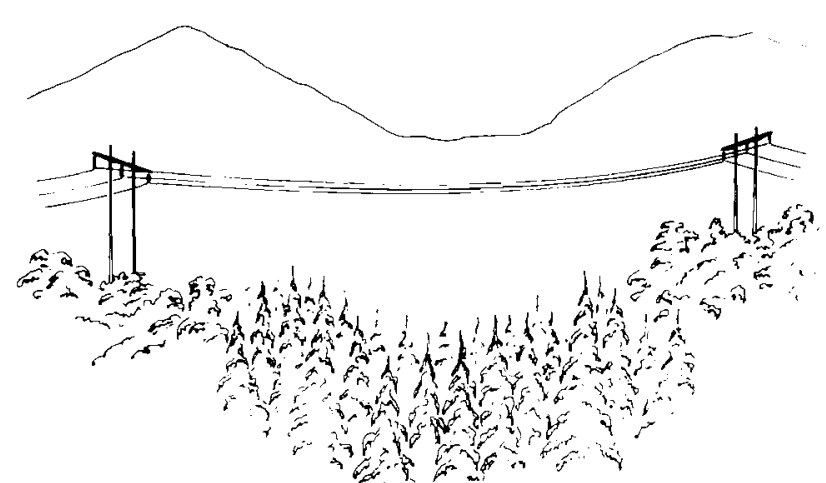

When crossing a forrested canyon

19. When crossing a canyon in a forest, high, long-span towers should be used to keep the conductors above the trees and to minimize the need to clear all vegetation from below the lines. Clearing in the canyon should be limited to that which is necessary to string the conductors.

20. It may be desirable to occasionally deflect right-of-way strips through scenic forest or timber areas. The resulting irregular patterns prevent the rights-of-way from appearing as tunnels cut through the timber.
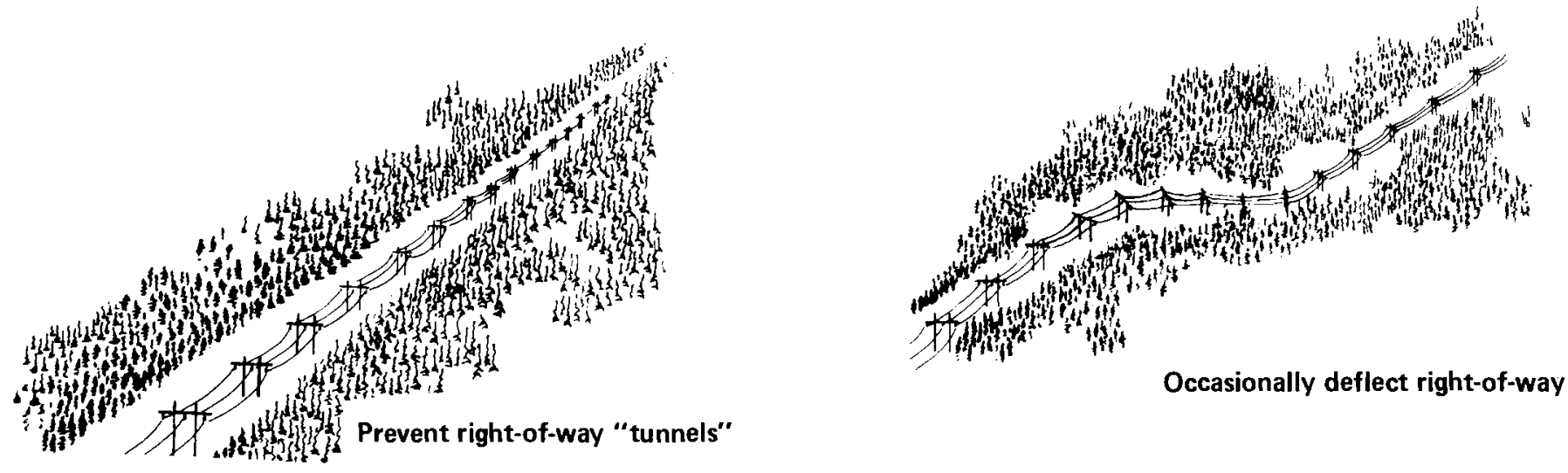


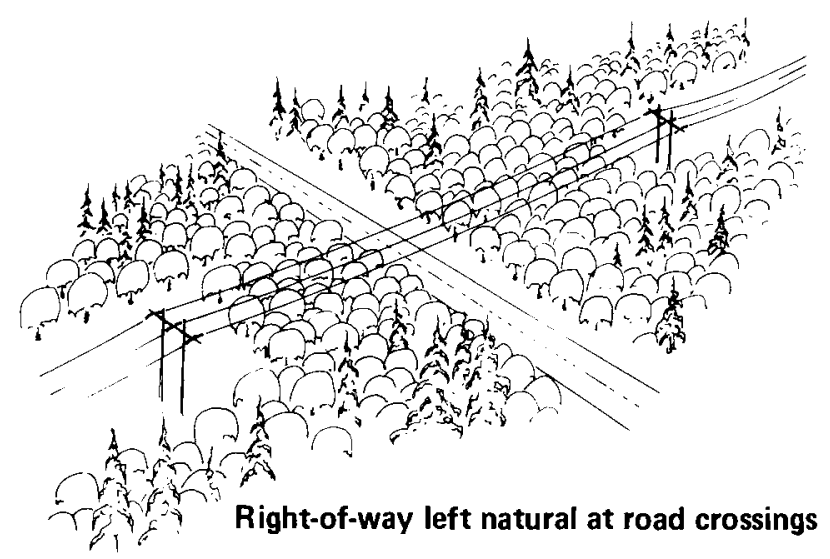

21. Locate access and construction roads in a manner that will preserve natural beauty and minimize erosion. Locate road grades and alignments to follow the contour of the land with smooth, gradual curves when possible. Commensurate with the topography, locate construction roads for later use as maintenance access roads or to provide access to recreational areas. Use existing roads to the maximum extent possible. Agencies administering the right-of-way lands involved may limit access and construction roads due to certain fragile or conservation aspects of the lands and associated resources.

22. Select a route that will maximize the use of natural screens to remove transmission facilities from view.

23. Where lines cross roads, the right-of-way should be left in its natural state as far back from the road as possible. 


\section{Design}

The present state of engineering design limits the extent to which a transmission line can be made unobtrusive. Additional work must be done in the areas of developing new, aesthetically pleasing, and functional towers; the use of new construction materials in these towers; and eventual development of economically feasible methods of undergrounding high-voltage, high-capacity transmission circuits. In the interim, design of transmission lines should consider placing of lines underground when crossing roads or traversing aesthetically sensitive areas of limited scope and distance.

The following factors used in the design of surface transmission facilities will minimize the adverse effects:

1. Towers should be strategically located to make maximum use of existing topography, vegetation, etc. for screening. 

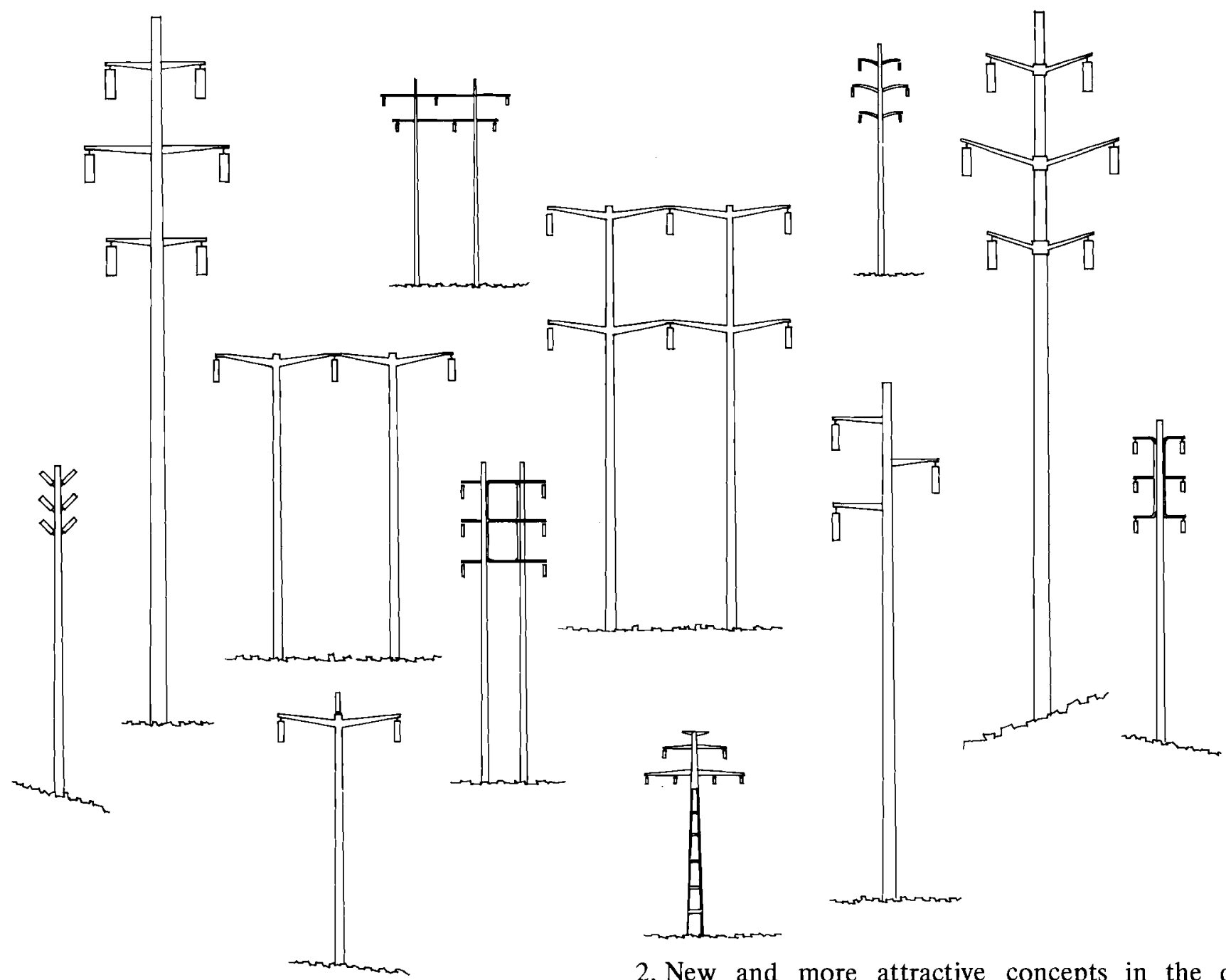

2. New and more attractive concepts in the design of transmission line towers should be considered. 
3. Coloring of transmission line towers to blend with the landscape may be desirable where they must be located in or near areas of high scenic value.

4. The materials used to construct transmission towers should harmonize with the natural surroundings. Selfprotecting bare steel is appropriate in many areas. Towers constructed of material other than steel, such as concrete, aluminum, or wood, should be considered.

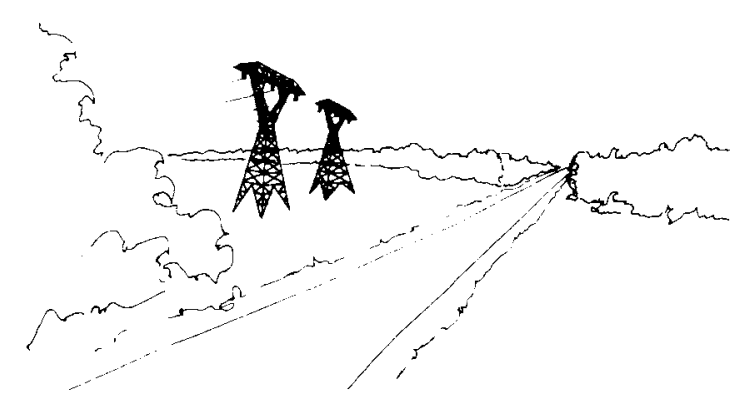

Two structures + two circuits $=$ too wide

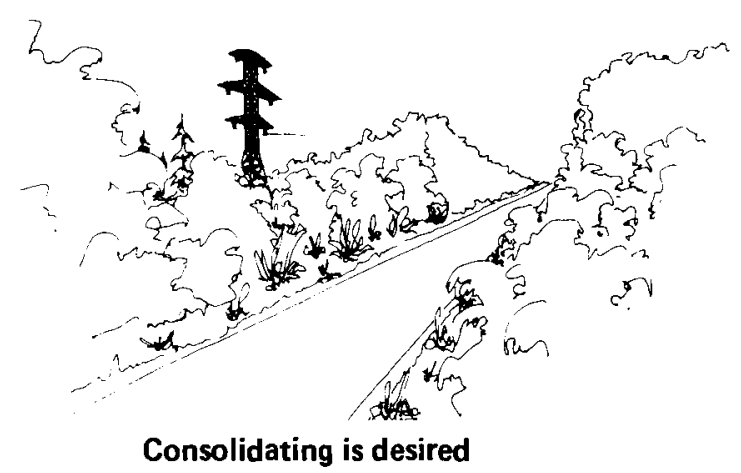

Consolidating is desired

5. At road crossings of two or more circuits, and where only a portion of the line is visible from the highway, the use of multiple circuit towers may be effective in minimizing the impact of the lines at that point. 
6. Where rights-of-way cross major highways and rivers, the transmission line towers should be strategically located for minimum visibility.

7. The use of high strength conductors should be considered, particularly at road, waterway and canyon or gorge crossings to pick up the line sag and allow for straighter line profiles.

8. Choice of conductor material should be carefully considered so as to avoid sheen or too strong a silhouette and to provide the best selection for blending the conductors into any given setting through which the line must pass.

9. When lines are adjacent to highways, guyed towers should be avoided whenever possible.

10. In situations where the minimum visibility sought in items $3,4,6$ and 8 conflicts with safety regulations, the safety regulations shall govern. These requirements are outlined in Part 77, F.A.A. Regulations "Objects Affecting Navigable Air Space". 


\section{Clearing}

Clearing plans, methods and practices are extremely important for success in any program designed to minimize the adverse effects of electric transmission lines on natural environment.

The following factors, if thoughtfully implemented and applied to each project, will help meet this goal:

1. Clearing shall be performed in a manner which will maximize preservation of natural beauty, conservation of natural resources, and minimize marring and scarring of the landscape or silting of streams.

2. Where rights-of-way cross major highways and rivers the clearing should be done in such a way that a screen of natural vegetation is left in the right-of-way on each side of the road or river. If natural vegetation is such that a screen cannot be left, the planting of native types of plants, low-growing trees, etc. should be considered to provide screening. 
3. The time and method of clearing rights-of-way should take into account soil stability, the protection of natural vegetation, and the protection of adjacent resources, such as the protection of natural habitat for wildlife and appropriate measures for the prevention of silt deposition in water courses.

4. Clearing of natural vegetation should be limited to that material which poses a hazard to the transmission line. Determination of a hazard in critical areas such as Park and Forest lands should be a joint endeavor of the utility company and the area manager in keeping with the National Electric Safety Code, State or other electric safety and reliability requirements.

5. The use of "brush blades" instead of dirt blades on bulldozers is recommended in clearing operations where such use will preserve the cover crop of grass, low growing brush, etc. 


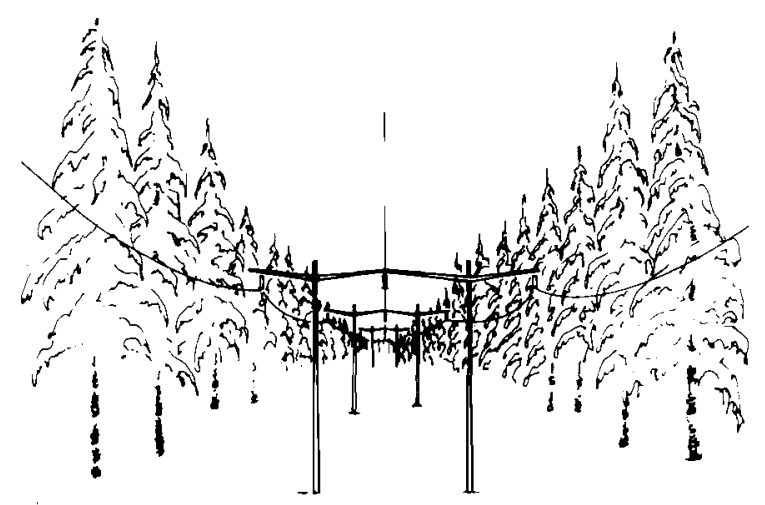

Avoid this notched effect

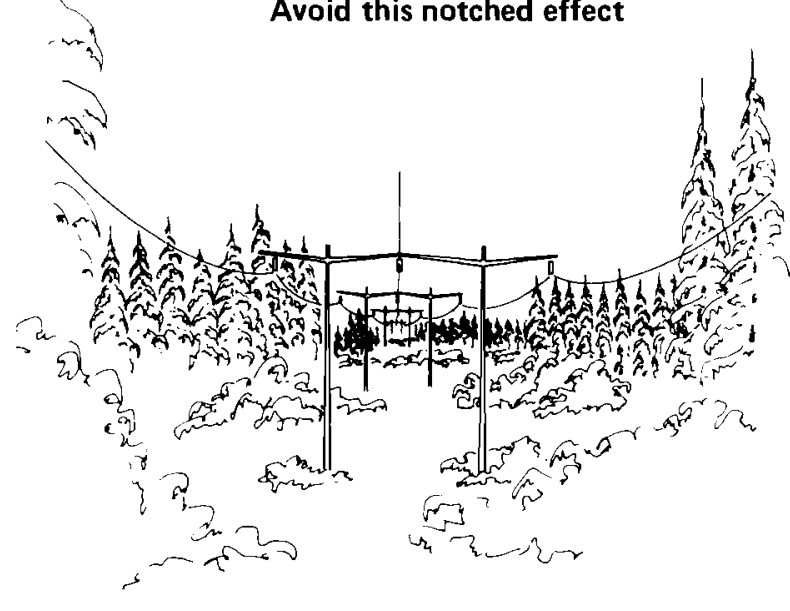

"Feather-back" the right-of-way
6. Where possible, right-of-way strips through sensitive forest and timber areas should be cleared with curved, undulating boundaries. The notched effect of a rightof-way cross section should be avoided. Careful topping and pruning of trees can contribute to this. Also, small trees and plants should be used to feather back the rights-of-way from grass and shrubbery to larger trees. If the rights-of-way are through dense areas of timber where trees are of equal height, and the right-of-way must be cleared to a straight line, the maintenance plan should provide for ultimately reaching the above desired results through seeding, planting and selective cutting of native material. Consideration should be given to the establishment of native vegetation of value as food and cover for wildlife.

7. Special care should be used when clearing through shelter belts, orchards, natural stands of trees, or other special areas with high exposure to public view which cannot be avoided. 


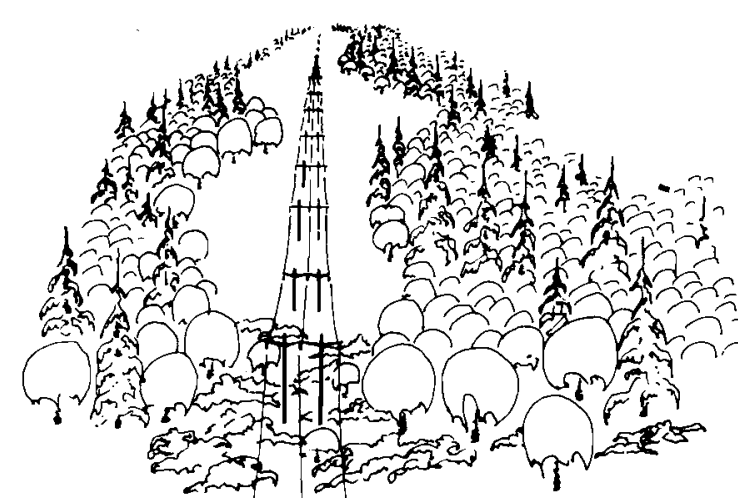

T1 Vegetation screens long-axis right-of-way viewsNote curved, undulating boundaries

8. Where rights-of-way enter dense timber from a meadow or where they cross major roadways, streams or rivers in forested areas, a screen of natural vegetation should be retained along the right-of-way.

9. Brush or small trees cleared and not otherwise disposed of may be piled in a way to provide cover habitat for small game animals and birds. Such brush piles should be screened from public view.

10. Trees and brush should be cleared only when necessary to provide electrical clearance, line reliability or suitable access and construction roads for operation, maintenance, and construction. (Recall the possible limitations mentioned under I-B-21.) Straight swath appearance should be avoided.

11. In any timber region where particular forest species can be grown for Christmas tree market, the right-of-way should be used for Christmas tree growing purposes if economically feasible. This will help to preserve the scenic beauty.

12. In other areas, consideration should be given to other uses of the right-of-way. (Refer to I-G-9 for typical multiple uses.) 


\section{E. Construction}

The best environmental planning can be reversed or defeated by uncontrolled construction activities. The entire force employed by contractors should be advised that all aspects of their construction activities are to be geared to the preservation and enhancement of natural beauty and the conservation of natural resources. The following criteria will help to attain this goal. (These criteria are particularly subject to adjustment befitting the rules and judgments of the various agencies across whose lands the line may be permitted to go.)

1. Clearing and grading of construction areas such as camp sites, storage areas, setup sites, etc. should be minimal. These areas should be graded in a manner which will minimize erosion and conform to the natural topography.

2. Borrow areas, rock quarries, etc., should be located away from public view. These areas should be restored to such condition that erosion will be avoided and appearance is acceptable. Borrow pits can be tastefully and aesthetically created to blend into the natural landscape and in some instances used for active resource purposes; for example, fish and wildlife management purposes.

3. Soil which has been excavated during construction and not used should be evenly back filled onto the cleared 
area or removed from the site. The soil should be graded to conform with the terrain and the adjacent land. Top soil should be replaced and appropriate vegetation planted and fertilized.

4. Terraces and other erosion control devices should be constructed where necessary to prevent soil erosion along the right-of-way.

5. The tops of spoil piles in arid locations should be shaped in a concave manner to retain moisture. Steep slopes on these piles should be avoided to prevent erosion.

6. Roads should be provided with side drainage ditches and culverts across the roads to prevent soil or road erosion.

7. Roads should not be constructed on unstable slopes. Where feasible, service and access roads should be used jointly.

8. As a general rule, machine clearing (bulldozing) should not be done on slopes which exceed $35 \%$.

9. Clearing and construction activities in the vicinity of stream beds should be performed in a manner to minimize damage to the natural condition of the area. Machine clearing should not be permitted within 100 feet of any stream bed.

10. Avoid oil spills and other types of pollution, particularly while performing work in the vicinity of streams, lakes and reservoirs. 
11. Blasting should not be done in or near stream channels without adequately protecting fish and other aquatic life.

12. Trees, shrubs, grass, natural features and topsoil which are not removed should be protected from damage during coñtruction.

13. Water used for construction purposes and taken from streams or other bodies of water should be limited to volumes which will not cause harm to the ecology or aesthetics of the area.

14. Every precaution should be taken to prevent the possibility of accidentally starting range or forest fires. Construction programs should include fire prevention planning, training of personnel in fire fighting and a fire inspection program. Full compliance with fire laws and regulations is a necessity.

15. The use of helicopters for construction on rights-of-way should be considered in mountainous or otherwise inaccessible terrain or areas of scenic and historic significance.

16. Undergrounding must be considered for lower voltage sub-transmission lines when alignments parallel or cross major highways, natural, scenic and historic sites, recreation areas, wildlife refuges, national and state monuments, etc. Consideration of underground 
installation must take into account the relative ecological damage, success of landscape restoration and the overall environmental quality retention as independent aspects of feasibility evaluation in comparison to aerial installations.

17. Tension stringing of conductors should be employed wherever possible so as to reduce the amount of vegetation clearing before the final conductor location is established. Tension stringing is also associated with helicopter construction where "Feed" or "Stringer" lines are aerial borne and where high-strength conductors are used.

18. When possible, construction should be performed during seasons of low-wildlife occurrence, such as between periods of water-fowl migrations.

19. Construction roads should be located and designed to prevent erosion and sedimentation, and to serve permanent service access requirements.

20. Soil disturbance during construction should be kept to a minimum, and restorative measures should be taken promptly. 


\section{F. Cleanup and Restoration}

The following criteria provide for the cleanup of construction debris and the restoration of the area's natural setting. Further requirements may be imposed by land management agencies across whose lands a line may be permitted to go.

1. Scars, cuts, fills, or other aesthetically degraded areas should be seeded or reseeded as soon as possible to reduce erosion and restore a natural appearance, and to provide food and cover for wildlife.

2. Temporary roads should be obliterated by restoring original slopes and planting natural ground cover.

3. Approach roads and existing low-standard roads which are to be used for access roads should be improved to provide proper drainage and control erosion.

4. Fertilize and seed restored areas as required to encourage growth of grass and other vegetation which is ecologically desirable.

5. Construction campsites, storage areas, etc. should be restored to their original or natural condition. 
6. Dismantle and remove all abandoned or useless buildings, equipment, supplies, and personal property.

7. Material to be burned should be piled in a manner and in such locations as will cause the least fire risk. Care must be taken to prevent fire or heat damage to desirable trees and shrubs within and adjacent to the right-of-way, to conform with local fire regulations, and to minimize air pollution.

8. If the natural vegetation cannot be effectively saved to provide an adequate screen, trees and shrubs native to that area should be planted to ultimately provide the necessary screening. Consideration should be given to the establishment of native vegetation of value as food and cover for wildlife.

9. If it is necessary to clear down to the mineral soil, the topsoil should be saved, replaced and stabilized without undue delay by the appropriate seeding of grass, shrubs, and other native vegetation compatible with the surrounding ground cover. 
10. Waste, cleared and trimmed material shall be ground up, burned, removed, concealed, or scattered as required prior to completion of the contract.

11. Replacement of earth adjacent to water crossings for access roads should be at slopes less than the normal angle of repose for the soil type involved. Sodding or seeding should be accomplished without undue delay.

12. Brush, timber and other wood products can be disposed of by chipping or shredding. After reduction in this manner the materials can be dispersed to serve as mulch, rather than burned.

13. Where site factors make it unusually difficult to establish a protective vegetative cover, other restoration procedures may be advisable, such as the use of gravel, rocks, concrete, etc. 


\section{G. Maintenance}

Preservation of both the environmental and natural resource conservation factors designed and built into a transmission system will require a thoughtful, comprehensive program for maintaining the facility. The following factors should be incorporated into such a program.

1. Native vegetation, particularly that of value to fish and wildlife, which has been saved through the construction process and which does not pose a hazard to the transmission line should be nurtured and allowed to grow on the right-of-way.

2. Native grass cover should be maintained if ecologically appropriate in the areas immediately adjacent to transmission towers.

3. Native trees, shrubs, herbs and grass should be allowed to grow and where ecologically appropriate in critical areas vegetation of this type should be planted at acceptable distances from transmission facilities.

4. Once a cover of vegetation has been established on a right-of-way, it should be properly maintained. 
5. Access roads and service roads, if and where permitted, should be maintained with native grass cover, water bars and the proper slope in order to prevent soil erosion.

6. Chemicals, when used, should be carefully selected to have a minimum effect on desirable indigenous plant life and selective application should be used wherever appropriate to preserve the natural environment. In scenic areas, the impact of temporary discoloration of foliage should be considered; and where this factor is critical, either mechanical means of vegetative control should be used, or the work should be scheduled in the early spring or late fall. It is essential that chemicals be applied in a manner fully consistent with the protection of the entire environment, particularly of the health of humans and wildlife.

7. Maintenance inspection intervals should be established so that routine maintenance occurs when access roads are firm, dry or frozen. Maintenance vegetative clearing in particularly critical areas should be done on a short cycle to satisfy minimal requirements and avoid heavy, long-term cutbacks. 
8. Aerial and ground maintenance inspection activities of the transmission line facility shall include observations of soil erosion problems, fallen timber and conditions of the vegetation which require attention. The use of aircraft to inspect and maintain transmission facilities should be encouraged.

9. Public acceptance of rights-of-way is generally broadened when compatible multiple use of a right-of-way is allowed or encouraged. Transmission line rights-of-way can be made available for appropriate types of multiple use concepts, such as:

Game food plots

Recreation areas

Access to

recreation areas

\section{Parks}

Golf courses

Equestrian or

bicycle paths

Orchards

Picnic areas

Storage facilities
Christmas tree nursery

Other nursery stock

Wildlife sanctuaries

Wildlife refuges

Wildlife

management areas

Hiking trail routes

General agriculture

Athletic facilities

Game cover 



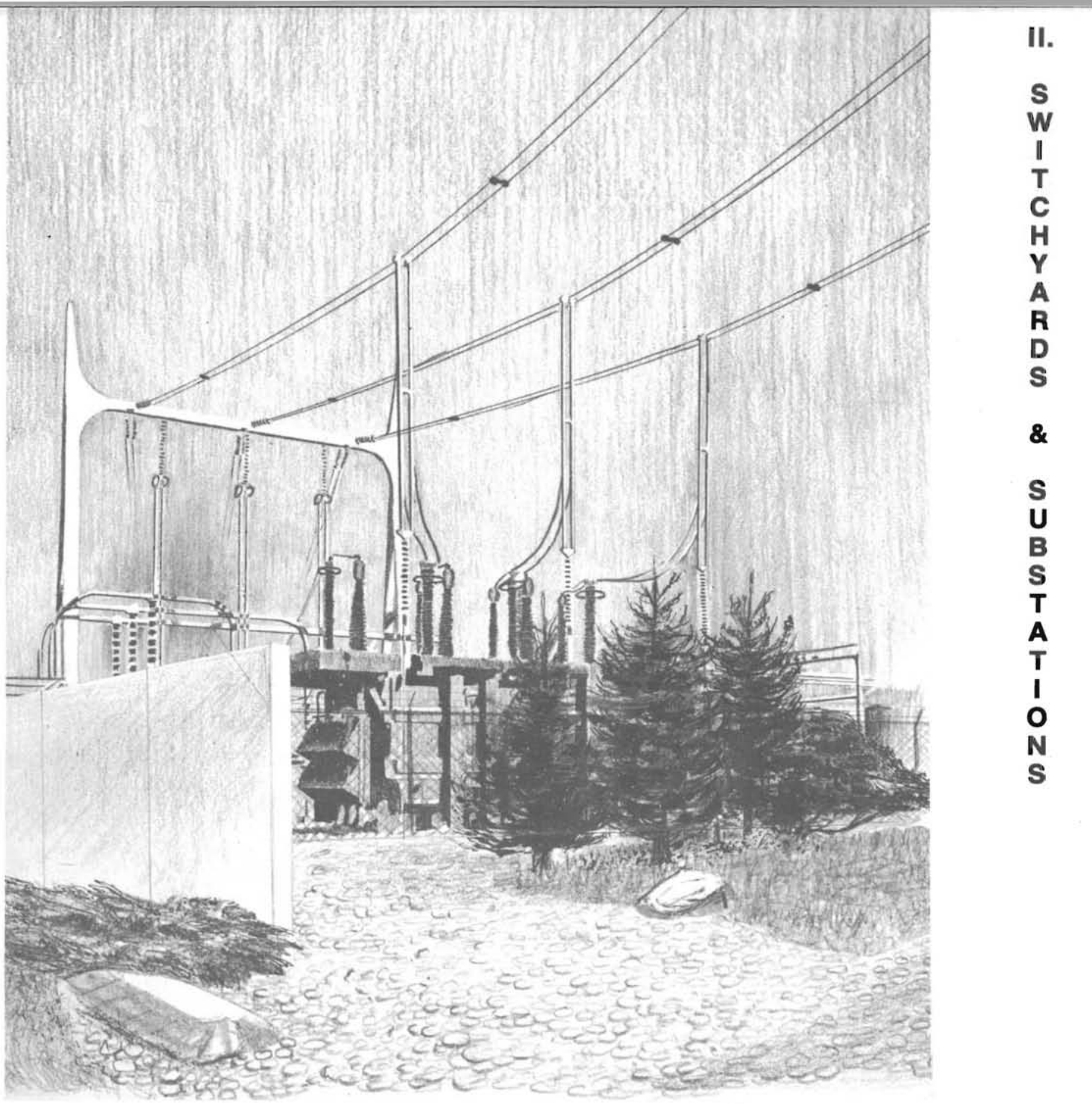





\section{A. General Comments}

The purpose of these facilities is to receive power; to transfer power from circuit to circuit; to protect circuits and equipment; to transform power to other voltage levels; to provide meters for billing, system power scheduling, and control; and to monitor system performance. The installation also often serves as a location for maintenance crew headquarters, warehouses, and storage facilities.

The most comprehensive appearance improvement programs throughout the electric utility industry have been in switchyards and substations. Appearance of these facilities has been receiving much consideration in the development of structural and electrical designs by many utilities. Color is being used to enhance the appearance of installations and to define the function of the electrical equipment. Landscaping and architectural fences have been effectively used. The objective is to design these facilities to be compatible with their surroundings.

Since the criteria for clearing, construction, cleanup, and restoration and maintenance of switchyards and substations are the same as for transmission lines, they have not been repeated in this section. Please refer to Sections I-D, I-E, I-F, and I-G. 


\section{B. Location}

The effective location of switchyards and substations requires careful consideration of the functional requirements of the facility and other factors understood and accepted by the utility industry, such as good access by road and rail and proximity to the load or generation station.

Consideration of the following additional factors would do much to minimize the adverse environmental impact of the facilities:

1. Switchyards and substations should be located with consideration both for their basic function and for the preservation of public views of scenic, historic, natural and recreation areas, parks, monuments, etc.

2. The proposed location, layout, and design parameters should be coordinated with appropriate local planning agencies to assure maximum compatibility between the facilities and present and future land use. 
3. The location should be coordinated with the needs of utilities delivering power into or receiving power from the station. This is particularly important in the development of the site's electrical layout to minimize costly, unsightly, transmission line crossovers and unnecessary duplication of facilities.

4. If possible, locations should avoid populated areas, parks, scenic areas, wildlife refuges, hilltops and natural or man-made structures.

5. Locations near existing or proposed interstate or state primary highways should be avoided.

6. Where possible, substations should be located where they may be naturally or artificially screened.

7. Potential noise should be considered when the locations for high-voltage substations are being determined. The facilities should be located in areas where sound will not be resonated.

8. Multiple level, terraced substations may be used to minimize excavation and provide a facility that will blend effectively with sloping terrain. 


\section{Design}

The following factors incorporated into the design of substations and switchyards will significantly contribute to the environmental compatibility of the facilities.

1. Facilities should be designed to be compatible with the area in which they are located and constructed from materials which are native to the area or which harmonize with their surroundings.

2. The size of switchyards and substations should be kept to the minimum which will accommodate the ultimate functional and aesthetic requirements.

3. Cut and fill slopes should be designed to achieve maximum compatibility with the surrounding natural topography.

4. Simplified, functional structures should be considered in preference to conventional lattice types.

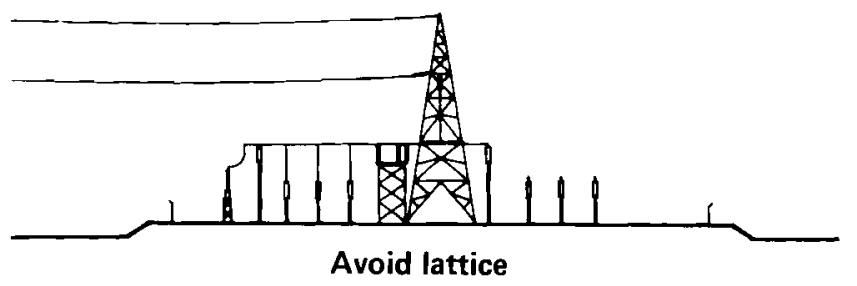


5. In general, the use of low profile concepts and simplified structures within switchyards and substations will enhance the overall appearance of the facility.

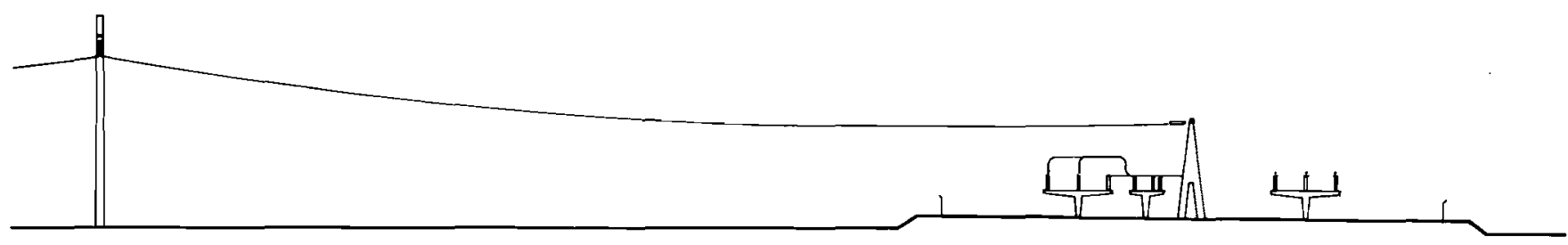

An uncluttered substation

6. Buildings should be designed to be architectually compatible with their surroundings.

7. Distinctive colors should be used wherever they appropriately enhance the appearance of substation structures and identify or express the function of electrical equipment; provided, however, that such colors are in harmony with the surrounding area. 
8. Architectural fences or architectural features should be used along the fence line to complement the surrounding landscape or other features. Architectural fences may in some instances complement the architecture of service or control buildings within the substation area.

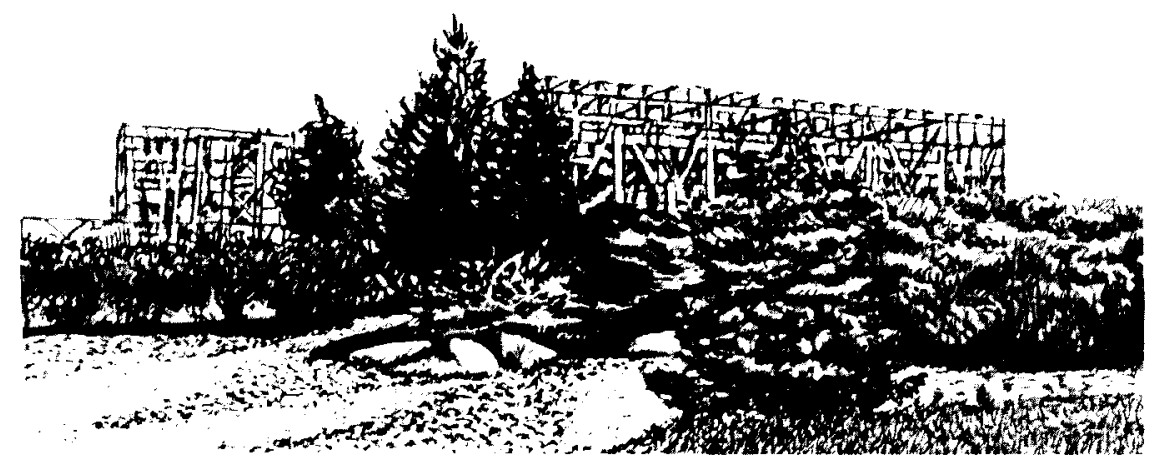

9. Creative landscaping practices should be developed and used to enhance the appearance of substation installation. However, the design may in some cases be compelled to abide with existing motifs, traditional forms and materials. 
10. Transformer circuits should be placed underground where economically feasible, or where natural features viewed by the public would be seriously despoiled by overhead circuits.

11. Consideration should be given to placing distribution, control, and telephone circuits underground.

12. Exterior lighting for switchyards, substations and buildings, adequate for work and for protection of the facilities from sabotage and malicious mischief, should be provided. In some cases exterior lighting may appropriately enhance the aesthetic values of the structured landscape elements.

13. Disconnect switches, fuses, and other similar devices should preferably be located on low ground mounted structures as contrasted with placing them on high substation dead-end structures.

14. Maintenance, warehouse, and storage facilities at the substations should be so located and maintained as to minimize their adverse effect upon the environment. 


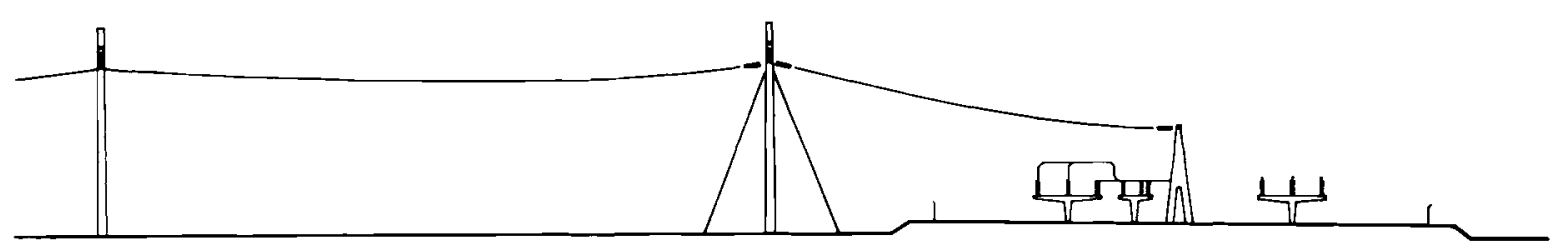

Avoid guys near substations

15. The use of guyed transmission structures adjacent to substations and switchyards should be avoided.

16. Signs, ground cover, etc., should be compatible with their surroundings.

17. Where feasible, transformers, power circuit breakers and other equipment should be designed for low, audible sound and so located and shielded as to minimize impact of sound on the neighborhood. 


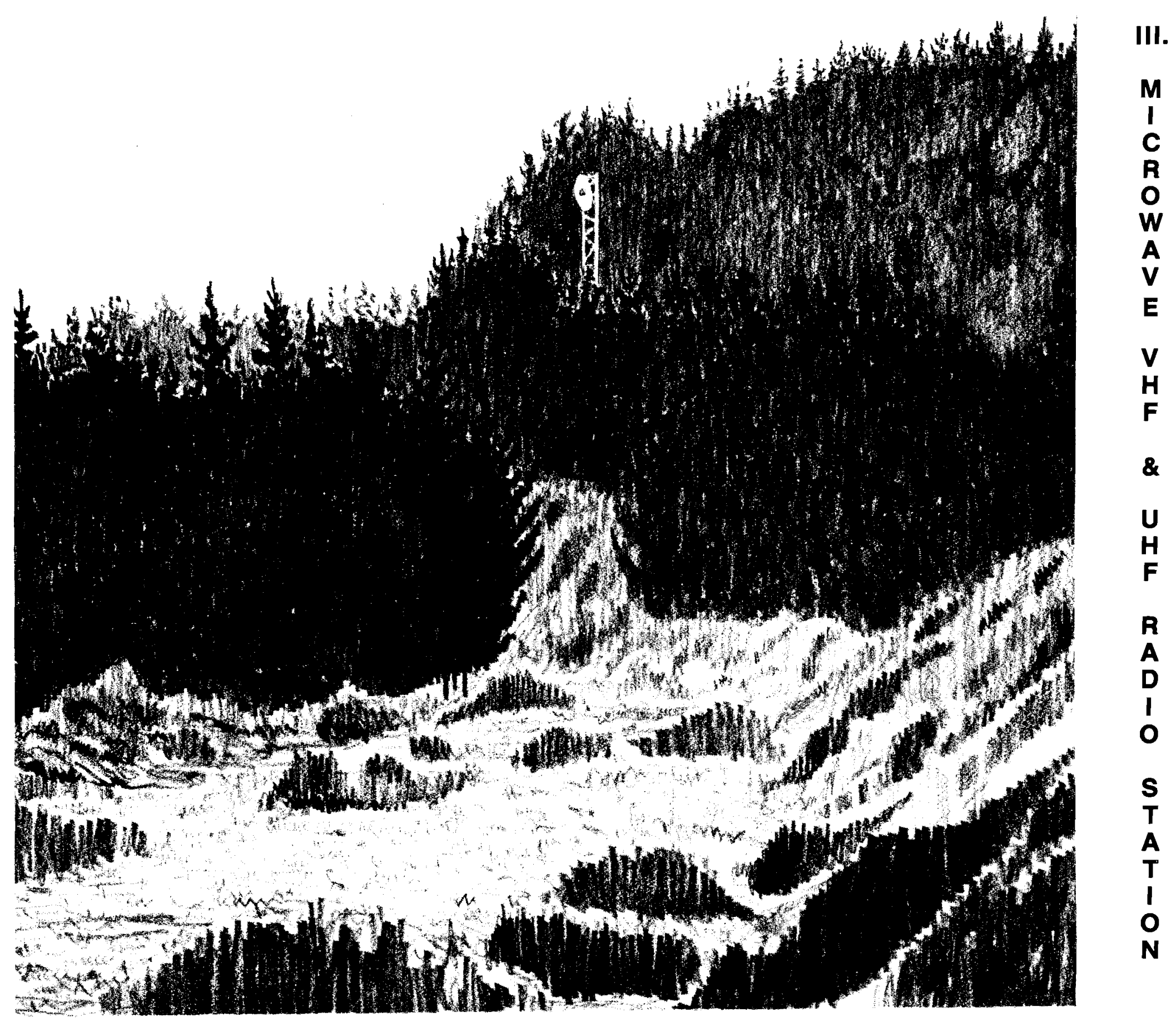




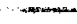




\section{A. General Comments}

Although this section is oriented to power systems communications, this criteria can appropriately apply to the treatment of any and all communications facilities.

A very important part of modern electric utility systems are the communication facilities which are required to effectively and efficiently operate the power system. Communication channels are required for high-speed protective relay systems, for transmitting information, for high-speed control and regulation, for reliable voice communications, and on the more sophisticated systems for computer inputs.

Very often the station sites required for main communication system link are also used as the locations for VHF and UHF mobile radio base and repeater stations. The proposed routes for communication system links usually follow the same general route followed by the transmission line.

Since the criteria for construction, cleanup and restoration, and maintenance are the same as transmission lines, they have not been repeated in this section. Please refer to Sections I-E, $\mathrm{I}-\mathrm{F}$, and I-G. 


\section{B. Radio Station Site Selection}

The functional requirements of microwave sites are such that a "line-of-sight" beam path must be available between adjacent stations. It is also desirable to obtain the maximum VHF mobile radio coverage from each station. For these reasons, radio and microwave stations usually occupy high ground.

The adverse environmental impact of these stations can be substantially minimized by selecting sites which:

1. Require the least development with respect to clearing and grading.

2. Require the least development with respect to stationservice power line and access road construction.

3. Afford adequate maintenance access during adverse weather conditions. 


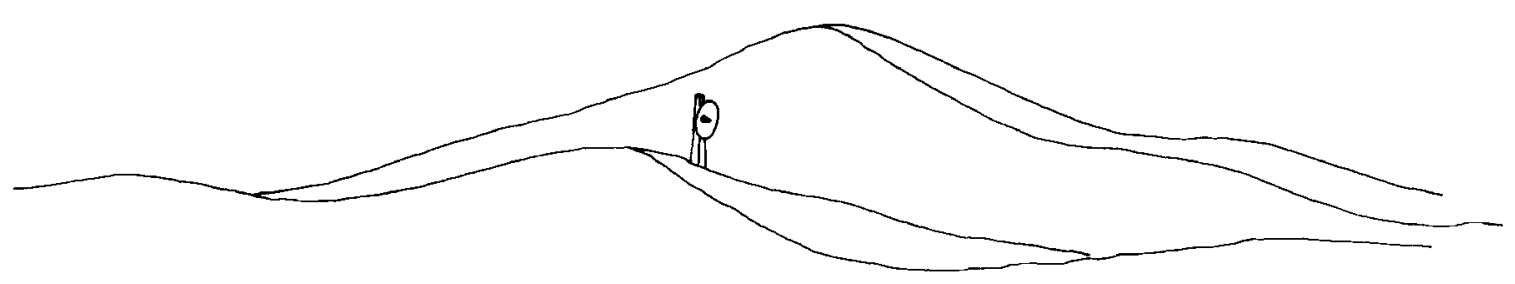

Microwave Tower

4. Are located on the slopes or brow of a hill to provide the necessary beam path, yet offer the minimum silhouette.

Refer to section I-B. Some of these criteria are pertinent to the location of the sites covered in this section. 


\section{Design}

The design for the development of any particular site should exploit all possibilities for minimizing the adverse environmental impact of the facility:

1. Maximum height of antenna towers should not exceed that required to provide the necessary beam path. Antenna-bearing structures and associated hardware should be adequate to withstand climatic stresses of the area, but should provide a minimum silhouette.

2. Buildings should be single story and of minimum size to satisfy present and future functional requirements.

3. To the extent that is feasible, all structures should be designed to be architecturally compatible with the area in which they are located, constructed from materials which either are native to the area or which harmonize with their surroundings.

4. Engines for emergency power supplies should be adequately muffled.

5. Where safety code permits, fuel tanks should either be buried or recessed below grade or otherwise screened. 
6. Burial of the alternating current station service power supply lines to and near the site should be considered with the same caution outlined in I-E-16.

7. The AC station service line to the site should follow ground contours instead of a straight line and be treated in the same manner as design and construction under transmission lines.

8. The access road to the site, if necessary, should be designed and located for minimum adverse impact and maximum landscape conservation with respect to all environmental effects.

9. Access to the site for emergency or routine maintenance is sometimes necessary when the access road is impassable. Facilities and site should both be developed so that a helicopter can land in the vicinity of the station.

Refer to section I-C. Some of these criteria are pertinent to the design of these facilities. 
D. Clearing

1. The clearing of trees and vegetation for the facility should be limited to the minimum area required.

2. To the extent possible, all foliage adjacent to the site should be left undisturbed to provide maximum screening of the installation.

3. Timber should be removed only as required for the site and beam paths. Wide swath beam paths should be avoided.

4. In heavy timber, consideration should be given to making the tower taller than the trees to avoid beam path clearing. The trees then provide a partial screen for both the tower and the site.

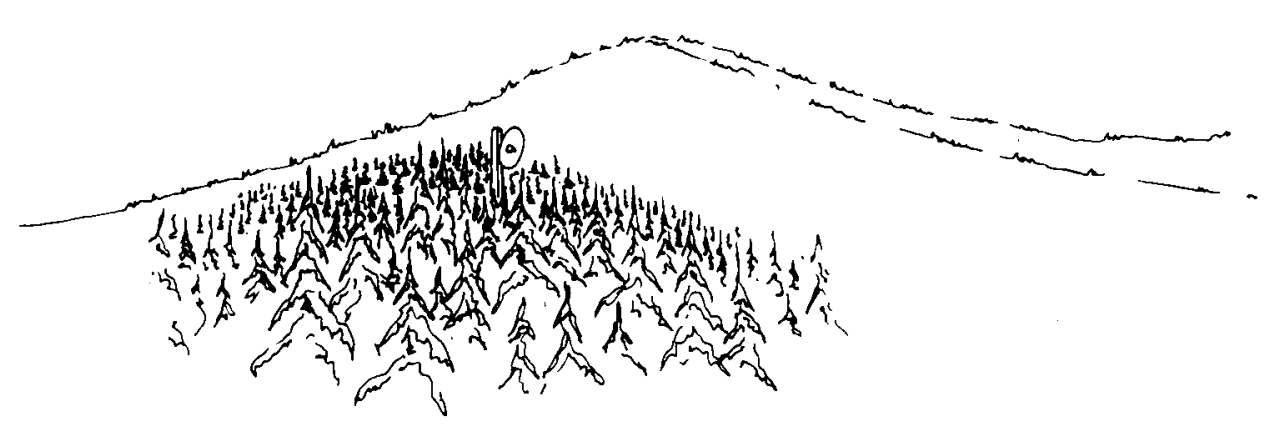

Trees screen tower and site 
5. Where possible, trees should be topped rather than removed. This alternative appears to be a satisfactory one where topping the trees leave at least 50 percent of the crown and foliage.

6. Debris resulting from the clearing operation should be removed or handled as indicated in I-D-9. All timber and other vegetative material without value should be mechanically chipped and spread in a manner that will aid seedling establishment and soil stabilization.

7. Clearing for the station service AC supply facility, whether buried or overhead, and for the access road to the site should be held to a minimum.

Refer to section I-D. Some of these criteria are pertinent to the clearing for these facilities. 


\section{REFERENCE LIST}

1. Applegate, L.M. HVDC has Little Hazard for Piping. Power 112(5):82-84. May 1968.

2. Barnes, C.C. Electric Cables. London, Chapman and Hall, 1966. 293p.

3. Barnes, C.C. Power Cables: Their Design and Installation. 2 ed. London, Chapman and Hall; New York, Barnes and Noble, 1966. 396p.

4. Bennett, N.B. Reclamation's Mead Substation. Power Engineering 72(1): 32-35. January, 1968.

5. Bishop, G.R. Elegant Tower Design Obtained with Precast Concrete. Electric Light and Power 45: 96-97. May, 1967.

6. Bleiweis, Jules, ed. Our Environment: How Utilities Protect It. Electrical World 166(8): 61-78. August 22, 1966.

7. Bleiweis, J., ed. Today's Overhead Systems Reflect the New Look. Electrical World 168(2): 99-118. July 10, 1967.

8. Brenman, H.F., and D.A. Covington. Environmental Considerations in Designed Transmission Lines. ASCE National Meeting on Transportation Engineering, Washington, D.C., July 21-25, 1969. Preprint No. 927. 28p.
9. Chang, D.R. Tapered-Steel Poles Put $230-\mathrm{Kv}$ Line on Narrow $\mathrm{R} / \mathrm{W}$. Electrical World 167(26): 55-58. June 26, 1967.

10. Christerson, P.D. Utility Poles: A Key National Asset. Paper presented at the Engineering and Operation Meeting, Northwest Electric Light and Power Association, May 2, 1968, Calgary, Alberta, Canada. Portland, Northwest Electric Light and Power Association, 1968. 13p.

11. Crowe, S. The Landscape of Power. London, Architectural Press, 1958. 118p.

12. Crowe, S. Tomorrow's Landscape. London, Architectural Press, 1956. 207p.

13. Columbia Basin Inter-agency Committee. A Report on the Impacts of Power Transmission Lines in Forested Areas of the Columbia Basin. Prepared by the Ad Hoc Subcommittee on Power Transmission Lines in Forested Areas. Portland, 1963. $11 \mathrm{p}$.

14. Culberson, R.T. Substation Harmonizes With Area. Electrical World 164(17): 28. October 25,1965 .

15. Dold, J.W. and R. Johnson, Jr. Low Profile Substation Cuts Objections. Electrical World 168(13): 30-31. September 25, 1967. 


\section{REFERENCE LIST}

16. Dominy, F.E. Reclamation Bureau Designs Facilities for New Look. Electrical World 169(23): 36-37. June 3, 1968.

17. Ewald, E. and D.W. Angland. Regional Integration of Electric Power Systems. IEEE Spectrum 1(4): 96-101. April, 1964.

18. Friendlander, G. Esthetics and Electric Energy IEEE Spectrum 2(6): 46-55. June, 1965.

19. Hamilton, A.J. How Much Beautility and Who Pays for It? Public Utilities Fortnightly 78(3): 15-24. August 4, 1966.

20. Henry Dreyfuss and Associates. Electric Transmission Structures; A Design Research Program. Sponsored by Electric Research Council New York, Edison Electric Institute, 1967. Pamphlet. (EEI Pub. No. 67-61)

21. Holford, W. Electricity and the Landscape. Central Electric Generating Board Newsletter, No. 12 n.p. January, 1961

22. Hore, R.A. Advanced Study in Electrical Power System Design. London, Chapman and Hall; New York, Barnes and Noble, 1966. 385p.
23. Johnson, R.L. The Current Status of Beautility. Public Utilities Fortnightly 78(4): 15-23. August 18, 1966.

24. Lynch, K. Site Planning. Cambridge, Mass., M.I.T. Press, 1962. 248p.

25. Miller, A.D. 'Copters Eliminate Pioneer Roads, Leave Land scape Undisturbed. Electrical World 170(14): 66-67. September 30, 1968.

26. New Art Form: EHV Towers. Transmission and Distribution 20(4): 130. April, 1968.

27. New York. Power Authority. Transmission Line Planning and Design for Preservation and Enhancement of Environments; BlenheimGilboa Pumped - Storage Power Project; Federal Power Commission Project No. 2685. Appendix A. New York, UHL, Hall and Rich, 1969. 44p.

28. O'Teter, T.R., R.D. Wiggins, and J.E. Danteler. Flexible Styling Enhance Urban Transmission Design. Electric Light and Power 46(3): 108-111. March, 1968.

29. Philadelphia Electric Company. Policy and Program for Improving Appearance of Overhead Transmission Lines. Philadelphia, 1968. $14 \mathrm{p}$. 


\section{REFERENCE LIST}

30. Plant Siting Task Force. Major Electric Power Facilities and the Environment. Prepared at the Request of Edison Electric Institute Committee on Environment. New York, 1970. 31 p.

31. Pohlman, J.C. Architectural Substations - An Obvious Approach. Transmission and Distribution 15(1): 22-23. January, 1963.

32. Pohlman, J.C. and R.L. Flucker. A New Look at the Substation Appearance Problem. IEEE Winter Power Meeting. Conference Paper CP-65-233. February 2, 1965, New York. New York, IEEE, 1965. 13p.

33. Robbins, George T. Plantings Enhance Lines and Substation. Electrical World 168(10): 38 . September 4, 1967.

34. Rose, E., Asce, M. and D.A. Covington. Improved Appearance of Switchyards and Substations. Journal of the Power Division, Proceedings of the American Society of Civil Engineers 95(NO. PO. 1): 17-33. March, 1969.

35. Sibley, S.L. Case Example - The Economics of Aesthetics, Industry Must Take Initiative. EEI Bulletin 34(1): 10-14. January, 1966.

36. Stanton, Boles, Maguire and Church. A Report on Appearance Planning for BPA. Portland, 1966. $50 \mathrm{p}$
37. Steel Pole Line Presents Pleasing Appearance. Transmission and Distribution 20(7): 52-53. July, 1968.

38. Stolshek, J.D. Functionalism, Flexibility and Esthetics. Electrical West 133(4): 37-38. August, 1966.

39. Transmission of the Future. Power Engineering 71(10): 67-68. October, 1967.

40. U.S. Ad Hoc Water Resources Council. Policies, Standards, and Procedures in the Formulation, Evaluation and Review of Plans for Use and Development of Water and Related Land Resources. Supplement No. 1. Evaluation Standards for Primary Outdoor Recreation Benefits. Washington, D.C. 1964.9v.

41. U.S. Bonneville Power Administration. Access Road Maintenance. Transmission Maintenance Standard No. 6351-2. Transmittal Letter No. T-(S)-68-2. Portland, 1967. 16p.

42. U.S. Bonneville Power Administration. Brush Control Standard. Transmission Maintenance Standard No. 6341-1 Rev. Transmittal Letter No. T-(S)-65-3. Portland, 1965. 29p.

43. U.S. Bonneville Power Administration. Transmission Line Maintenance Right-of-Way Appearance. Transmission Maintenance Standard No. 6340-1. Portland, 1967. 42p. 


\section{REFERENCE LIST}

44. U.S. Bonneville Power Administration. Transmission Line Right-of-Way Maintenance Standard. Transmission Maintenance Standard No. 6341-6. Transmittal Letter No. (S)-68-1. Portland, $1967.43 \mathrm{p}$.

45. U.S. Bonneville Power Administration. Transmission Systems Definitions; A Handbook on Technical Terms for BPA Employees. Portland, 1969. $91 \mathrm{p}$.

46. U.S. Bureau of Land Management. Environmental Quality and Natural Beauty. BLM Manual Section 2031, Release 2-42. Washington, D.C., 1969. 25p.

47. U.S. Bureau of Reclamation Manual. Series 350 General Instructions: Part 376 Environmental Quality - Preservation and Enhancement. Washington, D.C., 1969. 32p.

48. U.S. Citizens' Advisory Committee on Recreation and Natural Beauty. Annual Report to the President and to the President's Council on Recreation and Natural Beauty. Washington, D.C., U.S. Government Printing Office, June 1968. 37p.

49. U.S. Congress. House. Message on Environment. Message from the President of the United States Outlining Legislative Proposals and Administrative Actions Taken to Improve Environmental Quality. Washington, D.C., U.S. Government Printing Office, 1970. 14p. (91st Cong., 2d. Sess. House. Doc. No. 225).
50. U.S. Congress. House. State of the Union. Address of the President of the United States Delivered Before a Joint Session of the Senate and the House of Representatives Relative to the State of the Union. Washington, D.C., U.S. Government Printing Office, 1970.9p. (91st Cong., 2d Sess. House Doc. No. 226).

51. U.S. Congress. Joint Committee on Atomic Energy. Environmental Effects of Producing Electrical Power. Part 1. Hearings, 91 st Cong., 1 st Sess. Washington, D.C. U.S. Government Printing Office, 1969. 1108p.

52. U.S. Congress. Senate. State Utility Commi ssions; Summary and Tabulation of Information Submitted by the Commissions. Prepared by the Subcommittee on Intergovernmental Relations, Committee on Government Operations, pursuant to S. Res. 55, 90th Congress. Washington, D.C., U.S. Government Printing Office, 1967. 73p. (90th Cong., 1st Sess., Senate Doc. 56).

53. U.S. Electric Utility Industry Task Force on Environment. The Electric Utility Industry and the Environment; A Report to the Citizens Advisory Committee on Recreation and Natural Beauty. New York, 1968. 105p.

54. U.S. Federal Aviation Agency. Objects Affecting Navigable Airspace. Part 77. Washington, D.C., U.S. Government Printing Office, 1965. 26p. Reprint of 14 C.F.R. Par. 77 et Seq. 


\section{REFERENCE LIST}

55. U.S. Federal Power Commission. Federal Power Commission Interests in Environmental Concerns Affecting the Electric Power and Natural Gas Industries. Washington, D.C., 1969. $31 \mathrm{p}$.

56. U.S. Federal Power Commission. New York Regional Office. Aesthetics of Power Facilities. New York, 1968. lv. (various pagings).

57. U.S. Forest Service. Land Treatment Measurements Handbook. Forest Service Handbook, FSH 2509.11. Washington, D.C., U.S. Government Printing Office, 1969. 124p.

58. U.S. Forest Service. Watershed Structural Measurer Handbook. Forest Service Handbook, FSH 2509.12. Washington, D.C., U.S. Government Printing Office, 1969. 103p.

59. U.S. Forest Service. Roadbank Stabilization at Low Cost. Technical Report No. 38. Washington, 1939. 20p.

60. U.S. Laws, Statutes, Etc. National Environmental Policy Act of 1969. 91st Cong. 1st Sess., Public Law 91-190. Washington, D.C., U.S. Government Printing Office, January 1, 1970. (83 Stat. 852).

61. U.S. President's Council on Recreation and Natural Beauty. From Sea to Shining Sea - A Report on the American Environment - Our Natural Heritage. Washington, D.C., U.S. Government Printing Office, 1968. 304p.

62. U.S. President's Science Advisory Committee. Environmental Pollution Panel. Restoring the Quality of Our Environment - Report. Washington, D.C. The White House, 1965. 317p.
63. United States Steel Corp. Power Styling. Pittsburgh, 1965. 18p. (United States Steel Booklet).

64. U.S. White House Conference on Natural Beauty, Washington, D.C., 1965. Beauty for America; Proceedings. Washington, D.C., U.S. Government Printing Office, 1965. 782p.

65. U.S. Working Committee on Federal Construction. Report to the Vice President and the President's Council on Recreation and Natural Beauty. Washington, D.C., 1968. 46p.

66. U.S. Working Committee on Utilities. Report to the Vice President and to the President's Council on Recreation and Natural Beauty, Washington, D.C., 1968. 126p.

67. Vitelli, E.R., and R.E. Bloche. Utility Designed Structures Provide Pleasing Low Profile Appearance. Transmission and Distribution 20(5): 57-59. May, 1968.

68. Welti, Carl. New Transmission Line Gives Clean Overhead Appearance. Wood Preserving 46(6): 6. June, 1968.

69. Wernick, R. Let's Spoil the Wilderness. Saturday Evening Post 22: 12-16. November 6, 1965.

70. Williams, D.M. Utilities Public Recreation Efforts Make Friends, But Seldom the Newspaper. Electric Light and Power 45: 40-45. June, 1967. 



\section{APPENDIX B}

RULE 232 OF THE NATIONAL ELECTRICAL SAFETY CODE, PART 2, SAFETY RULES FOR THE INSTALLATION OF OVERHEAD ELECTRICAL SUPPLY AND COMMUNICATION LINES, APRIL 1976 

RULE 232 OF THE NATIONAL ELECTRTCAL SAFETY CODE, PART 2,

SAFETY RIRES FOR THE INSTALLATTON OF OVERHEAD ELECIRICAL SUPPLY AND COMMNICATION LINES, APRIL 1976

232. VERTICAL CLEARANCE OF WIRES, CONDUCTORS, CABLES, AND LIVE PARTS OF EQUIPMENT ABOVE GROUND, RAILS OR WATER

The vorticel clearance of all wirea, conductors, cables, and 11vo parts of equipment above ground in generally eccensible placos, or above the top of the ralle or wator ahall be not less than the following

A. Baslc clearances for wires, Conductors, and Cables The clearances in Table 232-1 apply under the following conditions:

1. Conductor temporature of $60^{\circ} \mathrm{P}$, no wind, with final unloadod aos in the wire, conductors, or cables, or with initial un loaded sag in cases where these facilltles are onintalned epproximately at initial unloaded oaga.

2. Span lengthe not greater than the following:

Londing Diotriet $\begin{gathered}\text { Span } \\ \text { Lengelis }\end{gathered}$

Foet

$\begin{array}{lr}\text { Heavy } & \text { Q } 175 \\ \text { Medium } & 250 \\ \text { Light } & 350\end{array}$

(a) 150 foot in heavy-loading district and 225 feat in mediumloading district for 3-atrand conductora, each wire of which 1s 0.09 inch or lose in diameter.

Fostnotes for TABLE 232-1

(1) Where subways, tunnels, or bridges require 1t, less clearances above ground or ralls than requirod by Table 232-1. may be used locilly. The trolley and electrified rallroed contact conductor ahould bo graded very sradualiy froat the regular construction down to the reducad el ovetion.

(2) For wire, conductora, or cables crosalng ovar mine, losging and didlar rallwaye which handle only care lower than scandard frelght car the clearance may be roduced by an amount equal to tho differanco in holght betwaon the highest loaded car handled and 20 feot, sut the clearances ohel not bo reduced below that requirad for atreat croseings.

(3) These cleerancen may be reduced to 25 feet where paralleled by trolley contact conductor on the same atreat or highway.

(4) In cormunitlos where 21 feet has been established, this clcarance may be continued if carefully maintained. The elavation of the contact conductor should be the samo in the crosaing and next ad jecent opans (See Rule $289, D, 2$ for conditione which must bo wet where uniforw hri $L_{1}$, he above rall 1: impractical.)
(5) In communities whera 16 fect has been ootablighed for trollsy and alectrifled rallroad contact conductors 0 to 750 volts to ground, or 18 fect for trolley and electrifled rallroad contact conductor exccecing 750 volte, or where local conditlons make it impractical to obtain the clearance given in the table, these reduced clearances may bo used if carefully mat intalned.

(6) If a communtation service drop or a guy which ls effectively grounded or 1s ingulated againgt the highest voltage to which it $1 E$ exposed, up to 8700 volta, crosecs realdential streets and roada, thu clear anc may be reduced to 16 faet at the alde of the travelod way provided the cicurance at the center of the traveled way 18 at least 18 feet. Thi reduction in clcarance does not apply to arterial otrects and highways whlch are primarlly for through traffic, usually on a continuous route.

(7) Thle clearance may be reduced to the followini valuos:

(1) For Inoulated comanication conductors and cormunication cables

(2) For conductors of other communication clreults Eent

(3) For guy:

(4) For supply cables meeting Rule 230, C,1

(8) Th1 clearence may be reduced to the following values:

(1) Supply conductors $11 \mathrm{~m} 1 \mathrm{tod}$ to 300 volts to ground if more than 25 foet maseured in to ground if more than 25 foet maseured 1 a or diving plateform.

(2) Supply conductors limited to 150 volte to ground and mooting Hulos $230, \mathrm{C}, 2$ or $230, \mathrm{C}, 3$ and located at the olectric eervice entrence to bulldings

(9) Spaces and ways accessible to pedestrlans only are areas where vehicular traffic 1. not normally encountered or not roasonably ant 1c1pated. Land abject to (but not limlted to) h1 glway right-of-way meintenance equipment, logging equipment, all-tarrain vehicles, etc., arall not be considered as acceselble to podestrians only.

(10)

a supply or comunleation 11 ne elong a road 1s located rolativo to fencea, ditches, ambankaents, etc, so that tho ground clearance may be roduced to the followlog valuos:

(1) Insulated communication conductor and cominutcation cable:

(2) Conductors of other comounlcation circults 
TABLE 232-1 MAnimum Vertical Clearance of W1res, Conductors, and Cables Above Ground, Ra11s, or Water

(Voltages are phase-to-ground for effectlvely grounded circuits and those other circuits where all ground faults are cleared by promply de-energlzing the faulted section, both initidly and following subsequent breaker operations. See Definitions for voltages of other systems.)

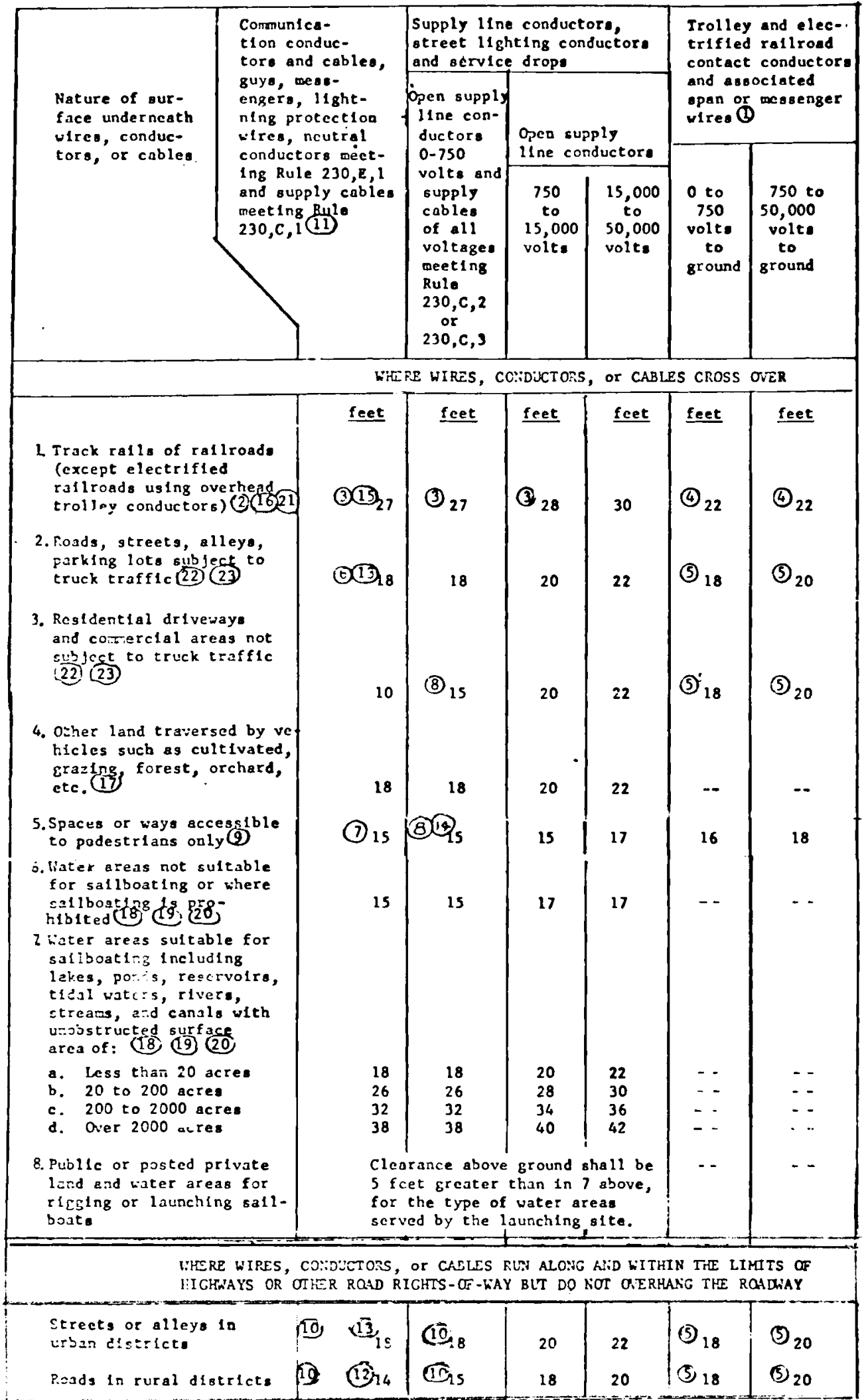


(3) Supply cables of any voltago meeting Rula 230, C, l and supply cables limited to 150 volts to ground meeting Rula $230, C, 2$ or $230, C, 3$

(4) Supply conductors limited to 300 volt to ground

(5) Guys

(11) No clearance from ground 10 required for anchor guye not croesing track ralle, etreots, drivewaya, roads, or pathways.

(12) Thia clearance may be reduced to 13 foot for comunication conductors where no part of the line overhangs any part of the highway which 10 ordinarily travoled, and where it 1: unlikely that

$$
\text { (13) }
$$

Where comonication wires or cables or supply cables meeting Rule $230, C, 1$ crose over or run along alloya, driveways, or parking lots, thie clearance may be reduced to 15 feet

(14) Where supply circuits of 600 volts or less, with trangitited power of 5,000 watts or leso, are run along fenced (or othorwiso guarded) private righta-of-way in accordanco with the provisione epecified in Rule 220,B,2, this clearance may be reducod to 10 feet.

(15) The value may be reduced to 25 feet for guyg, for cables carried on messengers and for supply cables meeting Rule $230, \mathrm{C}, 1$. Th1s value may be reduced to 25 foet for conductors effectively grounded throughout their longth and assoclated with supply clrculte of 0 to 22,000 volts, only if such conductors are stranded, are of corrosion-resiatant miteriel, and confora to the strongth and tension roquitements for mosoangers given in Rule $261, I$.

(16) Adjacent to tunnels and overhead bridges which restrict the h. 1 ght of loaded rall cars to leas than $20 \mathrm{feet}$, these cloarances way be re uced by the difference between the highoet loaded rail car handlod and
20 feet, if mutually agreed to by the partes at intereet.

(17) These clearances are for land cultivated or traversed by vehtcles and equipment whou overall operating helght 1 s leas than 14 foet.

\section{(1B)}

The ourface area and corresponding clearance shall bo based upon the uncontrollod lo-year flood lovol or, for controllod lopoundments, upon tho doolgn high vater lovol. Tho clcarance ovar rivors, etreams, and canal. hall be bused upon the surface area of the largeat one-mile long negment which lncludes the crosslng and which has the greatest urfaco area.

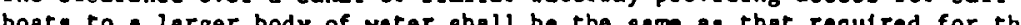
boato to a larger body o where an over-vater obstruction reotricte vesuel helght to lene than the following,

\begin{tabular}{|c|c|}
\hline For a surfincn of & A Referenchn Vinnol lletght of \\
\hline $\begin{array}{l}\text { iegs than } 20 \text { acres } \\
20 \text { to } 200 \text { acrao } \\
\text {. } 200 \text { to } 2000 \text { acrea } \\
\text { Ovor } 2000 \text { acres }\end{array}$ & $\begin{array}{l}16 \text { feot } \\
24 \text { feat } \\
30 \text { feet } \\
36 \text { feot }\end{array}$ \\
\hline
\end{tabular}

Thin ropul red cloaranco may be reduced by the difference between the reference veasel helpht given above and tho ovor-vater obatruction height, except that tho rodiced cloaranco shall not be lcsa than that requited for the aurface

(20) Where the U.S. Army Corps of Engineore or 1ts surrogate has lasued a crosing permit, clesrances of that pormit shall govern.

(21) See Rule $234, \mathrm{H}$ for the required horizontal and diagonal clearances to rall cara.

(22) Theso clearances do not allow for future road resurfacing.

(23) For the purpose of this rule, trucka are defined as any vehicle exceeding 8 feet in hoight.

B. Additional clearances for hilros, Conductors, and Cables Greater clearances than apeclfled in Table 232-1 (Rula: 32.1 ) ahall be provlded where requlred by 1 or 2 below. Increases are cumulative whero moro than one apply.

Exception 1: Additional iloarances ate not required for guye.

Exception 2: Additional ciearances are not required for communication cables osupported on messengors and commun1cations wires which do not overhang the traveled way, but run along and within the limits of public highwaya or
other public rigltta-of-way for trafflc.

1. Voltage, Exceeding 5c,000 volte

- For voltages between 50,000 yolta and 470,000 volta, the clearance specifled in Tablo 232-1 (Rulo 232, A) shail be lncreased at the rate of 0.4 loch.par klyovolt lan axcess of 50,000 volts. For voltages oxceeding 470,000 volts, the clearance shall be determined by the alternate method
of Rulo $232, D$. All clearances for Il nes over 50,000 volts shall bo based on the maxiaum operating voltage. 
Exception: For voltages exceeding 140,000 volte AC $r m a$ to ground or 197,000 volts $D C$ to ground

permitted for eystems with known maximum awitch-

ing surgo factors (aee Rule $232, \mathrm{D}$ )

b. The additional cloarance for voltegee exceeding 50,000 volts specified in Rule $232, \mathrm{~B}, 1$, a above shall be increased 3\% for each 1000 feet in excese of 3300 feet above man sea lavel.

c. For voltages exceeding 140,000 volte AC to to ground, or 197,000 volts $D$ to ground, the clearances shall be $1 n-$ creased or the olectric field shall bo reduced by other means, as required, to limit the current dus to lectrostatic offects to 5.0 mill1ampores, $r m s$, if the largest enticlpated truck, vehicle, or oquipmont undar the 11 ne vore chore-clrculced to ground. por thio dateralnation, tho

\section{Seg Increaso}

No additional clearance to required for trolloy and electrifled rallroad contact conductors.

b. No edditional clearance 19 required where epan lengthe are lase than those listed in Rule $232, A, 2$ and tho maximum conductor temperature for which tho aupply line 1s denlgned to oporate $10^{\circ} 120^{\circ} \mathrm{F}$ or lans.

c. Whero supply lines are dezlgned to operate at or below a conductor temperature of $120 \%$ and spans are longor than specificd In Rule $232, \Lambda, 2$, the alnimum clearance at uldapan ahall be Increased by the following:

(1) General. For spans exceeding the limits apocifled In Rulo $232, A, 2$ above, the clearance specified in Table 232-1 shall be increased by 0.1 foot for each 10 teet of the excese of epan length over such limita. See (3) below.

(2) Rallroad Crosolinge. For spana exceeding the llalta specified in Rule $232, A, 2$ above, the clearance spoclfled in Tablo 232-1 anall be 1ncreased by the follow ing amount for each 10 fect by which the crossing See (3) belou.

\begin{tabular}{|c|c|c|}
\hline \multirow{2}{*}{ Louding Dletrict } & \multicolumn{2}{|c|}{$\begin{array}{c}\text { Amount of Increase } \\
\text { per } 10 \text { feet }\end{array}$} \\
\hline & $\begin{array}{l}\text { Lergo } \\
\text { Conductore }\end{array}$ & $\begin{array}{l}\text { Smal1 (1) } \\
\text { Conductors }\end{array}$ \\
\hline & Foet & Feet \\
\hline $\begin{array}{l}\text { Heavy and madium } \\
\text { L1ght }\end{array}$ & $\begin{array}{r}0.15 \\
.10\end{array}$ & $\begin{array}{r}0.30 \\
.25\end{array}$ \\
\hline
\end{tabular}

(1) A amall conductor 14 a conductor having an ovor-all diameter of metallic material equal co or leet then the following values:

\begin{tabular}{|l|l|l|}
\hline \multirow{2}{*}{ Matorial } & \multicolumn{2}{|c|}{$\begin{array}{c}\text { Outs1de Dlameter } \\
\text { of Conductor }\end{array}$} \\
\cline { 2 - 3 } & Solld & Stranded \\
\hline & Inches & Inches \\
\hline \multirow{3}{*}{$\begin{array}{l}\text { All copper } \\
\text { Other than all copper }\end{array}$} & 0.160 & 0.250 \\
.250 & .275 \\
\hline
\end{tabular}

(3) Limito. The maximum addifional clearance need not exceed the arithmetic difference botween flasl unloaded sag at a conductor tomporature of $60^{\circ} \mathrm{F}$, no wind, and final sag at the following conductor temperature and condition, whichever difference computed for the croselng apen.

(a) $32^{\circ} \mathrm{F}$, no wind, with radial chickness of $1 \mathrm{ce}$, $1 \mathrm{f}$ any, concerned.

(b) $120^{\circ} \mathrm{F}$, no wind

d. Where rupply linces aro designed to operate at conductor temperature alwir $120^{\circ} \mathrm{F}$ regind lese of apan length, tho oinimum clearance at midrpan speclfied in Rule $232, \Lambda$ and Rule $232, \mathrm{~B}, 2$ shall bn increased by the differenco between final unloaded sas at a conductor temperature of $60^{\circ} \mathrm{F}$, no wind, and final sag at the following conductor temperaturo and condition, whlchover difference 1, groater, computed for tho crosaing span.

(1) $32^{\circ} \mathrm{F}$, no wind, with radial thickness of 1ce, if any, specifled in Rule 250 B for the loading district concerned.

(2) The maximum conductor temperature, with no horizontal displacement, for which the suppiy line is designed to operate.

e. Where minimum clearance is not at midspan, the additional clearance spe ified in Rules $232, B, 2, C$, and d may be reduced by multiplying by the following factors: 


\begin{tabular}{|c|c|} 
Dratance from nearer support & \\
of crossing span to point of & \\
croseing in percontage of & Factora \\
croseing ipan length & \\
5 & \\
10 & 0.19 \\
15 & 0.36 \\
20 & 0.51 \\
25 & 0.64 \\
30 & 0.75 \\
35 & 0.84 \\
40 & 0.91 \\
45 & 0.96 \\
50 & 0.99 \\
\hline
\end{tabular}

Ințępolate for intermediate values

In npplying tho above rule, the "point of crosaing" is the location under the conductors of any topograp

C. Clearances to Live Parts of iquipment Mounted on Structure.

1. Basic Clearances

The vertical clearance above ground for unguarded live parts -uch as potheads, transformer bushings, Ifhenlng srrasters, and ahort lengthe of auply conductors connected thereto, which are not subjoct to variation in seg, whell be as ohown in Table 232-2.

2. Additional l wearances for Voltages Excoeding 50,000 volts

a. For voltages betwean 50,000 volte and 470,000 volts, the clasance apecifled in Table 232-2 (Rulo 232, C,1) ahall be increased at the rate of 0.4 inch por klluvolt in excuas of 50,000 volts. For voltagas excceding: 470,000 volta, the clearance oliall be dotermined by the alternate method of
Rule 232,D. All clearances for 11 nes over 50,000 volt shail be besed on the maximum operating volte:

Exception: For voltages exceeding 140,n00 volts AC to ground RMS or 197,000 volts $D C$ to ground, clearancos less than thoee required above oro perailted for yatem with known maximim sultch ing curge factors. (Sce Rulo 232, D.)

b. The additional clearance for voltages exceading 50,000 volts specified in Rulo $232, \mathrm{C}$, 3 above shall be increaued 37. for oach 1000 feet in excess of 3300 foet above mean sea level.

c. For voltage exceeding 140,000 volta AC rms to yround, of 297,000 volts $D C$ to ground, the clearances shall be increased or the electric fleld shall be reduced by other means, as required, to 11 mit the current due to electrostatic effect: co 5.0 milliamperes, nws, if the largest anticlpated truck, vehicle, or equipment under the line were short-circuited to ground.
TABLE 232-2 - Minlinum Vertical C.learance of Rlgid l.1vas t'art: p.bove Groun:

Voltafes are phase-to-ground for effectlvely grounded clrcults and those other clrcults whera all ground faults aro claared by promply do-energlz!ns senuent braker operations. See Dafinitions for voltages of other cystems.)

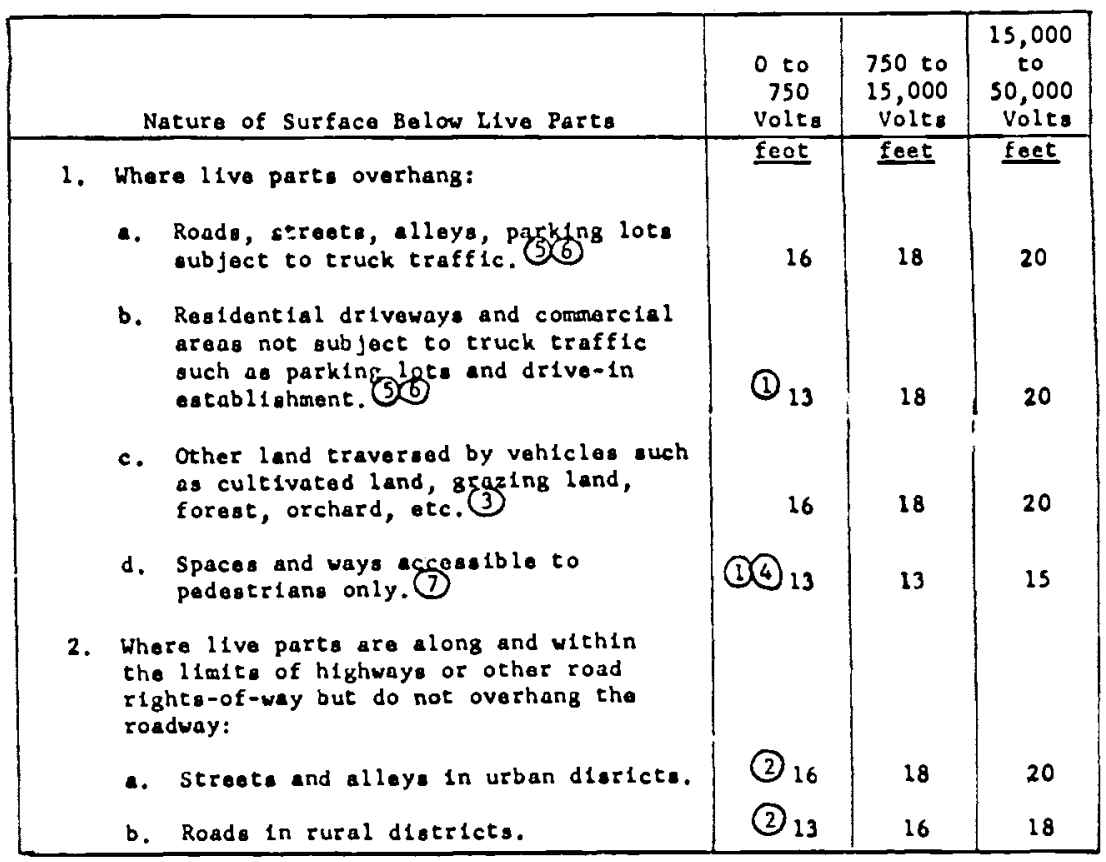

Footnoted for Table 232-2

(1) This clearance may be reduced to the following values:

(1) Live parts 11 mited to 300 volta-to-ground

(2) Live parte 1 imited to 150 volts-to-ground and chort lengths of supply cables meat ing Rules $230, C, 2$ or $230, c, 3$ and located at the electric ecrulce ontrance to building

(2) Where a supply 1 ine along a road is $11 \mathrm{~m}$ tted to 300 volta-to-ground and 18 located relative to foncos, ditchos, embankments, atc., so that the ground under the lino will never be travoled excopt by pedestriena, this clearance may be reduced to 12 faet.

(3) These clearances are for land cultivated or traversed by vehiclos and equipment whose overall operating halght 1 s lass thas 14 feet. 
(4) Where supply circulte of 600 volts or less, with transaltted powor of 5,000 vatiou or loge, aro run along fon $r$ ighte-of-way in accordance with the proviatone apecified in Rule 220,B,2 this clearance may bo raduced to 10 feet.

(5) For the purpose of this rule, trucks are dafined an eny vehicle exceeding 8 feet in height.

(6) Theos clcarances do not allow for future road resurfacing.

(7) spacco and ways accessible to pedeotrians only are areas where vchicular traffic is not normally encountered or not rensonably ant1clpated. Land subject to (but not $11 \mathrm{~m} 1 \mathrm{ted}$ to) highwy right-of -way maintenance equipment, logging cquipment, all-tarrain vohiclo

D. Alternato Cleatances for Voltarics Exceeding 140,000 Volte $\mathrm{AC}$ to Ground RMSS or 197,000 Volts DC to Ground

The clearances specificd in Ruies $232, \Lambda, B$, and $C$ may be raducod for

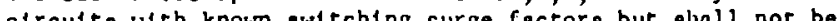
than the values computed by adding the reference helght to the - lectrical component of clearance.

1. Sag conditione of Line conjuctor Minimim vertical clearances shall be malntalried undir the following conductor teriperat ares and conditions:

a. $32^{\circ} \mathrm{F}$, no wind, with radial thickness of 1 ce epecified In Rule 250, B for the loading dietrict concerned.

b. $120^{\circ} \mathrm{P}$, no $w \ln 1$

c. Maximum conductor cemperature, no wind for which the 11 no 10

2. Reference Ho1ghte

A. Track rall, of rallroad. (except olectrifled Track rallo of rallroad (except olectrifled

b. Streots, Hlloys, roads, driveways, and parking lote.

c. Spaces and way accoselble zo pedestrians only.

d. Orher land traversed by vehicles euch as cultivated land, grazing land, forest, orchard, etc. (1)

- Water areas nor sulcable fur allboafing f. Wator arbas autcable for anllboating lncluding lakes, ponde, reservolrs, tidal waters, rivers, etreams ang canal. with watern, rivers, etreams ang

(1) Less than 20 acres

(2) 20 to 200 acres

(3) 200 to 2000 acres

(4) Ovor 2000 acres

8. In public or posted private land and vater areas for rigging or launching allboata, the minimum clearance above ground ahall be 5 feet greator than In Rule $232, D, 2, f$ above, for the typa of water erose sorved by the launching site.

(1) These clearances are for land cultivated or traversed by and equipment whose overall operating hel cht is less than 14 feet.

(2) For controlled Inpoundments, the surface area and corresponding clearance shall be based upon the design high water level. For other waters, the surface area shall be that area normally enclosed by its high water mark, and clearances shall be based on the unconirolled 10 year flood level. The clearance over rivers, streams, and canals thall be based upon the largest surface area of the one-mile long segment which includes the crossing. The a larger body of water shall be the same as that required for the larger body of water.

(3) Whare an over-water obstruction restricte vessel helght to lese than the following,

\section{For a Surfaco of A Reference Vessel lletght of}

$\begin{array}{ll}\text { a. Less than } 20 \text { acres } & 16 \text { feet } \\ \text { b. } 20 \text { to } 200 \text { acros } & 24 \text { feet } \\ \text { c. } 200 \text { to } 2000 \text { acres } & 30 \mathrm{fect} \\ \text { d. Ovor } 2000 \text { acres } & 36 \text { foot }\end{array}$

The required cloarance may be reduced by the difference between the refarence vosel helght given above and the over-water obstruction helght, except that the reduced clearance shall not be lese than that required for tho ourface area on the line crosalng side of the obstruction.

(4) Sce Rule 234 , H for the required horizontal and diagonal claarances to ra11 cars. 
3. Electrical Component of Clearance (D)

a. The clearance computsd by the following aquation and liated In Table 232-3 shall bo

$$
D=3.28\left[\frac{v(P U) a}{500 \mathrm{~K}}\right]^{b c} \quad \text { in feet }
$$

Whare $V=$ maximum AC crest oparating voltage to ground or maxlmum DC operating voltage to ground in $k V$

PU - maximum sultching surge factor expressed in per unit peak voltaga to ground and definod a a sultching surge lavel for clrcult breakers corresponding to $98 \%$ probabllity that the maximum sultehing surge gencrated per breaker operation does not exceed this surge level, or the maximum anticlpated witching surge level generated by other maana, whichever is greater.

a - 1.15 , allowance for 3 standard devlationa

- 1.03, allowance for non-atandard atmoapheric conditions

c - 1.2, margin of sofaty

$K=1.15$, configuration factor for conductorto-plane gap

b. The value of $D$ above shall be Increased 32 for each 1000 feet in excess of 1500 feat above maan sas levol.

c. Thie claarances shall bu increasod or tho aloctric flald ohali be raducad by othor mans, to $11 \mathrm{mlt}$ the currant due to electrostatic effects to 5.0 millampures, rms, if the largest anticlpatod truck, vehicle, or equipment under the line ware short-circuited to ground. Por this determination, the conductor as ahall be at final unloaded sag at $120^{\circ} \mathrm{F}$
Table 232-3 Electrical Component of Clearance (D)
Above Ground or Rail in Rula 232, D,3,a

(Add 37. for each 1000 fect in excose of 15.J foot above mean ece level. Inc.'esie eloarance 5 lintt olectrostatic offects in acco dance with Rulo $232,0,3, c$ )

\begin{tabular}{|c|c|c|c|c|}
\hline $\begin{array}{c}\text { Nominal } \\
\text { Vnitngn } \\
\text { Clnsa } \\
\text { Line-to-Line } \\
\text { (kV) }\end{array}$ & $\begin{array}{c}\text { Mixtmum } \\
\text { Opcrating } \\
\text { Voleage } \\
\text { Line-to-Line } \\
\text { (kV) }\end{array}$ & $\begin{array}{c}\text { Sultehlng } \\
\text { Surge } \\
\text { Factor } \\
\text { (p.u.) }\end{array}$ & $\begin{array}{l}\text { Switch Ing } \\
\text { Surge } \\
\text { (kV) }\end{array}$ & $\begin{array}{c}\text { Electrical } \\
\text { Component of } \\
\text { Clearance } \\
\text { (feet) }\end{array}$ \\
\hline 345 & 362 & 3.0 or lese & 887 or leas & $11,0 *$ \\
\hline 500 & 550 & $\begin{array}{c}2.0 \text { or lose } \\
2.1 \\
2.2 \\
2.3 \\
2.4 \\
2.5 \\
2.6\end{array}$ & $\begin{array}{c}898 \text { or log. } \\
943 \\
988 \\
1033 \\
1079 \\
1123 \\
1168\end{array}$ & $\begin{array}{l}11.0 \\
11.7 \\
12.7 \\
13.6 \\
14.6 \\
15.7 \\
16.7\end{array}$ \\
\hline 765 & 800 & $\begin{array}{c}1.5 \\
1.6 \\
1.7 \\
1.8 \\
1.9 \\
2.0 \\
2.1 \text { or more }\end{array}$ & $\begin{array}{r}980 \\
1045 \\
1110 \\
1176 \\
1241 \\
1306 \\
1372 \text { or more }\end{array}$ & $\begin{array}{l}12.5 \\
13.9 \\
15.4 \\
16.9 \\
18.5 \\
20.1 \\
21.8\end{array}$ \\
\hline
\end{tabular}

* L1mitad by Rula 232, D, 4

* Limited by Rule 232 , A and B 

APPENDIX C

BIBLIOGRAPHY 
. 


\section{BIBL IOGRAPHY}

Anderson, J. G., J. R. Doyle and E. J. O'Brien, "Project UHV - Construction and Technical Plan," paper 71-TP-150-PWR, IEEE Winter Power Meeting, New York, NY, January 31-February 5, 1971.

Annestrand, S. A., E. J. Harrington, M. Marjerrison and R. Stevens, "800-kV do Transmission," Power Engineering, pp. 50-53, June 1968.

Annestrand, S. A., E. J. Harrington, M. N. Marjerrison and R. F. Stevens, "800-kV de Transmission," Power Engineering, pp. 46-49, July 1968.

Application for Certification of a Transmission Line Between Branford and 01d Saybrook, submitted to Connecticut Power Facility Evaluation Council by Northeast Utilities Service Company for the Connecticut Light and Power Company, July 1972.

Avila, C. F. and A. F. Corry, "Underground Transmission in the United States," IEEE Spectrum, pp. 42-48, March 1970.

Avila, C. F., "Underground Transmission Technology," Power Engineering, pp. 35-38, March 1969.

Barnes, H. C. and T. J. Nage1, "AEP 765-kV System: General Background Relating to Its Development," IEEE Transactions on Power Apparatus and Systems, pp. 1313-1319, September 1969.

Barrett, S., "Resistive Cryogenic Work Enters Phase 2," Electric Light and Power, pp. 42-46, August 1972.

Barrett, S., "Underground Transmission: 2000 MVA Here Today, Larger Capacities 10 Years Away," Electric Light and Power, p. 33, August 1972.

Black, D. S., "Northwest Power Program," Power Engineering, pp. 38-41, August 1967.

Breuer, G. D., "HVDC Transmission Systems and the Flow of Earth Currents," Materials Protection and Performance, vo1. 10, no. 9, pp. 35-37, September 1971.

Burke, F. D., "Sample Impurities on Live EHV Insulators," Electric Light and Power, pp. 69-71, November 1972.

"Canada's First 500-kV Line Nears Completion," Power Engineering, pp. 45-47, March 1966. 
Clark, C. F. and M. 0. Loftness, "Some Observations of Foul Weather EHV Television Interference," IEEE Transactions on Power Apparatus and Systems, vol. Pas-89, no. 6, pp. 1157-1165, July/August 1970.

Clipp, L. L., "Concrete, Steel or Rock? Water Cannon Blasts Right Thru," Electric Light and Power, pp. 47-49, August 1972.

Denbrock, F. A., "Transmission Design Scope Increases Rapidly For EHV Lines," Power Engineering, pp. 55-58, November 1966.

Derbes, M. J., "ROW Costs Sky High? Try Grass-Roots PR," Electric Light and Power, pp. 56-57, August 1972.

"Design and Operating Problems Highlight EHV Conference," Power Engineering, pp. 59-62, January 1966.

Dey, P., B. Gaylard, C. W. Mott and J. A. Nicholson, "Influence of Conductor Designs and Operating Temperature on the Economics of Overhead Lines," Proc. IEE (English), vol. 118, no. 3/4, pp. 573-590, March/April 1971.

EHV Transmission Line Reference Book, written and edited by Project EHV, General Electric Company, published by Edison Electric Institute, NY, 1968.

Eich, E. D., "Research Needed in Forced Cooling of Conventional Cables," Electric Light and Power, pp. 38-39, August 1972.

Enrietto, J. B. and R. L. MacNary, "Thortec - A New Distribution System," IEEE Transactions on Industry and General Applications, vol. IGA-6, no. 2, pp. 140-145, March/Apri1 1970.

Environmental Report - Gilboa Leeds 345-kV Transmission Line, Power Authority of the State of New York, NY, March 1971

Falls, Jr., 0. B., "Changing Patterns in Energy Transport," Power Engineering, pp. 28-33, May 1969.

Friedlander, G. D., "Is Power to the People Going Underground?," IEEE Spectrum, pp. 62-71, February 1972.

Gideon, D. N., "Telluric Current Effects on Buried Pipelines," Materials Protection and Performance, vol. 10, no. 7, pp. 5-10, July 1971.

Hauspurg, A., G. S. Vassel1, G. J. Stillman, J. H. Charkow and Jorn C. Haar, "Overvoltages on the AEP 765-kV System," IEEE Transactions on Power Apparatus and Systems, vol. Pas-88, no. 9, pp. 1329-1342, September 1969.

Hazan, Earl, "Transmission Line Losses," Power Engineering, pp. 42-43, September 1969. 
Heisler, H. C., "EHV Hot-Line Maintenance: Savings and Safety," Electric Light and Power, pp. 62-63, March 1972.

Heisler, H. C., "Foam Backfi11 Cures Many Pole Setting I11s," Electric Light and Power, pp. 52-64, Apri1 1972.

Heisler, H. C., "Think Security is a Nickel-Dime Problem? Don't Believe It.," Electric Light and Power, pp. 39-45, May 1972.

Holum, K., "Underground Transmission," Power Engineering, pp. 58-59, November 1967.

Horowitz, S. H. and H. T. Seeley, "Relaying the AEP 765-kV System," IEEE Transactions on Power Apparatus and Systems, vol. Pas-88, no. 9, pp. T3821388, September 1969.

"Industry Developments," Transmission and Distribution, p. 90, June 1972. Jansen, J., "EHV Lines in the Federal Republic of Germany," IEEE Spectrum, pp. 33-40, Apri1 1970.

Johnson, P. F., "Folded Plate Structures Improve Substation Appearance with No Cost Penalty," Transmission and Distribution, pp. 20-22, August 1972.

Juhnke, Jr., E. W., "Transmission Ice-Melting Procedure Extended to Distribution Lines," Power Engineering, pp. 61-63, Apri1 1966.

Kauferle, J., "Using dc 1 inks to Enhance ac System Performance," IEEE Spectrum, pp. 31-37, June 1970 .

Kilar, L. A. and J. S. Engelhardt, "HPOF - Where is the Pipe-Type Ceiling?," Electric Light and Power, pp. 36-37, August 1972.

King, R. M. and N. Diffrient, "Functional Aesthetics Highlight Bulk Power Sub Design," Electric Light and Power, pp. 58-60, August 1972.

Koleio, Nestor, Vincent Caleca, Stephen J. Marmaroff and W. L. Gregory, "Radio Influence and Corona-Loss Aspects of AEP 765-kV Lines," IEEE Transactions on Power Apparatus and Systems, vol. Pas-88, no. 9, pp. 1343-1364, September 1969.

Marks, J. A., "Consultants and Contractors: Where Wi11 They Fit Into Future T\&D Work?," Electric Light and Power, p. 43, March 1973.

Marks, J. A., "IEEE Underground Transmission Conference," Electric Light and Power, pp. 50-51, Apri1 1972.

Marks, J. A., "Transfer Capability: How Much Is Enough," Electric Light and Power, pp. 39-45, March 1972. 
Metcalf, Jr., K. B., "500-kV Line Costs," Power Engineering, pp. 50-51, September 1967.

Methe, M., "The Distribution of Power in Large Cities," The Engineering Journal, vol 54, no. 10, pp. 15-18, October 1971.

Meyerhoff, R. W., "AC Super Conductors: Can You Wait 12 Years to Save 50\%," Electric Light and Power, pp. 44-46, August 1972.

Moore, D. W., "Pardee Substation," Transmission and Distribution, pp. 28-30, September 1972.

"New T-1ine Structure Makes Its Debut," Electric Light and Power, p. 19, July 1972.

1972 IEEE Underground Transmission Conference - Supplement, IEEE Power Engineering Society Report No. 72-CH0-608-0-PWR (SUP.), January 1973.

Papamarcos, John, "ERC's Underground Transmission Program: A Status Report," Power Engineering, pp. 26-30, February 1970.

Paris, L., "The Future of UHF Transmission Lines," IEEE Spectrum, pp. 44-51, September 1969.

Peabody, A. W. and A. L. Verhiel, "The Effects of High-Voltage AC Transmission Lines on Buried Pipelines," IEEE Transactions on Industry and General Applications, pp. 395-402, May/June 1971.

"Perspective," Electric Light and Power, p. 17, August 1972.

Pohlman, J. C., "What IS The Public's Opinion on Transmission Towers and Poles," Electric Light and Power, pp. 59-61, April 1973.

Porter, A. G., "Underground for Rural Areas," IEEE Transactions on Industry and General Applications, vol. IGA-6, no. 1, pp. 71-73, January/February 1970.

Ramthun, M. K. and L. M. Robertson, "High-Altitude Transmission Lines," Power Engineering, pp. 42-44, June 1967.

Rikh, V. N., "Angular Winds Set Critical Design Criteria for 400-kV Towers," Transmission and Distribution, pp. 40-43, January 1972.

Riordan, M. A., "Electrical Effects of AC Transmission Lines on Pipelines," Materials Protection and Performance, vol. 11, no. 10, pp. 26-30, 0ctober 1972.

Rolf, C. F. and D. R. Young, "Tower Design - Modified vs New," Power Engineering, p. 67, November 1967. 
Samuelson, A. James, "American Electrical Power 765-kV Transmission Line Project," IEEE Transactions on Power Apparatus and Systems, vol. Pas-88, no. 5, pp. 703-709, May 1969.

Samuelson, A. James, R. L. Retallack, R. A. Kravitz, "AEP 765-kV Line Design," IEEE Transactions on Power Apparatus and Systems, vol. Pas-88, no. 9, pp. 13661371 , September 1969.

Sargent, M. A. and M. Darveniza, "Lightning Performance of Double-Circuit Transmission Lines," IEEE Transactions on Power Apparatus and Systems, pp. 913-924, May/June 1970.

Scherer, H., B. J. Ware and C. H. Shih, "Gaseous Effluents Due to EHV Transmission Line Corona," paper No. T72 550-2, IEEE Power Engineering Society Summer Meeting, San Francisco, July 9-14, 1972.

"700/765-kV AC Substation Design Criteria: Summary of Industry Practices," IEEE Transactions on Power Apparatus and Systems, vol. Pas-89, no. 7, pp. 1521-1524, September/0ctober 1970.

Shankle, D. F., "Build a New Line or Uprate?," Electric Light and Power, pp. 66-69, January 1973.

Snith, B. E., "34.5-kV Distribution at the Virginia Electric and Power Company," IEEE Transactions on Industry and General Applications, vol. IGA-7, no. 3, pp. 439-442, May/June 1971.

"The Development of Electrical Transmission Systems," Power Engineering, vol. 72, no. 11, pp. S-1 to S-24, November 1968.

Thompson, P. and R. Billinton, "Generating Capacity Benefits Associated with Power System Interconnections," Engineering Journal, pp. 28-31, October 1971.

Tomlinson, D. B., "Vandals: Big on Guns - Low on Brains," Electric Light and Power, pp. 99-100, June 1972.

Tranen, J. D. and G. L. Wilson, "Electrostatically Induced Voltages and Currents on Conducting Objects Under EHV Transmission Lines," IEEE Transactions on Power Apparatus and Systems, vol. Pas-90, no. 2, pp. 768-775, March/Apri1 1971.

"Transmission," Electric Light and Power, p. 41, June 1972.

"Transmission," Electric Light and Power, p. 19, Apri1 1972.

"Transmission," Electric Light and Power, p. 19, August 1972. 
"Transmission of the Future," Power Engineering, pp. 67-68, October 1967.

Tucker, H. M., "Modular Concrete Troughs Speed Substation Construction," Electric Light and Power, pp. 84-86, June 1972.

Verhiel, A. L., "HVDC Interference on Major Canadian Pipel ine Counteracted," Materials Protection and Performance, vol. 11, no. 3, pp. 37-40, March 1972.

Verhiel, A. L., "The Effects of High-Voltage DC Power Transmission Systems on Buried Metallic Pipelines," IEEE Transactions on Industry and General Applications, vol. IGA-7, no. 3, pp. 403-415, May/June 1971.

Zastrow, 0. W., "Interference of Pipeline Protection Rectifier Systems with Electrical Power Grounds, "Materials Protection and Performance, vol. 12, no. 3, pp. 36-40, March 1973.

Underground Power Transmission, Report no. C-73411, Prepared by Arthur D. Little, Inc., for The U.S. Department of Interior and The Edison Electric Institute, October 1971. 
